\title{
EXAMINING THE LANGUAGE LEARNING POTENTIAL OF A TASK-BASED APPROACH \\ TO SYNCHRONOUS COMPUTER-MEDIATED COMMUNICATION
}

By

Nik Aloesnita bt. Nik Mohd Alwi

A thesis

submitted to the Victoria University of Wellington in fulfilment of the requirements for the degree of

Doctor of Philosophy

in

Applied Linguistics

Victoria University of Wellington

2010 


\begin{abstract}
This study investigates the influence of two task implementation features, the level of task structure and the use of language support, on learner language production during task-based text synchronous computer-mediated communication (text-SCMC) interactions. The study draws on two theoretical sets of claims concerning the process of second language acquisition (SLA). The first, broadly described as cognitive accounts of language learning, the Cognition Hypothesis (Robinson, 2001b, 2003b, 2005) and the Trade-off Hypothesis (Skehan, 1998, 2009), has generated a large body of research on the role of implementation features (a means of varying task complexity) in influencing learner language production. The second, the Interactionist Approach (Gass \& Mackey, 2006) has also claimed the facilitative role of interaction in promoting second language production. Most of the studies in both these areas were conducted in face-to-face settings (e.g. Gilabert, 2007b; Michel, Kuiken \& Vedder, 2007; Robinson, 2007b; Tavakoli \& Foster, 2008; Tavakoli \& Skehan, 2005). Because SCMC is growing more pervasive in academic and professional communication, it is timely for empirical research into the effect of task complexity on interaction and language production to be conducted in this setting (Lee, 2008; Smith, 2008). It is this gap that the current study aims to address.
\end{abstract}

The participants were 96 engineering learners at a technical university in Malaysia in an English for Professional Communication course. Using a $2 \times 2$ experimental design, the learners were placed in one of four experimental groups defined by high or low task structure (+TS or $-\mathrm{TS})$, and with or without language support (+LS or -LS). Each group was subdivided into teams of four. In each team, the students engaged in a 45-minute chat session performing a simulation of a decision-making task on an engineering problem. The chat exchanges were captured and then analyzed to determine the role of these task implementation features on the occurrence of focus on form sequences and on the accuracy, complexity, and quantity of language produced during the tasks.

Results showed that the two task implementation features (+/-TS and +/-LS) influenced the occurrence of language-related episodes (LREs), accuracy, complexity and quantity of output. The findings on the effects of task structure (TS) 
revealed that the learners engaged in more LREs and their output was more accurate when task performance was highly structured (+TS). However, task structure did not have a significant effect on the structural and lexical complexity of the output nor on the amount of language produced and equality of participation.

The findings on the effects of language support (LS) demonstrated that the participants engaged in more LREs and their language use was more accurate when performing the task with language support (+LS) than without it (-LS). In contrast, they produced more complex language when performing the task without language support (-LS). Without language support (-LS), the learners were also found to produce fewer turns but with more words per turn. The finding for equality of participation was non-significant which suggests that participation was not affected by language support.

To summarize, the current study lends qualified empirical support to the Interactionist Approach (Gass \& Mackey, 2006) and the trade-off effects proposed by Skehan $(1998,2009)$ in that cognitively simple tasks promoted more accurate, but less complex production than cognitively complex tasks as they apply to taskbased interactions in a text-SCMC context. Additionally, the finding demonstrates partial support for the Cognition Hypothesis (Robinson, 2001b; 2003b, 2005) in that increasing task complexity along the resource-dispersing dimension decreased the accuracy of language production. The visual salience of language in a text-SCMC setting may be an important explanatory factor in accounting for this finding. The study, therefore, provides evidence that the nature of text-SCMC may be facilitative to L2 learning, particularly as a medium for learning of form during communicative practice. 


\section{ACKNOWLEDGEMENTS}

First and foremost, I would like express my deep and sincere gratitude to my supervisors, Dr. Jonathan Newton of Victoria University of Wellington and Dr. Rebecca Adams of the University of Auckland for their detailed and constructive comments on every inch of my work. I am also grateful for their understanding, continuous support, encouragement and personal guidance throughout my $\mathrm{PhD}$ journey, particularly during those difficult as well challenging moments. Their support has been the key to my success and the fuel that kept me going. It has been a real pleasure to work with them and I am deeply indebted to them!

I warmly thank Professor Paul Nation for his wonderful assistance and valuable, fatherly advice. He has advised me of the different ways to approach a research problem and the importance of being persistent in accomplishing any goals. My sincerest thanks also go to Professor Janet Holmes whose kind support and guidance have been of great value throughout my journey as a doctoral student in New Zealand. To Associate Professor Paul Warren, thank you for your invaluable feedback around my work that has provided further insights into the study. I would also like to thank my thesis examiners, Professor Paul Nation, Dr. Rosemary Erlam and Dr. Ana-Maria Nuevo as well as the rest of the thesis committee for the insightful comments and reviews of my work.

My profound appreciation goes to Professor Abu Azam Yassin, the former Rector of Universiti Malaysia Pahang (UMP), Malaysia (formerly known as University College of Engineering and Technology) for giving me the golden opportunity to further my PhD studies in New Zealand. Thank you for the trust! I would like to extend my heartiest gratitude to Professor Nuraihan Mat Daud of the IIUM for introducing me to the world of CALL. Thank you for the inspiration! I am also grateful to all my colleagues and friends at UMP and VUW particularly my office mates Dr. Polina Kobeleva and Dr. Leilarna Kingsley and two special group of friends, the LALS PhD support group and the Malaysia-Wellington Postgraduate Association for the friendship, support and encouragement that kept me on track all these years! To my editor, Gillian Halba, thank you so much for proofreading the chapters and offering suggestions for improvement. And to the students who have 
participated in this research, thanks for your cooperation, I appreciate your assistance!

The financial support throughout my $\mathrm{PhD}$ studies in New Zealand from UMP is gratefully acknowledged. I would also like to express my heartfelt appreciation to the following bodies for the research awards and grants awarded to me during my PhD studies: New Zealand Asia Award \& Malay Studies Scholarship, New Zealand Postgraduate Study Abroad Award, VUW Scholarship Office, Faculty of Humanities and Social Sciences, VUW and the School of Linguistics and Applied Language Studies, VUW.

My deepest gratitude goes to my amazing husband, Suffian Kadir and my lovely little honey, Ayra Safia who have always been the loves of my life. Thank you for all your constant support and understanding, for holding my hand in the good and in the bad times. I love you more than words can say! I owe my loving thanks to my wonderful parents, $\mathrm{Hj}$. Nik Mohd Alwi b. Hj. Nik Omar and Hjh. Hoesniah bt. Hj. Hussain, who absolutely deserve huge recognition for encouraging me to pursue my goals and for giving me the best gift in life, your unconditional love. Your love means the whole world to me and I love you more! And last but not least, to the rest of my siblings, Nik Aloesnida, Nik Mohd Alimin, Nik Aloesniha, Nik Aloesnisa, Nik Mohd Al-Syukreen and Nik Aloesni Amalina, nephews, nieces and in-laws, thank you for sharing my dreams and believing in me! God bless! 


\section{TABLE OF CONTENTS}

\section{ABSTRACT}

ACKNOWLEDGEMENTS

TABLE OF CONTENTS

LIST OF TABLES viii

LIST OF FIGURES $\quad \mathrm{x}$

\section{CHAPTER ONE:}

INTRODUCTION

1.1 Introduction 1

1.2 Computer-mediated communication in L2 learning and teaching 1

1.3 Computer-mediated communication: Synchronous (SCMC) vs. 2 asynchronous (ACMC)

1.4 Rationale for using text-SCMC in the current study 3

1.5 Overview of task-based interaction 4

1.6 Motivation for the current study 5

$\begin{array}{lll}1.7 & \text { Significance of the study } & 6\end{array}$

$\begin{array}{lll}1.8 & \text { Summary } & 7\end{array}$

CHAPTER TWO:

INTERACTION, TASKS AND LANGUAGE-RELATED EPISODES

2.1 Introduction 8

2.2 Input, output, attention and interaction $\quad 8$

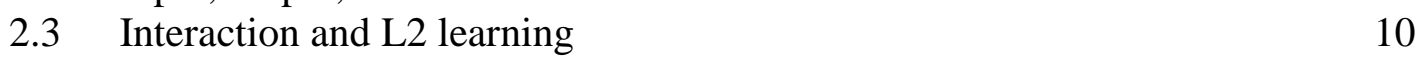

2.3.1 Interaction between native and non-native speakers $\quad 11$

2.3.2 Interaction between non-native and non-native speakers $\quad 12$

$\begin{array}{lll}2.4 & \text { Overview of task-based approach in L2 classroom } & 13\end{array}$

2.4.1 Defining tasks $\quad 13$

2.4.2 Tasks and L2 interaction $\quad 15$

2.5 Language-related episodes (LREs) and L2 learning 18

$\begin{array}{lll}2.6 & \text { Summary } & 23\end{array}$

CHAPTER THREE:

\section{TASK COMPLEXITY}

3.1 Introduction 24

3.2 Skehan's view of task complexity 25

3.3 Robinson's view of task complexity 26

$\begin{array}{lll}3.4 & \text { Task complexity and language production } & 29\end{array}$ 
3.4.1 Task complexity in monologic tasks $\quad 30$

3.4.2 Task complexity in interactive tasks 36

3.5 Summary of task complexity dimensions 38

3.6 Operationalisations of task structure and language support in the current $\quad 40$ study

3.7 Summary

CHAPTER FOUR:

COMPUTER-MEDIATED COMMUNICATION

4.1 Introduction 43

4.2 Features of text-SCMC 43

4.3 Text-SCMC as a context for SLA research 43

4.3.1 Encouraging meaning negotiation and interactional 45 modification

4.3.2 Promoting noticing and focus on form 46

4.3.2.1 Accuracy of L2 production 48

4.3.2.2 Complexity of L2 production 50

4.3.3 Fostering active and equal participation $\quad 52$

4.3.3.1 Participation in teacher-learner interaction 53

4.3.3.2 Reduction of communication anxiety and increased 54 motivation

4.3.4 Developing oral competence $\quad 56$

$\begin{array}{lll}4.4 & \text { Task-based approach in text-SCMC } & 57\end{array}$

4.4.1 Task-based interaction in text-SCMC $\quad 57$

4.4.2 Task types in text-SCMC $\quad 59$

$\begin{array}{lll}4.5 & \text { Task-based text-SCMC in the current study } & 60\end{array}$

$\begin{array}{lll}4.6 & \text { Summary } & 61\end{array}$

CHAPTER FIVE:

METHODOLOGY

$\begin{array}{lll}5.1 & \text { Introduction } & 62\end{array}$

$\begin{array}{lll}5.2 & \text { Research questions } & 62\end{array}$

$\begin{array}{lll}5.3 & \text { Hypotheses } & 64\end{array}$

$\begin{array}{lll}5.4 & \text { Setting } & 65\end{array}$

5.4.1 Participant background $\quad 66$

$\begin{array}{ll}\text { 5.4.2 The English language program } & 67\end{array}$

$\begin{array}{lll}5.5 & \text { Data collection } & 68\end{array}$

$\begin{array}{ll}\text { 5.5.1 Learner groupings } & 68\end{array}$

$\begin{array}{lll}\text { 5.5.2 Procedures } & 69\end{array}$

$\begin{array}{ll}\text { 5.5.3 The data } & 70\end{array}$

$\begin{array}{lll}\text { 5.5.4 The instructor's role } & 71\end{array}$

$\begin{array}{lll}5.6 & \text { Task used in the current study } & 71\end{array}$

$\begin{array}{lll}\text { 5.6.1 Task implementation conditions } & 72\end{array}$

$\begin{array}{lll}5.7 & \text { Pilot study } & 73\end{array}$

5.7.1 Rationale for the selection of the linguistic items for the 73 language support 
$\begin{array}{lll}5.8 & \text { Language support } & 73\end{array}$

$\begin{array}{lll}5.9 & \text { Task structure } & 74\end{array}$

5.10 Coding systems and language production measures 75

$\begin{array}{lll}5.10 .1 & \text { Language-related episodes (LREs) } & 75\end{array}$

5.10.2 Analysis of speech unit (AS-unit) 77

5.10.2.1 Language production measures: Accuracy 79

5.10.2.1.1 Types of errors 80

5.10.2.1.1.1 Auxiliary verb errors 81

5.10.2.1.1.2 Modal verb errors 81

5.10.2.2 Language production measure: Complexity 81

$\begin{array}{lll}\text { 5.10.2.2.1 } & \text { Structural complexity } & 82\end{array}$

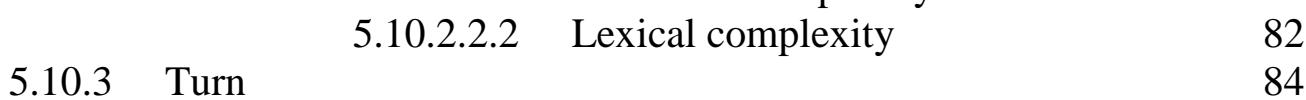

5.10.3.1 Language production measure: Quantity $\quad 85$

5.10.4 Summary of the language production measures 86

$\begin{array}{lll}5.11 & \text { Intrarater and interrater reliability } & 87\end{array}$

$\begin{array}{lll}5.12 & \text { Statistical instruments and procedures } & 87\end{array}$

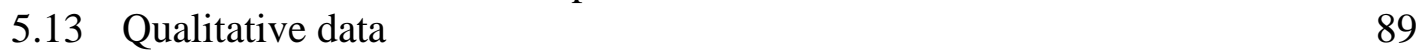

$\begin{array}{lll}5.14 & \text { Summary } & 90\end{array}$

CHAPTER SIX:

RESULTS

$\begin{array}{lll}6.1 & \text { Introduction } & 91\end{array}$

6.2 Language-related episodes (LREs) 91

$\begin{array}{lll}\text { 6.2.1 MANOVA results and analysis } & 92\end{array}$

6.2.1.1 Language-related episodes on meaning: 93

Univariate results and analysis
6.2.1.2 Language-related episodes on form:

$\begin{array}{lll}\text { 6.2.2 Summary } & 96\end{array}$

$\begin{array}{lll}6.3 & \text { Accuracy } & 96\end{array}$

6.3.1 MANOVA results and analysis $\quad 96$

6.3.1.1 Error/AS-unit: Univariate results and analysis $\quad 98$

6.3.1.2 Targetlike use of auxiliary verbs: Univariate results 100 and analysis

6.3.1.3 Targetlike use of modal verbs: Univariate results 101 and analysis

6.3.2 Summary 103

$\begin{array}{lll}6.4 & \text { Complexity } & 103\end{array}$

$\begin{array}{lll}\text { 6.4.1 MANOVA results and analysis } & 104\end{array}$

6.4.1.1 Clause/AS-unit: Univariate results and analysis 106

6.4.1.2 Words beyond the first 1,000 words: Univariate 107

6.4.1.3 Guiraud Index: Univariate results and analysis 108

$\begin{array}{lll}6.4 .2 \text { Summary } & 110\end{array}$

$\begin{array}{lll}6.5 & \text { Quantity } & 110\end{array}$

6.5.1 Quantity: Amount of talk 111

6.5.1.1 MANOVA results and analysis $\quad 111$ 
6.5.1.1.1 Number of words: Univariate results and analysis

6.5.1.1.2 Number of turns: Univariate results and analysis

6.5.1.1.3 Words per turn: Univariate results and analysis

6.5.2 Quantity: Distribution of talk within teams

\section{CHAPTER SEVEN:}

\section{DISCUSSION}

$\begin{array}{lll}7.1 & \text { Introduction } & 119\end{array}$

$\begin{array}{lll}7.2 & \text { Independent variable: Task structure } & 119\end{array}$

7.2.1 The effects of task structure on LREs 121

7.2.2 The effects of task structure on accuracy and complexity 126

$\begin{array}{ll}\text { 7.2.3 The effects of task structure on quantity } & 130\end{array}$

7.2.4 Additional perceptions of task structure 132

7.2.5 Summary of the effects of task structure on the 132 dependent variables

$\begin{array}{lll}7.3 & \text { Independent variable: Language support } & 134\end{array}$

7.3.1 The effects of language support on language-related episodes 136 (LREs)

7.3.2 The occurrences of LREs on meaning and form 139

7.3.3 The frequency of LREs in text-SCMC 140

7.3.4 The effects of language support on accuracy and complexity 141

7.3.5 The effects of language support on quantity 146

7.3.5.1 Quantity- Amount of talk 147

7.3.5.2 Quantity- Distribution of talk 149

7.3.6 Summary of the effects of language support on the dependent 151 variables

7.4 Interaction effects between task structure and language support 153

7.4.1 The interaction effect between task structure and language 153 support on accuracy

7.4.2 The interaction effect between task structure and language 155

7.5 Summary support on complexity

\section{CHAPTER EIGHT:}

\section{CONCLUSION}

$\begin{array}{lll}8.1 & \text { Introduction } & 160\end{array}$

$\begin{array}{lll}\text { 8.2 Summary of the results } & 160\end{array}$

8.2.1 Summary of the effects of task structure on the dependent 161 variables

8.2.2 Summary of the effects of language support on the dependent 161 
variables

$\begin{array}{lll}\text { 8.3 Theoretical implications } & 163\end{array}$

$\begin{array}{lll}8.4 & \text { Pedagogical implications } & 164\end{array}$

8.5 Limitations and suggestions for further research directions 166

$\begin{array}{lll}8.6 \text { Conclusion } & 167\end{array}$

\section{APPENDICES}

Appendix A: Information sheet and consent form 169

$\begin{array}{ll}\text { Appendix B: Unstructured interview questions } & 172\end{array}$

$\begin{array}{ll}\text { Appendix C: } & 173\end{array}$

Appendix D: Language support materials (+LS) 181

Appendix E: $\quad$ Task structure material (+TS) or Sheet B 195

Appendix F: Recommendation worksheet or Sheet A 196

Appendix G: Effective communication skills checklist or Sheet C 197

$\begin{array}{ll}\text { REFERENCES } & 198\end{array}$ 


\section{LIST OF TABLES}

Table 3.1: Task sequencing features $\quad 25$

Table 3.2: Pedagogic L2 task classification: Triadic Componential 27

$\begin{array}{lll}\text { Table 5.1: } & \text { Learner characteristics } & 66\end{array}$

Table 5.2: Task conditions $\quad 69$

$\begin{array}{ll}\text { Table 5.3: An example of text chat } & 70\end{array}$

Table 5.4: $\quad$ LREs on meaning $\quad 76$

Table 5.5: $\quad$ LREs on form $\quad 76$

$\begin{array}{lll}\text { Table 5.6: } & \text { AS-units and clauses } & 78\end{array}$

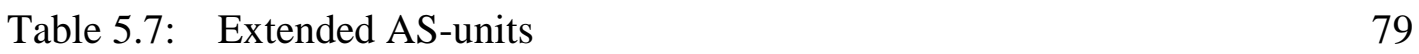

Table 5.8: Type of errors $\quad 80$

Table 5.9: Non-targetlike use of auxiliary verbs $\quad 81$

$\begin{array}{ll}\text { Table 5.10: Non-targetlike use of modal verbs } & 81\end{array}$

Table 5.11: Turn $\quad 85$

Table 5.12: Measures of learner language production 87

Table 5.13: Dependent variables used in the current study 88

Table 6.1: $\quad$ Language-related episodes: Descriptive statistics 92

Table 6.2: Language-related episodes: Multivariate tests 93

Table 6.3: Language-related episodes on meaning: 93

Test of Between-Subjects Effects

Table 6.4: Language-related episodes on form: 95

Table 6.5: Accuracy: Descriptive statistics 97

Table 6.6: Accuracy: Multivariate tests 98

Table 6.7: Error/AS-unit: Test of Between-Subjects Effects 99

Table 6.8: Targetlike use of auxiliary verbs: 100

Test of Between-Subjects Effects

Table 6.9: Targetlike use of modal verbs: 101

Test of Between-Subjects Effects

Table 6.10: Complexity: Descriptive statistics 104

Table 6.11: Complexity: Multivariate tests 105

Table 6.12: Clause/AS-unit: Test of Between-Subjects Effects 106

Table 6.13: Words beyond the first 1,000 words: 107

Test of Between-Subjects Effects

Table 6.14: Guiraud Index: Test of Between-Subjects Effects 109

Table 6.15: Quantity- Amount of talk: Descriptive statistics 112

Table 6.16: Quantity- Amount of talk: Multivariate tests 113

Table 6.17: Number of words: Test of Between-Subjects Effects 113

Table 6.18: Number of turns per learner: Test of Between-Subjects Effects 114

Table 6.19: Words per turn: Test of Between-Subjects Effects 115

Table 6.20: Quantity- Distribution of talk: Descriptive statistics 117

Table 6.21: Quantity- Distribution of talk: Multivariate tests 117

Table 7.1: Independent variable: Task structure 120

Table 7.2: $\quad$ The effects of task structure on LREs 121

Table 7.3: The effects of task structure on accuracy and complexity 127

Table 7.4: The effects of task structure on quantity 131

Table 7.5: Independent variable: Language support 135 
Table 7.6: The effects of language support on LREs

Table 7.7: The effects of language support on accuracy and complexity

Table 7.8: The effects of language support on quantity (amount of talk)

Table 7.9: The effects of language support on quantity (distribution of talk)

Table 7.10: Interaction effects between task structure and language support 


\section{LIST OF FIGURES}

Figure 6.1: $\quad$ Mean number of LREs on meaning 94

Figure 6.2: Mean number of LREs on form $\quad 95$

Figure 6.3: Mean number of error/AS-unit $\quad 99$

Figure 6.4: Mean percentage of targetlike form of auxiliary verbs 101

Figure 6.5: Mean percentage of targetlike form of modal verbs 102

$\begin{array}{ll}\text { Figure 6.6: } & 107\end{array}$

Figure 6.7: Mean percentage of words beyond the first 1,000 words 108

$\begin{array}{ll}\text { Figure 6.8: } & 109\end{array}$

$\begin{array}{ll}\text { Figure 6.9: } & 114 \\ \text { Mean number of turns } & 115\end{array}$

$\begin{array}{ll}\text { Figure 6.10: Mean number of words per turn } & 115\end{array}$

Figure 7.1: $\quad$ Interaction effects between TS and LS 154 on targetlike use of auxiliary verbs

$\begin{array}{lll}\text { Figure 7.2: } & \text { Interaction effects between TS and LS } & 155\end{array}$ on Clauses/AS-unit

Figure 7.3: Interaction effects between TS and LS 157 on Guiraud Index 


\section{CHAPTER ONE \\ INTRODUCTION}

\subsection{Introduction}

This thesis examines how learners develop second language communication skills through the use of text-based synchronous computer mediated communication (text-SCMC). The study used a task-based approach to look at how task implementation features (in this case task structure and language support) influence learner language production during task performance in text-SCMC. This was done with engineering learners at a Malaysian university, where English is the medium for instruction for all the subjects. The research was motivated theoretically by the Interactionist Approach (Mackey \& Gass, 2006), Robinson's Cognition Hypothesis (2001b, 2003b, 2005) and Skehan's $(1996,1998)$ cognitively oriented approach to task-based learning and second language acquisition (SLA).

The thesis is organised as follows: Chapter One introduces the dissertation, and Chapters Two, Three and Four outline the theoretical frameworks underpinning the research, and review the research literature related to these frameworks. Chapter Five presents the methodology and procedures used to gather and analyse the research data. Chapter Six presents the results of the research, which are discussed in Chapter Seven. Finally, Chapter Eight outlines the conclusions, including recommendations and implications of the research for second (L2) and/or foreign (FL) language learning and teaching through task-based learning in a text-SCMC environment.

\subsection{Computer-mediated communication in L2 learning and teaching}

Developments in information and communication technologies (ICT) have greatly influenced how people communicate, and over recent years have had a profound impact on literacy and education (see Gerjets \& Heese, 2004; Goodfellow, 2005; Hirvela, 2006; Kenning, 2007; Koskimaa, Lehtonen, Heinonen, Ruokamo, Tissari, Vahtivuori-Hänninen, \& Tella, 2007; Warschauer, Grant, Del Real, \& Rousseau, 2004, for comprehensive analysis of this topic). Warschauer (1998) 
suggests that to be proficient in an L2, a person must have the ability "to read, write and communicate in an electronic environment" (p.757).

The field of language learning and teaching has also been widely influenced by the use of computers (Chen, 2005; Figura \& Jarvis, 2007; O'Bryan \& Hegelheimer, 2007; Raby, 2007). The main impact has been in computer-assisted language-learning (CALL) and computer-mediated communication (CMC) (Chapelle, 2004; Levy \& Stockwell, 2006; Thorne \& Payne, 2005). A growing body of literature shows the benefits that CALL, particularly CMC, offers to language learners (Chenoweth, Ushida, \& Murday, 2006; Ishihara, 2007; Janssen, Erkens, Jaspers, \& Broeken, 2005; Nguyen \& Kellogg, 2005; Payne \& Ross, 2005).

With the fast pace of technological innovation the area of CMC is constantly evolving, and educators are constantly exploring how they can make the best use of these innovations to assist language learners (D'Eça \& González, 2006; Heins, Duensing, Stickler, \& Batstone, 2007; Hubbard \& Levy, 2006; Lafford \& Lafford, 2005; Lamy \& Hampel, 2007; Stockwell, 2007). CMC technology holds great potential for increasing opportunities for L2 learning as it greatly expands the virtual space available for communication and collaboration (Beauvois, 1998; Chapelle, 2004; Warschauer, 2003; Blake, 2007; Chinnery, 2008; Warschauer \& Grimes, 2007).

\subsection{Computer-mediated communication: Synchronous (SCMC) vs. asynchronous (ACMC)}

CMC has been defined as, “... communication that takes place between human beings via the instrumentality of computers" (Herring, 1996, p.1). CMC occurs in two modes: asynchronous (ACMC) and synchronous (SCMC) computermediated communication. ACMC (e.g. e-mail and bulletin board discussion) involves delayed interaction in a written form, which usually allows a person extra time to compose and edit thoughts before making their postings to the public (Kim, Anderson, Nguyen-Jahiel \& Archodidou, 2007; Shang, 2007). ACMC is more likely to be thoughtful and well written than SCMC, which involves real-time communication that requires each interlocutor to be online at the same time (Ramsay, 2003). 
SCMC (e.g. Internet-relay chat and text multi-object-orientation) is suitable for discussing specific questions or problems that require a prompt answer, and may spontaneously stimulate additional questions. SCMC can work in three different modes: text, audio (which produces sounds), and video (which produces images) (Anderson \& Elloumi, 2004; Johnson \& Sheehan, 2006; Su, 2005). Having these modes available simultaneously may help diversify the practical applications of using computers in the learning processes, while making learning more comprehensive (Beyth-Marom, Saporta, \& Caspi, 2005; Chang, 2007; Hegelheimer \& Tower, 2004; Kenning, 2007; Lamy \& Hampel, 2007).

However, technical constraints, such as bandwidth limitations, network restrictions and screen resolution compatibility, mean simultaneous use of these modes may not be possible in remote or technologically underdeveloped areas. Also, when operating text, audio, and video simultaneously, significant financial investments are needed to pay for the additional equipment that would be required (e.g. headphones, a microphone and webcam) to ensure clear communication, and to maintain up-to-date computer hardware accessories.

\subsection{Rationale for using text-SCMC in the current study}

ACMC and SCMC have been shown to promote language learning in educational settings (Pérez, 2003; Thorne \& Payne, 2005), but SCMC is used less than ACMC forms such as email and discussion boards (Coffin, Painter, \& Hewings, 2005; Matsumura \& Hann, 2004; Ramsay, 2003; Suzuki, Watanabe, \& Yoshihara, 2006). The focus of previous research has compared the use of ACMC and SCMC (Sotillo, 2000; Pérez, 2003), SCMC and face-to-face (Böhlke, 2003; Iwasaki \& Oliver, 2003), or examined the simultaneous use of the three SCMC modes (Hampel, 2006; Hauck \& Young, 2008; Turani \& Calvo, 2006; Wang, 2004), with less research focusing on SCMC in its own right.

Text-SCMC ${ }^{1}$ was chosen for the current study because when it was conceived text-SCMC was the most common, reliable and affordable means of SCMC used for educational purposes (Gonzalez, 2003), particularly for L2 learning and teaching. This has been reported in a number of SLA research studies (e.g.

\footnotetext{
${ }^{1}$ In this dissertation, text-SCMC is used interchangeably with online text chat.
} 
Blake, 2005; E Sá \& Melo, 2007; Lai \& Zhao, 2006; Sotillo, 2005). Furthermore, the association between text-SCMC and L2 development relates to Vygotsky's (1987) concept of texts as thinking devices. Warschauer (1997) discusses the role of text-SCMC in drawing learners' attention to linguistic structures when they pause during on-line interaction and reflect on their language use as seen on screen particularly in an attempt to resolve miscommunication. Similarly, these opportunities may illustrate the metalinguistic and reflective roles of output in language acquisition as indentified by Swain (2005). Thus, when learners view the output of their text communication in the computer screen, they may be able to correct the grammatical errors and consequently, may produce modified output. As stated by Smith (2003a), "learners elicit modified input from one another, are pushed to modify their own linguistic output, and receive important feedback on their TL use, thus potentially focusing their attention on their problematic utterances" (p39). This, therefore, may be facilitative to L2 acquisition and learning. As such, text-SCMC may serve as a potential medium for language learning and practice.

\subsection{Overview of task-based interaction}

Access to technology does not in itself ensure quality learning experiences. It is also important that learners are set well constructed tasks that allow them to practice their target language via text-SCMC. As Ellis (2000) states, “Tasks, ... are seen as the external means by which we can influence the mental computations that learners make. These computations determine how effectively they communicate and how they acquire language" (p.198). For example studies have shown that manipulating the inherent characteristics of tasks (i.e. task complexity) provides opportunities for L2 learning through learner language production (Skehan, 1996, 1998, 2009; Robinson, 2001b, 2003b, 2005, 2007b) and through encouraging learners to focus on form (Adams, 2007; Doughty \& Williams, 1998; Foster \& Ohta, 2005; Gass, Mackey \& Ross-Feldman, 2005; Mackey, 1999). Thus, interaction may serve as a potential means for learners to acquire facility with particular aspects of language use that the task entails (e.g. the meaning of a lexical items, how to express 
a particular meaning) and, at the same time, creates a context for authentic language use in its own right.

\subsection{Motivation for the current study}

There are three main motivations for the current study:

- whether language learners can assist each other to develop their L2 communication skills

- how tasks assist learners to improve their language learning

- how useful text-SCMC is for language learning.

These are outlined in more detail below.

For language learners in a foreign language environment opportunities for L2 interaction are limited. They occur mostly between peers or with teachers, who in the case of this study are second language speakers of English. A motivation for the current study was to determine if these learners can help each other develop their language skills in the context of task-based text-SCMC, by recognising and drawing attention to each other's problematic language issues, and providing modified outputs that help facilitate L2 learning and development.

Tasks are also an important part of L2 learning. As Ellis (2003) points out, "through tasks, we can engage learners in the kinds of cognitive processes that arise in communication outside the classroom" (p.336). There is an ongoing need to investigate how and which features of tasks facilitate the kinds of cognitive and interactional processes associated with second language learning.

Researchers have demonstrated the benefits of using SCMC to foster language learning (Fitze, 2006; Freiermuth \& Jarell, 2006; Sanders, 2006). However, to date only a few have investigated the use of tasks in the SCMC environment (Lee, 2008; Smith \& Gorsuch, 2004; Schwienhorst, 2004; Smith, 2005), an area that Warschauer (2001) argues is in urgent need of further research. For educators at tertiary institutions tasks need to be relevant to the learners' future industrial settings, with learners' behaviour reflecting how they would behave in their future professions (Stevens, O’Connor, Garrison, Jocuns, \& Amos, 2008; Valcke, 2005). The current study takes up this challenge by investigating the 
implementation of the task-based approach via text-SCMC for electrical and electronic engineering learners.

The use of SCMC in the field of English for Specific Purposes (ESP) is underdeveloped, as is research in this area (Al-Jarf, 2006; Shamsudin \& Nesi, 2006; Vetter \& Chanier, 2006). For participants in the current study using technology, particularly SCMC, as a medium of instruction was equally important to them as learning English (Fisher, Usrey, \& Beasley, 2003; Ware \& Warschauer, 2005; Warschauer, 2003). This is because communicating electronically is pervasive in their academic and professional communications, as engineering jobs increasingly require people to have electronic communication skills (Lee \& Yeap, 2005; Reese, 2001). To work in global contexts they must be proficient e-communicators in English, as it is the language used by many international businesses (Acar, 2006; Foo \& Richards, 2004; Riemer, 2002; Rompelman, 2001). They must also demonstrate skill handling and solving engineering tasks typical to engineers' jobs in a real world context (Brophy, Klein, Portsmore, \& Rogers, 2008; Fouger, Almgren, Gopalakrishnan, \& Mailhot, 2008; Redish \& Smith, 2008), which was one of the mandatory requirements stated in the EC2000² (Williams, 2002).

\subsection{Significance of the current study}

To highlight the value of CALL, previous studies typically compared CALL and traditional face-to-face classes. However, Burston (2003) argues for a move away from comparative studies towards studies that evaluate CALL in its own right. She claims that the findings from comparative research are by now well established, that CALL is now an established mode of instruction and communication, and that many language practitioners employ technological tools in language teaching and learning as a standard component of instruction, as in the context of the current study.

This study aims to make a contribution to the practical applications of CMC in education. In particular, this study aims to provide insights for educational practitioners and technologists, instructional designers, and curriculum specialists

\footnotetext{
2 EC2000 stands for 'Engineering Criteria 2000' that outlines learning skills that engineering graduates should master, one of which is the ability to effectively communicate in an engineering environment.
} 
who use text-SCMC as a medium of instruction in language teaching through evaluating the effect of different variables associated with the implementation of tasks in text-SCMC.

This study also intends to enhance awareness of the importance of second language interaction mediated by computers. More specifically, it highlights the experience of learners with an engineering background doing a course on English for Professional Communication communicating in their second language via textSCMC. As future engineers, these learners need to be exposed to innovative educational technology to complement their professional knowledge and skills.

It also looks at the use of tasks that are relevant to the learners' future profession. When learners have been trained to communicate electronically while solving tasks relevant to their profession, they should have increased confidence if they need to communicate with engineers in other countries in the future.

\subsection{Summary}

This chapter has briefly introduced the main themes that are addressed in this study, including the importance of CMC and appropriate tasks in L2 learning and teaching. The next chapter reviews the literature on interaction, tasks and languagerelated episodes (LREs). 


\section{CHAPTER TWO \\ INTERACTION, TASKS AND LANGUAGE-RELATED EPISODES}

\subsection{Introduction}

The first chapter introduced a broad overview of the theoretical foundations underpinning the current study. This chapter elaborates on the roles of interaction, tasks, and language-related episodes (LREs) in L2 learning and development.

\subsection{Input, output, attention and interaction}

Input is linguistic data that plays a role in language learners' morphosyntactic, lexical and phonological development. Early second language acquisition (SLA) research has emphasised the importance of comprehensible input for enhancing second language (L2) acquisition. Krashen's Input Hypothesis (1978, $1985,1994)$ is founded on the concept of ' $i+1$ ', where understandable input in the L2 that is just a little beyond the learner's current linguistic competence is necessary and sufficient for language development. He emphasised that the L2 is only acquired when learners receive messages they understand (Krashen, 1996). However, input can also be manipulated to enhance its comprehensibility (Crossley, Louwerse, McCarthy \& McNamara, 2007; Farley, 2005; Larsen-Freeman \& Long, 1991; M. Smith, 1993; Trahey \& White, 1993).

However, merely decoding input does not guarantee language acquisition (Ellis, 1994; Larsen-Freeman \& Long, 1991; Long, 1996), as engaging in conversational interaction is also seen as important to facilitate L2 learning and development. The Interactionist Approach (Mackey \& Gass, 2006) proposes that providing language learners with comprehensible input alone is insufficient. Rather, successful language acquisition requires comprehensible input achieved through the active production of output, including interactional adjustments and modifications (Doughty \& Pica, 1986; Gass \& Varonis, 1985a; Pica \& Doughty, 1985). As Gass and Torres (2005) explain, "it is widely recognised that input is essential for language acquisition. In addition to input, it is also accepted that interaction plays a crucial role in the process of learning a second language" (p.1). During interactions 
learners may notice a gap in their target language input. In relation to this Schmidt (1993, 1995, 2001) argued that noticing, as a conscious process in language acquisition, was necessary. This Noticing Hypothesis is where learners become aware of differences between their interlanguage and the target language then form hypotheses about the linguistic rules of that language.

In a recent version of the Noticing Hypothesis Schmidt (2001) argues that, "SLA is largely driven by what learners pay attention to and notice in the target language input, and what they understand the significance of the noticed input to be" (pp.3-4). Nevertheless, Schmidt acknowledges that access to attentional resources is limited for language learners, which in turn limits their processing capacity (cf. Skehan 1998).

In the same vein, Swain (1985) was unconvinced that learners could "pay attention to meaning and form simultaneously" (p. 248). She believed that negotiation of meaning is an initial step that frees the learner to pay attention to form. For this reason Swain $(1985,1995,2005)$ proposed the Output Hypothesis, which explains the three main functions of output and how they interact with input. These functions are:

- noticing gaps in one's interlanguage

- testing hypotheses about the L2

- metatalk, or using language to talk about language.

First, output serves as a trigger for noticing. That is, learners may notice the gap between what they want to produce and what they can actually produce in the target language. In 'noticing the gap' learners consciously recognize the difficulty in expressing a meaning due to a gap in their language resources. This draws attention to something they need to discover about the gap and to relevant input. As such, the learners may engage in cognitive processes in which new linguistic knowledge is generated or their current existing linguistics knowledge is consolidated (Swain \& Lapkin, 1995). Swain added that the feedback a learner seeks or receives on a gap that they have noticed also promotes language learning (Loewen \& Philp, 2006; Mackey, 2006; McDonough, 2005).

The second function of output involves hypothesis testing. This is a situation in which learners have the opportunity to test their interlanguage knowledge by trying out new structures and forms they have constructed. The learners' attempts to 
produce clearer messages can push them to use more targetlike language. Swain (1995) termed such output 'pushed output'. This is where the output serves as the mechanism for stretching learner competence, as they have to re-express their ideas in more accurate and/or appropriate language to be understood (Izumi, 2003; Leeser, 2008).

Finally, Swain noted that the third function of output is the metalinguistic function. It is the process involving learners engaging in metatalk which provides opportunities for them to reflect on, discuss and analyse language problems or linguistic gaps during interaction. This process pushes learners to shift from a semantic level of processing to a syntactic level. In this way, Swain claimed that learner talk assists in the process of controlling and internalizing linguistic knowledge. As such, producing output promotes more learning than comprehension alone (Watanabe \& Swain, 2007).

Interaction may provide an instructional context in which input, output, and noticing connect for L2 learning and development to occur. The following section shows how interaction acts as a resource that assists in the process of L2 learning.

\subsection{Interaction and L2 learning}

In an earlier statement of the Interactionist Approach, Long's Interaction Hypothesis (1996) proposes that the process of interaction facilitates language learning because it connects "input, internal learner capacities, particularly selective attention, and output in productive ways" (pp.451-452). Long (2006) argues that when learners have the opportunity to interact and negotiate for meaning they can make input comprehensible. Interaction may also force learners to draw deeply on their language resources (Gass, Mackey \& Pica, 1998; Lyster \& Mori, 2006; Mackey, 2006), which may draw their attention to mismatches between their output and the target language forms (Ellis, 1991; Williams, 1995). These adjustments, which occur during interaction, serve to make L2 target forms salient to learners (Long, 1983). In turn, this increased salience is beneficial to L2 development (Ellis \& He, 1999; Ellis, Tanaka, \& Yamazaki, 1994; Foster \& Ohta, 2005; Gass, 1997; Mackey, 2002; Oliver, 2002; Pica, 1994; Shehadeh, 2002; Swain 1995, 2005). 


\subsubsection{Interaction between native and non-native speakers}

Interaction occurs when two or more speakers communicate messages using language. A number of studies framed under Long's Interaction Hypothesis (1996), which is the earlier statement of the Interactionist Approach, claimed that conversational interaction between native (NSs) and non-native speakers' (NNSs) promotes language learning (Ellis, et al., 1994; Gass \& Varonis, 1985a, 1994; Mackey, 1999). Language learning is assumed to occur when the NNSs adopt the correct use of the target language from the NSs as they engage in the process of negotiation of meaning.

A growing body of research supports this. That is, that language learning is facilitated when learners engage in interactional modifications with NSs (Carpenter, Jeon, McGregor, \& Mackey, 2006; Gass \& Torres, 2005; Ellis \& He, 1999; Ellis, Loewen, \& Erlam, 2006; Lyster \& Mori, 2006; Mackey, 1999; Mackey, Oliver \& Leeman, 2003; McDonough, 2005; Oliver \& Mackey, 2003; Polio, Gass, \& Chapin, 2006). For example, Mackey and Silver (2005) found that learners who received interactional feedback from an adult NS demonstrated development in the targetlike question form. Mackey (2006) also reported that interactional feedback positively contributed to noticing of L2 form, and Philp (2003) found that interaction between NS-NNSs encouraged noticing of implicit feedback. Other studies reported that interaction between NSs and NNSs resulted in recasts, a form of feedback facilitative to L2 learning (Sheen, 2004). Loewen and Philp (2006) showed that recasts offered by NS teachers to learners resulted in successful uptake.

While these studies support the claim that interaction between native and non-native speakers facilitates L2 learning and development, Mackey and Gass (2006) emphasise that interaction is not a comprehensive causal theory of L2 learning. Rather, it is a window for viewing important aspects of the L2 learning processes and acts as a facilitator of many of these processes (Gass \& Torres, 2005), particularly "recasts, negotiation, LREs and modified output" (Mackey \& Gass, 2006, p.173). Aspects of interaction found in NS-NNSs interaction can also be found in NNS-NNS interaction. This suggests that interaction between learners may also have potential benefits for language learning (Pica, Lincoln-Porter, Paninos, \& Linnell, 1996; Varonis \& Gass, 1985b). 


\subsubsection{Interaction between non-native and non-native speakers}

Research has shown that interaction between learners can improve the comprehensibility of input (in part through opportunities for negotiation for meaning), encourage learners to focus on form (Adams, 2006) and can lead learners to improve the quality of their output through negotiation and feedback (Oliver, 2002; Storch, 1999, 2001; Swain, 1995; Swain \& Lapkin, 1998, 2001, 2003). Varonis and Gass (1985b), for example, have acknowledged the value of learnerlearner interaction, stating that the interlanguage talk generated during these conversations may serve as a source of opportunity for negotiating meaning.

Oliver (2002) found that the highest amount of negotiation facilitative to L2 learning was produced by NNS-NNS dyads, as compared to NS-NNS and NS-NS dyads. Similarly, Leeser (2004) found that learner-learner interaction promoted attention to noticing the gaps in their target language. Other studies reported that the benefits of learner-learner interaction include an increase in the likelihood of attention to form (Adams, 2006), improved production of target forms (McDonough, 2004), and syntactic priming (McDonough, 2006).

Foster and Ohta (2005) examined interactional processes, particularly the negotiation of meaning that occurs during learner-learner interaction while performing information exchange tasks. The quantitative analysis revealed that signaling communication problems through negotiation of meaning and modification of the output were infrequent. However, it was also illustrated that during L2 interactions negotiation of meaning was a subset of a larger variety of conversational moves, namely co-construction, other- and self-correction, and continuers.

This shows that more empirical research is needed to evaluate other aspects of L2 interactional features (for example, language-related episodes or LREs as suggested by Mackey \& Gass, 2006) that could lead to L2 learning and development (Jenks, 2007; Mackey, 2002). However, the question that remains is: what mechanism can induce aspects of L2 interaction? The following section explains how tasks could serve as the mechanism to elicit aspects of L2 interaction that may facilitate L2 learning. 


\subsection{Overview of task-based approach in L2 classroom}

Task-based language teaching is based on the dual premise that language learning can occur analytically through holistic language use activities (c.f, Samuda \& Bygate, 2008) and that these activities should reflect the things learners need to be able to do beyond the classroom (Long \& Crookes, 1992). The large body of research on tasks shows that the use of tasks in L2 classroom is beneficial for promoting communication, interaction, and negotiation, which facilitates language acquisition (Gass \& Varonis, 1994; Iwashita, 2003; Mackey, et al., 2003; Newton \& Kennedy, 1996; Philp, 2003; Pica, Kanagy, \& Falodun, 1993). The use of tasks may also assist learners to develop linguistic and cognitive skills (Adams, 2006; Long \& Crookes, 1992; Pinter, 2006; Robinson, 2001b; Skehan, 2003a; Yuan \& Ellis, 2003), and offer an optimal active learning space. For example, tasks build a learner's autonomy, and support a learner-centred approach by providing meaningful and authentic activities (Lingley, 2006; McDonough \& Chaikitmingkol, 2007; Mori, 2002). In addition, tasks allow for diverse learning styles, which will increase learner motivation and interest (Appel \& Gilabert, 2002; Dörnyei \& Kormos, 2000).

\subsubsection{Defining tasks}

Various definitions of task have been proposed (Bygate, Skehan, \& Swain, 2001; Long, 1985; Nunan, 2006; Oxford, 2006; Skehan, 1996; Willis \& Willis, 2007). For example, Skehan (1998) defines a task as an activity in which:

- meaning is primary

- there is some communication problem to solve

- there is some sort of relationship to comparable real-world activities

- task completion has some priority

- the assessment of the task is in terms of outcome (p.95).

Similarly, Ellis (2003) proposes that a task:

- is a workplan

- involves primary focus on meaning

- involves real-world processes of language use 
- can involve any of the four language skills

- engages cognitive processes

- has a clearly defined communicative outcome (pp.9-10).

Skehan (1998) and Ellis (2003) agree that a task is a goal-oriented activity involving a meaningful, real-world process of language use, which engages language skills and cognitive processes. As such, the primary focus of a task is meaning where L2 proficiency is developed through communicating, rather than learning specific linguistic items.

For the purpose of the current study, the task I used follows the definition of tasks outlined by Ellis (2003) above in the following ways. First, the task as workplan recognizes that the learners' engagement in the task may vary from that intended by the teacher according to their learning style and motivation. Second, it was a meaning-based task which required the learners to use language communicatively in order to solve a problem related to their future profession, and in this case the learners had to argue for and against each other in order to justify the choice of their own engineering software. Third, while the task simulated real world communicative events, the target language in this case, the English language, has served as the vehicle for the learners in performing the task. Fourth, the task required dialogic language use in which the learners were asked to engage in discussions or communicate with each other via text-SCMC. Fifth, the learners were pushed to engage in the cognitive processes as they reasoned out, analysed, evaluated the information and finally solved this engineering problem-solving task. Engaging in this kind of activity also was particularly relevant for these learners, who were engineering students, because it may assist in developing the learners' communication and professional skills as described in EC2000 3 (Williams, 2002). Finally, the task was determined to be successfully completed when the learners reached a non-linguistic outcome, in this case, suggesting the most suitable software to be purchased by the organization they were working with.

Tasks can be manipulated for pedagogic and research purposes (Van den Branden, 2006). As learner performance varies according to task characteristics, researchers looking at language tasks have been concerned with identifying which

\footnotetext{
${ }^{3}$ Refer to p.6, note 2 .
} 
task characteristics to manipulate to promote L2 learning. Various approaches, which may affect the interactional design, intrinsic structure or conditions under which tasks are performed, have been proposed regarding task manipulation to test and measure their effect on L2 learning and development. In this regard, two different agendas have inspired research into task manipulation (although see Platt \& Brooks, 2002, for an alternative view).

The first is an Interactionist Approach (Mackey \& Gass, 2006), which examines what modifications can be applied to tasks for them to generate negotiation routines or conversational episodes that facilitate L2 learning. The second approach is an Information-processing Approach which puts emphasis on task complexity. This approach puts emphasis on manipulating tasks to elicit learner output, which leads to differentials in the areas of fluency, complexity, and accuracy (Robinson, 2001b, 2003; 2005; Skehan, 1998; Skehan \& Foster, 1999; Tavakoli \& Foster, 2008). In this chapter, the interactionist view is discussed in detail, while Chapter Three presents the task complexity approach.

\subsubsection{Tasks and L2 interaction}

From the interactionist perspective, tasks are seen as an effective way of providing context for interaction, particularly negotiated interaction. Tasks that provide opportunities for interactional processes and negotiation through modifications of the linguistic structures assist in the comprehension of linguistic input, and the production of linguistic output (Mackey \& Silver, 2005; Mackey, et al., 2003; McDonough, 2004). However, if interaction is believed to be facilitative for language learning, the challenge for language practitioners is to offer learners every opportunity to engage in active interaction while performing a communicative task. The question is how do we accomplish that?

Studies have examined and compared different types of tasks and their impact on learning processes and performance. For example, tasks have been manipulated to look at:

- the flow of information during interaction (Gass \& Varonis, 1985b; Pica \& Doughty, 1988) 
- $\quad$ split versus shared information among participants (Newton \& Kennedy, 1996; Pica \& Doughty, 1988)

- the convergence or divergence of goals (Duff, 1986)

- closed or open-ended outcomes (Long, 1989)

- the optional or required exchange of information gap (Doughty \& Pica, 1986).

These studies were conducted to examine what types of tasks can lead to negotiation and interactional modifications during interaction, and are facilitative to L2 learning and development.

Several studies on different task types have shown that tasks with an information gap generate more interactional modifications that appear to facilitate L2 learning (Ellis, 2003; Mackey, et al., 2003; Pica \& Doughty, 1985; Pica, Kang \& Sauro, 2006). The information gap task is characterised by a number of features, including an exchange of information between participants, and because only one answer is considered appropriate, they have to ensure that information is precise and understood (Pica, et al., 1993). However, during the interactional processes, when one learner has difficulty understanding the message the others (or one person) may need to clarify by rephrasing, modifying or elaborating the output. Such interactional processes may go on until the message appears to be understood. As the interlocutors engage in negotiation episodes (Varonis \& Gass, 1985) their attention is drawn to the meaning of the message and how the message is encoded.

Foster and Ohta (2005) found that tasks involving two-way information exchange may prompt significantly more negotiation routines and conversational adjustments than one-way information gap tasks (cf. Doughty \& Pica, 1986). In a two-way task, each partner holds relevant, but incomplete, information. This necessitates co-operation and information sharing between each partner for the task to be successfully completed. During the exchange of information learners may be prompted to modify their utterances, allowing them to engage in conversational adjustments (Pica, 2005), which in turn facilitates their language acquisition.

However, Slimani-Rolls (2005) reported a different finding. She found that learners who engaged in a two-way task focused more on acquiring the missing information than engaging in meaningful negotiation. This indicates that the twoway task was less effective in providing negotiation. In contrast, the one-way and 
decision making tasks generated more negotiation, and so offered more opportunities for driving L2 development forward. Nevertheless, Slimani-Rolls acknowledged that learners' familiarity with the context of the task, their classmates, and even their perceptions of the tasks, may have influenced the scarcity of meaning negotiation in her study.

While these studies show that task types may influence the occurrence of meaning negotiations that are perceived to be beneficial for promoting L2 learning, Slimani-Rolls (2005) and Foster (1999) found that some may be less efficient for L2 learning. Foster examined the effect of task types (i.e. optional or required information exchange) and participant structure (i.e. dyads or small group) on the quality of learner output when performing tasks in a normal classroom setting. She found task types alone did not influence the amount of meaning negotiation. Instead, the dyad setting, together with the required information exchange task, promoted language production, negotiations, and modified output. Additionally, Foster suggested that the experimental setting may have promoted the learners' engagement in more negotiations and modifications.

Gass, et al. (2005), replicated Foster's study by comparing learner-learner interaction while they performed tasks in classroom and laboratory settings to see which setting was more conducive to promoting interactional modifications. The participants worked in dyads performing three different types of communicative tasks: the consensus, picture differences, and map tasks. Their interaction was coded based on the occurrences of negotiation of meaning, language-related episodes, and recasts. The results revealed that setting did not influence interactional patterns. Instead, the types of tasks, particularly the two information exchange tasks (picture differences and map), promoted more occurrences of interactional patterns than optional information exchange task (consensus). The researchers concluded that successful interaction is independent of setting, as was also suggested by Philp, Oliver and Mackey (2006).

Considering the empirical studies reported above, research on task types seems to indicate that certain types of tasks may promote more negotiated interaction than others, which may in turn promote L2 learning. Beyond negotiation of meaning, research has also indicated that explicitly attending to form while 
performing tasks may promote L2 learning and development (Ellis, 2002, 2003, Farrokhi \& Gholami, 2007; Loewen, 2003; Murphy, 2005).

Proponents of task-based L2 learning and teaching have argued that the approach is an ideal medium for implementing focus on form, where learner attention is drawn to form in the context of meaning (Révész, 2009). In the context of task-based interaction, noticing and focus on form can take the form of languagerelated episodes (LREs), or short episodes where learners turn their attention from discussing content to focusing on linguistic form (Swain \& Lapkin, 2001). This notion is discussed further in the following section.

\subsection{Language-related episodes (LREs) and L2 learning}

Many researchers have addressed the importance of prompting learners to notice or attend to language form (Adams, 2003; Basturkmen, Loewen \& Ellis, 2002; Doughty \& William, 1998; Klapper \& Reese, 2003). Opportunities to focus on form arise in task-based teaching (Ellis, 2003) where through learner interaction and engagement in meaningful tasks, they may notice certain input features and compare them with their own output (Ellis, Basturkmen \& Loewen, 2001a; Loewen, 2004; Williams, 2001). Long (1991) illustrates the concept of focus on form as drawing “... students' attention to linguistic elements as they arise incidentally in lessons whose overriding focus is on meaning and communication" (pp.45-46). As such, focus on form in L2 learning requires engagement in meaning before attention to linguistic features can be expected to be effective (Long \& Robinson, 1998).

Studies have shown that one way focus on form can take place during task performance is through language-related episodes (LREs) (Adams, 2006; Hanaoka, 2007; Loewen, 2005). Swain and Lapkin (2001) define an LRE as:

any part of a dialogue where students talk about language they are producing, question their language use, or other- or self-correct their language production (Swain \& Lapkin, 1995). LREs thus entail discussion of meaning and form, but may emphasise one of these more than another (p. 104).

In this definition, language uses include meaning, word order, word choice, spelling, and others. Therefore, following Swain and Lapkin's (1995; 2001) definitions, LREs in the current study were categorized into two; LREs on meaning (segments in the 
data where the learners dealt with word meaning and lexical choices) and LREs on form (segments in the data where the learners dealt with aspects of morphology or syntax $)^{4}$. Basturkmen, et al. (2002) have identified similar episodes to LREs, but named them Form-focused episodes (FFEs). That is, "sequences of moves that focused on linguistic items and that occurred in interaction primarily concerned with meaning" (p.4). Therefore, in this dissertation, LREs and FFEs are taken to be equivalent terms.

Studies have shown that the occurrences of LREs may demonstrate the positive correlation with L2 learning (Gass \& Mackey, 2007) For example, Swain and Lapkin (2002) examined the interaction between a pair of grade seven French immersion learners for the occurrence of LREs as a result of their 'metatalk', i.e. the talk about language. During the pre-test stage (30 minutes allocation of time), the learners were asked to collaborate in completing a jigsaw story task first orally and in writing. After completing the task, the learners engaged in a noticing session for 10 minutes, i.e. the learners compared their written stories to a reformulated version written by a native speaker. The next stage required the learners to respond to a stimulated recall task for 40 minutes. Finally, the learners were instructed to independently revise and re-write the story. This 15 minutes re-written stage was treated as a post-test. Interviews were carried out to gauge their perceptions of the tasks. Based on the data gathered from one pair of learners, a considerable number of LREs (47) were produced during the pre-test writing stage. Although the reformulator made 29 changes to their written text, the pair produced 21 LREs during the noticing session. Next, in the stimulated recall session, the pair produced 23 LREs. Interestingly, most of the LREs produced were form-based, instead of lexis- or discourse-based. During the post individual writing test, both learners achieved $78 \%$ correct linguistic items. The interview with the learners indicated that they perceived the collaborative learning approach to be very helpful because through discussion they could learn from each other. While this was not a task-based study, understanding how the task was implemented may provide further explanation of the higher occurrence of LREs on form. The researchers noted that because the learners were able to notice the language form they used during the initial writing session, read the reformulated version then engage in a stimulated

\footnotetext{
${ }^{4}$ See Chapter 5, Section 5.10.1 for details.
} 
recall session, they managed to incorporate more appropriate linguistic items in their individual writings. This may suggest that in meaning-based tasks, although it is expected that learners prioritise meaning over form, their attention could be shifted to the language use when they receive some kind of attention to form.

Additionally, meaning-based tasks under certain conditions can also elicit focus on form in ways that appear conducive to language learning (Ellis, et al., 2001a; Ellis, Basturkmen, \& Loewen, 2001b; Loewen, 2005). For example, this was reported by Leeser (2004), who investigated the extent to which performing collaborative tasks pushed learners to reflect on their language use. 42 L2 Spanish learners (21 dyads) engaged in a dictogloss or passage reconstruction task which was assumed to facilitate focus on form. The processes involved a series of stages. In the first stage, without writing any notes, the learners listened to a short, dense passage. The next stage involved learners jotting down some notes as they listened to the passage for the second time. In the final stage, the learners worked collaboratively, making comparison between each other's notes in an attempt to individually reconstruct the written passage. During this final stage, the learners searched for and discussed appropriate grammatical forms and lexical items to complete their writing. The occurrence of LREs at this stage was studied. Similar to Swain and Lapkin's (2002) finding, Leeser found that learners engaged in LREs on grammar $(60 \%)$ more than LREs on lexis $(40 \%)$. He claimed that higher proficiency learners engaged more in LREs on grammar, while lower proficiency learners engaged more in LREs on meaning. According to Leeser, high proficiency learners had little trouble understanding the meaning of the task, so were able to focus their attention to linguistic form. Low proficiency learners had to struggle to understand the meaning first to perform the task. However, most LREs were resolved regardless of the learners' proficiency. The study shows that the language help provided to the learners prior to the task performance could have provided the language model that encouraged them to focus on grammatical items. Therefore, it appears that when learners' communicative burden is eased (in this study when they received language models), interaction between learners may encourage occurrences of LREs (in this case more LREs on grammar than meaning). As this study suggests, learner-learner interaction while performing meaning-based tasks could result in learners discussing the language forms they found to be problematic, and as such, be facilitative in L2 
learning. Fortune (2005) also reported a similar finding to Leeser's. Learners in Fortune's study were familiarised with the use of correct form prior to the task performance, which may have heightened their awareness of form. As a result, they were found to focus more on discussing the form than meaning.

Focus on form was also investigated by Malmqvist (2005), who looked at LREs produced by learners during group discussions. In this study learner attention was directed more at discussing problematic form than meaning during interaction. It was found learners focused their attention to grammatical items the most (42\%), followed by content $(31 \%)$, and lexical $(27 \%)$ items. Malmqvist noted that each group had at least one participant with a proficiency level beyond beginner level. Therefore, the knowledge this learner had regarding the overall meaning of the task may have meant they were able to direct other group members' attention to focus more on grammatical items, rather than trying to figure out the meaning of the content. However, it was not highlighted whether the level of demand of the task on learners may have influenced their attention to the grammatical items (the study used adult learners, and the texts were taken from the newspaper). Therefore, task demand, with regard to learners understanding the meaning, might not be high. Hence, they could focus more on grammar during interaction.

While the studies reported above examined the occurrences of LREs on meaning and form during task performance, Philp et al. (2006) raised a question about what learners are actually doing during the planning time they are provided with prior to task performance. To examine this, Truong and Storch (2007) investigated LREs that occurred during 20 minutes planning time while learners interacted in group discussions preparing for their individual presentation. The learners were found to focus more on content than form during group discussion, as well as their individual presentations. The researchers attributed this to the nature of the task (i.e. the presentation task), which was meaning-focused and not graded. Therefore, the learners did not worry about their linguistic accuracy, rather, understanding the meaning was important for them to complete the task (for presentation purposes). The researchers suggested that because of the learners' low proficiency levels their limited attentional resources were directed towards expressing meaning, rather than refining their grammar. Also, because the planning session was unguided in terms of the language forms, it was unlikely that learners 
would focus on the linguistic aspects. This study may suggest that when task demand is lowered, by providing learners with planning time, they were able to focus on their language output even if their proficiency level is low. Ellis (2003) suggested that when planning time is available, learners' cognitive loads can be reduced, allowing them to focus on their production.

In looking at the production of LREs, Poole (2005) reported a different finding from Swain and Lapkin (2002), Leeser (2004), and Malmqvist (2005). He found that learners engaged in LREs on meaning (89.8\%) more than form (10.2\%). Poole suggested that because the learners in his study were learners with advanced language proficiency, they tended to focus on lexical more than grammatical items. It should be noted that the material/task that Poole used was more specific to an anthropology course and not particularly for use for L2 learners. However, while it was not stated, task demands could be the other reason for the greater production of LREs on meaning than form in Poole's study. If the cognitive demand of the task is high (in this case, the task content required learners to process meaning simultaneously with language form), the learners had to prioritise their attentional resources. In this case they appeared to prioritise meaning over form. As a result, learners tended to produce more LREs on meaning than form.

Studies of LREs in interaction have typically compared the occurrences of LREs on meaning and form, and it appears that L2 learners face difficulty allocating their attentional resources to both. This may be influenced by task complexity, (e.g., Skehan 1998; Robinson 2001b, 2005). Additionally, a number of the findings reported above have implied that certain inherent task characteristics or the cognitive complexity of tasks may promote more negotiation and interactional modifications than others as evident by the occurrences of LREs (Leeser, 2004; Poole, 2005).

Kim (2009) examined the effects of task complexity on the occurrence of LREs in dyadic interactive tasks among low and high proficiency learners. Two task types were used; a picture narration task and a picture difference task. These tasks were manipulated along two resource-directing variables, i.e. \pm reasoning demands and \pm few elements, respectively (following Robinson, 2007b ${ }^{5}$ ). For the picture narration tasks, the results indicated that more LREs were produced by low proficiency learners during the simple picture narration task than the complex

\footnotetext{
${ }^{5}$ Refer to Chapter 3 for details.
} 
picture narration task. In contrast, more LREs were evident in the complex picture narration task than the simple picture narration task among the high proficiency learners. With regards to the picture difference tasks, the low proficiency learners produced a higher number of LREs during the complex task than the simple picture. However, no significant difference was evident in the high proficient learners. The relationship between the production of LREs and task complexity therefore differed according both to task type and to learner proficiency. Kim argued that the findings demonstrated that different types of learning opportunities may be promoted by different task complexity.

Like Kim (2009), one of the objectives of the current study is to examine the effect of task complexity in promoting focus on form, as reflected in the amount of LREs produced during task-based learner-learner interaction. In the case of the current study, the focus is on the relationship between increasing task complexity through resource-dispersing variables and focus on form.

\subsection{Summary}

This chapter has reviewed research based on input, interaction, and outputbased SLA theoretical frameworks. Research on the use of tasks and LREs were also reviewed. Studies like those reviewed in this chapter provide evidence that the way that the task is implemented may create learning opportunities by influencing the extent to which learners attend to form (c.f., Skehan 1998; Robinson 2001, 2005). Because learner performance varies according to task characteristics, researchers looking at language tasks have been concerned with identifying ways to optimize L2 learning through tasks. One means of doing this may be through manipulating task complexity (Robinson 2001b, 2005, 2007b; Skehan, 1998, 2009). The next chapter elaborates the relation between task complexity and language production. 


\section{CHAPTER THREE \\ TASK COMPLEXITY}

\subsection{Introduction}

This chapter reviews theoretical accounts that highlight the influence of the cognitive complexity of a task on language learning and language production (Robinson, 2001a, 2003b, 2005, 2007b; Skehan, 1996, 1998, 2009; Skehan \& Foster, 2001). In relation to this, Lyster (2004) argued that cognitive theory drawing on information processing models should be used when explaining and evaluating L2 learning and development. Researchers have investigated how manipulating the cognitive features of tasks can lead to different outcomes in the accuracy, complexity and fluency of learner language production (Foster \& Skehan, 1996; Gilabert, 2007b; Izumi, 2003; Kuiken \& Vedder, 2008; Larsen-Freeman, 2006; Mehnert, 1998; Michel, Kuiken, \& Vedder, 2007; Ortega, 1999; Peters, 2007; Skehan \& Foster, 1997; Tavakoli \& Skehan, 2005; Yuan \& Ellis, 2003). Skehan (1996) defines three aspects of language production as:

- accuracy, which concerns “the learner's capacity to handle whatever level of interlanguage complexity s/he has currently attained"

- complexity, which relates to "the stage and elaboration of the underlying interlanguage system"

- fluency, which involves "the learner's capacity to mobilise an interlanguage system to communicate meanings in real time" (p.46).

The effects of task complexity on production have been measured with reference to:

- the degree of familiarity (Robinson 2001b)

- $\quad$ task structure (Hardy \& Moore, 2004)

- planning time allotted to learners (Yuan \& Ellis, 2003)

- here-and-now/ there-and-then references (Iwashita, McNamara, \& Elder, 2001a)

- the number of elements (Gilabert, 2007a; Michel, Kuiken, \& Vedder, 2007).

In general, tasks have been manipulated using the concept of task complexity dominated by two constructs: Skehan's (1996, 1998, 2009) Trade-off Hypothesis, 
which is based on the Limited Attentional Capacity Model, and Robinson's (2001b, 2005, 2007b) Cognition Hypothesis.

\subsection{Skehan's view of task complexity}

In Skehan's $(1996,1998)$ view, task complexity can be manipulated during task design to obtain the desired elicitation of learner language. Skehan considers several sources of task complexity that may influence the task design and sequencing criteria, as outlined in table 3.1 .

Table 3.1

Task sequencing features by Skehan (1996, p.52)

Code complexity

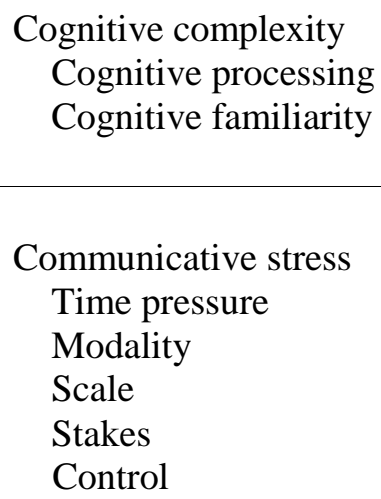

As seen in table 3.1, code complexity is concerned with the linguistic demands of a task, cognitive complexity deals with the content of a task and how it is structured, and communicative stress refers to performance conditions.

Skehan (1996, 1998), and Skehan and Foster (2001) view L2 learning in terms of the Limited Attentional Capacity Model (Levelt, 1989, 1993), and therefore, a trade-off between attentional resources when learners are confronted with complex tasks. In this model an increase in task complexity will put pressure on cognitive processing capacity. As such, the Trade-off Hypothesis (Skehan, 2009) argues that this pressure on learners' attentional resources forces them to prioritise their processing capacity to one or some aspects of language production (i.e. fluency 
or accuracy or complexity) at the expense of others. Of the three aspects, Skehan claims that accuracy and complexity are in competition for such attention.

In the Limited Attentional Capacity Model task types also influence the allocation of attention. Skehan (1998) suggests that unlike simple tasks, more complex tasks require a higher degree of cognitive processing, affecting at least one aspect of their production. He emphasises that "... more demanding tasks consume more attentional resources simply for task transaction, with the result that less attention is available for focus on form" (Skehan, 1998, p.97). Consequently, learners who have to carry out a more complex task will have fewer attentional resources left to focus on particular forms or structures.

The Trade-off Hypothesis (Skehan, 2009) claims that “... simultaneously advantaging all three (CAF) performance areas is unusual" (p.512). Nevertheless, Skehan $(1996,2009)$ proposes options to implement tasks in ways that address this. For example, providing planning time and clear task structure to mitigate the tradeoff effect and assist learners to balance their attentional resources. This will ease their processing load, allowing them to focus their attention on performing the task, which will result in accurate and complex language production.

\subsection{Robinson's view of task complexity}

Another view of task complexity was proposed by Robinson (2001b, 2005) in his Cognition Hypothesis, where he identified it as "the result of the attentional, memory, reasoning, and other information processing demands imposed by the structure of the task on the language learner" (Robinson, 2001b, p.28). Robinson asserts that designing a task to be simple or complex along different dimensions will influence whether and how trade-offs will be made. He emphasises that increasing the cognitive complexity of tasks "will facilitate the 'means' of language learning, and therefore lead to a transition in the learner's knowledge states" (Robinson, 2001a, p.301). Thus, the Cognition Hypothesis places a strong emphasis on the need for tasks to be designed and sequenced for learners on the basis of increasing their cognitive complexity. Based on this foundation, Robinson (2007b) developed the Triadic Componential Framework for task design, which is outlined in table 3.2: 
Table 3.2

Pedagogic L2 task classification: Triadic Componential Framework by Robinson (2007b, p.15)

\begin{tabular}{lll}
\hline \multicolumn{1}{c}{ Task complexity } & \multicolumn{1}{c}{ Task condition } & \multicolumn{1}{c}{ Task difficulty } \\
\hline (Cognitive factors) & (Interactive factors) & (Learner factors) \\
\hline (Classification criteria: & (Classification criteria: & (Classification criteria: \\
cognitive demands) & interactional demands) & ability requirements) \\
\hline (Classification procedure: & (Classification procedure: & (Classification procedure: \\
information-theoretic & behaviour-descriptive & ability assessment analyses) \\
analyses) & analyses) & \\
\hline Sub-categories: & Sub-categories: & Sub-categories: \\
(a) Resource-directing & (a) Participation variables & (a) Ability variables and \\
variables making & making interactional & task-relevant resource \\
cognitive/conceptual & demands & differentials \\
demands & & \\
& & \\
+/- here and now (Robinson, & +/- open solution (Long, & h/l working memory \\
1995) & 1989) & (Mackey et al., 2002) \\
+/- few elements (Kuiken et & +/- one-way flow (Pica et & h/l reasoning (Stanovich, \\
al., 2005) & al., 1993) & 1999) \\
//+ spatial reasoning (Becker & +/- convergent solution & h/l task-switching (Monsell, \\
\& Carroll, 1997) & (Duff, 1986) & 2003) \\
//+ causal reasoning & +/-few participations & h/l aptitude (Robinson, \\
(Robinson, 2005a) & (Crookes, 1986) & 2005b) \\
//+ intentional reasoning & +/- few contributions needed & h/l field independence \\
(Baron-Cohen, 1995) & (McGrath, 1984) & (Skehan, 1998) \\
//+ perspective-taking & +/- negotiation not needed & h/l mind/intention-reading \\
(MacWhinney, 1990) & (Long, 1983) & (Langdon et al., 2002) \\
& & \\
\hline & &
\end{tabular}

\begin{tabular}{|c|c|c|}
\hline $\begin{array}{l}\text { (b) Resource-dispersing } \\
\text { variables making } \\
\text { performative/procedural } \\
\text { demands }\end{array}$ & $\begin{array}{l}\text { (b) Participant variables } \\
\text { making interactant demands }\end{array}$ & $\begin{array}{l}\text { (b) Affective variables and } \\
\text { task-relevant state-trait } \\
\text { differentials }\end{array}$ \\
\hline $\begin{array}{l}\text { +/- planning time (Skehan, } \\
\text { 1998) } \\
\text { +/- prior knowledge (Urwin, } \\
\text { 1999) } \\
\text { +/- single task (Robinson et } \\
\text { al., 1995) } \\
\text { +/- task structure (Skehan \& } \\
\text { Foster, 1999) } \\
\text { +/- few steps (Fleishman \& } \\
\text { Quaintance, 1984) } \\
\text { +/- independency of steps } \\
\text { (Romiszowski, 1988) }\end{array}$ & $\begin{array}{l}\text { +/- same proficiency (Yule } \\
\text { \& MacDonald, 1990) } \\
\text { +/- same gender (Pica et al., } \\
\text { 1991) } \\
\text { +/- familiar (Plough \& Gass, } \\
\text { 1993) } \\
\text { +/- shared content } \\
\text { knowledge (Pica } \text { et al., } \\
\text { 1993) } \\
\text { +/- equal status and role } \\
\text { (Yule \& MacDonald, 1990) } \\
\text { +/- shared cultural } \\
\text { knowledge (Brindley, 1987) }\end{array}$ & $\begin{array}{l}\text { h/1 openness (Costa \& } \\
\text { Macrae, 1985) } \\
\text { h/1 control of emotion } \\
\text { (Mayer } \text { et al., 2000) } \\
\text { h/1 task motivation (Dornyei, } \\
\text { 2002) } \\
\text { h/1 processing anxiety } \\
\text { (MacIntyre \& Gardner, } \\
\text { 1994) } \\
\text { h/1 willingness to } \\
\text { communicate (MacIntyre, } \\
\text { 2002) } \\
\text { h/1 self-efficacy (Bandura, } \\
\text { 1997) }\end{array}$ \\
\hline
\end{tabular}


The framework consists of three factors: task complexity, task condition and task difficulty, which influence second language acquisition. Task complexity deals with the intrinsic, cognitive complexity of task features. The two complexity dimensions are resource-directing and resource-dispersing. The resource-directing dimension makes increased conceptual demands while the resource-dispersing dimension makes increase procedural demands on learners' attentional and memory resources. These are discussed in more detail below. Task condition involves the situational setting that determines task features. Robinson classifies these into two factors; participation and participant. Finally, task difficulty involves learners' perceptions of task demands, which could be affected by ability and affective factors. While these factors are equally important, Robinson (2005) asserts that effective task-based instruction should use the intrinsic complexity of an individual task as the task sequencing criteria. In Robinson's view, task complexity should be the foundation for sequencing the tasks to be performed by language learners.

For monologic tasks, Robinson (2001b, 2005) argues that manipulating task complexity along the resource-directing variables such as +/- here-and-now vs. +/there-and-then and $+/$ - few elements, directs learner attention to a wide range of functional and linguistic requirements. According to Robinson (2005), this happens as increasing complexity in monologic tasks along this dimension "... has the potential to direct learners' attentional and memory resources to the way the L2 structures encode concepts, and so leading to interlanguage development” (p.4). This should result in more accurate and complex though less fluent production compared to simpler counterpart tasks.

On the other hand, Robinson (2005) argues that increasing task complexity along the resource-dispersing variables in monologic tasks "does not direct learners to any particular aspects of language code" (p.7) and disperses attentional and memory resources, which will have negative consequences for production. This means accuracy, complexity and fluency of language production are expected to decrease in more complex tasks, such as when the task elements that support mental processing, such as structural support or planning time, are gradually removed.

Robinson (2007a) adds that for monologic as well as interactive tasks, more negotiations will be found in the complex rather than simple versions when manipulated along resource-dispersing dimensions. Robinson (2005) emphasises 
that “... more cognitively complex oral interactive tasks simply lead to greater quantities of interaction and modified repetitions" (p.11). Robinson (2001b) also suggests that this will result in more interactional modifications. This in turn promotes a high number of overlaps and interruptions, which may mitigate learners' attempts at using complex language. Additionally, more complex interactive tasks manipulated along the resource-dispersing variables make increased procedural demands on learners' attentional and memory resources, but do not direct them to any aspect of the language code. This therefore, does not facilitate development or acquisition of new L2 form-concept mapping. As a result, less accurate language will be evident.

In regards to Robinson's view of task complexity, it should be noted that, as Samuda and Bygate (2008) has pointed out, the model is incomplete in a number of respects, for instance, the different factors (e.g. planning time or the number of elements) hypothesized to contribute to task complexity have not been specified in terms of their importance and/or equality. In their opinion, Samuda and Bygate also believe that Robinson's task complexity model “... has to be read as a preliminary hypothesis, and hence is open to modification and refinement" (p.106). Nevertheless, Ellis (2009) asserts that “... task complexity is clearly a key variable affecting L2 performance and for this reason alone is attracting considerable attention in its own right" (p.492). As such, the current study was designed to examine the effects of task complexity on learner language production, as elaborated in Section 3.6.

\subsection{Task complexity and language production}

Robinson's (2001b, 2003b, 2005, 2007b) and Skehan's (1996, 1998) models of task complexity demonstrate that manipulating the cognitive demands of tasks may have specific consequences for learners' production. However, it should be emphasised that the current study was not designed to determine the effect of sequencing task dimension, i.e. simple to complex or complex to simple. In addition, the current study did not aim to resolve any disputes inherent in the two views of task complexity (Robinson, 2005; Skehan, 1998). Rather the current study aimed to provide further insight into the effects of manipulating the cognitive demands of an 
interactive task on learner language production manipulated along the resourcedispersing variable. According to Robinson (2001b), it is important to understand the most efficient way for a task to be designed and practiced in language classrooms to support "learners in channelling their attention to needed aspects of language code" (p.31). One of the ways to do this, as suggested by Robinson (2001a), is through manipulating task complexity, "the (inherent) cognitive demands of tasks" (p.287). Therefore, the current study is in line with Robinson's (2001b) suggestion for more research to be conducted to investigate the effects of interactive tasks along resource-dispersing variables on learner language production. The following sections review studies examining the effects of resource-directing and/ or resource-dispersing variables on learner language production first in monologic and, next in interactive tasks.

\subsubsection{Task complexity in monologic tasks}

A number of studies reported in the task complexity literature have shown support for the Cognition Hypothesis. Robinson (2005) emphasises that increasing the cognitive complexity of monologic tasks along resource-directing variables encourages learners to push production, stretch interlanguage and destabilise fossilised forms. Robinson (1995) believes that in such situations learners will be pushed to produce more complex and accurate language. He demonstrated this assertion in his study of learners' oral language production in two task conditions:

- a here-and-now condition, where learners were required to tell stories using cartoon strips (simple version)

- a there-and-then condition, where they were required to tell stories without cartoon strips (complex version).

The results showed that learners produced a greater utterance length while doing the simple task. However, an increase in the target-like use of articles and a high percentage of lexical words were found in the language production by learners doing the complex task. These findings show that increasing complexity along resourcedirecting variables will result in greater dysfluency, but higher accuracy and complexity. This is in line with the Cognition Hypothesis. 
Other recent studies that manipulated resource-directing variables in monologic tasks also reported findings consistent with the Cognition Hypothesis. However, a trade-off effect was also demonstrated. For example, Gilabert (2007b) asked learners to perform three task types manipulated along Robinson's (2007b) resource-directing variables. These were:

- a narrative task manipulated along $+/-$ Here-and-Now

- an instruction-giving task was manipulated along $+/-$ elements

- a decision-making task, which was manipulated along +/- reasoning demands.

The effects of the tasks were measured in terms of accuracy of language production. Gilabert found that increasing the cognitive complexity of tasks along resourcedirecting variables resulted in positive effects for accuracy, particularly for the instruction-giving task. This suggests that learner attention could be drawn to how messages are being encoded during the performance of monologic complex tasks.

In a similar study, Kuiken and Vedder (2007) examined the accuracy and complexity of learner language production doing complex versus simple writing tasks. The learners were required to take into account a varying number of requirements when performing the task; six in the complex while three in the simple condition. This task complexity factor seems to function as a $+/-$ few elements variable which is framed under the resource-directing dimension. The finding demonstrated that in the complex task, learners produced more accurate and lexically complex production relative to the simple task. This finding supports the Cognition Hypothesis. However, some learners produced lexically complex production when performing a simple task, which supports the Limited Attentional Capacity Model.

A study reported by Nuevo (2006) yielded a contrary view to the Cognition Hypothesis. Nuevo investigated the relationship between L2 learning opportunities and development by means of manipulating a resource-directing variable, i.e. +/reasoning demands. The tasks with +reasoning demand were treated as the high complexity version while the tasks with -reasoning demand were treated as the low complexity version. Specific L2 features were used, i.e. past tense and locative prepositions while the learning opportunities were identified as nine different interactional processes such as recasts, metalinguistic talk and confirmation checks. 
Three groups $(n=113)$ of learners participated in two different tasks, i.e. picture narration tasks and decision making tasks. In the picture narration tasks, the learners in the +reasoning demand condition had to reason more to create a plot from an unordered set of pictures frame than the learners in the -reasoning demand condition who had an ordered set of picture frames. In the decision making tasks, the learners had to decide on an appropriate seating arrangement for a meeting, class, or dinner party. The +reasoning demands condition required learners to infer and take into account people's intentions in order to decide where to seat them whereas the -reasoning condition only required them to seat people based on the information provided. The result revealed no significant effect of task complexity and L2 learning, counter to the prediction of the Cognition Hypothesis that increasing in task complexity along the resource-directing variable will direct learner attention to linguistics forms that encode concepts required by the task.

While the studies reviewed earlier have focused on the resource-directing variables, very few studies have focused on the resource-dispersing variables. One such study was carried out by Révész (2009). In her study, Révész manipulated a resource-dispersing variable, i.e. +/-single task feature that imposes cognitive demands on the learners. In the study, the -photo condition was viewed as a cognitively demanding task (a number of task demands were imposed), relative to the +photo condition which was the simpler version of the task. 90 EFL learners enrolled in elementary or pre-intermediate language classes in three high schools in Hungary participated in the study. The learners were required to perform three tasks: a written picture description task, an oral photo description task with photo support, and an oral photo description task without photo support. The learners were grouped into the following four conditions: +photo recast condition, -photo recast condition, +photo condition, - photo condition. In the recast condition, the learners consistently received recasts from the researcher when they erroneously used the past progressive. The result from multifaceted Rasch indicated a weak confirmation of the hypothesis that the group that viewed photos but did not receive recasts achieved greater L2 gains than the group who neither viewed photos nor received recasts. As such, this study by Révész provides support for the prediction derived from the Cognition Hypothesis that a decrease in task complexity when manipulated along 
the resource-dispersing dimension positively contributes to, even if to a small extent, the learners' development in using the target form.

In a view of task complexity, while these studies provide evidence for the Cognition Hypothesis, the trade-off effects which is based on the Limited Attentional Capacity Model was also seen in learner language production. This has been extensively verified in a series of studies (Lambert \& Engler, 2007; Yuan \& Ellis, 2003). For example, Skehan and Foster (1999) ${ }^{6}$ used the task structure resource-dispersing variable, contrasting the effect of one task complexity variable (the predictability of the narrative structure) on the language production of learners who were required to retell the story of Mr. Bean television clips (structured narrative "restaurant" and unstructured narrative "golf"). This was done under four conditions:

- watch-and-tell simultaneously

- storyline given, watch-and-tell simultaneously

- watch first, then watch-and-tell simultaneously

- watch first, then tell.

The findings revealed that the main effect of the 'watch first, then tell' condition influenced the learners to produce the most accurate and complex language. Learners in the structured narrative "restaurant" produced the most accurate language in the 'watch first, then tell' condition. This means, the interaction effect between the structured narrative and the 'watch first, then tell' condition promoted more accuracy. In contrast, the structure of the task was not influential in promoting complex language. This suggests that learners could focus more on accuracy if the task was cognitively simple (having the structured organisation of relevant information) and they were given more processing time (in the 'watch first, then tell' condition). Additionally, this suggests that the learners were able to produce more complex language in the condition that reduced their processing demands. As such, this study casts doubt on the Cognition Hypothesis claim that increasing the complexity of monologic tasks along resource-dispersing variables, in this case the structured task (task structure) and the 'watch first, then tell' condition (planning processes) will deplete learner attention, causing a poorer result on several

\footnotetext{
${ }^{6}$ Note that Skehan and Foster (1999) is not a true task complexity study because the narratives used in simple and complex versions were completely different content.
} 
dimensions of language performance. Instead, the variables amplify the delegation of attention more effectively, resulting in accurate and complex language production.

It should be noted that with regard to L2 accuracy, the Skehan and Foster's study is consistent with another study by Tavakoli and Foster (2008), which showed that clear ordering in structured narrative tasks led to more accurate production. This supports Skehan's (2009) proposal that simplifying the communicative burden for learners leads to improved performance in language production. This relates to Schmidt's Noticing Hypothesis, where learners' ability to monitor their output and apply knowledge about the grammatical rules to the output, resulted in enhanced accuracy.

A growing number of studies have investigated the Cognition Hypothesis claim that manipulating task complexity along resource-dispersing variables will cause learner attention to be dispersed, including one that examined the effect of planning conditions on production (Ellis, 2005, Robinson, 2005). The assumption behind these studies was that planning time reduces the cognitive load of a task, which in turn improves the quality of various aspects of language production.

In their study manipulating planning time, Foster and Skehan (1996) found a trade-off effect between complexity and accuracy with narrative tasks, in that attention devoted to complexity had negative effects on accuracy. In a subsequent study, Skehan and Foster (1997) demonstrated that planning time resulted in greater gains in fluency and accuracy. While increased planning time was not associated with complexity, the result suggested that accuracy and complexity may have been in competition with each other. These two studies illustrate that although planning time is associated with a decrease in cognitive burden, language production shows the trade-off effects.

Yuan and Ellis (2003) investigated the effects of pre-task planning, online planning, and no planning on oral language production. One group of participants was given no planning time, and were required to complete the monologic task in five minutes. A second group was given 10 minutes planning time, but had the same time constraint when performing the task. An online planning group did not have pre-task planning, but had no time limit for task completion. The findings revealed that the online planning group produced more accurate output. They were found to 
speak slower and use more self-repairs than the other groups. This suggests that the online planning time seemed to allow participants to access their grammatical knowledge, which enabled them to monitor their language output more than those in the pre-task planning condition. In terms of complexity, learners in the pre-task planning group produced more syntactically complex, but less accurate language than those in the online planning group. The researchers related the effect of planning to Levelt's (1998) Speech Production Model, where learners' prioritise conceptualisation over formulation and articulation when they have more processing space to formulate the language needed to express their thoughts. This in turn will result in more complex production. Seen from the perspective of task complexity, the online planning condition increases task complexity, while the pre-task planning condition decreases task complexity. It suggests that increasing task complexity promoted more accurate, but less complex production. In contrast, decreasing task complexity promoted more complex, but less accurate production. These results do not lend support to the Cognition Hypothesis proposal that increasing task complexity along resource-dispersing variable in monologic tasks will result in negative consequences on all aspects of language production. Rather, it shows the trade-off effect, as suggested by Skehan and his colleague (1996; Foster \& Skehan, 1996).

Another study that manipulated planning time to examine oral interaction and language production during task performance was conducted by Philp, et al. (2006). In this study 42 children in dyads, were asked to performed three, two-way information gap tasks. The tasks used were typical of their classroom activities, so were familiar to the learners. The researchers examined the task performances under three pre-task planning time conditions: no minutes (no planning time), two minutes and five minutes of planning. The results revealed that the most non-targetlike turns were produced by the learners with no planning time (47\%), as compared to the two minute $(23 \%)$ and five minute $(32 \%)$ planning time conditions. Because feedback was used in response to the non-targetlike production, no-planning time was the most conducive for the provision of feedback (23\%), as compared to the learners who had two minutes and five minutes planning time (21\% and $12 \%$ respectively). Similarly, in the no planning time condition the learners produced the most words per turn. No significant difference was reported with regard to the effect of planning 
time on fluency and accuracy. In terms of complexity, the five minute planning time condition encouraged the use of the most complex language. Although not mentioned, these findings could be interpreted in light of the task complexity perspective. The researchers explained that in the no-planning time condition (an increase in task complexity) the highest amounts of words per turn were produced, which may suggest that the learners engaged in more negotiation rather than merely carrying out the task. As such, the study supports Robinson's (2001a, 2001b) prediction that increasing task complexity will result in more negotiation, with negative consequences for language complexity. The study also supports Skehan's (1996, 2009) proposal that simplifying the communicative burden during task performance will promote learner attention to their production. In this study, this is illustrated by more complex production being produced when the learners had planning time.

These studies demonstrate the effect of task complexity variables on L2 production. However, they dealt with oral monologic tasks (although see Ellis \& Yuan, 2004; Ishikawa, 2007; Sercu, de Watcher, Peters, Kuiken, \& Vedder, 2006, which address the view of task complexity in written monologic tasks). The following section considers the effects of task complexity in interactive tasks on learner language production.

\subsubsection{Task complexity in interactive tasks}

When looking at the effect of task complexity in interactive oral tasks, the Cognition Hypothesis (Robinson, 2007a) claims that increasing the complexity of tasks along the resource-directing dimension will have a negative consequence over one or some aspects of production, most notably, accuracy and complexity of language production are increased while fluency is decreased. A study by Michel, Kuiken and Vedder (2007) demonstrates this. It contrasted the effect of a resourcedirecting variable, i.e. + /- few elements (simple vs. complex) on monologic (leaving a message on an answering machine) and interactive tasks (discussing a topic on the phone). Learners were found to produce more accurate, but less complex language (except with regard to Guiraud's Index in which lexical complexity was increased) while performing complex interactive tasks. Learners' use of less complex language, 
as evident in syntactically simpler structures in complex interactive tasks, suggests that the task promoted interactivity. As such, interactivity is seen as beneficial for promoting attention to language form, which leads to the production of more accurate language with negative consequences for structural complexity. The finding did not support the prediction made under the Cognition Hypothesis that learners who are engaged in a complex dialogic task along resource-directing variables would produce more accurate and complex language. In contrast, it provided a proof for the notion of trade-offs.

The Cognition Hypothesis, however, does not allow for trade-offs when tasks are made complex along the resource-dispersing dimension in interactive oral tasks. According to the Cognition Hypothesis (Robinson, 2001b; 2005), increasing task complexity along this dimension will disperse attentional resources and, thus, will make the task more complex, which, as a result, will negatively affect the accuracy, complexity and fluency of their language production.

Relatively few studies have examined the effect of task complexity in oral interactive tasks along the resource-dispersing dimension on learner language production. Among these, Robinson (2001b) investigated an oral interactive task by manipulating three variables along the resource-dispersing dimensions on a map tasks. These were:

- +/- planning time

- $\quad+/$ - single task

- $\quad+$ - prior knowledge.

$\mathrm{He}$ also included one variable along the resource-directing dimension: +/- few elements. By progressively increasing the cognitive demands of the task to make it more complex (removing planning time, then not marking the route, then using a map of an unfamiliar area, and increasing the map's size) Robinson was able to compare the effects of increasing complexity along both dimensions. Robinson found that the complex version of the map task prompted significantly more lexically varied speech than the simple version, but non-significant effects were found on structural complexity and accuracy. Nevertheless, he claimed that the complex version induced deeper attentional resources towards linguistic elements, displaying a trend towards greater accuracy. In addition, greater use of comprehension checks was found in the complex version. This resulted in brief 
responses, illustrating a tendency towards less structurally complex production. Robinson's study illustrated mixed findings with regard to the Cognition Hypothesis. Also, the study failed to distinguish the effect of each of the dimension, i.e. resource-directing and resource-dispersing dimension on language production. As such, this warrants further empirical investigation.

The Cognition Hypothesis also proposes that more complex tasks encourage more negotiation. Hardy and Moore (2004) examined the effect of task complexity in oral interactive tasks on learner-learner interaction produced by 28 intermediate low-level learners of German. Each pair was randomly assigned a different task condition based on structural task support and content familiarity (resourcedispersing variables). Their interactions were videotaped then analysed on a functional level, which included question codes and interactional codes, and a topical level, which included number and mean length of topical co-construction. The results revealed that low task structure promoted higher used of questions codes and interactional codes than high task structure. This was expected, as there was a need to engage in highly communicative exchanges to establish a common ground between the participants. Additionally, significantly greater mean lengths of topical co-construction were found for the low task structure group. The researchers attributed this to the writing and providing response requirement in the low task support group, which led to more negotiation of linguistic content. With regard to content familiarity, it was predicted that learners with unfamiliar content would engage in more interaction because they had to negotiate more to reach similar base knowledge. However, no significant effects were found. The researchers suggested that the pre-tasks comprehension exercises may have affected learners' linguistic comprehension, which reduced the need to engage in active conversation. The findings of this study support Robinson's (2001a, 2001b) prediction that more complex tasks lead to greater quantities of conversational negotiation. However, further claims on the effects of task complexity on the accuracy and complexity of language production cannot be made as they were not measured. 


\subsection{Summary of task complexity dimensions}

This chapter has reviewed the effects of task complexity on learner language production based on the Cognition Hypothesis and the Trade-off Hypothesis which is based on the Limited Attentional Capacity Model. According to the Cognition Hypothesis (Robinson, 2001b, 2005) increasing task complexity along certain dimensions may affect language production. For monologic or non-interactive tasks (e.g. narrative tasks) the hypothesis predicts that increasing complexity along resource-directing variables may encourage accuracy, complexity but not fluency, while increasing task complexity along resource-dispersing variables may reduce accuracy, complexity and fluency. For both monologic and interactive tasks (e.g. discussion or information transfer tasks) the Cognition Hypothesis predicts that increasing complexity along resource-directing and resource-dispersing variables may result in less accurate and complex production. Because engaging in complex tasks should result in more negotiation, overlaps and short answers responses, learners' attempt at using complex language is reduced.

On the other hand, Skehan $(1996,1998,2009)$ argues that language production may show trade-off effects because learner cognitive capacity is insufficient to simultaneously allocate resources to accuracy, complexity and fluency. Most importantly, he suggests that accuracy and complexity are in competition with each other. The model that proposes limited attentional capacity also proposes that limits in processing capacity mean that increasing complexity will cause increasingly noticeable trade-offs between complexity and accuracy. The direction of the trade-off is not necessarily specified, and may be related to the complexity variable under investigation. Nevertheless, Skehan claims that there are ways to mitigate the trade-off effects. For example, by easing or simplifying communication burden. Therefore, when learners perform cognitively simple tasks, the accuracy and complexity of their language production are expected to increase.

The empirical research up to now has not given a conclusive picture of the effect of resource-dispersing variables. Much of the research has focused on monologic tasks, so the picture is less conclusive for interactive tasks. In light of this gap, the current study aimed to examine the effects of manipulating an interactive task along the resource-dispersing dimension on learner language production. Two 
variables were manipulated, task structure and language support. These two variables are discussed below.

3.6 Operationalisations of task structure and language support in the current study

Based on the Triadic Componential Framework by Robinson (2007b), task structure is a resource-dispersing variable under task complexity factor. In the current study, high task structure (+TS) refers to the degree of structural support provided to learners during a chat session (Appendix E). As high task structure (+TS) serves to guide task performance, the learners' online processing burden may be reduced. This allows for a shift of attention from managing task content to language production. In contrast, the low task structure (-TS) leaves the sequencing of discourse processes open, which requires increased demand on online processing to determine the procedures for completing the task and communicating meaning.

According to the Cognition Hypothesis (Robinson, 2001b, 2003b, 2005), a task with low structural support (-TS) would be considered more complex because it demands a higher degree of simultaneous allocation of cognitive resources. This is predicted to result in more negotiation and interactional modifications, leading to less accurate and less complex language production.

Similarly, the Triadic Componential Framework proposed by Robinson (2007b) outlines planning as one of the resource-dispersing variables under task complexity factor. As reviewed above, studies have shown that planning time affects task performance. The current study does not include planning as a variable However, it is important to emphasize here that the pre-task language support activity used in the current study is analagous to language oriented pre-task planning. Language oriented pre-task planning allows students prior to task performance to focus on how they will encode meaning in linguistic form during the task. This frees up the learners' attentional resources to focus on other aspects of the task and therefore decreases resource demands. As such, it is a resource-dispersing variable. It is crucially different in that the learners in the current study did not know what the task was when they engaged in the language support activity. However, because it also provided them with a chance to focus on how they can encode 
important meanings through linguistic form prior to the task, its effect should be similar to that of language-oriented pre-task planning. So while language support is not a Cognition Hypothesis variable as laid out by Robinson (2007b), it is predicted to have similar effects to resource dispersing variables.

Skehan and Robinson have made different predictions about the effect of planning time on language production. Skehan (1996), who argues for the notion of the trade-offs, claims that this type of focused planning may mitigate the trade-off effects, allowing learners to produce more accurate, complex and fluent language. Therefore, when learners receive language support (+LS) prior to, and while performing the task, their attention might be oriented to the use of correct form. In addition, providing linguistic models that learners can refer to during the task, reduces their cognitive load. This may allow more attention to accuracy. Following Skehan's predictions, learners who received language support would be expected to produce more accurate, complex, and fluent language.

So in conclusion I argue that supplying language support in a pre-task activity (as an alternative to language oriented pre-task planning) (+LS) will decrease the cognitive complexity of the task along the resource-dispersing dimension in the same way that planning does (Ellis, 2005; Ortega, 2009) by reducing the demands on the learner's attention during task performance. This focusing of the learner's attentional resources is predicted by the Cognition hypothesis to improve task performance in terms of the linguistic complexity, accuracy and fluency of their language production. No language support (-LS) would be considered more complex in terms of the learners' need to allocate their cognitive resources simultaneously to meaning and language form. Therefore, based on the Cognition Hypothesis, increasing the cognitive complexity of interactive tasks along resource-dispersing dimension is predicted to result in learners producing less accurate and less complex language because greater mental effort will be needed to simultaneously process task content and communicate meaning.

\subsection{Summary}

This chapter has reviewed studies that investigated the effects of task complexity on learner language production particularly in regards to accuracy, 
complexity and fluency of language production. The tasks analysed in these studies were manipulated using Skehan's $(1996,1998,2009)$ Trade-off Hypothesis which is based on the Limited Attentional Capacity Model, and Robinson's (2001b, 2005) Cognition Hypothesis. Results from the studies provided somewhat mixed support for both hypotheses. Thus, further empirical research is warranted.

It should be noted that the studies reviewed in this chapter were conducted in face-to-face settings. Overall, these studies show that resource-directing and resource-dispersing variables that alter the complexity of a task can influence learner language production. The role of these variables in tasks carried out in textSCMC may be even more important because of the already challenging nature of communication in this context, which lacks paralinguistic features that aid communication in face-to-face settings (Smith, 2003a). However, research on the role of task complexity along these variables has not yet been extended to textSCMC. Hence, the aim of the current study was to uncover the extent to which task complexity may impact the quantity of learner language production in text-SCMC. The next chapter reviews studies on the application of text-SCMC in L2 learning. 


\section{CHAPTER FOUR \\ COMPUTER-MEDIATED COMMUNICATION}

\subsection{Introduction}

Chapter Two discussed how a task-based approach to L2 learning and teaching may provide a platform for successful L2 interaction to occur, while Chapter Three reviewed studies illustrating the effect of task complexity on L2 production. The studies reviewed in both chapters were conducted in face-to-face settings. In this chapter, the review is extended to studies conducted in text-SCMC setting.

\subsection{Features of text-SCMC}

Text-SCMC is in some way a paradox, as it is a hybrid of speech and writing that bridges a divide between the two (Bordia, 1996; Herring, 1996; Weininger \& Shield, 2004; Werry, 1996; Yates, 1996). It is similar to spoken language because of the rapid, spontaneous exchange of information that takes place in real time. On the other hand, it is part of written language because it produces a relatively permanent record of the discourse, and punctuation and other writing devices are used to make up the text. Text-SCMC also has unique characteristics, including simplified register and syntax, abbreviations, and the use of symbols to express emotions (Smith, 2003a). It is possible to replicate prosody to give additional meaning to communication using italics, boldfaced text or emoticons. In addition, openings and closings during interactions in text-SCMC have been reported to be optional in cases where they would be expected in face-to-face communication.

\subsection{Text-SCMC as a context for SLA research}

Researchers acknowledge the use of text-SCMC as an effective medium for L2 learners learning and practicing their target language (Blake, 2005; Ortega, 2009; Smith, 2004, 2008). It is employed for practicing language learning in various ways, including interacting with native speakers (Belz, 2006; Blake, 2005; Lee, 2004), 
developing intercultural understanding (Belz \& Müller-Hartmann, 2003; Lam, 2004; O’Dowd, 2007; Ware \& Kramsch, 2005), conducting collaborative tasks (Newlands, Anderson \& Mullin, 2003), and creating autonomous learning (Emde, Schneider \& Kötter, 2001). To evaluate the potential for text-SCMC to provide a productive environment for language acquisition, most studies have drawn on the Interactionist Approach $^{7}$ (Mackey \& Gass, 2006). Chapelle (1997) describes the approach in the following way:

CALL researchers can turn to the work of interactionist SLA researchers who operate under the assumption that the L2 is acquired through learners' interaction in the target language because it provides opportunities for learners to: (a) comprehend message meaning, which is believed to be necessary for learners to acquire the L2 forms that encode the message; (b) produce modified output, which requires their development of specifics of morphology and syntax; and (c) attend to L2 form, which helps to develop their linguistic systems (p.22).

The central question from this perspective is whether text-SCMC offers opportunities for the kind of meaningful interactions that facilitate L2 learning and development in face-to-face settings. Findings have shown that interaction between NSs and NNSs via text-SCMC is beneficial (Lee, 2004; Toyoda \& Harison, 2002; Tudini, 2003), particularly in helping learners to reach a higher proficiency level (Blake, 2007). Evidence of learning benefits through learner-learner interaction have also been reported (Jepson, 2005). For example, Böhlke (2003) examined the language produced by 27 German learners communicating with their peers via faceto-face and text-SCMC. Learners were found to produce targetlike structures at a similar rate in both modes, which is an indication that learner-learner interaction via online text chat proves to be beneficial for L2 learning.

Sotillo (2005) carried out a study that shows benefits of learner-learner interaction by examining the interactions of five dyads (2 NNS-NNS and 3 NS-NNS dyads) via the SCMC tools Yahoo Instant Messaging (YIM). She found that the NNS-NNS dyads spent more time chatting, which resulted in more error correction episodes $(70 \%)$, as opposed to those in the NS-NNS dyads (30\%). Grammatical problems triggered the most episodes $(41 \%)$ across all dyads, although they were

\footnotetext{
${ }^{7}$ Sociocultural and constructivist theories have also been applied by a small amount of research in this field, for example Chung, Graves, Wesche \& Barfurth (2005), Hampel (2006), O'Rourke (2008), Simpson (2005), and Wildner-Bassett (2005).
} 
mostly found in NNS-NNS dyads (67\%). The NS-NNS dyads focused more on resolving misunderstanding of content instead of problems in lexical or grammatical items. These findings illustrate the evidence that learner-learner interaction in textSCMC may contribute to L2 learning and development. This is further discussed in the following sections.

\subsubsection{Encouraging meaning negotiation and interactional modification}

Various studies have evaluated text-SCMC from the interactionist perspective, where interaction is seen as one of the important factors in the process of language acquisition (Fernández-García \& Martínez-Arbelaiz 2002). Because of its synchronous nature, online chat is a valuable way for learners to interact and engage in meaning negotiation using various interactional modifications in their attempts to resolve miscommunication (Blake, 2000; Cheon, 2003; DiGiovanni \& Nagaswami, 2001; E Sá \& Melo, 2007; Lai \& Zhao, 2006; Sotillo, 2000). In his

study on text-SCMC, Smith (2003a) explains “... learners elicit modified input from one another, are pushed to modify their own linguistic output, and receive important feedback on their TL use, thus potentially focusing their attention on their problematic utterances" (p.39).

To illustrate this point, Kung (2004) examined the interactional features produced during 40 minutes of online text chat discussions among 47 EFL learners in Taiwan. The chat transcripts revealed that various types of interactional features were produced. For example, the learners asked questions, requested clarifications, gave feedback, and even acted as teacher by providing explanations and examples to each other. Kung also reported that learners enjoyed the learning experiences via online text chat because they were able to use the target language and initiate different interactional features that they may not have had the opportunity to do in a face-to-face classroom setting.

In another text-SCMC study based on the interactionists' claim, Lai and Zhao (2006) compared the interaction that took place in face-to-face and online settings between six dyads. Learners were found to engage in explicit negotiation of meaning in the online text chat (69\%) more than face-to-face discussion (30\%). In text-SCMC, the learners were able to precisely indicate if they did not understand 
the messages; for example by typing 'what is it?' or 'I don't understand X'. This finding corroborates Blake (2000), and Fernández-García and Martínez-Arbelaiz's (2002) research.

These studies show how the written modality of text-SCMC can positively influence the occurrence of negotiation of meaning and interactional modifications during learner-learner interaction. During such actions, learners' attention to focus on form may also be heightened as they view and reflect on the messages on the screen. This is discussed in the following section.

\subsubsection{Promoting noticing and focus on form}

According to Schmidt (2001), noticing is an important factor that contributes to language learning. In the context of face-to-face setting, Williams (2005) argues that noticing could be a difficult process for L2 learners because of the highly ephemeral nature of oral communication (although see Loewen \& Philp, 2006 and Nassaji, 2007 for their examples on how enhancement techniques were used in oral feedback to encourage noticing). The written modality of text-SCMC allows learners the opportunity to re-read information by scrolling the messages backward and forward, which enhances attention or noticing (Fiori, 2005; Pérez, 2003; Sauro, 2009; Sotillo, 2005). This also allows the interlocutors to continually "refresh memory traces" (Payne \& Whitney, 2002, p.14). As such, communication via textSCMC makes it possible for learners to focus and reflect on their output.

Unlike face-to-face communication, the saliency of the written interaction provided by text-SCMC may increase the visual saliency of linguistic forms (Chapelle, 2001; Deusen-Scholl, et al., 2005). According to Meskill (2005), "computer screens can serve to anchor attention to forms..." (p.48). Similarly, Gass (1997) emphasises that "salience can be said to help ensure that particular forms are noticed by the learner and hence lead to rule strengthening" (p. 19). Thus, the visual saliency of language forms produced during text-SCMC may allow for deeper processing of language forms, as well as opportunities to attend in more detail to problematic forms.

Pellettieri (2000) examined the potential of using YTalk, a text-SCMC tool, to enhance noticing in the context of communication between the NNSs. Learners 
were found to notice and modify problematic forms, and incorporate target language forms into their subsequent production as a result of feedback from each other. Pellettieri claimed that these opportunities were products of the written modality of text-SCMC, which permitted the learners to view their writings and take time to think before posting the messages. This finding is similar to Kötter (2003), Salaberry (2000) and Samuel (2001). Fiori (2005), Lai and Zhao (2006) and Okuyama (2005) are among other researchers who have reported that online text chat allows learners to generate ongoing interaction. This is because they are able to understand the information by scrolling the text messages backward and forward, and rectify errors as they noticed any linguistic problems.

The notion that the written modality of text-SCMC may anchor noticing is further investigated by Shekary and Tahririan (2006). Sixteen EFL Persian learners in dyads were required to engage in an online text chat using the dictogloss, jigsaw and free discussion tasks. The occurrences of LREs were identified as the evidence for noticing. The result revealed that quite a large number of LREs were produced by the dyads; about 718. The learners were also able to discover problematic forms and supply the appropriate answers themselves. To find out if such noticing led to learning, immediate and delayed post-tests were administered. The researchers designed the post-tests based on the specific linguistic items found in the LREs. It was confirmed that noticing led to subsequent learning, as learners were found to remember almost $70.3 \%$ of the targeted linguistic items during the immediate posttests and $56.7 \%$ during the delayed post-tests. These findings corroborate Blake's (2005) finding that learners had ample opportunity to focus on form and reflect on their language production while interacting via text-SCMC.

These studies demonstrate that text-SCMC is a conducive platform for L2 learning, particularly with regard to noticing and focus on form, which facilitates L2 learning. Nevertheless, Smith (2004) reported that the occurrence of uptake in his learners' subsequent production in text-SCMC was rather limited, although this did not necessarily mean there was no acquisition of form. In a subsequent study, Smith (2005) argued that the heightened saliency of output was increased largely as a result of written modality of text-SCMC. Therefore, less explicit evidence of learners' uptake could be demonstrated in their subsequent production. This was because the communication can be seen on the screen, which enabled the learners to digest 
output without explicitly demonstrating that they had understood the messages. In text-SCMC, learners demonstrate their understanding or respond to corrected errors might be by simply stating 'yes' or 'ok' instead of repeating the whole targetlike expression. According to Sotillo (2005), that is an indication of general uptake.

While the studies mentioned above reported benefits of the visual nature of text-SCMC because of extra opportunities for planning, noticing and reflecting on language output, other studies have reported the opposite effect. It has been argued that language learners faced difficulty decoding or encoding messages because of the demands of maintaining the rapid information exchange (Iwasaki \& Oliver, 2003). Also, because turn-taking between the interlocutors in text-SCMC is full of overlaps and delays (Smith, 2003a), learners may miss out the feedback given on any particular errors (Loewen \& Erlam, 2006). However, overall the evidence supports the prediction that the written modality of text-SCMC will anchor noticing and focus on form. When learners' attention to language production is increased, the production of accurate and complex production is also likely to increase.

\subsubsection{Accuracy of L2 production}

Skehan (1998) claims that in a face-to-face setting the brain's limited capacity to process language in real time means the greater time pressure of realtime communication will reduce attention to form and accuracy. However, communicating in the text-SCMC setting may yield a different result with regard to language production. Smith (2003a) asserts that text-SCMC provides the interlocutors with "more processing time while reading and typing messages" (p.39). In this way, they are communicating in what Beauvois (1998) characterises as "conversation in slow motion" (p.198). When they opt to slow down their typing speed, processing and planning time are likely to increase (Payne \& Whitney, 2002). Hence, when online planning time is available learners' cognitive loads can be reduced (Ellis, 2003). This reduces the pressure to process information, which may promote greater opportunity to monitor and pay close attention to language production (Gonzalez-Lloret, 2003; Warschauer, 1996).

A study by Blake and Zyzik (2003) found that learners communicating in a text-SCMC setting engaged in self-corrections as they modified their output. The 
ease of scrolling backward and forward through messages at their own pace meant they were found to refer to their initial output when trying to compose or modify the output. As a result, they produced more targetlike output.

One way to encourage more accurate output in learners is to manipulate input to enhance noticing. Fiori (2005) compared the accuracy of learner language production between two groups; the first $(n=27)$ is the form-and-meaning-focused (FMF) group and the second $(\mathrm{n}=17)$ is the meaning-focused (MF) group. Three preand posttest measures were administered; elicited imitation/sentence repetition testing, oral exams and grammaticality preferences component. The data for eight weeks of the chat session (once weekly, approximately 40-50 minutes for each session) was analyzed. During the chat session, the grammatical errors particularly the local errors that did not impede comprehension of the learners in the MF group were not corrected. Rather, only global errors (e.g. clarification requests focusing on the message's content rather than its grammatical structure) were attended to.

In contrast, the learners in the FMF group received the following consciousness raising (CR) activities prior to each chat session; the learners were required to prepare prechat questions based on the target forms one day earlier to prepare them for discussion, then 10 minutes were dedicated for the instructor to review these prechat questions. During the chat session, the instructor was engaged in a number of corrective strategies with the learners. In addition, the learners in this FMF group were given access to a consolidated version of the textbook's grammar pages as references during the semester and not to be used during the chat sessions. The posttest results revealed significant differences on two measures, i.e. the learners in the FMF group outperformed the learners in the MF group on elicited imitation/sentence repetition testing and grammaticality preferences component. Fiori attributed the success of the learners in the FMF group to the CR approach, i.e. the target structures and language models provided to the learners. In addition, she did recognise the influence of the written modality of the online text chat, which enabled the learners to review the messages as often as they wanted. Fiori hypothesized that the combined effects of text-SCMC and the CR method were the key for learners to produce more accurate output. This study suggests that to increase attention to form in text-SCMC, learners should be provided with some form of language support (or enhancement of input). 
However, a number of studies questioned the grammatical benefits of practicing a target language in text-SCMC (C. Lee, 2007). For example, teachers can set explicit expectations for grammatically correct language to be used in textSCMC (Lee, 2002), but learners may not be so concerned with this as long as the messages are understood. Kern (1995) reported that Daedalus InterChange, one of the online text chat tools, did not offer an environment that was conducive for learners to practice more accurate, targetlike production. He emphasised that "Formal accuracy, stylistic improvement, global coherence, consensus, and reinforcement of canonical discourse conventions are goals not well served by InterChange" (p.470).

Another study that did not support the notion of text-SCMC encouraging accurate language production was done by Cheon (2003). She argued that the written modality of text-SCMC meant learners seemed to be inclined towards incorporating non-targetlike forms (e.g. omissions of the 'be' verb, misuse of singular/plural and confusions in word order) into their subsequent production. Similarly, Kung (2004) found that his 47 EFL learners produced quite a large number of spelling, grammatical and lexical errors in text-SCMC. Based on the interview data, the learners claimed that the errors were the result of the medium. That is, the rapid online text interaction pushed them to increase their typing speed at the expense of accuracy. These findings have opened up a critical view of language learning via text-SCMC, with regard to accuracy of learner language production. Therefore, more empirical evidence is needed to examine the accuracy of learner language produced in the context of text-SCMC.

\subsubsection{Complexity of L2 production}

Another important question in text-SCMC research is if it influences the complexity of learner language production. Some have argued that in text-SCMC, the interlocutors are not expected to chat using formal, complex structures because the writing style of text-SCMC is casual. Additionally, ellipsis and abbreviations are the usual practice, and in fact, the norm of this setting (Lund, 2006; Pena-Shaff, Martin \& Gay, 2001). Kung (2004) reported that his learners' writing was made up of sentence fragments, an indication of less complex production. The learners 
claimed that this was the effect of their typing styles, in which abbreviations, ellipses and other simplifications were an accepted norm.

However, other studies show evidence of complex learner language production in text-SCMC. A study by Warschauer (1996), for example, showed that his participants produced lexically and syntactically more formal and complex language in online text chat than in a face-to-face setting. A similar finding was reported by Payne and Whitney (2002) in a study with 58 Spanish learners that showed they produced more complex language using text-SCMC than in a face-toface classroom setting. Similarly, Cheon (2003) conducted a study on Korean learners learning English. She reported that text-SCMC enabled the learners to view their output, which resulted in the production of syntactic complexity in their subsequent output.

As noted above, Fiori (2005) analysed the complexity of learners' production in text-SCMC. Unlike the MF group, the FMF group had the opportunity to do language practice by means of consciousness raising (CR) activity. As mentioned earlier, the learners in the FMF group, who did the CR activity, had the opportunity to engage in language activity prior to the chat session. The results revealed a significant difference between the two approaches, in that the FMF group produced syntactically more complex language than the MF group. Fiori contributed this finding to the CR activity did by the FMF group of learners prior to the chat session.

The mixed findings regarding the impact of communicating via text-SCMC on accuracy and complexity of learner language production means more empirical research is needed to evaluate its effect. Sanders (2006) argued that while textSCMC enables learner-learner interaction to be extended beyond face-to-face class space and hour, the mixed findings reported in some studies (C. Lee, 2007; Cheon, 2003; Kung, 2004) shows the need for ongoing research into the effectiveness of text-SCMC as a medium for language practice. 


\subsubsection{Fostering active and equal participation}

Another area of text-SCMC research addresses the quality of learner participation (Böhlke, 2003; Chun, 1994; Coniam \& Wong, 2004; Freiermuth \& Jarell, 2006; Kern, 1995; Sullivan \& Pratt, 1996; Warschauer, 1996). Chun (1994), who studied first year German learners, reported that in a normal L2 oral discussion classroom learners usually needed to be told what to talk about, and how to begin the conversation and interact with others in their group. In contrast, when learners used text-SCMC they were more enthusiastic in managing the discourse. For example, they did not feel inhibited in initiating discussions, responding to others and requesting clarification using a wide array of discourse features. The results of a study by Sullivan and Pratt (1996) echo Chun's finding. They compared ESL learners performing discussions in two modes: face-to-face and online text chat discussions. The data showed that the discussions dramatically differed between these two modes in that only $50 \%$ of the students participated in the oral class discussion, as opposed to $100 \%$ participation in the computer-assisted classroom environment.

Similarly, in a study examining communicative language use among college learners in two elementary French courses, Kern (1995) found that the learners produced more words and sentences in text-SCMC than face-to-face settings, which was an indication of increased participation. Kern (1995) summarised the effects of using online text-chat, i.e. Daedalus InterChange as “...unfettered self-expression, increased student initiative and responsiveness, generation of multiple perspectives on an issue, voicing of differences, and status equalization are supported by InterChange" (p.470). Likewise, Warschauer (1996) found that learners had more equal and increased participation rates in text-SCMC than in oral discussions. This was supported by Darhower (2002), who examined chat exchanges of his L2 Spanish participants. He found that the learners not only formed a supportive online community, but also successfully helped each other learning the target language.

A study by Pérez (2003) on learners participating in group discussions in a chat room revealed that they engaged in relatively active feedback on each others' class work and progress. Such collective interaction could minimise communication barriers, and as emphasised by Lee (2002), text-SCMC provides a setting in which 
learners "help each other to achieve a performance that they typically cannot execute alone" (p.276).

As illustrated above, learners engaged in active and equal participation in text-SCMC despite the reduction of social context and nonverbal cues. Such active collaboration and equal participation lead to social equity among the interlocutors (Fitze, 2006; Jarell \& Freiermuth, 2005).

\subsubsection{Participation in teacher-learner interaction}

In a traditional face-to-face classroom setting the need to facilitate active and meaningful participation among learners may require instructors to moderate interaction. This ensures learners stay on track and prevents them from producing too many off-task comments. It also prevents one or two learners dominating the class discussion. However, in a text-SCMC setting the instructor's or teacher's role is different (Ene, Görtler, \& McBride, 2005). Kern (1995) argued that in text-SCMC the teacher's role is less dominant and authoritative. Typically during text SCMC sessions there is a more equal balance of participation between learners and their teacher. According to Kern it was difficult for any one person, including the teacher, to dominate. Sullivan and Pratt's (1996) findings echo Kern's. When comparing oral and online text chat discussion data from ESL learners, they found that teachers took only $15 \%$ of the total turns in the text-SCMC discussions, as opposed to $65 \%$ turntaking in the oral class.

Teachers and learners are challenged by new roles in text-SCMC. Teachers are more like guides and collaborators, while learners must assume a more autonomous participatory status. Using the text tool IRC Français, Hudson and Bruckman (2004) examined participation patterns among learners learning French as a foreign language. The researchers evaluated the participation of two learners, one shy learner and a vocal, confident learner, and their instructor in both settings, i.e. traditional face-to-face and text chat settings. It was observed that in the online environment, both learners actively responded to the instructor's questions. In addition, the instructor's participation rate was equivalent to the learners'. In contrast, in the face-to-face setting the teacher had to put a lot of effort into increasing learner engagement. In a study focusing on text-SCMC, Simpson (2005a) 
analysed the discourse patterns found on Webheads, a virtual language learning space. He found that the teacher's role was minimised as learners had greater control over the learning, as evident in a greater ratio of learner talk to teacher talk.

Another study that demonstrates the benefits of text-SCMC to promote equal learner participation during L2 discussion was done by Lim and Sudweeks (2006). They conducted a case study on learners' engagement in 13 weeks of online tutorial sessions. At the end of the study, the participants said that they felt the presence of most of their colleagues during the online meetings, and their motivation to take part in the discussion was increased by the teacher's facilitation style. This type of situation has strengthened the importance of the teacher as a facilitator rather than a dictator (Blake \& Delforge, 2004).

The corollary of this is that, when learners actively participate in text-SCMC without relying solely on teachers they can become more self-directed (DeusenScholl, Frei \& Dixon, 2005). This change from teacher control to learner autonomy represents a more effective means of preparing learners for work environments, where they will be responsible for seeking knowledge together and collaboratively solving problems in real and virtual environments (Jeon-Ellis, Debski \& Wigglesworth, 2005).

However, text-SCMC research has also pointed out some weaknesses when there is a lack of teacher intervention in L2 learning. For example, if learners receive feedback from each other they might not have sufficient resources to correct each other or the inclination to do so (Blake, 2000; Jepson, 2005). As a result, they may pay less attention to their language production, and consequently less feedback to language errors could be evident (Loewen \& Reissner, 2009; Kern, 1995).

\subsubsection{Reduction of communication anxiety and increased motivation}

One reason why learners seem to participate more in a text-SCMC setting than a face to face setting is that text-SCMC appears to provide a less stressful language learning environment (Beauvois \& Eledge, 1995), as learners have more time to think and organise those ideas before sharing them with their peers. This is particularly useful for learners who are shy or introverted, and less competent using the target language in a face-to-face classroom setting, as it increases their 
motivation and decreases their anxiety level (Coniam \& Wong, 2004). This point has been supported by Cheon (2003), who examined the practicality of using textSCMC for pre-intermediate Korean EFL learners. It was reported that the learners felt more relaxed expressing themselves in the target language via text-SCMC because nobody could see their faces if they made mistakes. As a result, they tended to contribute to the discussion without hesitation. This may suggest that interactive competence could be developed within a text-SCMC context because of learners' motivation to actively participate in the discussion without feeling inhibited.

Freiermuth and Jarell (2006) compared the online text chat transcripts and spoken data of 69 EFL learners. They found that learners engaged in online text chat more actively than face-to-face conversation. This was reflected in more turns produced in the online text chat setting. Learners noted that their preference for contributing more to the discussion during the online text chat than face-to-face settings was because they were 'invisible'. This suggests that the anonymity of the interlocutors in an online context reduces the social barrier, which motivated them to practise the target language.

As text-SCMC gives a good opportunity to learn and practise the target language, it may also increase learners' motivation (Roed, 2003). This was demonstrated in Fitze's (2006) study, which investigated face-to-face and online text chat discussions of ESL learners from various first languages (e.g. Korean, Japanese, Russian, Spanish). Fitze found that unlike in the face-to-face environment, the online text chat contributions were made equally by each member of the group. Overall, these studies indicate that text-SCMC may facilitate language learning because being able to articulate ideas without hesitation will motivate learners, and ultimately increase their target language production.

However, a number of studies report unfavourable results for text-SCMC in relation to anxiety. For example, Lee (2004) found that her participants were still anxious during task performance in text-SCMC. She suggested that with sufficient network training, such effect could be reduced and as a result, the potential benefits of employing text-SCMC in language learning may be maximised. Arnold (2007) also reported that for a group of 56 learners doing German as a foreign language, neither ACMC nor text-SCMC made any different in reducing communication apprehension. However, Arnold explains that this finding may be attributed to 
particular circumstances and group dynamics in this setting rather than to the intrinsic nature of text-SCMC, and so despite this result, Arnold reiterated the importance of $\mathrm{CMC}$ as a beneficial medium for learners to practice their oral communication.

\subsubsection{Developing oral competence}

Researchers who examined the potential of text-SCMC in L2 learning also reported that it can promote interlanguage development, particularly as a bridge to oral interaction (AbuSeileek, 2007; Jeon-Ellis, et al., 2005). Gruba (2006) reported that interactive computer programs provide activities for learning oral skills, as they help learners to interact in a communicative way. Beauvois (1998) claimed that the writing practice provided to learners in text-SCMC interactions helps not only their written language skills (Coniam \& Wong, 2004; Deusen-Scholl, et al., 2005), but may also extend their oral skills.

A number of studies demonstrate the positive effects of practicing a target language via text-SCMC on subsequent oral production (Weininger \& Shield, 2004). For example, Payne and Whitney (2002) compared oral proficiency between two groups of L2 Spanish learners, where one used text-SCMC as the medium of learning while the other received face-to-face classroom instruction. Although both groups demonstrated significant improvement from pre-test to post-test scores, those who learnt via text-SCMC showed greater gains in their oral proficiency. This was reflected in a higher mean gain score. The researchers concluded that "L2 oral proficiency can be indirectly developed through chatroom interaction in the target language" (p.23). This finding corroborates the result of Payne and Ross's study (2005), where learners learning via online text chat produced greater language output in their oral performance.

Similarly, Abrams (2003) in her study, found differences in the effect of using CMC on oral performance of her FL German learners. She compared the performance of three groups of learners, i.e. face-to-face (the control group), textSCMC (treatment A) and ACMC (treatment B), on three oral discussion tasks. The results suggested that the text-SCMC group outperformed the control and ACMC groups with regard to the amount of speech used. This was indicated by a higher 
mean of number of words and c-units. Together, these studies show that engagement in text-SCMC can enhance oral communication abilities and increase the volume of language practice.

While the literature reviewed above suggested a range potential benefits of using text-SCMC to contribute to L2 learning and development, Ingram, Hathorn, and Evans (2000) have addressed their concerns about the problematic issues of using SCMC in education. For example, providing unstructured activities for learners to discuss online may lead to them producing trivial, grammatically incorrect and unstructured messages because of their engagement in rapid information exchange over careful thought. However, tasks that are appropriately designed to elicit target language production may be useful to combat these issues. This issue is addressed in the next section.

\subsection{Task-based approach in text-SCMC}

As reviewed in chapters Two and Three, task-based language teaching is the subject of a substantial research literature. However, the studies cited were conducted in face-to-face settings. Also, although research on TBLT is not new in computer-based setting, most are based on the Interactionist Approach (Mackey \& Gass, 2006) rather than the task complexity perspectives, which motivate the research reported in this thesis. The following sub-section specifically focuses on research around task-based interaction in text-SCMC.

\subsubsection{Task-based interaction in text-SCMC}

Interaction between learners in text-SCMC has been shown to facilitate the occurrence of several interactional features linked to second language development, as shown in the literature in the previous sections (Blake, 2000; Chapelle, 1998; 2001; 2003; Dickinson, Eom, Kang, Lee, \& Sachs, 2008; Doughty \& Long, 2003; Fuente, 2003; Oskoz, 2005; Smith, 2003a; Warschauer, 1997). Similarly, task-based interaction in text-SCMC may also offer benefits to L2 learning (Skehan, 2003b). For example, Smith (2004) found that the retention of unknown lexical items 
negotiated through task-based text-SCMC was significantly higher compared to learners that only received pre-emptive input.

In another task-based text-SCMC study, Blake and Zyzik (2003) had learners solve a two-way jigsaw task collaboratively. The learners repeatedly engaged in negotiation of meaning and interactional modifications; for example, using clarification requests, expansions, recasts and self-corrections. In doing so, the learners noticed unfamiliar lexical items on the screen, and used them in their subsequent language production. This demonstrates that performing L2 tasks in textSCMC may contribute to a positive change in learners' target language knowledge.

During learner-learner interaction in task-based text-SCMC, occurrences of self repairs are sometimes evident. Smith (2008) used four jigsaw tasks and two sequential ordering tasks to look at this. As well as chat transcripts (referred to as method A), the researcher used an extra CMC feature, Camtasia (referred to as method B), to record data. Using Camtasia meant the chat sessions were recorded in their entirety, showing every step learners took during the sessions. This included if they deleted or inserted words or texts before posting the message to the screen. Instances of self repairs in both methods were examined. When comparing the data gathered from methods A and B, significant differences were found in regard to selfrepairs. Nine instances of self-repairs were revealed in method A, compared to 68 in method B. This indicates that occurrences of self repairs (error correction episodes) in text-SCMC are likely to be much higher than has been reported in other studies that only analysed online text chat transcripts (method A) (Ene, et al., 2005).

These studies suggest that employing a task-based approach in an interactive setting, such as text-SCMC, may allow for greater participation of learners with more negotiated interaction and self-repair. This could result in a higher amount of targetlike language production (Chapelle, 1997; Liu, Moore, Graham, \& Lee, 2002; Leahy, 2008; Lingley, 2006; Smith, 2003a; Warschauer \& Healey, 1998).

However, a challenging barrier for task-based implementation in a textSCMC or networked setting is how to employ the most appropriate tasks for the particular language learning context (Doughty \& Long, 2003; González-Lloret, 2003; Lafford \& Lafford, 2005; O’Dowd \& Ware, 2009; Warschauer, 2001). This is because the quality of learner language production will be influenced by different task types, conditions and implementations (Chapelle, 1999; Thoms, Liao, \& 
Szustak, 2005). More research is needed to evaluate this claim in text-SCMC settings, as mixed findings have been reported to date. These are reviewed in the following section.

\subsubsection{Task types in text-SCMC}

In a face-to-face setting, task types have been shown to influence negotiation and learner language production (Foster \& Ohta, 2005; Mackey, et al., 2003; Newton \& Kennedy, 1996; Pica \& Doughty, 1985; Pica, et al., 1993). Evidence that this notion may apply to text-SCMC is illustrated by Blake (2000). He studied pair work in online text chat discussions between NNSs of Spanish performing different tasks; jigsaw, information gap or decision making tasks. The finding showed that the jigsaw task was the most appropriate task to promote negotiation of meaning, while lexical confusion served as the main trigger for negotiations. Blake concluded that "these tasks appear to constitute ideal conditions for SLA, with the CMC medium being no exception" (p. 133). Blake's findings illustrate that similar to a face-to-face setting, task types influence the occurrences of meaning negotiation in text-SCMC. Similarly, Morris (2005) reported that his participants engaging in jigsaw tasks produced a considerably higher amount of feedback in the form of recasts and negotiations when communicating in text-SCMC.

Lee (2008) also examined the potential of performing different types of tasks via text-SCMC on L2 learning. She investigated 15 dyads, expert-novice partners, performing three types of tasks: jigsaw, spot-the-difference and open-ended question tasks. The first two tasks required learners to exchange information, and specific lexical or grammatical items were required to understand the content. The open-ended tasks did not require specific information exchange, allowing learners to use free responses. The findings revealed that the open-ended tasks yielded the highest amount of self repair (42\%), indicating that these tasks generated attention to form. Although the finding contradicts the others on the superiority of jigsaw tasks (Blake, 2000; Morris, 2005), it indicates that task type is not the only variable that could influence learner language production.

Cheon (2003) also investigated what type of tasks could elicit a higher amount of negotiation when performed via text-SCMC. Twenty pre-intermediate 
EFL learners were asked to perform two task types; jigsaw tasks (task 1: picture drawing, task 2: picture drawing, task 3: holiday plans, task 4: four people) and twoway information gap tasks (task 5: biographies, task 6: it's a fact, task 7: find differences, task 8: find differences), in dyads. The results showed these two task types are productive in eliciting negotiation of meaning.

These studies hint at a role for task complexity in influencing learner language production in text-SCMC. For example in Cheon's (2003) study, the tasks that elicited the highest occurrence of meaning negotiation were the picture drawing (jigsaw) tasks in which the learners performed the tasks without language help. As a result of the vagueness of the lexical choice and unfamiliarity with the lexical items, the learners faced communicative problems. This in turn, triggered a considerable number of negotiation episodes. In Lee's (2008) study, the tasks that pushed learners to engage in self-repair that resulted in more accurate production were open-ended tasks. These two tasks could be viewed as cognitively demanding tasks because in both tasks there was neither language input provided nor language model to follow during task performance. Nevertheless, both tasks encouraged attention to form. As such, these studies indicate that the cognitive demand of a task (task complexity) also plays a role in tasks performed via text-SCMC, an area investigated in the current study.

\subsection{Task-based text-SCMC in the current study}

In studies about spoken discourse, researchers have found that a task implementation feature that alters the complexity of the task can influence the occurrence of interactional modifications (Hardy \& Moore, 2004). It can also influence the fluency, accuracy, and complexity of language production (Skehan \& Foster, 1997, 1999). Task performance in text-SCMC may be challenging, particularly because of the absence of paralinguistic features (Smith, 2003a), and as such, learner language production could be affected. However, little is known about the effects of task implementation features on learner language production in textSCMC setting. The degree of task structure is an important task implementation feature to consider in relation to text-SCMC, as interlocutors engaged in a task with relatively more task structure may rely on that structural support to manage their 
performance. As such, they may be able to focus more on their language production. A second implementation feature, the use of language support, may reduce learners' cognitive load in terms of the allocation of attention to both meaning and form. Providing the language support may heighten learner attention to form, and hence the production of more accurate language can be expected. The current study examines the influence of both of these factors (task structure and language support) on learner language production while performing task-based text-SCMC.

\subsection{Summary}

This chapter has reviewed the application of text-SCMC in the context of SLA. Together, this body of research indicates that text-SCMC represents a positive medium for learners to engage in meaningful interaction, focus on and learn forms. However, it is not simply the technology, but the design and use of appropriate tasks via the technology that is likely to maximise the L2 learning opportunities. Prior research has shown that tasks can be designed to elicit language output in ways that promote L2 learning and development. Aspects of language production, including noticing and discussion of form, can be promoted through careful design and implementation of tasks (c.f., Gass, et al., 2005; Robinson, 2003). While the studies discussed above show text-SCMC to be a powerful site for learning, little is known about how the use of tasks in varying levels of complexity in text-SCMC can influence learner-learner interaction, engagement in discussions, and ultimately learning of forms. 


\section{CHAPTER FIVE \\ METHODOLOGY}

\section{$5.1 \quad$ Introduction}

The current study used a quantitative, quasi-experimental research design to examine the effect of language support and high task structure on learner language production. Four measures of language production were used:

- Language-related episodes

- Accuracy

- Complexity

- Quantity

The study used a "one shot design" (Mackey \& Gass, 2005, p156). This means learner performance was investigated at one particular time rather than tracking language development or acquisition across time. The participants were 96 engineering learners at a technical university in Malaysia who were doing an English for Professional Communication course (see Section 5.4.1).

Using a 2x2 factorial design, these learners were placed in one of four experimental groups (see Section 5.6.1):

- No language support, low task structure (-LS/-TS)

- No language support, high task structure (-LS/+TS)

- With language support, low task structure (+LS/-TS)

- With language support, high task structure (+LS/+TS)

Each group was divided into six teams, with four learners in each team. The groups participated in a 45-minute chat session where they performed a problem-based task relating to an electrical engineering topic (Section 5.6). The chat transcripts provided the main data for the study. The data from interviews were also used to gauge learners' perceptions of the task-based approach in text-SCMC.

\subsection{Research questions}

The current study sought to answer the following questions: 
How do task implementation features influence language use in interactions between learners performing problem-solving tasks in SCMC?

a. How does the degree of task structure influence:

i. the occurrence of LREs?

ii. the accuracy and complexity of learner language?

iii. the quantity of language production?

b. How does language support influence:

i. the occurrence of LREs?

ii. the accuracy and complexity of learner language?

iii. the quantity of language production?

Language production is typically measured by accuracy, complexity and fluency. Fluency in speech production is defined by Wolfe-Quintero, Inagaki and Kim (1998) as "rapid production of language" (p.117) and it is seen developing as more production processes become automatic (Chambers, 1997). In spoken communication, fluency is largely measured through speech rate (Kormos \& Dénes, 2004; Michel, et al., 2007; Ortega, 1999) and pauses (Tavakoli \& Skehan, 2005) while in written communication, revisions is one of the fluency measures based on the process writing approach (Cumming, 1989).

The hybrid nature of text-SCMC makes it difficult to measure language fluency because fluency in text-SCMC is conflated with typing ability which was not measured in this study ${ }^{8}$. Problems in the reliability of measuring fluency in textSCMC are compounded by the fact that these learners were typing in their L2, whereas much of their computer use for social communication is carried out in their L1. Therefore, instead of measuring fluency which in this particular study is likely to be confounded with typing ability, I chose to focus on language production in terms of quantity, i.e. the amount of talk produced by each learner and the distribution of talk within each team.

\footnotetext{
${ }^{8}$ Although keystroke-logging software (Lindgren \& Sullivan 2006) or Camtasia (Smith, 2008) have been used, they are typically used to measure typing skill and text revision processes, not fluency.
} 


\section{$5.3 \quad$ Hypotheses}

In the current study, high task structure (+TS) and low task structure (-TS) refer to the amount of information learners were given on how to complete each stage of the task. Low task structure required a higher degree of cognitive, online processing to manage the information and communicate meaning because learners were given less support on how to organise their discourse.

Language support (+LS) refers to the exercises and notes on helpful linguistic structures that learners received prior to and while performing the task. Learners in the no language support condition did not receive these. Providing high task structure (+TS) or adding language support (+LS) simplifies the task, which decreases task complexity. Accordingly, low task structure (-TS) or no language support (-LS) conditions refer to increased task complexity (see Chapter 3, Section 3.4).

Based on the above, the hypotheses for the current study are formulated as below:

- Hypothesis 1a:-TS will elicit higher occurrence of LREs than +TS.

- Hypothesis 1b: -LS will elicit higher occurrence of LREs than +LS.

Hypothesis 1a and 1b test Robinson's speculation that interactive complex tasks are likely to produce more negotiation relative to simple tasks (Robinson, 2001b, p.36). This means learners may engage in more discussion or talking about the language they use when performing a task with -TS or -LS (see Chapter 3, Section 3.4).

- Hypothesis 2a:-TS will lead to less accuracy than +TS.

- Hypothesis 2b:-LS will lead to less accuracy than +LS.

- Hypothesis 3a:-TS will lead to less complexity than +TS.

- Hypothesis 3b: -LS will lead to less complexity than +LS.

Hypothesis 2a, 2b, 3a and 3b test the Cognition Hypothesis that in interactive tasks, increasing the cognitive demands of the task along the resource-dispersing 
dimension may result in a decrease in accuracy and complexity of production (see Chapter 3 for details).

Studies of the effect of task implementation features on language production have typically been carried out in face-to-face settings, where fluency is also measurable. As noted earlier, quantity of language is a more appropriate language production variable for SCMC-based tasks.

Quantity is not accounted for in either Skehan's or Robinson's models for task complexity and language production measures. Therefore, it is not possible to generate hypotheses about the effect of task structure and language support on the amount of language learners produced or the equality of participation across group members based on their models. However, when comparing the quantity of language production between the face-to-face and SCMC settings, researchers agree that discussion carried via the SCMC setting encourages increased language production and equal participation than face-to-face discourse (Böhlke, 2003; Fitze, 2006; Freiermuth \& Jarell, 2006). Therefore, the hypotheses formulated for quantity are:

- Hypothesis 4a: Neither task structure nor language support will affect the amount of language produced.

- Hypothesis $4 \mathrm{~b}$ : Neither task structure nor language support will affect the equality of participation.

\section{$5.4 \quad$ Setting}

The study took place at a technical university in Malaysia, which specialises in various engineering majors, including electrical and electronics, chemical and natural resources, and computer systems and software engineering. The university aims to produce graduates who are competent not only in engineering knowledge and skills, but also in communication skills, including communication in a range of L2. Particular emphasis is placed on competence in various electronic forms of communication. For example, communication between the administration and academic staff and learners is normally carried out electronically. Free Internet access is available 24 hours a day throughout the campus, and the university provides fully equipped computer labs to support L2 learning and teaching. In 
addition, assessment tasks require learners to negotiate engineering problems in scenarios that involve global electronic communication. For this reason, task design is an important consideration since the aim is to provide opportunities for English language competence and profession specific communication skills to develop in tandem.

\subsubsection{Participant background}

Ninety-six second year electrical engineering undergraduates at a technical university in Malaysia were randomly selected to participate in this study. Their ages ranged from 20 to 24 years. Bahasa Melayu was the native language for approximately $80 \%$ of the learners. Table 5.1 summarises the characteristics of the learners.

Table 5.1

Learner characteristics

\begin{tabular}{lll}
\hline Characteristic & & \\
\hline \multirow{2}{*}{ Gender } & Male & 68 \\
\cline { 2 - 3 } & Female & 28 \\
\hline Age & Mean & 21.78 years \\
\cline { 2 - 3 } & Range & $20-24$ years \\
\hline \multirow{2}{*}{ L1 background } & Malay & 77 \\
& Chinese & 7 \\
& Tamil & 4 \\
& Others & 8 \\
\hline
\end{tabular}

The participants were enrolled in a course on English for Professional Communication, the final, compulsory English language course for all learners at the university. They had also completed three levels of English language courses in the previous semesters. Prior to this, the learners had learnt English language for about 11 years as a compulsory subject in primary and secondary school. Instruction was typically grammar-based, with limited opportunity for communicative language use. The opportunity to participate in oral language in the classroom was limited to answering questions formulated by the teacher. At the end of their secondary schooling, they sat for a national examination with English language as one of the 
subjects tested. The English language results in the national examination indicate that their English language proficiency was intermediate ${ }^{9}$.

All participants stayed in the university accommodation located within the campus area. Because they had 24-hour free Internet access throughout the campus, most of them used computers extensively for a variety of purposes, such as gaming, surfing the Internet for resources and chatting socially, and study. Overall, they were very comfortable with computers and text communication, especially in Bahasa Melayu, via computer.

\subsubsection{The English language program}

While the first language of the majority of the students is Malay, Tamil, or Chinese, English language is used as the medium of instruction for all the university's engineering courses. Out of the one hundred and twenty credits determined by the Engineering Accreditation Council (EAC) ${ }^{10}$ for engineering degree programs at Malaysian universities, the university has specified eight credits to courses from the Language and Communication Department. The eight credits allotted to the Language and Communication Department are divided into four compulsory ESPbased courses spread over four academic semesters. The courses are English for Academic Communication, English for Technical Communication, English for Business Communication and English for Professional Communication. None of the bachelor degree students are exempted from these courses since they form part of their graduation requirement.

The four levels of the courses integrate all the language skills in the teaching materials, assignments and evaluations with greater focus on speaking and writing skills. In English for Academic Communication, students are taught various skills needed for general academic success, such as skimming and scanning skills, notetaking and note-making techniques and some fundamentals of listening skills. The students are also exposed to the basics of writing and are taught a logical, step-by-

\footnotetext{
${ }^{9}$ The grade in the national examination is based on the following; $1=$ highest (high proficiency learners) $5=$ middle (intermediate proficiency learners) and $9=$ lowest (low proficiency learners). Most learners in this study obtained grade 4, 5 and 6 for the English language subject in the national examination.

${ }^{10} \mathrm{EAC}$ is the only recognized accrediting body for engineering degree programmes offered in Malaysia (http://www.eac.org.my/web/index.html).
} 
step process for conducting and participating in small group discussions and certain aspects of presentation skills. In English for Technical Communication, the students are exposed to technical writing and analytical report writing while English for Business Communication provides students with opportunities to engage in writing business letters and memorandum as well as performing role play for job interview. English for Professional Communication incorporates three modules, namely, public speaking skills, meeting skills and principles of effective communication. Tasks and activities in English for Professional Communication simulate much more realworld communicative events while English language serves as the vehicle for the students in performing and completing the tasks. As such, these English language modules are designed to ensure that learners can communicate effectively in English for business and professional purposes in the context of the global engineering profession and business world.

The English language program, is therefore, not intended to teach learners new linguistic knowledge or explicit grammatical structures and items. Rather, it is designed to provide learners with opportunities to engage in meaningful activities using the grammatical knowledge they have already learnt during the eleven years at school. The learners are grouped according to their specific engineering majors (for example, electrical and electronics engineering, chemical engineering and computer and software engineering), rather than their proficiency levels.

\subsection{Data collection}

The information on data collection is explained in the following sub-sections.

\subsubsection{Learner groupings}

The chat sessions took place during the learners' normal class hours. Ninetysix learners participated in the study, with 24 participating in each of the four task implementation conditions. Learners in each condition were divided into six teams, with four learners in each team (see Table 5.2). Research on chat room conversations shows that small teams with four to five members is sufficient for successful text communication (Beauvois, 1992; Böhlke, 2003; Bump, 1990; 
Kearsley, 2000). Furthermore, working collaboratively in smaller teams closely simulates the teamwork environment common in engineering jobs. Research also indicates that collaborative learning aids language development in general (Curtis \& Lawson, 2001; Donato, 2004).

Table 5.2

Task conditions

\begin{tabular}{lll}
\hline & $\begin{array}{l}\text { Low task structure } \\
(-\mathrm{TS})\end{array}$ & $\begin{array}{l}\text { High task structure } \\
(+\mathrm{TS})\end{array}$ \\
\hline $\begin{array}{l}\text { No language support } \\
\text { (-LS) }\end{array}$ & $\mathrm{G} 1$ & $\mathrm{G} 2$ \\
$\mathrm{n}=24$ & $\mathrm{n}=24$ \\
\hline With language support & $\mathrm{G} 3$ & $\mathrm{G} 4$ \\
$(+\mathrm{LS})$ & $\mathrm{n}=24$ & $\mathrm{n}=24$ \\
\hline
\end{tabular}

\subsubsection{Procedures}

Learners were connected to each other by networked computers using a chat program called Microsoft Internet Relay Chat (mIRC). It was chosen because it is the simplest, user-friendly and free online text chat tool ${ }^{11}$. Users join a chat room channel via a mIRC client program by means of an applet in the browser. They normally use nicknames, and once they $\log$ in are able to view the screen immediately to read and write messages. The messages are exchanged when the users hit the enter key. New and subsequent chat messages are added at the bottom of a scrolling screen, allowing the interlocutors to view messages as they are delivered.

Learners were asked to participate in a 45 minute chat session to solve a problem-based, authentic, engineering task (Appendix C). Prior to performing the task, learners were reminded that they were required to use proper English words and sentence structure. As learners were in English language classes they were already aware of this requirement and expectation. Nevertheless, they were allowed to use Internet chat jargon. Learners were informed that they had access to the Internet to look for relevant, extra information about the software discussed during the task performance. Team members were seated far enough apart to ensure they

\footnotetext{
${ }^{11}$ The preference to utilize mIRC in this study is to make it easier for the findings and pedagogical recommendations to be applied to a wider audience. Also, using $\mathrm{mIRC}$ is straightforward and the users do not need to purchase the expensive, commercially available software packages from the market.
} 
could not directly speak to each other during the chat sessions. They were also not told who their team members were, and each learner used a nickname ${ }^{12}$.

The instructor and the researcher monitored and captured each learner's screen from the main terminal using the classroom management systems. Following the chat session, the chat exchanges were saved in log files, which served as the primary data source for this study. The transcripts were coded and analysed quantitatively.

\subsubsection{The data}

The chat transcripts were in an automatically recorded electronic format, and did not go through the transcription process. Chapelle (2003) terms this kind of data as "process data" (p.98), which is naturally divided by an individual's turn as illustrated in table 5.3. The table illustrates the chat exchanges between four learners ${ }^{13}$, Adam, Bo, Kieran and Lisa.

Table 5.3

An example of text chat

\begin{tabular}{lll}
\hline Line & Learner & Chat exchange \\
\hline 1 & Lisa & i have the best ever software in the world \\
2 & Bo & can you ellaborate \\
3 & Lisa & Yeah \\
4 & Kieran & what is the software? \\
5 & Lisa & of course \\
6 & Adam & i eager to know.... \\
7 & Lisa & it is maxplus 2 \\
8 & Bo & Proceed \\
9 & Adam & ooo... i i see \\
\hline
\end{tabular}

According to Levy and Stockwell (2006), qualitative data is useful in helping a researcher to better understand the results from the quantitative, experimental data,

\footnotetext{
${ }^{12}$ It should be noted here that during the interview sessions some learners admitted they successfully recognised one or two of their team mates, but only towards the end of the chat sessions. However, these learners took their involvement in performing the task seriously and therefore, did not identify themselves to any team members. Anonymity in this case was important for two main reasons. First, it allowed the learners to express themselves in the L2 without the threat of their proficiency being judged. Second, because the learners were all in the same room (a computer lab) anonymity reduced the risk that the students in given teams would interact verbally.

${ }^{13}$ The learners' names found in this dissertation are pseudonyms.
} 
particularly in an attempt to learn about learners' perspectives. In this study, qualitative data in the form of semi-structured interviews (Appendix B) was employed to gauge the learners' perceptions of the task-based approach in textSCMC. The interviews were conducted with 12 teams, i.e. three teams from each of the conditions. During each team's interview their chat transcript was used as a stimulus. While reviewing the transcript there were several occasions where learners themselves chose to discuss the chat exchanges they found to be interesting.

\subsubsection{The instructor's role}

The instructor and researcher were on-site during the data collection. The instructor was the lecturer for the learners' English for Professional Communication course for that particular semester. They met twice a week in two hourly sessions for each meeting. Since this study took place approximately two months after the semester commenced, the instructor and learners were familiar and comfortable with each other during data collection. The instructor went through the task instructions with the participants prior to the task performance. Learners were informed that the task they were about to engage in was useful practice for one of the course assessments.

During the task-based text communication, the instructor and researcher monitored the chat sessions using the classroom management system. This allowed the learners' screens to be captured from the main terminal. The discussions among the learners were not interfered with, and no feedback or other assistance with the discourse and language production was provided. Following the chat sessions the chat transcripts were saved in log files.

\subsection{Task used in the current study}

The task was designed as an interactive problem-solving activity. It required the learners to role play as engineers in a multinational company where they had to decide what type of electrical engineering software the company should adopt for electrical designs, simulations, analyses and technical diagramming and drafting. Each learner had their own software option, including a technical description of the 
software, to propose. They were instructed to listen to each other's proposals, compare and contrast the appropriate software, and discuss it until they reached a consensus on the best software to be purchased, based on the criteria of practicality (e.g. user-friendly), utilisation (e.g. multi-purpose) and cost (Appendix C). By the end of the meeting each learner was expected to have filled in a sheet providing their recommendations on the ranking of the software, which was to be sent to the CEO (Appendix F).

To retain the learners' interest and engagement in completing the task and ensure they communicated effectively to promote their software, they were asked to evaluate and rate their team members using a checklist. This consisted of factors that contributed to effective communications (Appendix G).

As mentioned above, the learners were reminded that the task they performed would be useful as a practice for one of the course assessments, and initial preparation for their future engineering profession.

\subsubsection{Task implementation conditions}

Two task implementation variables were investigated in this study. The first, task structure (TS) was chosen because of the challenge for learners communicating via text-SCMC of structuring a task performance collaboratively. The second, language support (LS) was chosen because it reflected a common pedagogic approach to using tasks in language classrooms; that is, an approach which involves some pre-task activities focused on useful task language.

As mentioned in Section 5.5.1, learners were grouped under four implementation conditions. In each group there were six teams consisting of four members per team.

- Group 1 - no language support and low task structure (-LS/-TS)

- Group 2 - no language support and high task structure (-LS/+TS)

- Group 3 - language support and low task structure (+LS/-TS)

- Group 4 - language support and high task structure (+LS/+TS)

\subsection{Pilot study}


Piloting of the task and other materials was carried out at the research site with four groups of four learners (one for each experimental condition) prior to data collection. The aim of this piloting was to refine the tasks and materials that would be used for data collection and identify linguistic targets for the design of the language intervention that would be helpful to learners while performing the task. All the task-based interactions from each group were recorded and examined to highlight any issues with task design and to identify language features that appeared challenging to the students. Piloting indicated that the tasks worked well as a medium for stimulating interaction between the learners although some minor rewording of the task content was carried out as a result of reviewing the group performances.

\subsubsection{Rationale for the selection of the linguistic items for the language support}

The pilot data indicated that students made various types of errors which include errors in auxiliaries, modal verbs, articles, tenses and lexical choice, during task performance. Non-targetlike use of auxiliary verbs and modal verbs contributed to the highest percentage of the errors, approximately $25 \%$ and $35 \%$ respectively. Malaysian students may struggle with these structures because they encode meanings that are not realised through morphosyntax in Bahasa Melayu (Svalberg \& Chuchu, 1998). However, because auxiliary verbs and modal verbs are widely used in English, learners need to be able to use them correctly. For those reasons, the researcher decided to focus the language support on auxiliary verbs and modal verbs.

\subsection{Language support}

Language support was given electronically during the fieldwork, prior to and during the task. This was based on feedback from the pilot and how pilot participants worked through the tasks.

Prior to engaging in the task, learners worked through a short language lesson. This was a three section computer-based form-focused activity, which targeted either auxiliary or modal verbs (half the learners received the auxiliary 
verbs exercise and the other half the modal verbs exercise $\left.{ }^{14}\right)$. The first section raised learner awareness of the targeted linguistic items (either auxiliary or modal verbs) by requiring them to read a dialogue seeded with the target form and underline the targeted items. The second section included an explicit metalinguistic explanation of the forms. After reviewing this information, the learners completed a short multiplechoice grammar exercise. The third section required learners to produce the targetlike forms by filling in blanks.

The language exercise and answers were uploaded into a computer using Renet software. This enabled learners to receive immediate feedback after completing each section. The language lesson was concluded by the instructor summarising important points of auxiliary and modal verbs. For this reason, in the $+\mathrm{LS}$ condition, although some learners received the auxiliary verbs exercise while others received the modal verbs exercise, all of them had the opportunity to review both linguistic items.

These learners were given a reference list consisting of either auxiliary or modal verbs that they could refer to while performing the task ${ }^{15}$. The reference was uploaded into the computers enabling learners to view the text chat and list screens alternately whenever they needed language help. Language support materials are provided in Appendix D.

\subsection{Task structure}

The low task structure (-TS) version of the task included basic information about the task requirements. Each learner also received information on their software with its technical description. This version of the task included no guidance on how to organise the interactive discourse (see Section 5.6 and Appendix C). In the high task structure (+TS) condition learners received the same information as the low task structure learners, as well as guidelines for learners to follow when

\footnotetext{
${ }^{14}$ In each team of four, half of the team was given input on one of the target forms and the other half of the team on the other target forms. This approach was taken to provide different team members with different linguistic expertise so as to encourage them to help each other with the target forms during the task performance.

${ }^{15}$ The learners who did the auxiliary verbs practice received the auxiliary verbs notes, while the learners who did the modal verbs practice received the modal verbs notes.
} 
completing the task. This was a worksheet that consisted of a comparison table for learners to fill in while discussing the different types of software (Appendix E).

\subsection{Coding systems and language production measures}

The following explains the coding systems and categories used in this study.

\subsubsection{Language-related episodes (LREs)}

Previous studies that examined verbal interaction among non-native speakers highlighted features of interaction that facilitate second language learning, among which was language-related episodes (LREs) (Farrokhi \& Gholami, 2007; Truong \& Storch, 2007). Swain and Lapkin (1995; 2001) define an LRE as any part of a dialogue where learners talk about the language (with regard to meaning and/or form) they produce, question or reflect on or correct their own language use and/or the interlocutors. Following their definition LREs in the current study were defined and coded into two categories:

- Language-related episodes on meaning (LREs on meaning)

- $\quad$ Discourse in which learners talk or ask or question implicitly or explicitly their own or others use about semantic components, content or lexical items including the word choice, spelling of vocabulary and so on

- Language-related episodes on form (LREs on form)

- $\quad$ Discourse in which learners talk or ask or question implicitly or explicitly their own or others use about linguistics or grammatical items including verb tenses, word order, prepositions or articles use and so on

Table 5.4 illustrates an LRE on meaning, while table 5.5 gives an example of an LRE on form (all episodes are from the data set).

Table 5.4

LREs on meaning 


\begin{tabular}{llll}
\hline Line & Learner & Chat exchange & \\
\hline 1 & Amet & Can it work in both platforms? & \\
2 & Azim & platforms? what? & $\leftarrow$ LRE initiation \\
3 & Maria & ya rick, what is that mean? & \\
4 & Amet & $\begin{array}{l}\text { i mean linux and windows } \\
\text { operating systmes }\end{array}$ & $\leftarrow$ LRE response \\
& & oic. no only windows & \\
5 & Azim & Oooooo & \\
\hline
\end{tabular}

Table 5.4 is an example of an episode in which an explanation of a lexical item is concerned. In line 1 of Table 5.4, Amet mentioned the word 'platforms'. Azim and Maria seemed confused by the word. In line 4, Amet responded to their confusion by (1) changing the word 'platforms' to 'operating systems' (modifying his output), and (2) elaborating on his output (he elaborates the word 'both' to 'linux and windows').

Table 5.5

LREs on form

\begin{tabular}{llll}
\hline Line & Learner & Chat exchange & \\
\hline 1 & Yasmin & madi... hani will explains first ok & \\
2 & Hani & kk thanks & \\
3 & Yasmin & b quick hani & \\
4 & Madi & wiat! after will, we canot put s & $\leftarrow$ LRE initiation \\
5 & Hani & what madi? & \\
6 & Jack & *yasmin- she will explain- & $\leftarrow$ LRE response \\
7 & Madi & will explain - don't pout s & \\
8 & Yasmin & oh ok ok. quick! & \\
\hline
\end{tabular}

Table 5.5 illustrates an LRE on form. It shows a discussion on syntax. In line 4, Madi said '... after will, we canot put s', indicating that the third person inflected form should not be used. In the subsequent line Hani seemed to be confused. Jack responded to Hani first by explicitly referring to the non-targetlike modal verb produced by Yasmin. Madi provided similar response in the next line. (Please note that Jack's and Madi's responses were likely composed simultaneously).

5.10.2 Analysis of speech units (AS-unit) 
Little is known about the most appropriate unit of analysis for text-SCMC, which combines features of spoken and written language. Being able to rapidly exchange information makes it similar to spoken language, while being able to scroll the text and read the information backwards and forwards renders the discourse more like written language. These actions have led to the unique formation of SCMC discourse characteristics. For example, disrupted turn adjacency, multiple threads of interaction within the same chat floors, an interrupted stretch of ideas and a delay of response between each of the enter key or chat exchange (Smith, 2003a). To date there is no standard unit for language analysis associated with text-SCMC in analysing the language production.

Previous studies that examined learner language production have used $\mathrm{C}$-unit and T-unit as the units of analysis (Kuiken \& Vedder, 2007; Larsen-Freeman, 2006; Robinson, 2007a). However, Foster, Tonkyn, and Wigglesworth (2000) argue that the scope and design of these units are limited to analysing either spoken or written language. They suggest AS-unit or 'Analysis of Speech unit' as the basic unit of analysis designed to capture highly interactive data. Foster, et al. (2000) define the AS-unit as
..... a single speakers' utterance consisting of an independent clause, or sub-clausal unit, together with any subordinate clause(s) associated with either. An independent sub-clausal unit will consist of: either one or more phrases which can be elaborated to a full clause by means of recovery of ellipted elements from the context of the discourse or situation OR a minor utterance, which will be defined as one of the class of 'Irregular sentences' or 'Nonsentences' identified by Quirk et al. (1985:838-53). A subordinate clause will consist minimally of a finite or non-finite Verb element plus at least one other clause element (Subject, Object, Complement or Adverbial) (pp.365-366).

Based on this definition the unit seems appropriate for text-SCMC data for its nature of simultaneous interaction, which is full of language fragments. Below is an example of how the chat transcript was coded for the AS-units and clauses.

Table 5.6

$A S$-units and clauses 


\begin{tabular}{lllll}
\hline Line & Learner & Chat exchange & AS-unit & Clause \\
\hline 1 & Afiq & $\begin{array}{l}\text { I do you think :: weve selected the } \\
\text { best I }\end{array}$ & 1 & 2 \\
2 & Chow & I looks good I & 1 & 1 \\
3 & Brad & I r u sure? I & 1 & 1 \\
4 & Afiq & I weve chosen matlab! I & 1 & 1 \\
\hline Note: & Following Foster et al. (2000), AS-unit boundary is marked by \\
& an upright slash I and a clause boundary is marked by a double colon ::
\end{tabular}

As mentioned by Foster and her colleagues, the coordination of verb phrases are considered as one AS-unit unless the speaker produces falling or rising intonations followed by a pause of at least 0.5 seconds. However, intonations and pauses do not occur in text-SCMC. Therefore, information regarding what learners used to indicate intonations and pauses during the chat sessions was gathered during the interviews. According to the learners, they mainly used punctuation to signify that they wanted to emphasise their points (of raising or falling intonations) and/or take breath (pause) as they continued typing. Smith (2003b) also reported the use of similar communication strategies in his study. Such strategies, unique to the textSCMC context, are illustrated in table 5.7. Thus, the application of AS-unit proposed by Foster and her colleagues was extended in the current study.

Table 5.7

Extended AS-units 


\begin{tabular}{lll}
\hline Punctuation & Example & AS-unit \\
\hline Period ( . ) & $\begin{array}{l}\text { I i need more information about } 2 \\
\text { MATLAB. I Can u xplain? I }\end{array}$ \\
More than one dot ( ... ) & $\begin{array}{l}\text { I it animates various automation } 2 \\
\text { tech... I this includes PLC and etc. I }\end{array}$ \\
Comma ( , ) & $\begin{array}{l}\text { I before we decide the product, I 2 } \\
\text { consider its practicalityy utilization } \\
\text { and cost I }\end{array}$ \\
Question mark ( $)$ & $\begin{array}{l}\text { I Shall we make our own ranking? I 2 } \\
\text { then we decide I }\end{array}$ \\
Hyphen ( - ) & $\begin{array}{l}\text { I let me introduce my sofware - I it 2 } \\
\text { is called OrCAD I }\end{array}$ \\
Colon ( : ) & $\begin{array}{l}\text { I fill in utilization colmn: I the 2 } \\
\text { specs include graphic editor, } \\
\text { Symbol editor, tex editor \& } \\
\text { complier I }\end{array}$ \\
\hline Fote: Following Foster et al. (2000), AS-unit boundary is marked by
\end{tabular}

Note: $\quad$ Following Foster et al. (2000), AS-unit boundary is marked by an upright slash $\mathbf{I}$

\subsubsection{Language production measure: Accuracy}

Researchers in SLA have employed different ways to measure accuracy; for example, targetlike use of articles (Robinson, 1995), error free clauses (Foster \& Skehan, 1996) and the proportion of error free T-units (Larsen-Freeman, 2006). Robinson and Gilabert (2007) suggested choosing specific versus general measures of accuracy. Likewise, Housen and Kuiken (2009) pointed out the need to evaluate both general and specific linguistic properties of L2 production “... so as to obtain more precise and objective accounts of an L2 learner's level within each (sub) dimension of proficiency" (p.464). Previous research has found such a global measure of accuracy to be sensitive to detecting differences between experimental conditions (Michel, et al., 2007). As such, in this study, mean errors per AS-unit was used as the general performance measure for accuracy. Two specific measures used for accuracy based on the linguistic items provided for language support, percentage of targetlike use of auxiliary verbs and percentage of targetlike use of modal verbs were also used. The following are the formulae for the calculation of these three measurements:

Number of errors per AS-unit: 
Number of errors

Number of AS-unit

Percentage of targetlike use of auxiliary verbs:

Number of accurately supplied auxiliary verbs

Number of obligatory contexts + Number of inappropriate suppliance

Percentage of targetlike use of modal verbs:

Number of accurately supplied modal verbs Number of obligatory contexts + Number of inappropriate suppliance

\subsection{Type of errors}

The line by line chat exchanges were thoroughly examined, and several types of linguistic errors were found. They included errors in the use of auxiliary, modals, articles, prepositions, subject-verb-agreement, lexical choice and word order. Examples are provided in table 5.8.

Table 5.8

Type of errors

\begin{tabular}{ll}
\hline Category & Example \\
\hline Auxiliary verb & $\begin{array}{l}\text { i think matlab do not provide any tools to deal } \\
\text { with digital processes }\end{array}$ \\
$\begin{array}{l}\text { Modal verb } \\
\text { (modal + non base form) }\end{array}$ & but u must renewal ur licence every year \\
Article & it prvides the discount for studnt- \\
Preposition & what is the advantage for that software \\
SVA & $\begin{array}{l}\text { maxplus provide digital processs and external } \\
\text { tool supports }\end{array}$ \\
Lexical choice & Let we start our discussion. use sht b ok? \\
Word order & gives us its information general... \\
\hline
\end{tabular}

5.10.2.1.1.1 Auxiliary verb errors 
Auxiliary verb errors were coded as the non-targetlike use (NTL). The examples of the non-targetlike use of auxiliary verbs are as below.

Table 5.9

Non-targetlike use of auxiliary verbs

\begin{tabular}{|c|c|}
\hline Category & Example \\
\hline Omission $*$ & we $*$ not need extra equipment \\
\hline Wrong auxiliary & but it $i s$ not say on this sheet... \\
\hline $\begin{array}{l}\text { Wrong verb form } \\
\text { with auxiliary }\end{array}$ & $\begin{array}{l}\text { If } \mathrm{u} \text { use my software... it doesn't carrying any } \\
\text { additional editing software.... }\end{array}$ \\
\hline
\end{tabular}

\subsection{Modal verb errors}

Modal verb errors were coded as the non-targetlike use (NTL). Below are examples of the non-targetlike use of modal verbs.

Table 5.10

Non-targetlike use of modal verbs

\begin{tabular}{|c|c|}
\hline Category & Example \\
\hline Omission * & we $*$ discuss your softawrae next \\
\hline Wrong modal & $\begin{array}{l}\text { for orcad u might install the additonal library tool. if } \\
\mathrm{u} \text { dont install, it canot operate }\end{array}$ \\
\hline $\begin{array}{l}\text { Modal + non base } \\
\text { form }\end{array}$ & it can minimizes re-design work \\
\hline
\end{tabular}

\subsubsection{Language production measure: Complexity}

In the current study, following a suggestion by Palloti (2009) with regards to the needs to evaluate the complexity of learner language production ${ }^{16}$ by means of general and specific complexity measures, structural complexity (representing general measure) and lexical complexity (representing specific measure) were used.

\footnotetext{
${ }^{16}$ In their recent publication, Norris and Ortega (2009) have provided comprehensive reviews on complexity measures.
} 


\subsection{Structural complexity}

Researchers have measured syntactic complexity using many different measures. For example:

- $\quad$ The number of clauses per C-unit (Foster \& Skehan, 1996)

- $\quad$ Average number of clauses per T-unit (Alderson, 2007)

- $\quad$ The percentage of occurrence of multi-propositional utterances (Robinson, 1995)

- $\quad$ The number of dependent clauses per clause (Kuiken \& Vedder, 2007) As stated earlier, the data was coded into AS-units that contained independent clauses, subordinate clauses and sub-clausal units. Therefore, in this study syntactic complexity was measured as the mean number of clauses per AS-unit. Recent task complexity studies have also used this measure for complexity (Michel, et al., 2007; Tavakoli \& Skehan, 2005). The formula is:

Number of clauses per AS-unit:

$$
\frac{\text { Number of clauses }}{\text { Number of AS-unit }}
$$

\subsection{Lexical complexity}

Various measures of lexical complexity have been proposed (Duran, Malvern, Richards, \& Chipere, 2004; Ellis, 2003). For example, studies have examined lexical complexity by looking at factors such as:

- The percentage of words functioning as lexical verbs (Philp, et al., 2006)

- Type-token ratio (Robinson, 2001a)

- Sophisticated type-token ratio (Larsen-Freeman, 2006)

- Giraud advanced (Daller, Hout \& Treffers-Daller, 2003)

- Lexical frequency profile (LFP) (Laufer \& Nation, 1995)

In this study two measures of lexical complexity were chosen. Following Laufer and Nation (1995), the LFP was employed when measuring lexical complexity. A Guiraud index of lexical complexity was also used. 
The LFP shows the percentage of words that learners use at different vocabulary frequency levels in their writing. The British National Corpus (BNC) word frequency list was used for the purpose of LFP (Nation, 2004). The BNC contains 14,000 most frequently used word families in English. For the purpose of this study, to use the range program that runs the LFP, it was essential that there was compatibility between the existing BNC wordlists and the words from the text chat transcripts. The transcripts were scrutinized and the following were edited:

- the inconsistency of spelling especially due to the typo errors, e.g. 'hwo' instead of 'how'

- variants of the word which were not in the BNC list, e.g. 'errrrr' instead of 'er'

- text chat slang, jargon and acronyms, e.g. 'b4' instead of 'before'

- learners' own style of typing/ spelling, e.g. 'evrybdy' instead of 'everybody'

The following were also corrected:

- no space in between words, e.g. 'veryexpensive' to 'very expensive'

- punctuation within a word, e.g. 'pneumatic!s' to 'pneumatics'

Once everything was standardised, the text chat transcripts were uploaded into and run by the range program (Nation \& Heatley, 2002), which matched words from the text chat transcripts with the $14,000^{17}$ BNC wordlists. Words from the transcripts that did not match any in the 14,000 wordlists appeared in the 'not in the list' column. In this study, the percentage of words that did not belong to the first 1,000 most frequent words was calculated. The formula is as below:

Percentage of words beyond the first 1,000 words:

\section{Wordlist 2 until14 $\times 100$ \\ Wordlist 1 until14}

The Guiraud index of lexical richness was also used to measure lexical complexity. According to Vermeer (2000), type/token ratio has been shown to be extremely sensitive to differences in text length because the higher the number of tokens, the lower the ratio. Therefore, Guiraud's index is a more appropriate measure for lexical complexity because by including the square root of the tokens it

\footnotetext{
${ }^{17}$ The fifteenth and sixteenth wordlists were excluded because they contained proper nouns and nonwords.
} 
compensates for differences in text length. Guiraud's index is calculated by dividing the number of types by the square root of the number of tokens.

Guiraud index:

\section{Types}

$\frac{\text { Types }}{\sqrt{T o k e n s}}$

\subsubsection{Turn}

For the quantity measures, turn was used as the unit of analysis. A turn was operationalised as a posting in a text chat session. This was considered appropriate because the objective of measuring quantity in the current study was not to analyse any linguistic structures or discourse features. Instead it involved the amount of talk produced by each learner, and the distribution of talk among the learners in each team when they performed tasks which instantiate different task implementation features. Therefore in this study the definition of turn follows Newlands, et al. (2003):

In the spoken dialogues a turn begins when one speaker takes over the conversational floor, and ends when that speaker relinquishes the floor to another speaker, or is interrupted. Turns in the CMC interactions begin when participants begin to type a message and end when the message is transmitted to their partner (p.335).

By this definition, when a learner typed a message and hit the enter key the posting was counted as one turn, even if the message was not yet completed or seemed to be interrupted or overlapped. It was treated in this manner because of the difficulty of identifying or determining the actual reason behind the action. For example, it could be:

- to manage the conversation when there was too much information to be delivered

- to intentionally draw others' attention to or emphasise his idea

- to keep the chat floor alive or lively

- an individual style in handling the keyboard 
The following table (table 5.11) provides an example of how a turn was coded in this study.

Table 5.11

Turn

\begin{tabular}{llll}
\hline Line & Learner & Chat exchange & Turn \\
\hline 1 & Wie & My software is automation studio. & 1 \\
2 & Yah & ok u may continue... & 1 \\
3 & $\mathrm{Ni}$ & Wie cont... & 1 \\
4 & Oes & ok u cont but.. & 1 \\
5 & Oes & b quick please & 1 \\
6 & Oes & I eman you should explain in brief & 1 \\
7 & Oes & sorry thats aworng spelling *mean & 1 \\
\hline
\end{tabular}

As portrayed in table 5.12, each line represents one turn. In line four Oes hit the enter key, but had not finished the message yet. The participant's stretch of idea was broken into four turns, which was completed in line seven. However, it is rather difficult to judge the reason behind this action. In a normal face-to-face setting such an action might resemble one's taking a breath for a couple of seconds before continuing the conversation. However, in the text-SCMC setting, as previously mentioned, it is difficult "to be able to distinguish accurately when a learner intended a new line to be a genuinely new turn and when the new line simply reflected a highly individualised technique of keyboarding" (Smith, 2003a, p. 42). Therefore, for consistency each time a learner hit the enter key it was considered as one turn.

\subsubsection{Language production measure: Quantity}

As indicated earlier, the current study investigated the quantity of learner language production. In oral interaction studies the quantity of learner participation is measured by examining the number of words and the number of turns taken (Beatty \& Nunan, 2004; Naughton, 2006). Quantity is also indicated by the number of words per turn (Philp, et al., 2006). In the current study quantity refers to the amount of talk and equality of participation when learners perform tasks which instantiate different task implementation features. The amount of talk by each 
learner was measured based on number of words, number of turns and number of words per turn.

Meanwhile, the evidence for equality of participation was measured by looking at the distribution of talk among participants in a group. This was quantified as entropy, which measures whether there is an equal contribution from all team members or whether one (or two) learner is dominating the conversation. The entropy words and entropy turns were used as the measures.

Entropy Words:

$$
\begin{aligned}
\sum p_{i} \ln \left(p_{i}\right) \quad \text { where } \quad & p_{i}=\frac{x_{i}}{X} \\
x_{i} & =\text { Number of words per student } \\
X & =\text { Total number of words per team }
\end{aligned}
$$

Entropy Turns:

$$
\begin{aligned}
& \sum p_{i} \ln \left(p_{i}\right) \quad \text { where } \quad p_{i}=\frac{x_{i}}{X} \\
& x_{i}=\text { Number of turns per student } \\
& X=\text { Total number of turns per team }
\end{aligned}
$$

5.10.4 Summary of the language production measures

There are five main measures of learner language production employed in the current study. Table 5.12 summarises the main as well as sub- language production measures used in this study. 
Table 5.12

Measures of learner language production

\begin{tabular}{|c|c|c|}
\hline Main measure & \multicolumn{2}{|c|}{ Sub measure } \\
\hline \multirow[t]{2}{*}{ Language-related episodes } & 1) & LREs on meaning \\
\hline & 2) & LREs on Form \\
\hline \multirow[t]{3}{*}{ Accuracy } & 1) & Number of errors per AS-unit \\
\hline & 2) & Percentage of targetlike use of auxiliary verbs \\
\hline & 3) & Percentage of targetlike use of modal verbs \\
\hline \multirow[t]{3}{*}{ Complexity } & 1) & Number of clauses per AS-unit \\
\hline & 2) & $\begin{array}{l}\text { Percentage of words } \\
\text { beyond the first } 1,000 \text { words }\end{array}$ \\
\hline & 3) & Guiraud index of lexical richness \\
\hline Quantity & 1) & Number of words \\
\hline \multirow{2}{*}{ (amount of talk) } & 2) & Number of turns \\
\hline & 3) & Number of words/turn \\
\hline Quantity & 4) & Entropy words \\
\hline (distribution of talk) & 5) & Entropy turns \\
\hline
\end{tabular}

\subsection{Intrarater and interrater reliability}

Intrarater and interrater measures were calculated based on simple agreement between raters. Intrarater reliability reached $96 \%$. Interrater reliability was assessed for the coding categories. The second rater coded $25 \%$ of the data. The agreement reached $90 \%$. Based on this, it was determined that the researcher could independently code the rest of the data.

\subsection{Statistical instruments and procedures}

Statistical analyses were carried out using the statistical package SPSS version 16.0 for Windows. The multivariate analysis of variance (MANOVA) procedure $^{18}$ was applied because there was more than one dependent variable. They are illustrated below:

\footnotetext{
${ }^{18}$ MANOVA test can be found under General Linear Model (GLM) in SPSS software version 16.0.
} 
Table 5.13

Dependent variables used in this study

\begin{tabular}{lll}
\hline Main dependent variable & Sub dependent variable \\
\hline Language-related episodes & 1) & Meaning \\
(team attribute) & 2) & Form \\
Accuracy & 1) & Errors per AS-unit \\
(individual attribute) & 2) & Percentage of targetlike use of auxiliary \\
& 3) & verbs \\
& Percentage of targetlike use of modal verbs \\
& 1) & Clauses per AS-unit \\
Complexity & 2) & Percentage of words \\
(individual attribute) & beyond the first 1,000 words \\
& 3) & Guiraud index of lexical richness \\
& 1) & Number of words \\
Quantity & 2) & Number of turns \\
(individual attribute) & 3) & Number of words per turn \\
& & \\
& 1) & Entropy words \\
Quantity- Distribution of talk & 2) & Entropy turns \\
\hline
\end{tabular}

When several variables are measured on the groups, MANOVA is more appropriate than an analysis of variance (ANOVA). This is because MANOVA can test multiple dependent variables simultaneously while keeping track of their correlation with each other. Using multiple ANOVA tests for correlated variables increases the likelihood of committing a type I error. For example, concluding that the groups were significantly different when they were not (Pallant, 2007).

The MANOVA, like the ANOVA, is robust against moderate violations of multivariate homogeneity of variance, especially when the sample sizes are equal. Several two-way MANOVA analyses were carried out because some dependent variables were measured for individuals and others for teams. Language-related episodes and quantity (distribution of talk among team members) are collaborative, so were measured based on LREs per team. The other variables, i.e. accuracy, complexity and quantity (individual participation), were measured for each individual, and thus were analysed in a MANOVA model respectively. Non-related dependent variables (e.g., LREs and quantity entropy) were not included in the same models, as increasing the number of dependent variables in MANOVA results in a loss of power. This increases the likelihood of Type II errors (in which significant 
differences are not detected). This is particularly important for studies (like this one) with moderate sample sizes. Finally, the likelihood of error-based interactions also increases as the number of dependent variables is increased.

A Box $M$ test was carried out for each MANOVA to see if the assumption of homogeneity of the covariance matrix was met. If the $p$ value was less than 0.001 this was taken to imply that the assumption was not met. Nevertheless, as this study had an equal sized group, the results of multivariate $\mathrm{F}$ tests were still used even if this assumption was not met. Additionally, since the Box test is quite robust to departures from the assumption of equality of covariance matrices, the F test (found under tests of Between-Subjects Effects) can still be used even if the covariances are different.

The first MANOVA output is the "Multivariate Tests" table, which focuses on the independent variables. It shows the effect of each independent factor on the groups of dependent variables. SPSS offers four alternative multivariate significance tests. In this study Hotelling's Trace was chosen because there were two groups formed by the independent variables. Akin to the F test in univariate ANOVA, the significance of the Hotelling's Trace F tests show if that effect is significant. When the overall multivariate test was significant, the univariate $\mathrm{F}$ tests are examined for each variable to identify the specific dependent variables that contribute to the significant overall effect. In addition, partial eta squared was used to measure effect sizes. Also, power analysis was carried out for all results to determine whether the sample size was sufficient to reliably show a non-significant result without risk of Type II error. The standard power analysis level of 0.80 minimum was adopted in this analysis.

\subsection{Qualitative data}

With a growing number of language practitioners using electronic delivery systems, for instance SCMC, it becomes increasingly important to gain in depth knowledge and understanding of learners' perceptions of this learning environment (Chenoweth, et al., 2006). Therefore, in addition to the quantitative analysis of language productions under each treatment condition, qualitative data was gathered to inform understanding of the quantitative results, particularly in regards to 
learners' perceptions of their involvement in task-based text-SCMC and the pedagogical values of the task-based text-SCMC.

The interview responses were gathered from three teams of each condition. During the interviews the chat transcript from the respective team was projected to the wall projector screen, allowing the learners to view their discourse in its entirety. Open ended interview questions were used as the guideline. Additionally, the learners were given the opportunity to discuss interaction patterns they found to be interesting. As such, the qualitative insights into the process have provided a clearer understanding of the quantitative trends.

\subsection{Summary}

This chapter has described the methodology involved in conducting the current study. This has included information about the questions and hypotheses that guided the research, the experiment settings, the tasks used to elicit data, and the coding used to quantify the data. It has also included information about what measures were used to analyse the LREs, the accuracy, complexity and quantity of learner production, statistical instruments employed to calculate the results, and the approach used in qualitative analysis. The next chapter presents the statistical results of this study. 


\section{CHAPTER SIX}

\section{RESULTS}

\subsection{Introduction}

This chapter presents the results of this study. It has been organised as follows:

- Language-related episodes (LREs)

- Accuracy of learner language production

- Complexity of learner language production

- Quantity (amount of language produced by each learner, and distribution of talk within teams)

\subsection{Language-related episodes (LREs)}

In this study the data was coded for two types of language-related episodes (LREs) which are LREs on meaning and LREs on form. Tasks that are designed to provide opportunities for LREs may facilitate language learning. As explained in Chapter 3, Section 3.6, learners who performed an interactive complex task (-TS) or (-LS) were predicted to engage in more negotiation, which resulted in a higher occurrence of LREs than those who performed an interactive simple task (+TS) or $(+\mathrm{LS})$.

In this study, the two independent variables were language support (LS) and task structure (TS). Learners were grouped under the following four task implementation conditions:

- No language support, low task structure (-LS/-TS)

- No language support, high task structure (-LS/+TS)

- With language support, low task structure (+LS/-TS)

- With language support, high task structure (+LS/+TS)

The dependent variables were LREs on meaning and LREs on form. A multivariate analysis (MANOVA) based on the teams' performances (Chapter 5, Section 5.12) was done to look at the effect of the independent variables on the dependent variables. 


\subsubsection{MANOVA results and analysis}

As indicated in Chapter 5, Section 5.12, a Box $M$ test was carried out for each MANOVA test. This was done to test whether the assumption of the homogeneity of variance-covariance matrices across the groups was met. The result indicates that the assumption was met, $(p=0.64)$. The cell means and standard deviations for the MANOVA test on the task implementation factors, and LREs on meaning and form are reported in Table 6.1.

Table 6.1

Language-related episodes: Descriptive statistics

\begin{tabular}{|c|c|c|c|c|c|}
\hline \multicolumn{6}{|c|}{ Descriptive Statistics } \\
\hline & TS & LS & Mean & SD & $\mathrm{N}$ \\
\hline \multirow{9}{*}{$\begin{array}{l}\text { LREs on } \\
\text { Meaning }\end{array}$} & $-\mathrm{TS}$ & -LS & 1.50 & 0.55 & 6 \\
\hline & & $+\mathrm{LS}$ & 3.33 & 0.52 & 6 \\
\hline & & Total & 2.42 & 1.08 & 12 \\
\hline & $+\mathrm{TS}$ & -LS & 2.50 & 0.55 & 6 \\
\hline & & $+\mathrm{LS}$ & 5.00 & 0.89 & 6 \\
\hline & & Total & 3.75 & 1.48 & 12 \\
\hline & Total & -LS & 2.00 & 0.74 & 12 \\
\hline & & $+\mathrm{LS}$ & 4.17 & 1.11 & 12 \\
\hline & & Total & 3.08 & 1.44 & 24 \\
\hline \multirow{9}{*}{$\begin{array}{l}\text { LREs on } \\
\text { Form }\end{array}$} & $-\mathrm{TS}$ & -LS & 2.17 & 0.75 & 6 \\
\hline & & $+\mathrm{LS}$ & 5.50 & 1.38 & 6 \\
\hline & & Total & 3.83 & 2.04 & 12 \\
\hline & $+\mathrm{TS}$ & -LS & 3.50 & 0.55 & 6 \\
\hline & & $+\mathrm{LS}$ & 6.50 & 1.05 & 6 \\
\hline & & Total & 5.00 & 1.76 & 12 \\
\hline & Total & -LS & 2.83 & 0.94 & 12 \\
\hline & & $+\mathrm{LS}$ & 6.00 & 1.28 & 12 \\
\hline & & Total & 4.42 & 1.95 & 24 \\
\hline
\end{tabular}

Note: LREs- Language-related episodes

In the descriptive statistics for the dependent variables the highest occurrence of LREs was apparent in the (+LS/+TS) group, and the lowest occurrence evident in the (-LS/-TS) group. A MANOVA test was done on the data to determine if the groups differed significantly with respect to the production of LREs on meaning and form. Table 6.2 shows the result of the MANOVA test. 
Table 6.2

Language-related episodes: Multivariate tests

\begin{tabular}{|c|c|c|c|c|c|c|c|c|}
\hline \multicolumn{9}{|c|}{ Multivariate Test ${ }^{\mathrm{C}}$} \\
\hline & & Value & $F$ & $\begin{array}{l}\text { Hypothesis } \\
\quad d f\end{array}$ & $\begin{array}{c}\text { Error } \\
\quad d f\end{array}$ & $p$ & $\eta_{p}^{2}$ & $\begin{array}{l}\text { Observed } \\
\text { Power }^{\mathrm{a}}\end{array}$ \\
\hline TS & Hotelling's Trace & 1.98 & $18.84^{\mathrm{b}}$ & 2.00 & 19.00 & $<0.0001$ & 0.66 & 1.00 \\
\hline LS & Hotelling's Trace & 7.70 & $73.20^{\mathrm{b}}$ & 2.00 & 19.00 & $<0.0001$ & 0.88 & 1.00 \\
\hline TS*LS & Hotelling's Trace & 0.08 & $0.78^{b}$ & 2.00 & 19.00 & 0.471 & 0.08 & 0.16 \\
\hline Note: & $\begin{array}{l}* p \leq 0.05 \\
{ }^{*} p \text { Computed using a } \\
{ }^{\mathrm{a}} \text { Comact statistic } \\
{ }^{\mathrm{b}} \text { Exact stic } \\
{ }^{\mathrm{c}} \text { Design: Intercept }\end{array}$ & ha $=0$. & $\mathrm{TS} *$ & & & & & \\
\hline
\end{tabular}

The MANOVA tests using the Hotelling's Trace criteria were statistically significant $(p<0.0001)$ for both main effects. The effect size for task structure was medium $\left(\eta_{\mathrm{p}}^{2}=0.66\right)$, while the effect size for language support was large $\left(\eta_{\mathrm{p}}{ }^{2}=\right.$ 0.88). This indicates that follow-up analyses of between-subjects effects (i.e. the effects of task structure and language support on the dependent variables) are necessary. However, the interaction between task structure and language support was not significant, $(p=0.471)^{19}$. This indicates that neither variable influenced the effect of the other.

6.2.1.1 Language-related episodes on meaning: Univariate results and analysis

Analysis of between-subjects effects on the LREs on meaning is presented in table 6.3.

Table 6.3

Language-related episodes on meaning: Test of Between-Subjects Effects

\begin{tabular}{lccccccc}
\hline \multicolumn{7}{c}{ Test of Between-Subjects Effects } \\
\hline & $\begin{array}{c}\text { Type III Sum } \\
\text { of Squares }\end{array}$ & $d f$ & $\begin{array}{c}\text { Mean } \\
\text { Square }\end{array}$ & $F$ & $P$ & $\eta_{\mathrm{p}}{ }^{2}$ & $\begin{array}{c}\text { Observed } \\
\text { Power }^{\mathrm{a}}\end{array}$ \\
\hline TS & 10.67 & 1 & 10.67 & 25.60 & $<0.0001$ & 0.56 & 1.00 \\
LS & 28.17 & 1 & 28.17 & 67.60 & $<0.0001$ & 0.77 & 1.00 \\
TS*LS & 0.67 & 1 & 0.67 & 1.60 & 0.220 & 0.07 & 0.23 \\
\hline Note: & $* p \leq 0.05$ & & & & & \\
& ${ }^{\mathrm{a}}$ Computed using alpha $=0.05$
\end{tabular}

\footnotetext{
${ }^{19}$ Note that the observed power of this test is 0.16 , which is well below 0.80 . Therefore, the chance of type II error is sufficiently low to be confident in this judgement. See Chapter 5, Section 5.12 for details.
} 
The univariate between-subjects test shows that task structure and language support were significantly related to the LREs on meaning. The test reveals that there were differences in the four groups as seen in figure 6.1 below.

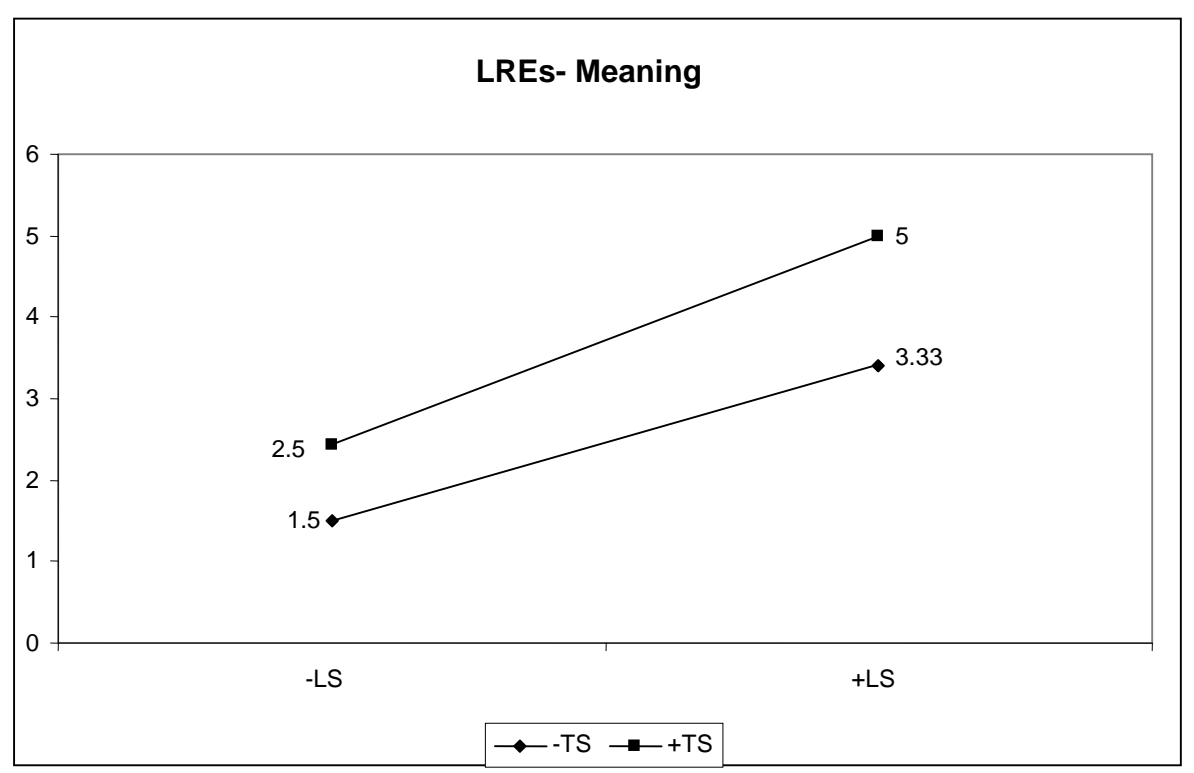

Figure 6.1 Mean number of LREs on meaning

The groups in the language support (+LS) condition had significantly more LREs on meaning $(M=4.17, S D=1.11)$ than the groups in the no language support (-LS) condition $(M=2.00, S D=0.74)$. This was quite a large difference $\left(\eta_{\mathrm{p}}{ }^{2}=\right.$ 0.77). Meanwhile, the high task structure (+TS) groups had significantly more LREs on meaning $(M=3.75, S D=1.48)$ than the low task structure $(-\mathrm{TS})$ groups $(M=$ $2.42, S D=1.08)$. This was a medium difference $\left(\eta_{\mathrm{p}}{ }^{2}=0.56\right)$.

6.2.1.2 Language-related episodes on form: Univariate results and analysis

This section presents the results and analysis of the between-subjects effects test on the LREs on form. 
Table 6.4

Language-related episodes on form: Test of Between-Subjects Effects

\begin{tabular}{|c|c|c|c|c|c|c|c|}
\hline \multicolumn{8}{|c|}{ Test of Between-Subjects Effects } \\
\hline & $\begin{array}{c}\text { Type III Sum } \\
\text { of Squares }\end{array}$ & $\overline{d f}$ & $\begin{array}{l}\text { Mean } \\
\text { Square }\end{array}$ & $F$ & $P$ & $\eta_{\mathrm{p}}^{2}$ & $\begin{array}{l}\text { Observed } \\
\text { Power }^{\mathrm{a}}\end{array}$ \\
\hline TS & 8.17 & 1 & 8.17 & 8.45 & 0.01 & 0.30 & 0.79 \\
\hline LS & 60.17 & 1 & 60.17 & 62.24 & $<0.0001$ & 0.76 & 1.00 \\
\hline TS*LS & 0.17 & 1 & 0.17 & 0.17 & 0.682 & 0.01 & 0.07 \\
\hline
\end{tabular}

$\begin{array}{ll}\text { Note: } & * p \leq 0.05 \\ & { }^{a} \text { Computed using alpha }=0.05\end{array}$

The univariate between-subjects test shows that task structure and language support were significantly related to the LREs on form. Figure 6.20 below, shows the mean difference between the four groups.

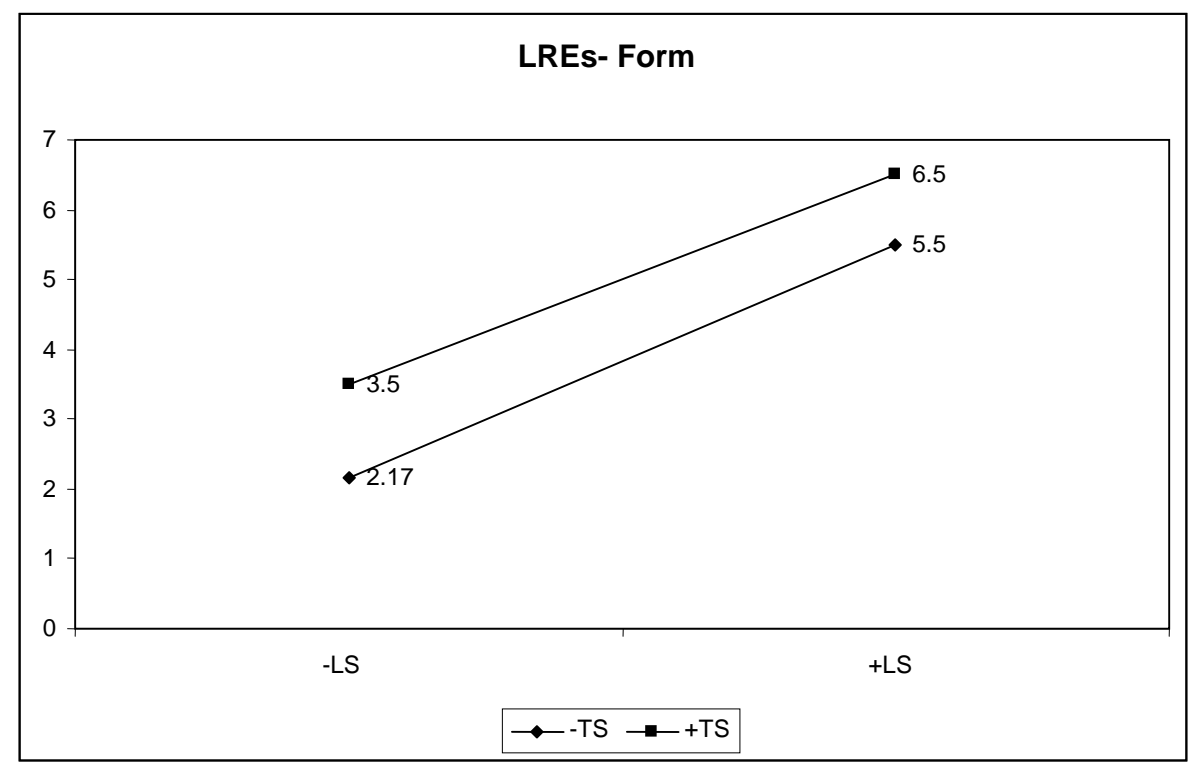

Figure 6.2 Mean number of LREs on form

Similar to the results of LREs on meaning, the language support (+LS) groups had significantly more LREs on form $(M=6.00, S D=1.28)$ than the no language support $(-\mathrm{LS})$ groups, $(M=2.83, S D=0.94)$. This was quite a large difference $\left(\eta_{\mathrm{p}}{ }^{2}=0.76\right)$. In the task structure scores, the high task structure (+TS) groups produced significantly more LREs on form $(M=5.00, S D=1.76)$ than low task structure $(-\mathrm{TS})$ groups $(M=3.83, S D=2.04)$. Although significant, the difference was quite small $\left(\eta_{\mathrm{p}}^{2}=0.30\right)$. 


\subsubsection{Summary}

Hypothesis 1a states that -TS will elicit higher occurrence of LREs than +TS. Hypothesis 1b states that -LS will elicit higher occurrence of LREs than +LS As shown above, an interactive simple task (+TS) /or/ (+LS) can elicit a higher occurrence of LREs than an interactive complex task (-TS) /or/ (-LS). Consequently, the results do not support hypotheses $1 \mathrm{a}$ and $1 \mathrm{~b}$.

\subsection{Accuracy}

The previous section has shown that task implementation conditions influenced the occurrence of LREs on meaning and form. This section looks at the effect of these implementation conditions on the accuracy of learner language production. As mentioned earlier (Chapter 3, Section 3.6), learners who performed an interactive complex task (-TS) or (-LS) were predicted to produce less accurate language than those who performed a cognitively simple task (+TS) or (+LS).

The analysis for accuracy used the same independent variables as the analysis for LREs. Treatments involved the four task implementation conditions as summarised in Section 6.2. The three dependent variables used for accuracy measures were:

- Number of errors per AS-unit

- Percentage of targetlike use of auxiliary verbs

- Percentage of targetlike use of modal verbs

Rather than using the MANOVA model based on the team performances for the analysis of LREs, an individual-based MANOVA analysis was done to investigate how accurate learner language production was under the four task implementation conditions (Chapter 5, Section 5.12).

\subsubsection{MANOVA results and analysis}

A Box $M$ test was carried out and the result indicates that the assumption of homogeneity of the variance-covariance matrices across the groups was not met $(p<$ 
$0.001)^{20}$. The cell means and standard deviations for the MANOVA analysis on the task implementation conditions and the dependent variables are reported in Table 6.5 .

Table 6.5

Accuracy: Descriptive statistics

\begin{tabular}{|c|c|c|c|c|c|}
\hline \multicolumn{6}{|c|}{ Descriptive Statistics } \\
\hline \multirow{10}{*}{ Errors $^{\mathrm{a}}$} & $\mathrm{TS}$ & LS & Mean & SD & $\mathrm{N}$ \\
\hline & $-\mathrm{TS}$ & -LS & 0.40 & 0.17 & 24 \\
\hline & & $+\mathrm{LS}$ & 0.11 & 0.05 & 24 \\
\hline & & Total & 0.25 & 0.19 & 48 \\
\hline & $+\mathrm{TS}$ & $-\mathrm{LS}$ & 0.31 & 0.16 & 24 \\
\hline & & $+\mathrm{LS}$ & 0.04 & 0.03 & 24 \\
\hline & & Total & 0.18 & 0.17 & 48 \\
\hline & Total & $-\mathrm{LS}$ & 0.35 & 0.17 & 48 \\
\hline & & $+\mathrm{LS}$ & 0.08 & 0.05 & 48 \\
\hline & & Total & 0.22 & 0.19 & 96 \\
\hline \multirow[t]{9}{*}{ Auxiliary $^{b}$} & $-\mathrm{TS}$ & -LS & 52.83 & 24.83 & 24 \\
\hline & & $+\mathrm{LS}$ & 73.94 & 16.98 & 24 \\
\hline & & Total & 63.38 & 23.59 & 48 \\
\hline & $+\mathrm{TS}$ & $-\mathrm{LS}$ & 52.34 & 22.88 & 24 \\
\hline & & $+\mathrm{LS}$ & 92.83 & 8.97 & 24 \\
\hline & & Total & 72.58 & 26.72 & 48 \\
\hline & Total & $-\mathrm{LS}$ & 52.58 & 23.62 & 48 \\
\hline & & $+\mathrm{LS}$ & 83.38 & 16.48 & 48 \\
\hline & & Total & 67.98 & 25.50 & 96 \\
\hline \multirow[t]{9}{*}{ Modals $^{c}$} & $-\mathrm{TS}$ & $-\mathrm{LS}$ & 74.85 & 15.62 & 24 \\
\hline & & $+\mathrm{LS}$ & 88.08 & 22.15 & 24 \\
\hline & & Total & 81.46 & 20.11 & 48 \\
\hline & $+\mathrm{TS}$ & -LS & 79.44 & 23.49 & 24 \\
\hline & & $+\mathrm{LS}$ & 99.30 & 3.40 & 24 \\
\hline & & Total & 89.37 & 19.41 & 48 \\
\hline & Total & $-\mathrm{LS}$ & 77.14 & 19.87 & 48 \\
\hline & & $+\mathrm{LS}$ & 93.69 & 16.67 & 48 \\
\hline & & Total & 85.42 & 20.05 & 96 \\
\hline
\end{tabular}

\footnotetext{
Note: $\quad{ }^{\mathrm{a}}$ Errors/AS-unit

b $\%$ of targetlike use of auxiliary verbs

c $\%$ of targetlike use of modal verbs
}

\footnotetext{
${ }^{20}$ Although the assumption was not met, the results of multivariate $\mathrm{F}$ tests can still be used because of the sensitivity of the test, and because the sample sizes are equal. See Chapter 5, Section 5.12 for details.
} 
For all three dependent variables, the most accurate performance was achieved in the language support and high task structure (+LS/+TS) condition. The least was achieved in the no language support and low task structure (-LS/-TS) condition. The data was submitted to MANOVA analysis to determine if the groups differed significantly with regard to the accuracy of learner language production, as measured by the errors/AS-unit, percentage of targetlike use of auxiliary and modal verbs.

Table 6.6

Accuracy: Multivariate tests

\begin{tabular}{|c|c|c|c|c|c|c|c|c|}
\hline \multicolumn{9}{|c|}{ Multivariate Test ${ }^{\mathrm{c}}$} \\
\hline & & Value & $F$ & $\begin{array}{c}\text { Hypothesis } \\
d f\end{array}$ & $\begin{array}{l}\text { Error } \\
\quad d f\end{array}$ & $p$ & $\eta_{p}^{2}$ & $\begin{array}{c}\text { Observed } \\
\text { Power }^{\mathrm{a}}\end{array}$ \\
\hline $\mathrm{TS}$ & Hotelling's Trace & 0.18 & $5.42^{b}$ & 3.00 & 90.00 & 0.002 & 0.15 & 0.927 \\
\hline $\mathrm{LS}$ & Hotelling's Trace & 1.83 & $54.93^{\mathrm{b}}$ & 3.00 & 90.00 & $<0.0001$ & 0.65 & 1.000 \\
\hline TS*LS & Hotelling's Trace & 0.11 & $3.21^{\mathrm{b}}$ & 4.00 & 90.00 & 0.027 & 0.10 & 0.724 \\
\hline Note: & $\begin{array}{l}{ }^{*} p \leq 0.05 \\
{ }^{\mathrm{a}} \text { Computed using al } \\
{ }^{\mathrm{b}} \text { Exact statistic } \\
{ }^{\mathrm{c}} \text { Design: Intercept }\end{array}$ & $a=0.0$ & $\mathrm{TS} *$ & & & & & \\
\hline
\end{tabular}

A Hotelling's Trace multivariate test was used to look at the effect of task structure. The results showed that overall differences among groups was statistically significant, $(p=0.002)$, as was the effect of language support, $(p<0.0001)$. However, the effect size for task structure was small $\left(\eta_{\mathrm{p}}{ }^{2}=0.15\right)$, while the effect size for language support was medium $\left(\eta_{\mathrm{p}}{ }^{2}=0.65\right)$. The interaction between task structure and language support was also significant $(p=0.027)$, but the effect size was very weak $\left(\eta_{\mathrm{p}}^{2}=0.10\right)$. This indicates that the analyses of between-subject effects (i.e. the effects of task structure and language support on the dependent variables and the interaction effect), are necessary. These are presented below.

\subsubsection{Error/AS-unit: Univariate results and analysis}

The analysis of error per AS-unit revealed how accurate learner language production was in relation to the number of errors per AS-unit committed under the different task implementation conditions. 
Table 6.7

Error/AS-unit: Test of Between-Subjects Effects

\begin{tabular}{lccccccc}
\hline \multicolumn{7}{c}{ Test of Between-Subjects Effects } \\
\hline & $\begin{array}{c}\text { Type III Sum } \\
\text { of Squares }\end{array}$ & $d f$ & $\begin{array}{c}\text { Mean } \\
\text { Square }\end{array}$ & $F$ & $p$ & $\eta_{\mathrm{p}}{ }^{2}$ & $\begin{array}{c}\text { Observed } \\
\text { Power }^{\mathrm{a}}\end{array}$ \\
\hline TS & 0.15 & 1 & 0.15 & 9.89 & 0.002 & 0.10 & 0.87 \\
LS & 1.84 & 1 & 1.84 & 124.18 & $<0.0001$ & 0.60 & 1.00 \\
TS*LS & 0.004 & 1 & 0.004 & 0.30 & 0.585 & 0.003 & 0.08 \\
\hline
\end{tabular}

$\begin{array}{ll}\text { Note: }: & * p \leq 0.05 \\ & { }^{a} \text { Computed using alpha }=0.05\end{array}$

The univariate between-subjects test shows that task structure was significantly related to the number of errors per AS-unit, and language support was significantly related to the number of error per AS-unit. However, this test also shows that the interaction between task structure and language support was not significantly related to the number of errors per AS-unit ${ }^{21}$. Figure 6.3 below shows the mean difference of the four groups.

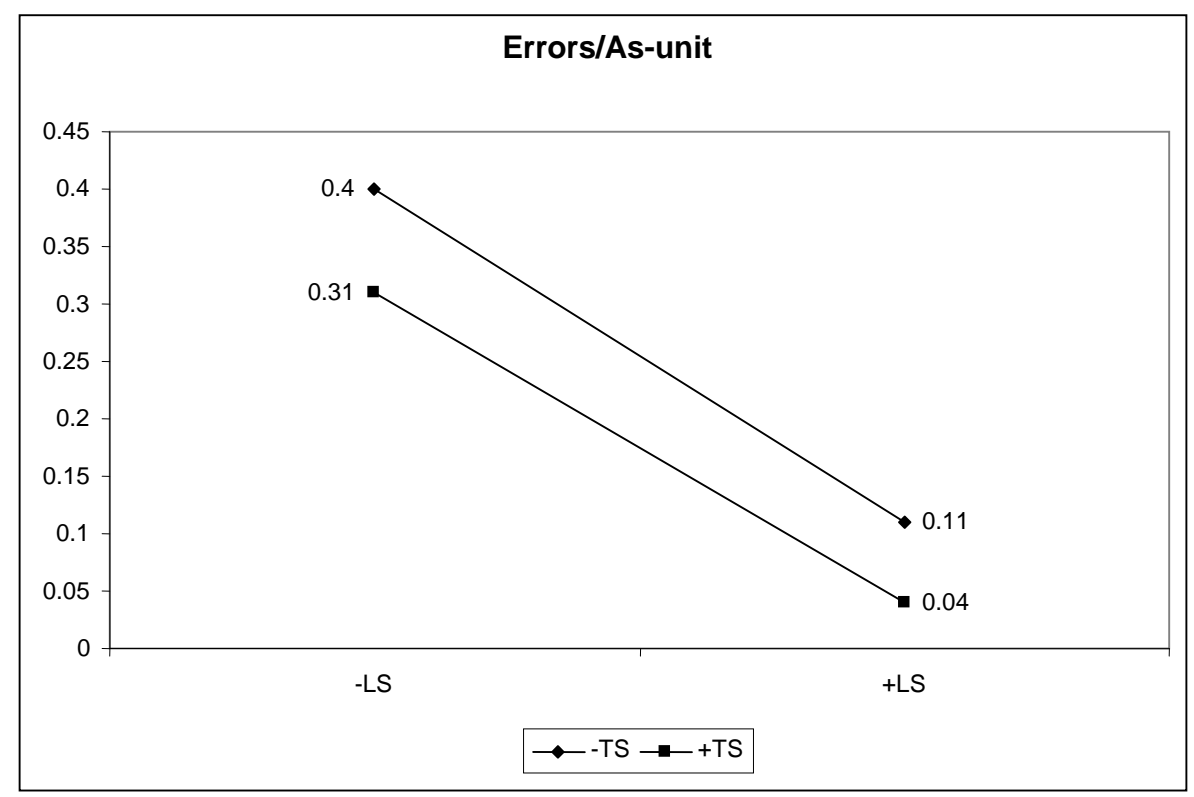

Figure 6.3 Mean number of error/AS-unit

With regard to the scores of language support, learners who received language support $(+\mathrm{LS})$ material had a lower error rate $(M=0.08, S D=0.05)$ than learners who did not receive language support $(-\mathrm{LS})$ material $(M=0.35, S D=0.17)$. This was a moderate difference $\left(\eta_{\mathrm{p}}{ }^{2}=0.57\right)$. The task structure scores revealed that

${ }^{21}$ Refer to footnote no. 19 . 
learners who had high task structure (+TS) material had a lower error rate $(M=0.18$, $S D=0.17)$ than learners who had low task structure $(-\mathrm{TS})$ material $(M=0.25, S D=$ 0.19). Although the effect was significant, the difference was relatively small $\left(\eta_{\mathrm{p}}{ }^{2}=\right.$ 0.10). The $F$-value of the interaction effect was not significant, indicating that the effects of language support and high task structure are independent of each other. This means that if learners received only language support or a high task structure, their language errors would still be reduced.

\subsubsection{Targetlike use of auxiliary verbs: Univariate results and analysis}

The analysis of the percentage of targetlike use of auxiliary verbs revealed how accurate learner language production was. This was measured by the correct use of auxiliary verbs under the different task implementation conditions.

Table 6.8

Targetlike use of auxiliary verbs: Test of Between-Subjects Effects

\begin{tabular}{|c|c|c|c|c|c|c|c|}
\hline \multicolumn{8}{|c|}{ Test of Between-Subjects Effects } \\
\hline & $\begin{array}{c}\text { Type III Sum } \\
\text { of Squares }\end{array}$ & $\overline{d f}$ & $\begin{array}{c}\text { Mean } \\
\text { Square }\end{array}$ & $F$ & $p$ & $\eta_{\mathrm{p}}{ }^{2}$ & $\begin{array}{l}\text { Observed } \\
\text { Power }^{\mathrm{a}}\end{array}$ \\
\hline $\mathrm{TS}$ & 2030.97 & 1 & 2030.97 & 5.38 & 0.023 & 0.05 & 0.63 \\
\hline LS & 22763.04 & 1 & 22763.04 & 60.33 & $<0.0001$ & 0.40 & 1.00 \\
\hline TS*LS & 2253.86 & 1 & 2253.86 & 5.97 & 0.016 & 0.06 & 0.68 \\
\hline
\end{tabular}

The univariate between-subjects test shows that task structure was significantly related to the percentage of targetlike use of auxiliary verbs. It also shows that language support was significantly related to the percentage of targetlike use of auxiliary verbs. Also, the interaction between task structure and language support was significantly related to percentage of targetlike use of auxiliary verbs. However, partial $\eta_{\mathrm{p}}{ }^{2}$ shows that the effect size is medium $\left(\eta_{\mathrm{p}}{ }^{2}=0.06\right)$. Below is the figure showing the mean difference. 


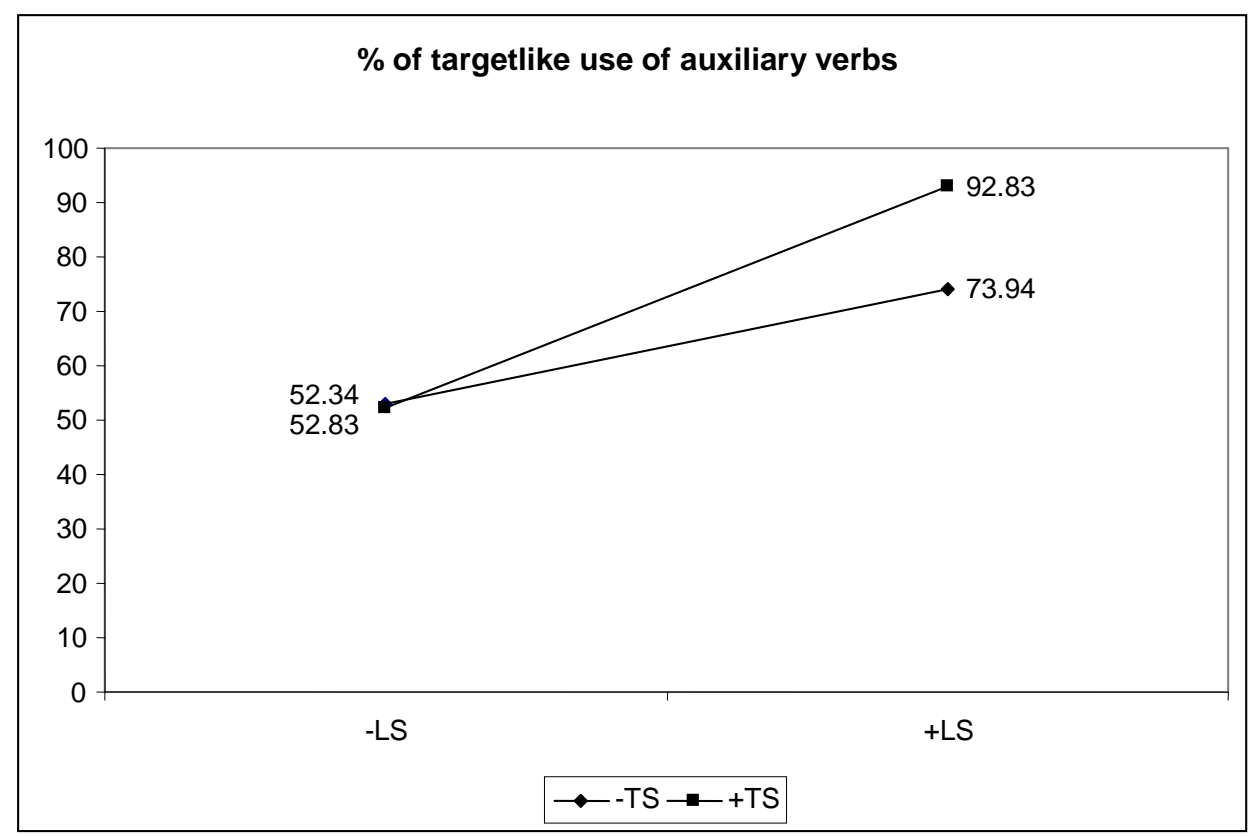

Figure 6.4 Mean percentage of targetlike form of auxiliary verbs

This figure illustrates an interaction effect between language support and task structure on the production of targetlike use of auxiliary verbs. In the language support condition (+LS), learners with high task structure (+TS) material used more targetlike auxiliary verbs $(M=92.83, S D=8.97)$ than learners with the low task structure $(-\mathrm{TS})$ material $(M=73.94, S D=16.98)$. In contrast, in the no language support (-LS) condition, TS did not seem to impact on the targetlike auxiliary verbs.

\subsubsection{Targetlike use of modal verbs: Univariate results and analysis}

Analysis of the percentage of targetlike use of modal verbs revealed how accurate learner language production was with regard to the most correct use of modal verbs under the different task implementation conditions.

Table 6.9

Targetlike use of modal verbs: Test of Between-Subjects Effects

\begin{tabular}{lccccccc}
\hline \multicolumn{7}{c}{ Test of Between-Subjects Effects } \\
\hline & $\begin{array}{c}\text { Type III Sum } \\
\text { of Squares }\end{array}$ & $d f$ & $\begin{array}{c}\text { Mean } \\
\text { Square }\end{array}$ & $F$ & $p$ & $\eta_{\mathrm{p}}{ }^{2}$ & $\begin{array}{c}\text { Observed } \\
\text { Power }^{\mathrm{a}}\end{array}$ \\
\hline TS & 1501.62 & 1 & 1501.62 & 4.63 & 0.034 & 0.05 & 0.57 \\
LS & 6572.50 & 1 & 6572.50 & 20.25 & $<0.0001$ & 0.18 & 0.99 \\
TS*LS & 264.46 & 1 & 264.46 & 0.81 & 0.369 & 0.01 & 0.14 \\
\hline
\end{tabular}

Note: $* p \leq 0.05$

${ }^{\mathrm{a}}$ Computed using alpha $=0.05$ 
The univariate between-subjects test shows that task structure and language support were significantly related to the percentage of targetlike use of modal verbs. It shows that the interaction between task structure and language support was not significantly related to percentage of targetlike use of modal verbs ${ }^{22}$. It also shows that there was a difference between the groups. Figure 6.5 below shows the mean difference.

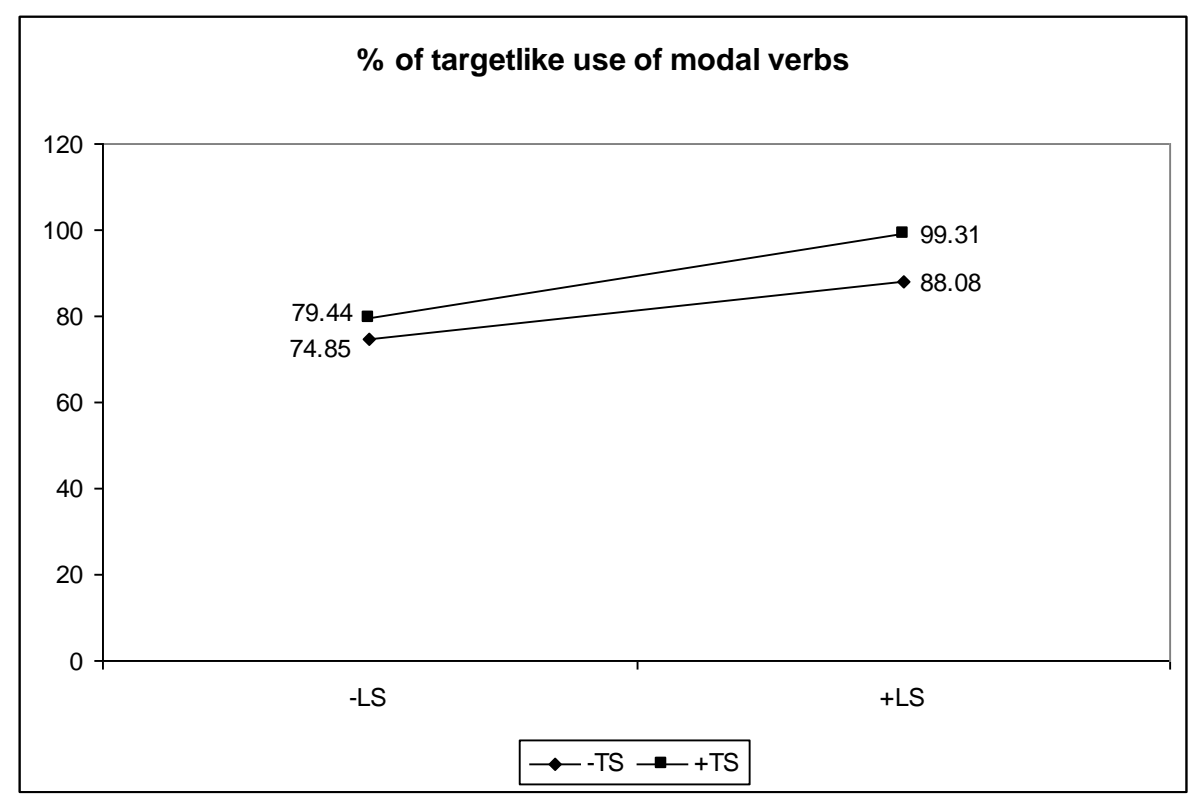

Figure 6.5 Mean percentage of targetlike form of modal verbs

The significant main effect of language support was shown by the following results; learners in the language support $(+\mathrm{LS})$ condition produced a higher percentage of targetlike use of modal verbs $(M=93.69, S D=16.67)$ than learners in the no language support (-LS) condition $(M=77.14, S D=19.87)$ but the difference was small $\left(\eta_{\mathrm{p}}{ }^{2}=0.18\right)$. A similar significant effect was found for task structure. Learners who belong to the high task structure group (+TS) produced a higher percentage of targetlike use of modal verbs $(M=89.37, S D=19.40)$ than learners who belong to the low task structure group $(-\mathrm{TS})(M=81.46, S D=20.10)$. Again, the difference was extremely small $\left(\eta_{\mathrm{p}}{ }^{2}=0.05\right)$. There was no significant interaction effect between language support and task structure in relation to the production of modal verbs. This indicates that their effects were independent of each other. That

\footnotetext{
${ }^{22}$ Refer to footnote no. 19.
} 
is, that either language support (+LS) or high task structure $(+\mathrm{TS})$ on its own increased the production of targetlike use of modal verbs.

\subsubsection{Summary}

Hypothesis 2a indicates that $-\mathrm{TS}$ will lead to less accuracy than +TS. Hypothesis $2 b$ indicates that $-\mathrm{LS}$ will lead to less accuracy than $+\mathrm{LS}$. As noted above, an interactive simple task (+TS) /or/ (+LS) promoted higher accuracy than an interactive complex task (-TS) /or/ (-LS). Therefore, the findings support both hypotheses. The next section presents the results and analysis of the complexity of learner language production.

\subsection{Complexity}

As evident in the previous section, providing learners with language support $(+\mathrm{LS})$ and high task structure (+TS) helped them to reduce their language error rates and produce the most correct use of auxiliary verbs and modal verbs. The next question is: does language support and task structure have any effect on the complexity of language produced by learners under the different task implementation conditions? As described earlier, increasing task complexity along the resource-dispersing dimension could result in less structurally complex production (Chapter 3, Section 3.6).

Similar to the analysis of accuracy, an individual-based MANOVA model (Chapter 5, Section 5.12) was applied to the data. To assess the complexity of learner language production, three language production measures were used:

- Syntactic complexity: Clause/AS-unit

- Lexical complexity: Percentage of words beyond the first 1,000 words

- Lexical complexity: Guiraud Index of lexical richness

The independent variables used for the complexity measure were similar to the ones used in the previous analyses. 


\subsubsection{MANOVA results and analysis}

Similar to the violation of one of the MANOVA assumptions in the accuracy measure, the result of the Box $M$ test for the complexity measure did not comply with the assumption ${ }^{23},(p<0.001)$. Table 6.10 shows the cell means and standard deviations for the MANOVA analyses on the task implementation factors and dependent variables.

Table 6.10

Complexity: Descriptive statistics

\begin{tabular}{|c|c|c|c|c|c|}
\hline \multicolumn{6}{|c|}{ Descriptive Statistics } \\
\hline & $\mathrm{TS}$ & $\mathrm{LS}$ & Mean & SD & $\mathrm{N}$ \\
\hline \multirow[t]{9}{*}{ Clause $^{a}$} & $-\mathrm{TS}$ & -LS & 0.73 & 0.14 & 24 \\
\hline & & $+\mathrm{LS}$ & 0.57 & 0.18 & 24 \\
\hline & & Total & 0.65 & 0.18 & 48 \\
\hline & $+\mathrm{TS}$ & -LS & 0.63 & 0.13 & 24 \\
\hline & & $+\mathrm{LS}$ & 0.59 & 0.15 & 24 \\
\hline & & Total & 0.61 & 0.14 & 48 \\
\hline & Total & -LS & 0.68 & 0.15 & 48 \\
\hline & & $+\mathrm{LS}$ & 0.58 & 0.16 & 48 \\
\hline & & Total & 0.63 & 0.16 & 96 \\
\hline \multirow{9}{*}{$\begin{array}{l}\text { Words } \\
\text { beyond } \\
1,000^{b}\end{array}$} & -TS & $-\mathrm{LS}$ & 20.68 & 4.61 & 24 \\
\hline & & $+\mathrm{LS}$ & 18.10 & 3.55 & 24 \\
\hline & & Total & 19.39 & 4.27 & 48 \\
\hline & $+\mathrm{TS}$ & $-\mathrm{LS}$ & 22.14 & 4.46 & 24 \\
\hline & & $+\mathrm{LS}$ & 17.64 & 3.72 & 24 \\
\hline & & Total & 19.89 & 4.66 & 48 \\
\hline & Total & -LS & 21.41 & 4.55 & 48 \\
\hline & & $+\mathrm{LS}$ & 17.86 & 3.60 & 48 \\
\hline & & Total & 19.64 & 4.45 & 96 \\
\hline \multirow{9}{*}{$\begin{array}{l}\text { Guiraud } \\
\text { Index }^{c}\end{array}$} & -TS & -LS & 8.20 & 0.92 & 24 \\
\hline & & $+\mathrm{LS}$ & 8.56 & 2.06 & 24 \\
\hline & & Total & 8.38 & 1.59 & 48 \\
\hline & $+\mathrm{TS}$ & -LS & 8.60 & 0.72 & 24 \\
\hline & & $+\mathrm{LS}$ & 7.97 & 0.80 & 24 \\
\hline & & Total & 8.29 & 0.82 & 48 \\
\hline & Total & -LS & 8.40 & 0.84 & 48 \\
\hline & & $+\mathrm{LS}$ & 8.27 & 1.58 & 48 \\
\hline & & Total & 8.33 & 1.26 & 96 \\
\hline
\end{tabular}

Note: ${ }^{\mathrm{a}}$ Clause/As-unit

b $\%$ of words beyond the first 1,000 words

${ }^{\mathrm{c}}$ Guiraud Index of lexical richness

${ }^{23}$ Refer to footnote no. 20 . 
The most complex language was produced in the no language support, low task structure (-LS/-TS) condition, while the least complex language was produced in the language support, low task structure (+LS/-TS) condition. The highest percentage of words beyond the first 1,000 words were produced by learners who did not receive language support, but with high task structure (-LS/+TS). The lowest percentage of words beyond the first 1,000 words was produced by learners who received language support and high task structure (+LS/+TS). Under the Guiraud Index measure, the highest number of lexical items was produced by learners who did not receive the language support, but received high task structure (-LS/+TS). However, the least number of lexical items was produced by learners who received language support and high task structure $(+\mathrm{LS} /+\mathrm{TS})$. This data was submitted to MANOVA analyses to determine if groups differed significantly in the complexity of learner language production. This was measured by the clause/AS-unit, percentage of words beyond the first 1,000 words and the Guiraud Index of lexical richness.

Table 6.11

Complexity: Multivariate tests

\begin{tabular}{|c|c|c|c|c|c|c|c|c|}
\hline \multicolumn{9}{|c|}{ Multivariate Tests $^{\mathrm{c}}$} \\
\hline & & Value & $F$ & $\begin{array}{c}\text { Hypothesis } \\
d f\end{array}$ & $\begin{array}{l}\text { Error } \\
\quad d f\end{array}$ & $p$ & $\eta_{p}^{2}$ & $\begin{array}{l}\text { Observed } \\
\text { Power }^{\mathrm{a}}\end{array}$ \\
\hline TS & Hotelling's Trace & 0.02 & $0.54^{b}$ & 3.00 & 90.00 & 0.656 & 0.02 & 0.16 \\
\hline LS & Hotelling's Trace & 0.37 & $11.09^{\mathrm{b}}$ & 3.00 & 90.00 & $<0.0001$ & 0.27 & 1.00 \\
\hline TS*LS & Hotelling's Trace & 0.11 & $3.41^{\mathrm{b}}$ & 3.00 & 90.00 & 0.021 & 0.10 & 0.75 \\
\hline Note: & $\begin{array}{l}{ }^{*} p \leq 0.05 \\
{ }^{\mathrm{a}} \text { Computed using a } \\
{ }^{\mathrm{b}} \text { Exact statistic } \\
{ }^{\mathrm{c}} \text { Design: Intercept }\end{array}$ & $\mathrm{ha}=0$ & $\mathrm{TS} *$ & & & & & \\
\hline
\end{tabular}

The Hotelling's Trace multivariate test of the effect of task structure on the dependent variables was not significant ${ }^{24}(p=0.656)$. This indicates that the effects of low and high task structure were similar. Therefore, further analysis on the effect of task structure on the dependent variables was not needed. However, the test of the effect of language support on the dependent variables was statistically significant ( $p$ $<0.0001)$, but with quite a weak effect $\left(\eta_{\mathrm{p}}{ }^{2}=0.27\right)$. This test also suggests that the interaction between task structure and language support was significant, $p=0.021$.

\footnotetext{
${ }^{24}$ Refer to footnote no. 19 .
} 
Again, the effect size was weak $\left(\eta_{\mathrm{p}}{ }^{2}=0.10\right)$. Follow up analysis of between-subjects effects for language support on the dependent variables, and the interaction effects are presented below.

\subsubsection{Clause/AS-unit: Univariate results and analysis}

The analysis of between-subject effects for language support on the dependent variable, and the interaction effects revealed how complex learner language production was with regard to the amount of clause/AS-units produced within the different task implementation conditions.

Table 6.12

Clause/AS-unit: Test of Between-Subjects Effects

\begin{tabular}{|c|c|c|c|c|c|c|c|}
\hline \multicolumn{8}{|c|}{ Test of Between-Subjects Effects } \\
\hline & $\begin{array}{l}\text { Type III Sum } \\
\text { of Squares }\end{array}$ & $d f$ & $\begin{array}{l}\text { Mean } \\
\text { Square }\end{array}$ & $F$ & $p$ & $\eta_{p}^{2}$ & $\begin{array}{l}\text { Observed } \\
\text { Power }^{\mathrm{a}}\end{array}$ \\
\hline TS & 0.03 & 1 & 0.03 & 1.39 & 0.241 & 0.01 & 0.21 \\
\hline LS & 0.25 & 1 & 0.25 & 10.73 & 0.001 & 0.10 & 0.90 \\
\hline TS*LS & 0.10 & 1 & 0.10 & 4.28 & 0.041 & 0.04 & 0.53 \\
\hline
\end{tabular}

The test shows that language support was strongly related to the number of clauses per AS-unit. The interaction between task structure and language support was also related to the number of clauses per AS-unit. Figure 6.6 below illustrates the mean difference between the groups with regard to the effect of the task implementation conditions on clauses per AS-unit. 


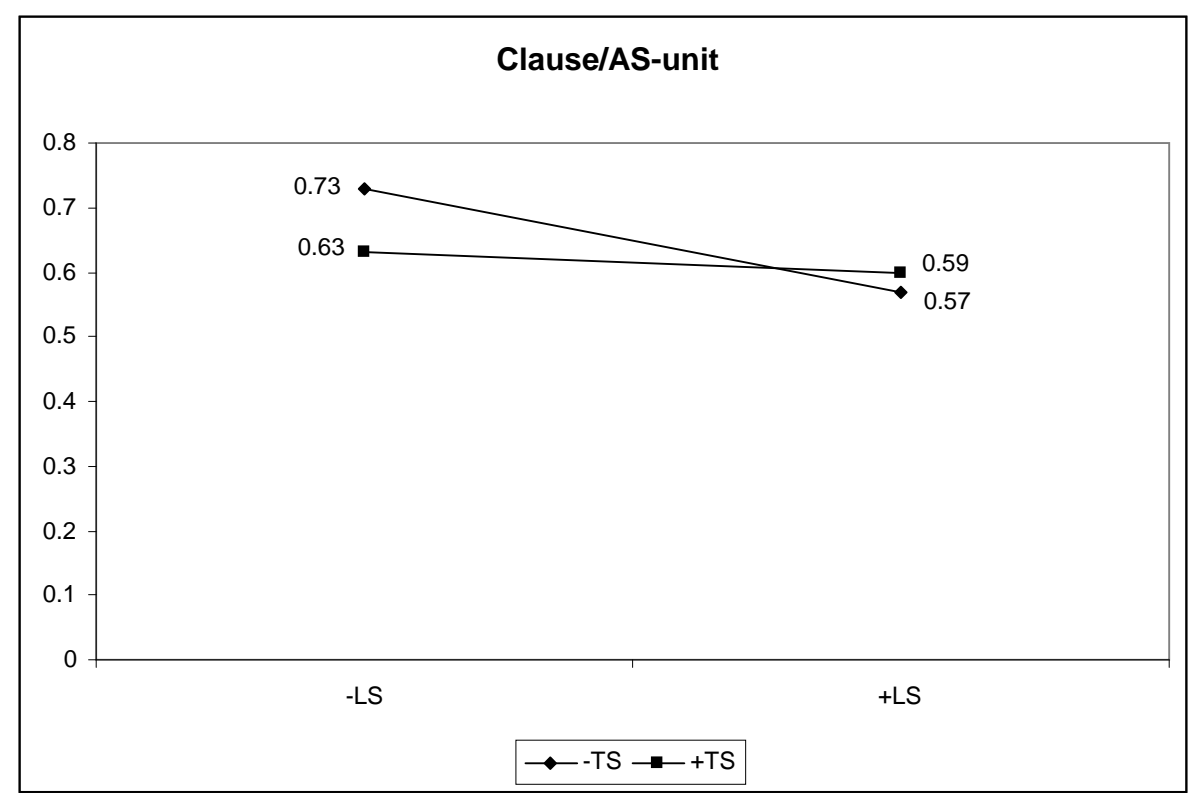

Figure 6.6 Mean number of Clauses/AS-unit

The interaction between task structure and language support was significant, though the effect size was very weak $\left(\eta_{\mathrm{p}}{ }^{2}=0.04\right)$. In the high task structure condition (+TS), learners with no language support (-LS) material produced more complex structure $(M=0.63, S D=0.13)$ than learners with the language support $(+\mathrm{LS})$ material $(M=0.59, S D=0.15)$.

6.4.1.2 Words beyond the first 1,000 words: Univariate results and analysis

The analysis of the percentage of words beyond the first 1,000 words revealed how lexically complex learner language production was under the different task implementation conditions.

Table 6.13

Words beyond the first 1,000 words: Test of Between-Subjects Effects

\begin{tabular}{lccccccc}
\hline \multicolumn{7}{c}{ Test of Between-Subjects Effects } \\
\hline & $\begin{array}{c}\text { Type III Sum } \\
\text { of Squares }\end{array}$ & $d f$ & $\begin{array}{c}\text { Mean } \\
\text { Square }\end{array}$ & $F$ & $p$ & $\eta_{\mathrm{p}}{ }^{2}$ & $\begin{array}{c}\text { Observed } \\
\text { Power }^{\mathrm{a}}\end{array}$ \\
\hline TS & 6.12 & 1 & 6.12 & 0.36 & 0.549 & 0.004 & 0.09 \\
LS & 302.07 & 1 & 302.07 & 17.88 & $<0.0001$ & 0.16 & 0.99 \\
TS*LS & 21.84 & 1 & 21.84 & 1.29 & 0.258 & 0.01 & 0.20 \\
\hline Note: $:$ & $* p \leq 0.05$ & & & & & \\
& ${ }^{a}$ Computed using alpha $=0.05$ & & & & &
\end{tabular}


The test demonstrates that language support was significantly related to the percentage of words beyond the first 1,000 words. Univariate between-subjects tests show that the interaction between task structure and language support was not significantly related to the percentage of words beyond the first 1,000 words. Figure 6.7 below illustrates the mean difference between the groups with regard to the effect of the language support on the percentage of words beyond the first 1,000 words.

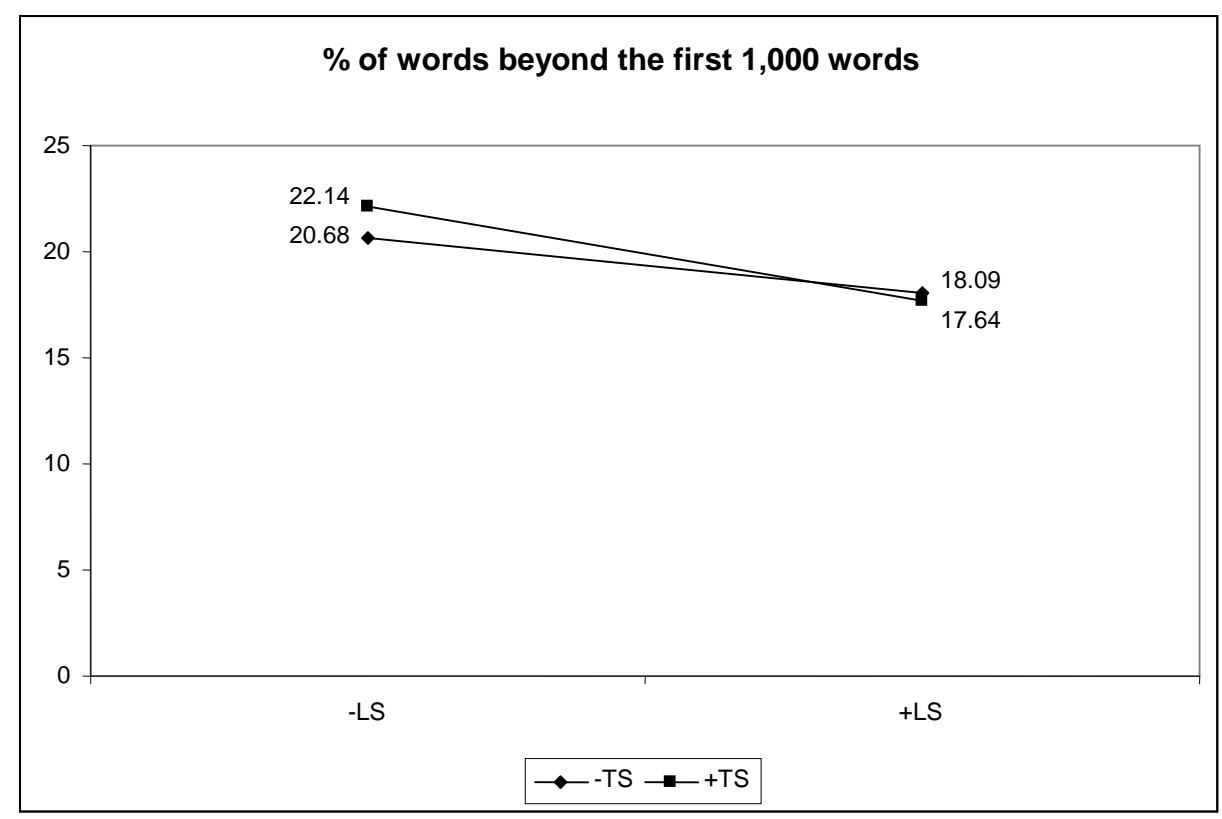

Figure 6.7 Mean percentage of words beyond the first 1,000 words

There was a significant language support effect on lexical complexity. The no language support condition (-LS) prompted a significantly higher use of low frequency words $(M=21.41, S D=4.55)$ than the language support condition $(+\mathrm{LS})$ $(M=17.86, S D=3.60)$. However, the difference was small $\left(\eta_{\mathrm{p}}{ }^{2}=0.16\right)$. While the figure seems to imply an interaction effect, group means are so similar to each other (within the margin of error for the mean), that no significant interaction was found.

\subsubsection{Guiraud Index: Univariate results and analysis}

The analysis of the Guiraud Index informs us how lexically rich learner language production was under the different task implementation conditions. 
Table 6.14

Guiraud Index: Test of Between-Subjects Effects

\begin{tabular}{lccccccc}
\hline \multicolumn{7}{c}{ Test of Between-Subjects Effects } \\
\hline & $\begin{array}{c}\text { Type III Sum } \\
\text { of Squares }\end{array}$ & $d f$ & $\begin{array}{c}\text { Mean } \\
\text { Square }\end{array}$ & $F$ & $p$ & $\eta_{\mathrm{p}}{ }^{2}$ & $\begin{array}{c}\text { Observed } \\
\text { Power }^{\mathrm{a}}\end{array}$ \\
\hline TS & 0.21 & 1 & 0.21 & 0.13 & 0.715 & 0.001 & 0.06 \\
LS & 0.44 & 1 & 0.44 & 0.28 & 0.599 & 0.003 & 0.08 \\
TS*LS & 5.99 & 1 & 5.99 & 3.82 & 0.054 & 0.04 & 0.49 \\
\hline Note: & $* p \leq 0.05$ & & & & & & \\
& ${ }^{a}$ Computed using alpha $=0.05$
\end{tabular}

Table 6.14 shows that only the interaction effect was significantly related to the Guiraud Index of lexical richness. Below is the figure that illustrates the interaction effect.

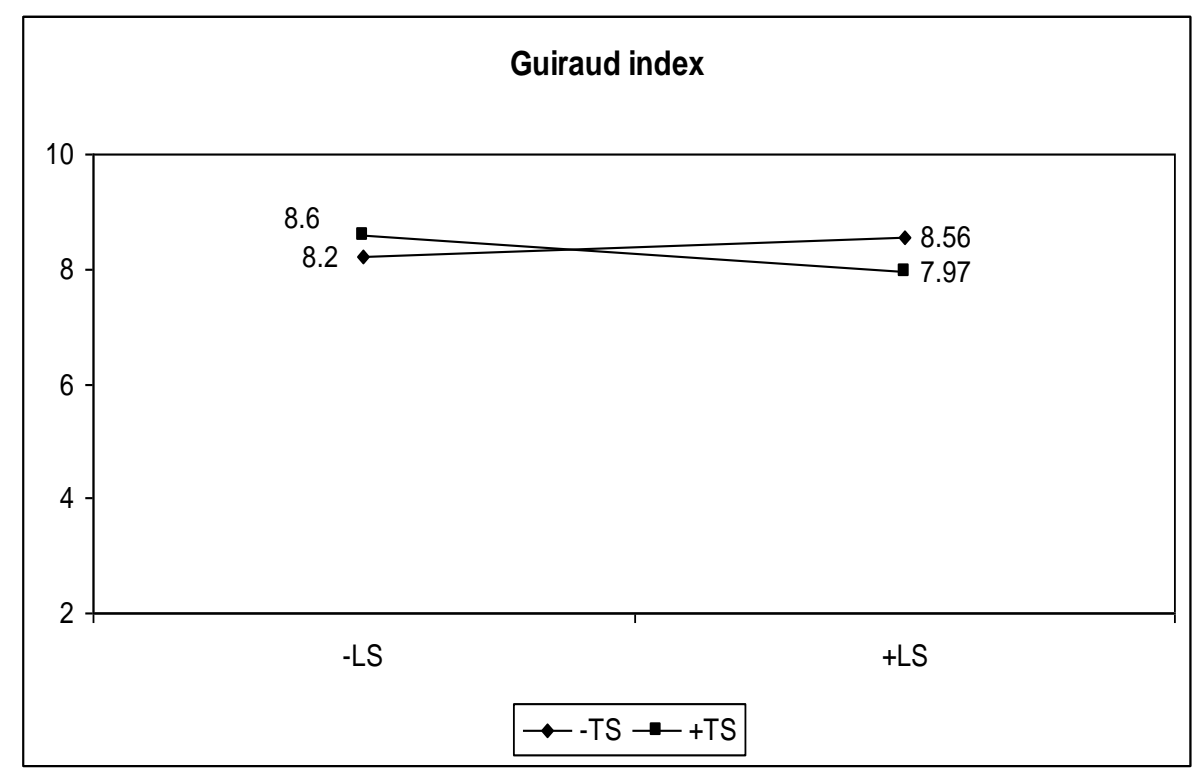

Figure 6.8 Mean Guiraud Index

There was a significant interaction found. However, the difference is extremely small $\left(\eta_{\mathrm{p}}{ }^{2}=0.04\right)$. This implies that the factors were dependent on each other in terms of their effects on the production of the lexical items. Language support with low task structure (+LS/-TS) or high task structure without language support (-LS/+TS) led to more lexically rich language than having neither (-LS/-TS) or both $(+\mathrm{LS} /+\mathrm{TS})$. 


\subsubsection{Summary}

Hypothesis 3 a claims that $-\mathrm{TS}$ will lead to less complexity than +TS. Hypothesis 3 b claims -LS will lead to less complexity than +LS. As seen above, neither hypothesis was supported by the data. The MANOVA revealed no significant effects of task structure on the dependent variables. The results show that an interactive simple task (+LS) promoted lower complexity than an interactive complex task (-LS). Therefore, hypothesis $3 \mathrm{~b}$ was not supported. The results and analyses of the quantity of learner language production are presented next. This will look at the quantity of an individual learner's production in Section 6.5.1 and equality of participation in Section 6.5.2.

\subsection{Quantity}

Providing learners with either language support $(+\mathrm{LS})$ or high task structure (+TS) has been shown to be beneficial in encouraging them to produce more LREs. These are believed to be an important feature of L2 learning, and an indication that these task features promote attention to linguistic form. Providing learners with more support (in terms of task structure and in terms of language support) also encouraged them to produce more accurate language. However, this has not been the case for complexity, where providing language support $(+\mathrm{LS})$ did not facilitate the production of complex language.

This section describes the effect of task implementation conditions on a third and final aspect of language production: the amount of language produced by each learner and the distribution of talks within teams. Participation levels were measured by the number of words, number of turns, and words per turn per learner. The distributions of talk within teams were measured by entropy words and entropy turns.

Neither the Cognition Hypothesis nor Limited Attentional Capacity Model has generated an explicit prediction regarding the effect of resource-dispersing variables on the quantity of learner language production. However, previous SCMC studies stated that as opposed to a face-to-face setting, text-SCMC promotes more active and equal participation (Böhlke, 2003; Fitze, 2006; Freiermuth \& Jarell, 2006; 
Simpson, 2005b). These studies provide little information on the effects, if any, of different task implementation conditions. Therefore, the current study aims to find out if the claim that text-SCMC promotes active and equal participation holds true when learners perform task-based text-SCMC under the different task implementation conditions.

\subsubsection{Quantity: Amount of talk}

To find out if task implementation conditions have any effect on the quantity of learner language production an individual-based MANOVA test (Chapter 5, Section 5.12) was performed at the first stage of analysis. The independent variables and task implementation features were similar to the previous analyses. The three dependent variables listed below were measured per learner:

- Number of words

- Number of turns

- Number of words per turn

\subsubsection{MANOVA results and analysis}

Although the assumption of the homogeneity of variance-covariance was not upheld, as indicated by the Box's $M$ test result $(p<0.001)$, the multivariate $\mathrm{F}$ tests can still be used ${ }^{25}$. Table 6.15 reports the descriptive statistics for the MANOVA analysis.

\footnotetext{
${ }^{25}$ Refer to footnote no. 20 .
} 
Table 6.15

Quantity-Amount of talk: Descriptive statistics

\begin{tabular}{|c|c|c|c|c|c|}
\hline \multicolumn{6}{|c|}{ Descriptive Statistics } \\
\hline & $\mathrm{TS}$ & LS & Mean & SD & $\mathrm{N}$ \\
\hline \multirow[t]{9}{*}{ Words } & $-\mathrm{TS}$ & -LS & 361.54 & 127.08 & 24 \\
\hline & & $+\mathrm{LS}$ & 354.96 & 173.79 & 24 \\
\hline & & Total & 358.25 & 150.65 & 48 \\
\hline & $+\mathrm{TS}$ & -LS & 282.37 & 102.67 & 24 \\
\hline & & $+\mathrm{LS}$ & 313.75 & 118.70 & 24 \\
\hline & & Total & 298.06 & 110.93 & 48 \\
\hline & Total & -LS & 321.96 & 121.09 & 48 \\
\hline & & $+\mathrm{LS}$ & 334.35 & 148.69 & 48 \\
\hline & & Total & 328.16 & 135.02 & 96 \\
\hline \multirow[t]{9}{*}{ Turns } & -TS & -LS & 66.58 & 20.37 & 24 \\
\hline & & $+\mathrm{LS}$ & 92.83 & 35.08 & 24 \\
\hline & & Total & 79.71 & 31.33 & 48 \\
\hline & $+\mathrm{TS}$ & -LS & 60.88 & 30.42 & 24 \\
\hline & & $+\mathrm{LS}$ & 80.54 & 32.24 & 24 \\
\hline & & Total & 70.71 & 32.56 & 48 \\
\hline & Total & -LS & 63.73 & 25.77 & 48 \\
\hline & & $+\mathrm{LS}$ & 86.69 & 33.91 & 48 \\
\hline & & Total & 75.21 & 32.10 & 96 \\
\hline \multirow[t]{9}{*}{ Words per turn } & $-\mathrm{TS}$ & -LS & 5.53 & 1.36 & 24 \\
\hline & & $+\mathrm{LS}$ & 3.81 & 1.23 & 24 \\
\hline & & Total & 4.67 & 1.55 & 48 \\
\hline & $+\mathrm{TS}$ & -LS & 4.97 & 1.43 & 24 \\
\hline & & $+\mathrm{LS}$ & 4.03 & 0.93 & 24 \\
\hline & & Total & 4.50 & 1.29 & 48 \\
\hline & Total & -LS & 5.25 & 1.41 & 48 \\
\hline & & $+\mathrm{LS}$ & 3.92 & 1.085 & 48 \\
\hline & & Total & 4.59 & 1.42 & 96 \\
\hline
\end{tabular}

Table 6.15 shows that learners in the no language support and low task structure (-LS/-TS) condition produced the most words and the most words per turn. In contrast, learners in the no language support but high task structure (-LS/+TS) condition produced the least number of words and turns. Learners in the no language support but high task structure (-LS/+TS) condition produced the most turns. This data was submitted to MANOVA analysis to determine whether the number of words, turns and words per turn differed significantly between each group. 
Table 6.16

Quantity-Amount of talk: Multivariate tests

\begin{tabular}{|c|c|c|c|c|c|c|c|c|}
\hline \multicolumn{9}{|c|}{ 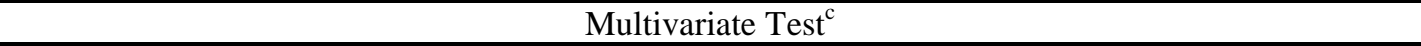 } \\
\hline & & Value & $F$ & $\begin{array}{c}\text { Hypothesis } \\
d f\end{array}$ & $\begin{array}{l}\text { Error } \\
\quad d f\end{array}$ & $p$ & $\eta_{\mathrm{p}}{ }^{2}$ & $\begin{array}{l}\text { Observed } \\
\text { Power }^{\mathrm{a}}\end{array}$ \\
\hline TS & Hotelling's Trace & 0.06 & $1.83^{\mathrm{b}}$ & 3.00 & 90.00 & 0.140 & 0.06 & 0.47 \\
\hline LS & Hotelling's Trace & 0.38 & $11.27^{\mathrm{b}}$ & 3.00 & 90.00 & $<0.0001$ & 0.27 & 1.00 \\
\hline TS*LS & Hotelling's Trace & 0.03 & $0.93^{\mathrm{b}}$ & 3.00 & 90.00 & 0.427 & 0.03 & 0.25 \\
\hline Note: & $\begin{array}{l}{ }^{*} p \leq 0.05 \\
{ }^{\mathrm{a}} \text { Computed using a } \\
{ }^{\mathrm{b}} \text { Exact statistic } \\
{ }^{\mathrm{c}} \text { Design: Intercept }\end{array}$ & $\begin{array}{l}\mathrm{a}=0.0 \\
\mathrm{TS}+\mathrm{LS}\end{array}$ & TS $*$ & & & & & \\
\hline
\end{tabular}

A multivariate test of the effect of task structure on the dependent variables using the Hotelling's Trace was not significant ${ }^{26}$, reflecting the similarity of the effects of low and high task structure. Therefore, further analysis on the effect of task structure on the dependent variables was not needed. The test of the effect of language support on the dependent variables was statistically significant, but the effect size was weak $\left(\eta_{\mathrm{p}}{ }^{2}=0.27\right)$. This test also indicates that the interaction between task structure and language support was not significant ${ }^{27}$. Therefore, the effect of language support on the quantity of learner language production was independent of task structure. The test of between-subjects effect of language support on the dependent variables was required. The results are presented below.

\subsection{Number of words: Univariate results and analysis}

Table 6.17 displays the result of the univariate between-subject effect of the task implementation conditions on the number of words.

Table 6.17

Number of words: Test of Between-Subjects Effects

\begin{tabular}{|c|c|c|c|c|c|c|c|}
\hline \multicolumn{8}{|c|}{ Test of Between-Subjects Effects } \\
\hline & $\begin{array}{l}\text { Type III Sum } \\
\text { of Squares }\end{array}$ & $d f$ & $\begin{array}{c}\text { Mean } \\
\text { Square }\end{array}$ & $F$ & $P$ & $\eta_{\mathrm{p}}^{2}$ & $\begin{array}{l}\text { Observed } \\
\text { Power }^{\mathrm{a}}\end{array}$ \\
\hline TS & 86940.84 & 1 & 86940.84 & 4.90 & 0.029 & 0.05 & 0.59 \\
\hline LS & 3687.76 & 1 & 3687.76 & 0.21 & 0.650 & 0.002 & 0.07 \\
\hline TS*LS & 8645.01 & 1 & 8645.01 & 0.49 & 0.487 & 0.005 & 0.11 \\
\hline
\end{tabular}

$\begin{array}{ll}\text { Note: } & * p \leq 0.05 \\ & { }^{\mathrm{a}} \text { Computed using alpha }=0.05\end{array}$

\footnotetext{
${ }^{26}$ Refer to footnote no. 19 .

${ }^{27}$ Refer to footnote no. 19.
} 
Although language support was significantly related to the dependent variables at the MANOVA test, follow up analysis indicates that language support was not significantly related to the number of words ${ }^{28}$.

\subsection{Number of turns: Univariate results and analysis}

The result of the univariate between-subject effect of language support on the number of turns is presented in table 6.18.

Table 6.18

Number of turns per learner: Test of Between-Subjects Effects

\begin{tabular}{lccccccc}
\hline \multicolumn{7}{c}{ Test of Between-Subjects Effects } \\
\hline $\begin{array}{c}\text { Type III Sum } \\
\text { of Squares }\end{array}$ & $d f$ & $\begin{array}{c}\text { Mean } \\
\text { Square }\end{array}$ & $F$ & $p$ & $\eta_{\mathrm{p}}{ }^{2}$ & $\begin{array}{c}\text { Observed } \\
\text { Power }^{\mathrm{a}}\end{array}$ \\
\hline TS & 1944.00 & 1 & 1944.00 & 2.15 & 0.146 & 0.02 & 0.31 \\
LS & 12650.04 & 1 & 12650.04 & 14.01 & $<0.0001$ & 0.13 & 0.95 \\
TS*LS & 3.60 & 1 & 3.60 & 2.29 & 0.593 & 0.003 & 0.08 \\
\hline
\end{tabular}

$\begin{array}{ll}\text { Note: }: & * p \leq 0.05 \\ & { }^{\mathrm{a}} \text { Computed using alpha }=0.05\end{array}$

Language support was significantly related to the number of turns, a sign that there was a difference between the groups. Figure 6.19 shows the mean difference.

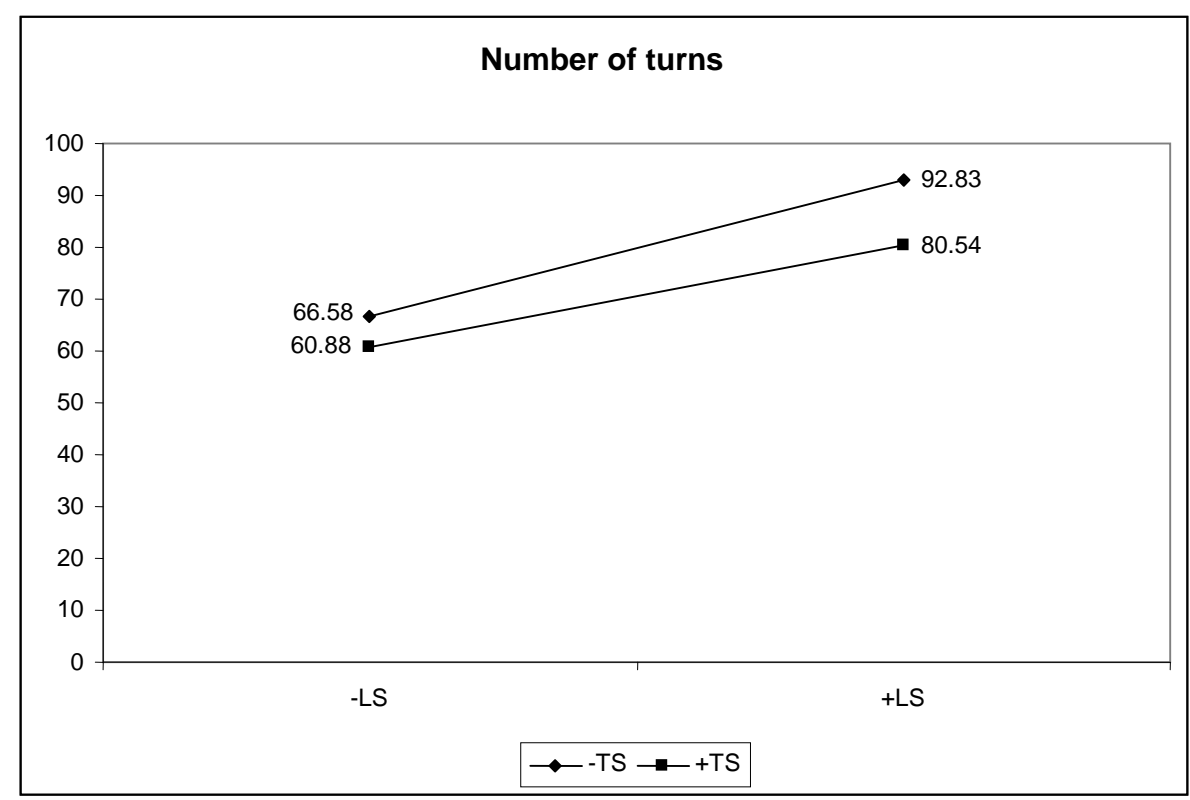

Figure 6.9 Mean number of turns

${ }^{28}$ Refer to footnote no. 19 . 
Language support was proven to influence the number of turns; learners in the language support $(+\mathrm{LS})$ condition produced significantly more turns $(M=86.69$, $S D=33.90)$ than learners in the no language support $(-\mathrm{LS})$ condition $(M=63.73, S D$ $=25.77)$. However, the effect size of this difference was small $\left(\eta_{\mathrm{p}}{ }^{2}=0.13\right)$.

\subsection{Words per turn: Univariate results and analysis}

Below are the univariate between-subject test results for the amounts of words per turn each learner produced under the four task implementation features.

Table 6.19

Words per turn: Test of Between-Subjects Effects

\begin{tabular}{|c|c|c|c|c|c|c|c|}
\hline \multicolumn{8}{|c|}{ Test of Between-Subjects Effects } \\
\hline & $\begin{array}{c}\text { Type III Sum } \\
\text { of Squares }\end{array}$ & $\overline{d f}$ & $\begin{array}{l}\text { Mean } \\
\text { Square }\end{array}$ & $F$ & $p$ & $\eta_{\mathrm{p}}{ }^{2}$ & $\begin{array}{l}\text { Observed } \\
\text { Power }^{\mathrm{a}}\end{array}$ \\
\hline $\mathrm{TS}$ & 0.70 & 1 & 0.70 & 0.45 & 0.505 & 0.005 & 0.10 \\
\hline $\mathrm{LS}$ & 42.52 & 1 & 42.52 & 27.04 & $<0.0001$ & 0.23 & 1.00 \\
\hline TS*LS & 3.60 & 1 & 3.60 & 2.29 & 0.134 & 0.02 & 0.32 \\
\hline
\end{tabular}

Table 6.19 reveals that language support was significantly related to the number of words per turn. Figure 6.10 shows the mean difference between the groups.

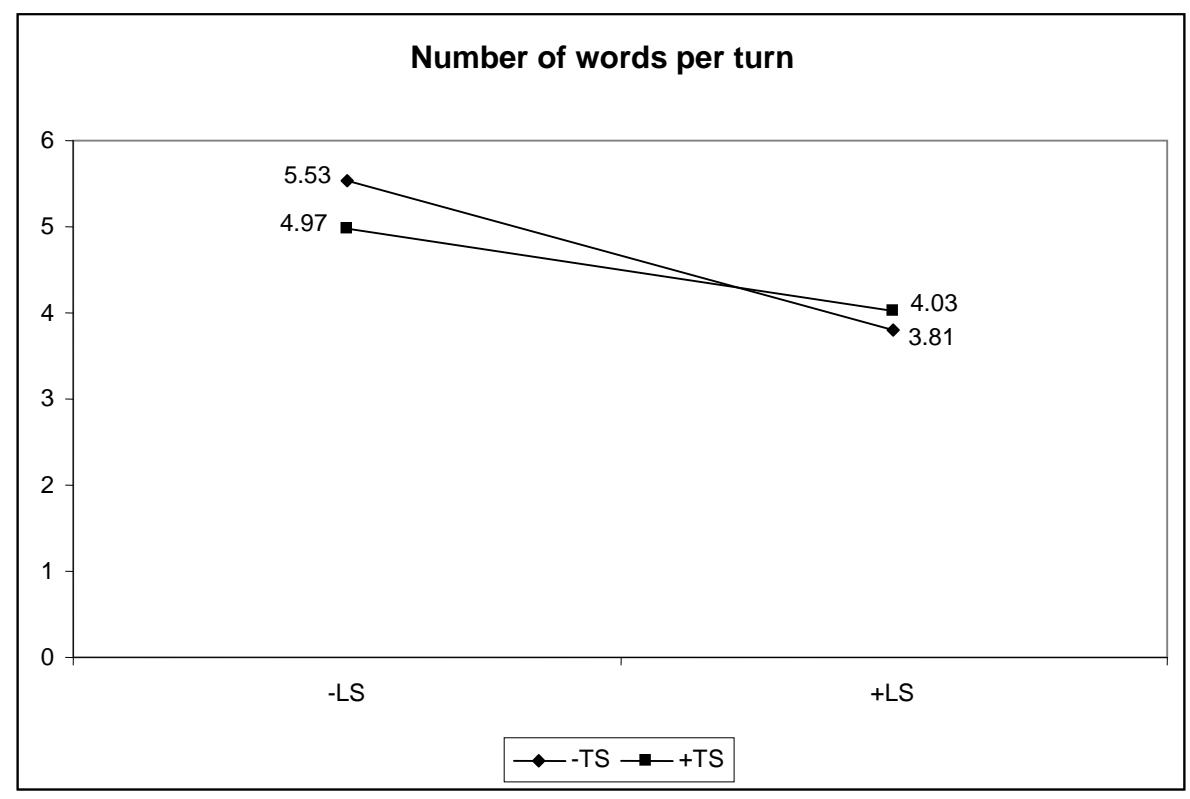

Figure 6.10 Mean number of words per turn 
Although the difference was small $\left(\eta_{\mathrm{p}}{ }^{2}=0.23\right)$, the learners in the no language support (-LS) condition produced significantly more words $(M=5.25, S D$ $=1.41)$ than those in the language support $(+\mathrm{LS})$ condition $(M=3.92, S D=1.08)$. The figure seems to illustrate an interaction effect. However, the group means were so similar to each other (within the margin of error for the mean) that it did not reach significance.

The last section in this chapter presents the results and analysis of the entropy words and turns that represent the distribution of talk within teams.

\subsubsection{Quantity: Distribution of talk within teams}

To find out whether the task implementation conditions have any effect on the quantity of learner language production, the second stage of analysis involved a MANOVA test based on the team scores (Chapter 5, Section 5.12). The two dependent variables were:

- Entropy words

- Entropy turns

The task implementation conditions were the same as the previous analyses.

\subsubsection{MANOVA results and analysis}

The Box $M$ statistic was used to test for the homogeneity of variancecovariance matrices. Its result was at a non-significant level $(p=0.846)$, confirming that the assumption has not been violated. The descriptive statistics are presented in table 6.20 below. 
Table 6.20

Quantity-Distribution of talk: Descriptive statistics

\begin{tabular}{|c|c|c|c|c|c|}
\hline \multicolumn{6}{|c|}{ Descriptive Statistics } \\
\hline & TS & LS & Mean & SD & $\mathrm{N}$ \\
\hline \multirow{9}{*}{$\begin{array}{l}\text { Entropy } \\
\text { Words }\end{array}$} & $-\mathrm{TS}$ & $-\mathrm{LS}$ & 1.33 & 0.04 & 6 \\
\hline & & $+\mathrm{LS}$ & 1.31 & 0.03 & 6 \\
\hline & & Total & 1.32 & 0.04 & 12 \\
\hline & $+\mathrm{TS}$ & -LS & 1.33 & 0.04 & 6 \\
\hline & & $+\mathrm{LS}$ & 1.36 & 0.02 & 6 \\
\hline & & Total & 1.34 & 0.03 & 12 \\
\hline & Total & $-\mathrm{LS}$ & 1.33 & 0.04 & 12 \\
\hline & & $+\mathrm{LS}$ & 1.33 & 0.03 & 12 \\
\hline & & Total & 1.33 & 0.03 & 24 \\
\hline \multirow{9}{*}{$\begin{array}{l}\text { Entropy } \\
\text { Turns }\end{array}$} & $-\mathrm{TS}$ & -LS & 1.35 & 0.03 & 6 \\
\hline & & $+\mathrm{LS}$ & 1.34 & 0.02 & 6 \\
\hline & & Total & 1.35 & 0.02 & 12 \\
\hline & $+\mathrm{TS}$ & $-\mathrm{LS}$ & 1.33 & 0.04 & 6 \\
\hline & & $+\mathrm{LS}$ & 1.35 & 0.01 & 6 \\
\hline & & Total & 1.34 & 0.03 & 12 \\
\hline & Total & -LS & 1.34 & 0.03 & 12 \\
\hline & & $+\mathrm{LS}$ & 1.35 & 0.02 & 12 \\
\hline & & Total & 1.34 & 0.03 & 24 \\
\hline
\end{tabular}

These statistics illustrate that for both dependent variables (i.e. entropy words and entropy turns), the means are similar. The data was submitted to MANOVA analysis to determine whether the groups differed significantly between the entropy words and turns.

Table 6.21

Quantity-Distribution of talk: Multivariate tests

\begin{tabular}{|c|c|c|c|c|c|c|c|c|}
\hline \multicolumn{9}{|c|}{ Multivariate Test ${ }^{\mathrm{c}}$} \\
\hline & & Value & $F$ & $\begin{array}{c}\text { Hypothesis } \\
d f\end{array}$ & $\begin{array}{c}\text { Error } \\
\quad d f\end{array}$ & $p$ & $\eta_{p}^{2}$ & $\begin{array}{l}\text { Observed } \\
\text { Power }^{\mathrm{a}}\end{array}$ \\
\hline TS & Hotelling's Trace & 0.24 & $2.26^{\mathrm{b}}$ & 2.00 & 19.00 & 0.132 & 0.19 & 0.40 \\
\hline LS & Hotelling's Trace & 0.03 & $0.27^{b}$ & 2.00 & 19.00 & 0.768 & 0.03 & 0.09 \\
\hline TS*LS & Hotelling's Trace & 0.19 & $1.82^{\mathrm{b}}$ & 2.00 & 19.00 & 0.189 & 0.16 & 0.33 \\
\hline Note: & $\begin{array}{l}* p \leq 0.05 \\
{ }^{\mathrm{a}} \text { Computed using al } \\
{ }^{\mathrm{b}} \text { Exact statistic } \\
{ }^{\mathrm{c}} \text { Design: Intercept }+\end{array}$ & $\mathrm{a}=0.0$ & $\mathrm{TS} *$ & & & & & \\
\hline
\end{tabular}


None of the multivariate tests of the main effects on the dependent variables using the Hotelling's Trace was significant ${ }^{29}$. Similarly, no interaction effect was found. This shows that neither TS nor LS influenced the distribution of language production during the tasks.

\subsubsection{Summary}

Hypothesis 4a proposes that neither task structure nor language support will affect the amount of language produced. The result for task structure supports this hypothesis, as no effect of task structure was found on any quantity measures. However, the results for language support relating to the number of turns and words per turn do not support the hypothesis. Hypothesis $4 \mathrm{~b}$ proposes that neither task structure nor language support will affect the equality of participation. The findings indicated that they did not affect the equality of participation, and so the hypothesis was supported.

\subsection{Summary}

This chapter has described the MANOVA and univariate results, and analyses of the task implementation conditions on the dependent variables. These results are discussed in the following chapter.

\footnotetext{
${ }^{29}$ Refer to footnote no. 19.
} 


\section{CHAPTER SEVEN \\ DISCUSSION}

\subsection{Introduction}

According to Robinson (2001b, 2003b, 2005) and Skehan (1996, 1998, 2009), the cognitive demands of a task will influence learner language production (see Chapter 3 for details). The current study was designed to examine this claim in the context of engineering learners performing task-based text synchronous computer-mediated communication (text-SCMC). The study focused on whether two implementation features, task structure and language support, would influence the occurrence of LREs, and the accuracy, complexity and quantity of learner language production.

This chapter presents a discussion of the results of the study. Information from interviews with the participants will be used to help interpret the quantitative findings.

\subsection{Independent variable: Task structure}

One of the resource-dispersing variables in Robinson's (2007b) Triadic Componential Framework is task structure. As explained in Chapter Three, Section 3.6, in the current study, a task with low task structure (-TS) contains few guidelines on how to organise the discourse and performance of the task. According to Robinson's hypothesis, such tasks require a higher degree of online processing, because learners need to invest more effort in determining how to complete the task. For this reason a task with low structure (-TS) is considered more cognitively complex than a task with high task structure (+TS). In contrast, a task with high structure (+TS) is considered a cognitively simple task because by providing guidelines for performing the task, it eases the demands on learners' online processing capacity.

Table 7.1 presents the summary of the statistical results on the effects of task structure on all dependent variables in the current study. 
Table 7.1

Independent variable: Task structure

\begin{tabular}{|c|c|c|c|c|}
\hline \multicolumn{3}{|c|}{ MANOVA } & \multicolumn{2}{|c|}{ Univariate } \\
\hline \multirow[b]{2}{*}{ Measure } & & \multirow[b]{2}{*}{ Dependent variable } & \multicolumn{2}{|c|}{ Independent variable } \\
\hline & & & $\begin{array}{l}\text { High task structure } \\
(+\mathrm{TS})\end{array}$ & $\begin{array}{c}\text { Low task structure } \\
(-\mathrm{TS})\end{array}$ \\
\hline \multirow{2}{*}{$\begin{array}{l}\text { Language- } \\
\text { related } \\
\text { episodes } \\
\text { (LREs) }\end{array}$} & $p<0.0001$ & LREs on meaning & $\uparrow$ & $\downarrow$ \\
\hline & & LREs on form & $\uparrow$ & $\downarrow$ \\
\hline \multirow[t]{3}{*}{ Accuracy } & $p=0.002$ & Error/AS-unit & $\uparrow$ & $\downarrow$ \\
\hline & & $\begin{array}{l}\% \text { TLU auxiliary } \\
\text { verbs }\end{array}$ & $\begin{array}{l}\text { Interaction effect } \\
\text { with } \\
\text { language support }\end{array}$ & $\begin{array}{l}\text { Interaction effect } \\
\text { with } \\
\text { language support }\end{array}$ \\
\hline & & $\begin{array}{l}\% \text { TLU modal } \\
\text { verbs }\end{array}$ & $\uparrow$ & $\downarrow$ \\
\hline
\end{tabular}

$\begin{array}{ll}\text { Complexity } \quad \text { n.s } \quad & \text { Clause/AS-unit } \\ & \% \text { of Words } \\ & \text { beyond the first } \\ & 1,000 \text { words }\end{array}$

Guiraud Index

\begin{tabular}{lll}
$\begin{array}{l}\text { Quantity - } \\
\text { Individual } \\
\text { participation }\end{array}$ & $n . s$ & No. of Words \\
& & No. of Turns \\
& Words/Turn \\
\hline $\begin{array}{l}\text { Quantity - } \\
\text { Entropy }\end{array}$ & $n . s$ & Entropy words \\
& & Entropy turns
\end{tabular}

\begin{tabular}{ll}
\hline Note: & $p \leq 0.05$ \\
& $\uparrow$ More LREs/more accurate $\quad \downarrow$ Fewer LREs/ less accurate \\
& $n . s$ - non-significant
\end{tabular}

These results are discussed in the following sections according to the dependent variables. 
7.2.1 The effects of task structure on language-related episodes (LREs)

Learners working in groups can deal with gaps in their L2 knowledge by discussing the language problems they encounter, and pooling their linguistic resources to try and solve such problems. This process is referred to as negotiation, leading to interactional adjustment (Long \& Robinson, 1998; Robinson, 2001b). Negotiation sequences that highlight linguistic form are also referred to as LREs (Swain, 1998; Swain \& Lapkin, 2001).

According to Robinson (2001a, 2001b), interactive complex tasks will increase the cognitive demands of the tasks and therefore, are more likely to produce a higher amount of negotiation than simple tasks (see Chapter 3, Section 3.4, and Robinson, 2001a, pp.302-303, 2001b, pp.35-36). In line with Robinson's prediction, the current study hypothesised that learners would engage in more negotiation, as shown by a higher occurrence of LREs when performing a task in the -TS condition as opposed to the $+\mathrm{TS}$ condition.

Table 7.2 summarises the results of the current study for the occurrence of LREs on meaning and form during task-based text-SCMC. The table also presents Robinson's prediction for the effect of task complexity on negotiation.

Table 7.2

The effects of task structure on LREs

$+\mathrm{TS}$

(Simple task)
$-\mathrm{TS}$

(Complex task)

\begin{tabular}{cccccc} 
& & \multicolumn{2}{c}{ (Simple task) } & \multicolumn{2}{c}{ (Complex task) } \\
\hline Measure & Specific measure & D & R & D & R \\
\hline LREs & & & $\downarrow$ & & $\uparrow$
\end{tabular}

LREs on meaning $\uparrow \downarrow$

LREs on form $\quad \uparrow$

Note: $\quad \mathrm{D}$ (Current data), $\mathrm{R}$ (Robinson's prediction ${ }^{30}$ )

$\uparrow$ More LREs $\quad \downarrow$ Fewer LREs

These results show that increasing the structure of the task (+TS) led to more LREs on meaning and form. To restate this result using Robinson's terminology, the interactive simple task (+TS) encouraged more negotiation than the interactive

\footnotetext{
${ }^{30}$ Note that Robinson's prediction on the effect of task complexity on negotiation is not part of the Cognition Hypothesis. See Robinson (2001a, pp.302-303; 2001b, pp. 35-36) for details.
} 
complex task (-TS). This result does not support Robinson's (2001b) claim that cognitively complex interactive tasks will result in more negotiation. Instead, the learners paid more attention to meaning and form while performing a cognitively simple task where the performance was carefully guided.

The results reported above will now be discussed with reference to evidence from the task performance and interviews. This evidence suggests that the structural support provided to learners in the +TS condition guided their text conversation, which eased their online processing demands. This allowed learners to focus on negotiating meaning and form, as well as engaging in interactional modifications, rather than managing their performance. The following extract ${ }^{31}$ (extract $7.1^{32}$ ) provides an example of an LRE in the +TS condition. It shows how the learners' performance was clearly structured using the +TS worksheet. As a result, learners took this opportunity to modify the problematic utterances that they had noticed.

\begin{tabular}{|c|c|c|}
\hline \multicolumn{3}{|c|}{ Extract 7.1} \\
\hline 1 & Aiman & $\begin{array}{l}\text { The setback is that it can only be used on } \\
\text { PLCs }\end{array}$ \\
\hline 2 & Aliya & wait wait- \\
\hline 3 & Aiman & $\begin{array}{l}\text { butr we can use it to design, document, } \\
\text { simulate and animate circuits }\end{array}$ \\
\hline 4 & Aisya & what aliya? \\
\hline 5 & Aliya & wat is setback? \\
\hline 6 & Ammar & $\begin{array}{l}\text { uish... setback= downside... or something } \\
\text { like the weakness of his software- point } \\
\text { towrite in the gen info colmn }\end{array}$ \\
\hline t & Aiman & disadvantage @ negative aspect \\
\hline 8 & Aliya & ooooo ok. Cont \\
\hline
\end{tabular}

In line five Aliya shows she does not understand the word 'setback', which was used by Aiman in line one. In lines six and seven, Ammar responds to Aliya's question by:

- using the equivalent symbol for 'setback' and 'downside' (modifying the output)

- elaborating on the output (providing the example)

- making reference to the information in the +TS material.

\footnotetext{
${ }^{31}$ Refer to Chapter 5, Section 5.6 for the details of the task used in the current study.

${ }^{32}$ As indicated in the methodology chapter, all learners' names in this dissertation are pseudonyms.
} 
In the subsequent line Aiman also modifies his output. (Please note that Ammar's and Aiman's responses are likely composed simultaneously).

In contrast, in the task without structural support (-TS), learner performance was typically much less well organised. As a result, they had to devote more attention to managing their performance in the task, and engaged in fewer LREs. We see this in the following extract (extract 7.2), which is typical of task performance in the -TS condition.

\begin{tabular}{|c|c|c|}
\hline \multicolumn{3}{|c|}{ Extract 7.2} \\
\hline 1 & Pian & bcoz my software has a readable source code- \\
\hline 2 & Lan & $\begin{array}{l}\text { my software is compatible for linux and } \\
\text { windows }\end{array}$ \\
\hline 3 & Pian & is easy for troubleshooting- can do ourselevs \\
\hline 4 & Din & Mmine is xpensve- must renewal the licence! \\
\hline 5 & $\mathrm{Ri}$ & $\begin{array}{l}\text { oowhhh pls people- xplain your software } \\
\text { using the specific criteria- will b easier for us } \\
\text { to compare! and use correct grammar pls! }\end{array}$ \\
\hline 6 & Lan & ??? \\
\hline 7 & Din & pls everybody...... one by one okay \\
\hline 8 & Pian & Ok \\
\hline 9 & Lan & can we start again? \\
\hline 10 & Din & no we dontt have time \\
\hline 11 & $\mathrm{Ri}$ & owhhh iam confised now. canwe start again \\
\hline 12 & Pian & $\begin{array}{l}\text { listento me guys. } i \text { think the idea is good- } \\
\text { westart again. one by one }\end{array}$ \\
\hline 13 & Din & no we have 20 minutes only \\
\hline
\end{tabular}

In lines one to four, the three learners describe their software based on the different aspects: Pian (starting in line one and ending in line three) states the practicality of his software; Lan (line two) explains the compatibility of his software; and Din (line four) talks about the cost of his software. As implied in Ri's statement (line five), the organisation of the information presented by each of them was muddled, which caused difficulty in making comparisons. Ri also reminds his teammates to use correct grammar. However, nobody responds to his reminder, instead the conversation continues with learners discussing the need to re-start the discussion (lines nine, 11 and 12). Din insists that they should continue as they do not have much time left (line 13). The subsequent chat exchanges show that they decide to proceed with the discussion. During the interview with this team they expressed their frustration at the difficulty of managing the conversation's flow. 
This may have prevented them from noticing Ri's reminder about using correct grammar, and Din's ungrammatical used of 'renewal' in line four.

Data gathered during post-task interviews with the learners confirms the beneficial role of +TS material. When asked about the use of +TS material, Sham, one of the participants in the +TS condition, commented that:

... because we relied solely on the information and steps in sheet $B$, we did not need a leader or chairman to be in charge. We used sheet $B$ to manage our conversation. It was so easy to organise the information received from my friends and because of that I managed to offer help if my friends were confused or needed extra information.

Similarly, Tara noted that:

Usually, when I chat with my friends it is very difficult to organise our conversation. Everybody wants to talk at the same time. Sometimes, you forgot the previous topic of discussion. However, when we have sheet B I can see that everyone knows whose turn should be next. We can wait until the person finishes his/her explanation. So, it is easier for us to track our conversation and we can pay attention to our language, especially our grammar.

In contrast, the evidence from the learners in the -TS condition shows that organising the task was difficult, which may have distracted the learners from paying attention to their language production. One of the learners, Ida, said that:

There is a lot of information about my software. And I know the same goes to my other teammates. So, everybody keeps on providing information to prove that his or her software is the best. It is so difficult to organise our conversation because for most of the time, we have to interrupt each other. This happens especially when we miss out the important points about the others' software as we are too busy providing ours. The problem is, because we keep on providing the information as much as possible, it makes us less concern about our grammar.

Ida specifically links difficulty of managing the discourse to difficulty of focusing on the use of language in the discussion. Another learner in the -TS condition, Qayyum, expressed his frustration over the difficulty in managing the task performance, and noted his perception that this impeded his ability to focus on form: 
You see how difficult it is to match the software description of your teammates with yours. For example, every time I receive a new message about one of my teammates' software, I have to scroll up to see the previous messages from the others' too. I'm sure that the four of us have the three criteria to discuss- utilisation, practicality and cost-but the information is just all over the place. It takes a lot of time and it is frustrating when I couldn't find the match. It is more frustrating when I don't correct my grammatical errors because I am occupied with looking for the match!

With no structural support (-TS), managing the task performance was more challenging for the learners. As a consequence, learners' attention was diverted from the content of the task and the language issues that emerged from this. This may have led to fewer LREs being produced by the learners in the -TS condition compared to learners in the +TS condition.

Some learners in the -TS condition developed their own strategies to manage the performance, which were described in the interviews. For example, some teams appointed a leader, while others managed the performance based on the role assigned, i.e. engineer A explained everything about his/ her software first, then engineer B, and so on. A few learners in the -TS condition also suggested that they should have been provided with structured information about the task and extra time prior to starting the task for them to organise the discourse. According to these learners, performing a task-based text-SCMC is manageable only when the discourse is properly organised or information is clearly structured.

In summary, the task with the $+\mathrm{TS}$ condition facilitated more opportunities to engage in LREs than in the -TS condition. Therefore, Robinson's claim that cognitively complex tasks (the -TS condition in the current study) would lead to more interaction and modified output was not confirmed. Rather, decreasing the complexity of the task (+TS) freed attention from procedural demands, thus allowing more attention to language used. This resulted in more LREs than increasing the complexity of the task (-TS). This may be related to the medium, rather than the design of the tasks as explained in Section 7.3.3. 


\subsubsection{The effects of task structure on accuracy and complexity}

A key issue in research into task complexity is whether attention can be devoted to one, some, or all areas of production. Based on the trade-off effects outlined in the Limited Attentional Capacity Model, Skehan (1998, 2009; Skehan \& Foster, 2001) has suggested that when task demands are high, attention can be allocated to either accuracy or complexity, but not both simultaneously. However, according to Skehan, this trade-off effect can be overcome by, for example, decreasing the complexity of a task that learners perform (e.g. providing a clear structure to a task is one way to do this). Robinson (2001b, 2003b) agrees with Skehan's notion of the trade-off effects for the resource-directing variables but not on the resource-dispersing variables (e.g. task structure). This is because increasing complexity along the resource-dispersing dimension, such as task structure, disperses learners' attentional and memory resources. As such it negatively affects the production of accurate, complex and fluent language.

Based on the Cognition Hypothesis, therefore, Robinson proposes that in complex interactive tasks along the resource-dispersing dimension, less accurate language will be produced by learners. He argues that the resource-dispersing dimension makes increased procedural demand on learners' attentional and memory resources, and as a result, disperses their attention over many non-specific L2 structures. Additionally, performing these tasks may elicit more negotiations and interactional modifications in learner language production. This would encourage more ellipses, and therefore reduce the production of complex structures (see Chapter 3, Section 3.4). In line with the Cognition Hypothesis, the current study hypothesised that a cognitively complex task (-TS) should disperse learner attention resulting in less accurate and less complex production than a cognitively simple task $(+\mathrm{TS})$.

Table 7.3 presents the prediction for accuracy and complexity in +TS and -TS tasks derived from Skehan and Robinson, and the results of the current study for this variable. 
Table 7.3

The effects of task structure on accuracy and complexity

\begin{tabular}{|c|c|c|c|c|c|c|c|}
\hline \multirow[b]{2}{*}{ Measure } & \multirow[b]{2}{*}{ Specific measure } & \multicolumn{3}{|c|}{$\begin{array}{c}+\mathrm{TS} \\
\text { (Simple task) }\end{array}$} & \multicolumn{3}{|c|}{$\begin{array}{c}-\mathrm{TS} \\
\text { (Complex task) }\end{array}$} \\
\hline & & $\mathrm{D}$ & LAC & $\mathrm{CH}$ & $\mathrm{D}$ & LAC & $\mathrm{CH}$ \\
\hline \multirow[t]{4}{*}{ Accuracy } & & & $\uparrow$ & $\uparrow$ & & $\uparrow \downarrow$ & $\downarrow$ \\
\hline & Error/AS-unit & $\uparrow$ & & & $\downarrow$ & & \\
\hline & $\begin{array}{c}\text { TLU auxiliary } \\
\text { verbs }\end{array}$ & $\begin{array}{c}\text { Interaction } \\
\text { effect with } \\
\text { language } \\
\text { support }\end{array}$ & & & $\begin{array}{c}\text { Interaction } \\
\text { effect with } \\
\text { language } \\
\text { support }\end{array}$ & & \\
\hline & TLU modal verbs & $\uparrow$ & & & $\downarrow$ & & \\
\hline \multirow[t]{4}{*}{ Complexity } & & & $\uparrow$ & $\uparrow$ & & $\uparrow \downarrow$ & $\downarrow$ \\
\hline & Clause/AS-unit & $n . s$ & & & & & \\
\hline & $\begin{array}{l}\text { Words beyond } \\
\text { the first } 1,000\end{array}$ & $n . s$ & & & & & \\
\hline & Guiraud Index & n.s & & & & & \\
\hline $\begin{array}{l}\mathrm{D}(\mathrm{C} \\
\uparrow \mathrm{M} \\
n . s-\end{array}$ & $\begin{array}{l}\text { rent data), LAC (Lin } \\
\text { accurate/ complex } \\
\text { on-significant }\end{array}$ & $\begin{array}{l}\text { ted Attention } \\
\downarrow \text { Less accura }\end{array}$ & $\begin{array}{l}\text { Capaci } \\
\text { / compl }\end{array}$ & & $\begin{array}{l}\text { 1), } \mathrm{CH} \text { (Cognit } \\
\text { Trade-off effec }\end{array}$ & & \\
\hline
\end{tabular}

As evident in table 7.3, learners in the +TS condition produced more accurate language, as measured by the number of Error/AS-units and the percentage of targetlike use of modal verbs, than those in the -TS condition. The other accuracy measure (the percentage of targetlike use of auxiliary verbs) showed an interaction effect between task structure and language support (this effect is discussed in Section 7.4). The results for all complexity measures, however, were not significant.

The results show that learners in the -TS condition produced less accurate language, while learners in the $+\mathrm{TS}$ condition produced more accurate language. As such, the results support the Cognition Hypothesis with regard to accuracy in that, performing cognitively simple tasks promoted more accuracy than cognitively complex tasks. Also, the non-significant results on all complexity measures did not confirm the Cognition Hypothesis that complex interactive tasks would result in less complex production than simple tasks.

A likely explanation of these results is clarified through examining examples from the task performance and interview below. Extract 7.3 provides an example of the task performance by the learners in the +TS condition. It shows learners' use of 
the +TS material to manage their performance, which allowed them to attend to their language production, with particular regard to accuracy.

$\begin{array}{lcl}\text { Extract } 7.3 & \\ 1 & \text { Min } & \begin{array}{l}\text { discuss the nxt colymn- utilization- do u guys } \\ \text { agree? }\end{array} \\ 2 & \text { Nor } & \text { shoot- who shud start first? } \\ 3 & \text { Da } & \text { Nan may starts first: discuss utilization ok. } \\ 4 & \text { Nan } & \text { mine: compatible with microsoft } \\ 5 & \text { Da } & \text { Nan may start first } \\ 6 & \text { Min } & \text { Da- may start- w/out s! }\end{array}$

In this extract on line one, Min initiates the change of topic for their discussion, which is according to the information in the +TS material. In line three, Da proposes that Nan should start first, but she does not use the base form after use of the modal 'may'. She may have noticed this error as it is modified in line five. Line six shows that Min explicitly corrects the grammatical error produced by Da. While Da modifies the output as seen in line five, it appears that Da and Min compose their messages simultaneously.

During the interview with this team they claimed that the +TS material was a useful reference for them, as they used it to guide their performance which helped them to focus their attention on the output. According to Min, when asked about his opinion of the +TS material:

When I received sheet $B$, I compared the information in it with the task instruction received earlier. Then I knew that I should promote my software based on the column in sheet B so that our team could discuss the task systematically. My assumption was true. During the task performance, for example, if it was Da's turn everybody waited until she posted her message on the screen. We knew exactly in which column in Sheet $B$ the message should appear. This means we did not have much trouble understanding the gist of the message, and I think that made us more attentive to the language our teammates used. I mean it allowed us to be more conscious of others' language expressions.

Consequently, high task structure (+TS) may have freed up the learners' cognitive burden from managing the content to monitoring language expression, similar to the effect discussed above for LREs. This is in line with Skehan's (1996) view that by simplifying the communication burden, i.e. making the task simpler in terms of its structural support, task designers can decrease learners' cognitive load. 
As a result, learners are able to apply their cognitive resources to the production of more accurate language. In terms of L2 accuracy, the findings for the current study (where an interactive task was used) are comparable to those of Skehan and Foster (1997, 1999) who manipulated task structure in monologic (narrative) tasks, and to Tavakoli and Foster (2008). These studies found that when the task had a high degree of structure (clear structural support), more accurate language was produced.

Table 7.3 shows that with regard to the complexity of learner language production all complexity measures were not statistically significant. Nevertheless, as illustrated in the descriptive statistics (Chapter 6, Section 6.13, Table 6.10), there is a trend in the opposite direction of the research hypothesis. Greater complexity in learner production was evident in the -TS condition for two of the complexity measures, which are Clause/AS-unit (syntactic complexity) and Guiraud Index (lexical complexity). This may imply that increasing the cognitive demands of tasks is likely to result in trade-off effects, causing poorer performance on one or several dimensions of language production. The trend towards an increase in complexity and a drop in accuracy in the -TS condition supports this explanation. The nonsignificant complexity finding could also be due to the small sample size in the current study, as indicated in the observed power in MANOVA results.

It should be noted that the use of the worksheet to focus the +TS group meant that this group composed on paper as they completed the text chat. Some students may have also written the description of their software in the worksheet before their turn to present it to their group, meaning that for the utterances about their own software, the worksheet served as a space for drafting output, which may have increased the accuracy of their production in the chat. However, this is unlikely to apply to the majority of the chat, where they discussed software from other students. In these cases, the chat served as a drafting stage for what they wrote in the worksheet. The worksheets were collected and reviewed following the chats. Most students simply wrote phrases or bullet points (e.g., practicality "helpdesk provided", utilization "compatible with linux", cost "discounted if buy in bulks) of terms mined from the information sheets in the column for their software. It is unlikely that this could significantly influence the accuracy or complexity of their production in the chat. 
To sum up the discussion on the effects of task structure on the accuracy and complexity of learner language production, Robinson (2001b) predicted that increasing task complexity along the resource-dispersing dimension will result in less accurate production. The current study found this effect. As such, it confirms the hypothesis. It seems that providing more structure to a task, which assisted the learners to plan and manage their performance (making the tasks to be cognitively simple), led them to pay greater attention to language production, resulting in more accurate output. The results suggest that to promote a focus on accuracy, tasks should be cognitively simple. This may be particularly important when performing tasks in text-SCMC. As text-SCMC discourse is characterised by interrupted turns and overlaps, these features make managing the flow of communication particularly difficult (Smith, 2003b). This means implementation features like high task structure that simplifies the process of managing the performance may be particularly effective in reducing the cognitive load of the task. As a result, learners could attend to the accuracy of their language production.

\subsubsection{The effects of task structure on quantity}

Language production in face-to-face settings is generally measured based on accuracy, complexity and fluency. However, as the current study uses text-SCMC as the medium of communication, quantity of language is a more appropriate language production variable than fluency. While quantity is not accounted for in Skehan or Robinson's models for task complexity and language production measures, researchers agree that text-SCMC discussions encourage a higher amount of language production, as well as equal participation than in face-to-face discourse (Böhlke, 2003; Fitze, 2006; Freiermuth \& Jarell, 2006). In the current study, it was hypothesised that the amount of language production and equality of participation were not affected by task structure, which was the first task complexity variable used in the current study.

Table 7.4 shows the summary of the results of the effects of task structure on quantity. This includes the amount of language produced (measuring individual participation) and equality of participation (measuring distribution of talk within team- entropy). 
Table 7.4

The effects of task structure on quantity

$+\mathrm{TS}$

(Simple task)
-TS

(Complex task)

Specific measure

\begin{tabular}{llll}
\hline $\begin{array}{l}\text { Quantity (Individual } \\
\text { participation) }\end{array}$ & No. of words & $n . s$ & \\
& No. of turns & $n . s$ & $n . s$ \\
& Words/Turn & $n . s$ & $n . s$ \\
\hline $\begin{array}{l}\text { Quantity (Distribution } \\
\text { of talk within team) }\end{array}$ & Entropy words & $n . s$ & \\
& Entropy turns & $n . s$ & $n . s$ \\
& & & $n . s$ \\
\hline Note: & n.s - non-significant & &
\end{tabular}

Note: $\quad n . s$ - non-significant

As indicated in table 7.4, none of the quantity measures show significant effects of task structure. Therefore, the results support the hypothesis that in the textSCMC setting the amount of language production and equality of learner participation was not affected by task structure.

A likely explanation for this could be due to the nature of the variable. As indicated in the earlier sections, +TS material consisted of the structural support to the task performance. It did not contain any extra information with regard to the description of the items in the task. Learners in the +TS condition had more organized discourse, but not more information to convey. Therefore, when the learners performed the task under either the +TS or -TS condition, the amount of language produced should not be affected by the structural support provided in the +TS material.

The non-significant result for the equality of participation measured by the distribution of talk within a team (entropy) may be due to similar reasons. Clear procedural guidelines may have helped the +TS groups manage task performance, but did not encourage or discourage learners from contributing to the discussion. These results are consistent with the findings of most of the SCMC studies which show that text-SCMC encourages participation by all members of a group because they feel more comfortable contributing in text-SCMC than in face-to-face settings 
(Fitze, 2006; Freiermuth \& Jarell, 2006; Sanders, 2006). Further discussions on quantity are found in Section 7.3.5.1 and Section 7.3.5.2.

\subsubsection{Additional perceptions of task structure}

As mentioned earlier, the most important use of the +TS material was as a tool for managing task performance. However, some learners did not consider it to be particularly useful. Rather, they felt it added an extra burden because they had to switch between referring to the worksheet and engaging in interaction. This was commented on by Azim, a learner in the +TS condition:

I think sheet B put me off. After I posted my message on the screen and continued typing the next message, sometimes another team member posted a message asking me a question like "is this the practicality of the software?" Sometimes I ignored and continued typing but sometimes I had to erase what I have already typed because I had to respond to the question first. I would prefer not to use sheet $B$.

While overall, learners in the +TS condition produced more LREs, some learners felt that the additional materials they received in the +TS condition prevented them from focusing on language production. During the interview, one of the learners, Julios, claimed that:

It was so difficult to contribute to the discussion when at the same time we had to fill in the columns in sheet B. It was quite stressful for me and I ended up focusing on writing the information in sheet $B$ instead of checking my grammar. I think my friends felt the same too.

Additionally, during the interview sessions the learners in the -TS condition were presented with the +TS material to gauge their perception of its value. While some learners in the -TS condition said that the +TS materials could have helped them manage the discourse, others were not convinced. The latter group believed that as long as they understood the task instruction, they could have performed the task.

7.2.5 Summary of the effects of task structure on the dependent variables

This section summarises the effects of task structure on the dependent variables based on their respective hypotheses. Hypothesis 1a suggests that -TS will 
elicit higher occurrence of LREs than +TS. As the results showed, an interactive simple task (+TS) elicited a higher occurrence of LREs than an interactive complex task (-TS). As such, hypothesis 1a was not supported by the findings. When the learners performed a cognitively simple task (+TS), they produced more LREs. Therefore in the context of text-SCMC, it appears that interactive simple tasks may be helpful to promote more LREs in contrast to Robinson's (2001b) prediction. Thus, it appears that task structure may not be an effective resource-dispersing variable for use in the text-SCMC context. Also, it is possible that the resourcedispersing effects of task structure are not seen because of the nature of the offline processing afforded by the medium of interaction itself, i.e. text-SCMC, which allows the interlocutors to think or refer to information at hand (Payne \& Whitney, 2002; Smith, 2003b).

Hypothesis 2 a suggests that $-\mathrm{TS}$ will lead to less accuracy than +TS. The results showed that an interactive simple task $(+\mathrm{TS})$ promoted higher accuracy than an interactive complex task (-TS). As such, hypothesis 2a was supported. Hypothesis $3 \mathrm{a}$ predicts that $-\mathrm{TS}$ will lead to less complexity than +TS. As reported, no significant result was found, indicating that this hypothesis was not supported. The results show that learners were encouraged to produce more accurate language when the task was cognitively simple (+TS). It seems that the structural support provided in the +TS condition may have eased learners' online processing burden, resulting in a shift of attention from managing the content to focusing on language accuracy. This result is in line with Skehan's $(1996,2009)$ proposal of reducing task complexity by means of providing a clear structural support to a task.

With regard to quantity, the hypotheses predicted that quantity (the amount of language produced and equality of participation) would not be affected by task structure. The findings for all the quantity measures were non-significant and so the hypotheses were clearly supported.

With regard to the Interactionist Approach (Mackey \& Gass, 2006), it should be noted that the current finding corroborates findings conducted in face-to-face (Leeser, 2004; Mackey, et al., 2007) and text-SCMC contexts (E Sá \& Melo, 2007; Kung, 2004; Smith, 2005) that learner task-based interaction may promote occurrences of LREs, which are believed to be facilitative of L2 learning (Mackey \& Silver, 2005; McDonough, 2004). 


\subsection{Independent variable: Language support}

Based on Robinson's (2007b) Triadic Componential Framework, planning time is a resource-dispersing variable. As mentioned earlier (see Chapter Three, Section 3.6), in the current study, while not specifically mentioned in the Triadic Componential Framework proposed by Robinson (2007b), the pre-task language support activity was conceptualized as similar to language-oriented pre-task planning and therefore functioned as a resource-dispersing variable. The pre-task language support activity was chosen to reflect the use of pre-task language focus common in classroom settings. As reported above, studies have shown the effects of planning time on performance in face-to-face settings (e.g., Philp et al., 2006) and in oral (e.g., Yuan \& Ellis, 2003) and written monologic tasks (e.g., Ellis \& Yuan, 2004). It is important to note that the use of pre-task language support in the current study is not a canonical use of pre-task planning, as learners studied pre-task language support materials prior to being given the task. This was done to ensure consistency with pedagogical practices common to the instructional site. However, care was taken to ensure that the language support activity gave learners opportunities to prepare for the particular target task. This was done by including in the activity an analysis of the interaction of speakers engaged in a similar task as well as by including opportunities to practice using the kinds of expressions they would need in the target task (see Appendix D). Therefore, while different from the operationalization of pre-task planning in the literature (Ellis, 2005; Ortega, 2009), language support was considered similar to language-oriented pre-task planning in its instantiation. Therefore, the effect of language support was hypothesized to be similar to that proposed for pre-task planning in the Triadic Componential Framework. No language support $(-\mathrm{LS})$ would be considered more complex in terms of the learners' need to allocate their cognitive resources simultaneously to meaning and language form. This would increase demands on learner attentional resources, which is predicted in the Cognition Hypothesis to lead to greater occurrence of interactional modification and a decrease in accuracy and complexity of language production. The summary of the statistical results of the effects of language support on all dependent variables is presented in table 7.5. 
Table 7.5

Independent variable: Language support

\begin{tabular}{|c|c|c|c|c|}
\hline \multicolumn{3}{|c|}{ MANOVA } & \multicolumn{2}{|c|}{ Univariate } \\
\hline \multirow[b]{2}{*}{ Measure } & & \multirow[b]{2}{*}{ Dependent variable } & \multicolumn{2}{|c|}{ Independent variable } \\
\hline & & & $\begin{array}{l}\text { With language } \\
\text { support }(+\mathrm{LS})\end{array}$ & $\begin{array}{c}\text { No language } \\
\text { support (-LS) }\end{array}$ \\
\hline $\begin{array}{l}\text { Language- } \\
\text { related }\end{array}$ & $p<0.0001$ & LREs on meaning & $\uparrow$ & $\downarrow$ \\
\hline $\begin{array}{l}\text { episodes } \\
\text { (LREs) }\end{array}$ & & LREs on form & $\uparrow$ & $\downarrow$ \\
\hline \multirow[t]{3}{*}{ Accuracy } & $p<0.0001$ & Error/As-unit & $\uparrow$ & $\downarrow$ \\
\hline & & $\begin{array}{l}\text { TLU auxiliary } \\
\text { verbs }\end{array}$ & $\begin{array}{l}\text { Interaction effect } \\
\text { with task structure }\end{array}$ & $\begin{array}{l}\text { Interaction effect } \\
\text { with task structure }\end{array}$ \\
\hline & & TLU modal verbs & $\uparrow$ & $\downarrow$ \\
\hline \multirow[t]{3}{*}{ Complexity } & $p<0.0001$ & Clause/AS-unit & $\begin{array}{l}\text { Interaction effect } \\
\text { with task structure }\end{array}$ & $\begin{array}{l}\text { Interaction effect } \\
\text { with task structure }\end{array}$ \\
\hline & & $\begin{array}{l}\text { Words beyond the } \\
\text { first } 1,000 \text { words }\end{array}$ & $\downarrow$ & $\uparrow$ \\
\hline & & Guiraud Index & $\begin{array}{c}\text { Interaction effect } \\
\text { with task structure }\end{array}$ & $\begin{array}{l}\text { Interaction effect } \\
\text { with task structure }\end{array}$ \\
\hline
\end{tabular}

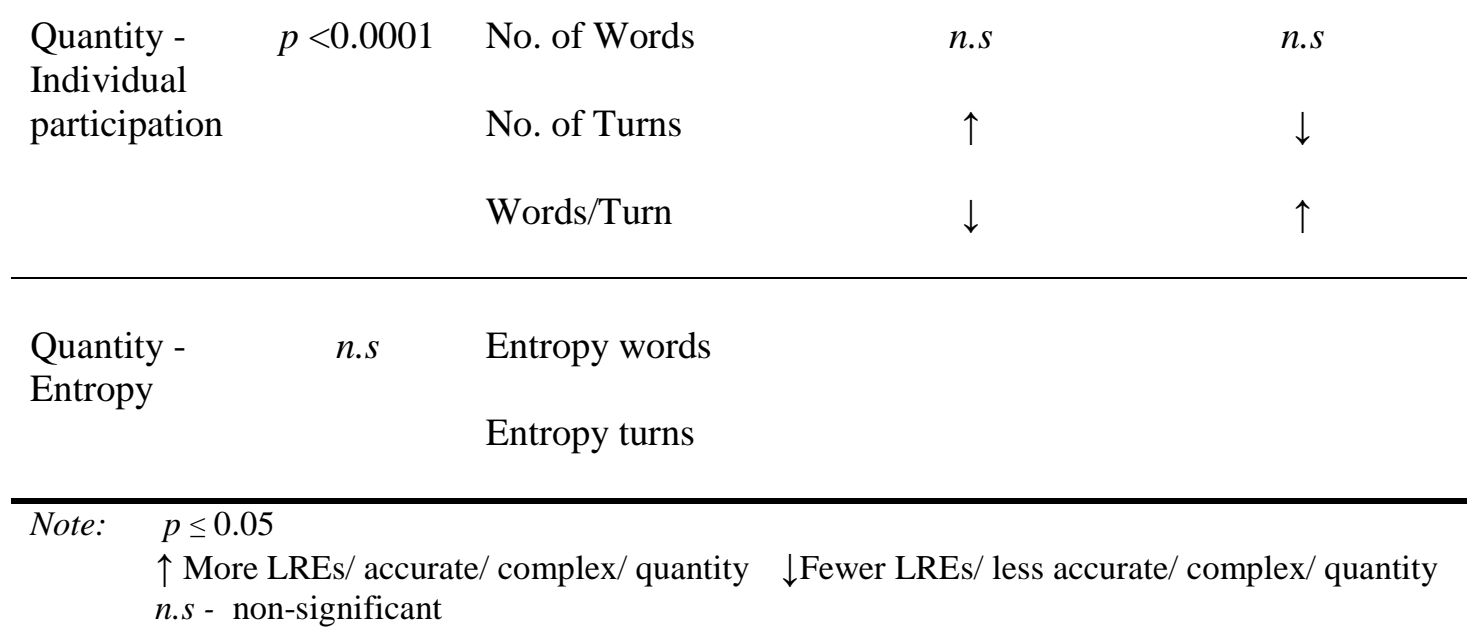

Based on table 7.5, the effects of language support on each of the dependent variable are elaborated in the following sections. 


\subsubsection{The effects of language support on language-related episodes (LREs)}

As indicated in Section 7.2.1, Robinson (2001a, 2001b) claims that more negotiation is likely to occur frequently in complex interactive tasks than simple interactive tasks. This is because cognitively demanding tasks may impose higher comprehension difficulty on learners, and as such cause more negotiations (see Chapter 3, Section 3.4 and Robinson, 2001a, pp.302-303, 2001b, pp.35-36). In line with Robinson's prediction, it was hypothesised in the current study that learners would engage in more negotiation as reflected in a higher occurrence of LREs when performing a task in the $-\mathrm{LS}$ condition, as opposed to the +LS condition.

Table 7.6 summarises the results of the current study for the occurrence of LREs on meaning and form during task-based text-SCMC. The table also presents Robinson's prediction for the effect of task complexity on negotiation.

Table 7.6

The effects of language support on LREs

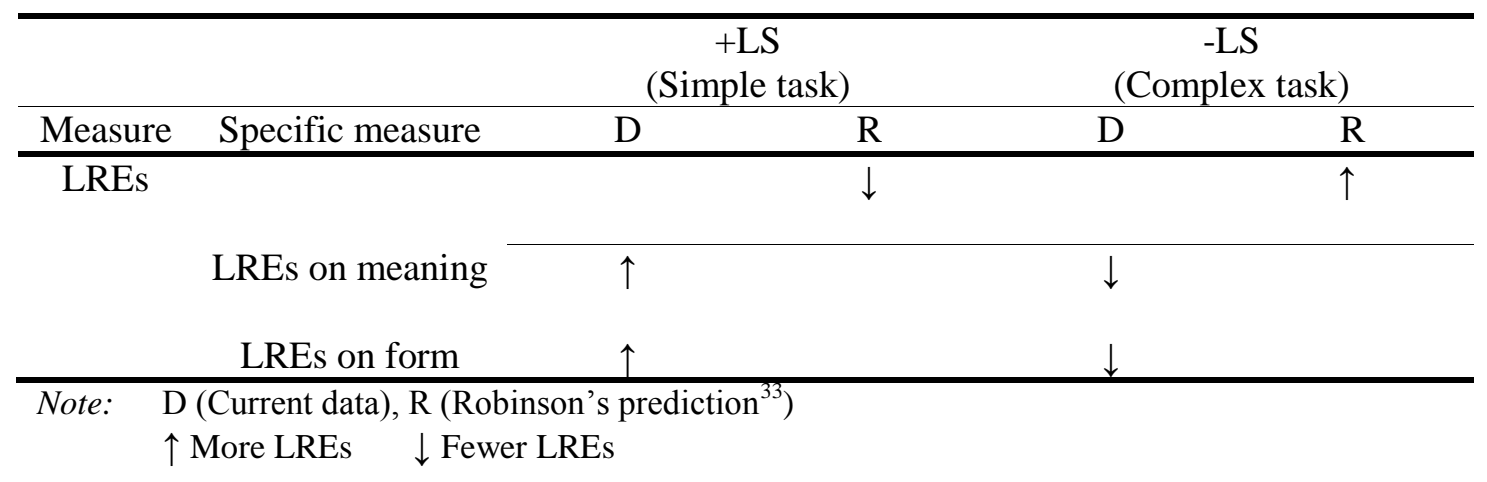

As shown in table 7.6, providing learners with +LS material encouraged them to produce more LREs on meaning and form. To restate this result using Robinson's terminology, the interactive simple task $(+\mathrm{LS})$ encouraged more negotiation than the interactive complex task (-LS). Therefore, the finding does not support Robinson's (2001a, 2001b) prediction that cognitively complex interactive tasks are likely to result in more negotiation. Instead, the learners paid more attention to meaning and form while performing a cognitively simple task.

\footnotetext{
${ }^{33}$ Note that Robinson's prediction about the effect of task complexity on negotiation is not part of the Cognition Hypothesis. See Robinson (2001a, pp.302-303; 2001b, pp. 35-36) for details.
} 
The above finding may be explained in terms of the $+\mathrm{LS}$ condition (Chapter Five, Section 5.8). Firstly, +LS material was given to the learners prior to the task performance, and during the performance they were reminded to use the targetlike language. They were also informed that they needed to rate their teammates based on the effective communication skills checklist after the task completion ${ }^{34}$ (Appendix G). This meant they were more likely to be conscious of their language production, and so notice gaps in expression. As a result, learner attention to language production may have been heightened, resulting in more opportunities to engage in discussion and receive feedback regarding those problems. This interpretation is illustrated in the following LRE in extract 7.4. It is taken from the chat transcript of one of the teams in the +LS condition and the post-task interview with the team. The chat exchange shown in the extract is typical of the +LS condition.

\begin{tabular}{lcl}
\multicolumn{2}{l}{ Extract 7.4} & \\
1 & Zul & oRcad can performs well \\
2 & Salim & meaning/?.. \\
3 & Adi & ZUL- *can perform \\
4 & Zaza & $? ? ?$ \\
5 & Zul & orcad *can perform* well. \\
6 & Zaza & owh grammar \\
7 & Salim & use correct english every1 \\
8 & Zaza & we have to give marks
\end{tabular}

One linguistic aspect provided in the +LS material was modal verbs. In extract 7.4, line one, Zul says "oRcad can performs...". Adi notices the nontargetlike use of the modal verb and corrects it in line three. In line five, Zul modifies his output. Line seven shows Salim's reminder to use targetlike form. In line eight, Zaza reminds the others of the requirement to rate each others' communication skill after the task completion.

During the interview with the team, Adi claimed that he was conscious of his and other teammates' language production. This was mainly because of the language activity completed prior to the task performance and the language support material received during the task. However, according to Zul, he only noticed the error he made when Adi pointed it out. Immediately after, he referred to the language notes

\footnotetext{
${ }^{34}$ Note that the learners in the -LS condition also completed the same checklist (Appendix G).
} 
and modified his language. Zul noted that it was easier to notice others' errors than his own, a point also noted by learners in a study by Storch (2005).

In contrast, in the -LS condition learners' attention was not focused on monitoring their language production. This seems to have resulted in task performance with lower attention to language production, less discussion and little feedback on the language output. Extract 7.5 is an example of the chat exchanges typically found in the - LS condition.

$\begin{array}{lll}\text { Extract } 7.5 & \\ 1 & \text { Asha } & \text { must renewal every year? } \\ 2 & \text { Maz } & \text { mine: doesnt need renewal. } \\ 3 & \text { Na } & \text { aa yerp- mine: must renewal } \\ 4 & \text { Asha } & \text { r u sure maz? } \\ 5 & \text { Dini } & \text { i think- all must renewed } \\ 6 & \text { Maz } & \text { iam very sure!!! }\end{array}$

As seen in this extract, lines one, three and five show the non-targetlike use of modal verbs (in lines one and three, the modal is followed by a noun; in line five, it is followed by a verb inflected for past tense). However, nobody points out the errors and the discussion goes on. In the post-task interview the team was asked about the non-targetlike use of a modal verb in extract 7.5. It appears that Maz was the only participant who noticed the error during the task performance, but he chose not to talk about the error while performing the task. According to Maz:

Although both Asha and Na do not use correct grammar, everyone understands what is going on. So, I don't think I need to talk about the error or correct it.

Researchers agree that during the interaction processes learners may focus on language production and help each other to strengthen their target language knowledge (Fortune, 2005; Izumi, 2003). As seen in extract 7.4, during learnerlearner interaction, providing learners with $+\mathrm{LS}$ material encouraged more peer input and feedback. Additionally, language support seems to have enhanced learner noticing of problematic output. Because of noticing, learners may engage in discussing and consequently, using the modified output in their subsequent production (Ene, et al., 2005). This may explain why a higher occurrence of LREs was witnessed in the +LS condition than -LS condition. 
Leeser (2004) also found benefits in using +LS material, with learners encouraged to produce more LREs when they received the language model. This may have reduced the complexity of the task, which eased the learners' communicative burden, or it may have oriented learners to monitor their output and engage in more negotiation. Therefore, Robinson's prediction that a cognitively complex task may promote more negotiation is not evident in either Leeser's or the current study.

To summarise, performing the task in the $+\mathrm{LS}$ condition facilitated more opportunities to engage in LREs than the -LS condition. Therefore, Robinson's prediction that cognitively complex tasks (the - LS condition in the current study) would lead to more negotiation was not supported. Rather, decreasing the complexity of the task (with the +LS material) encouraged learners to pay more attention to the language they used. At least for the use of language support, increasing task complexity does not increase the amount of negotiation.

\subsubsection{The occurrences of LREs on meaning and form}

This section discusses the occurrence of LREs on meaning and form in the current study. It has been reported that in writing, problems in lexical features are relatively easier to notice and express than grammatical ones (Hanaoka, 2007). Similarly, lexical negotiation was found to be the main trigger in networked (e.g. text-SCMC) exchanges (Blake, 2000; Cheon, 2003). However, in the current study the descriptive statistics revealed that task performance under the +TS condition elicited more LREs on form $(M=5.00, S D=1.76)$ than meaning $(M=3.75, S D=$ 1.48). Likewise, performing the task in the +LS condition promoted more LREs on form $(M=6.00, S D=1.28)$ than meaning $(M=4.17, S D=1.11)$. So, what prompted these learners to pay greater attention to form than meaning in their LREs? Some possible explanations are described below.

From a task complexity perspective decreasing task complexity (particularly when providing the learners with +LS material) may have freed up attentional capacity and thus allowed greater attention to form. A decrease in task complexity may be particularly important for learners in the current study, who were at an intermediate proficiency level. Storch and Wigglesworth (2007) claimed that 
intermediate or lower proficiency learners are more likely to focus on grammatical forms than meaning during meaning-based communication (see also work by Qi \& Lapkin, 2001 and Williams, 2001 with advanced learners).

Another explanatory factor is the grammar-focused nature of the activities in the $+\mathrm{LS}$ condition. Learners performing tasks in the $+\mathrm{LS}$ condition produced the most LREs on form, and so it is likely that these activities may have oriented these learners to talk about grammatical features more than lexical items during their task performance. In Leeser's (2004) and Fortune's (2005) studies, the learners were also directed to the use of well-formed structures prior to task performance and so heightened their attention to language form. The topic or content of the tasks in the current study is another factor that may have influenced the results. The topic of engineering software was related to the students' engineering studies and so the content and technical vocabulary required for the task was familiar. With the lexical difficulties kept to a minimum, learner attention may have been freed up to focus more on discussing problematic grammatical items. Malmqvist (2005), and Vetter and Channier (2006) also found that learners' prior knowledge of task content made it easier for them to comprehend the meaning. Similarly, in Alegría de la Colina and Gárcia Mayo's (2007) study, the use of a task relevant to the learners' future profession may have led to greater attention to discussing the grammatical forms than lexical items that were familiar to them. In other words, using a task on a familiar topic may have allowed for attentional trade-off effects, as proposed by Skehan (1996; 1998).

In short, the current study shows that learners in the $+\mathrm{LS}$ condition paid greater attention to form than meaning particularly because of a decrease in task complexity. Additionally, providing the learners with familiar content may have lowered the processing demands to understand meaning and as such, allowed for more attention to language form.

\subsubsection{The frequency of LREs in text-SCMC}

The findings show that the occurrences of LREs in the current study were infrequent when compared to the studies conducted in the face-to-face settings (e.g. Storch \& Wigglesworth, 2007). One explanation for this is that online chat 
transcripts fail to capture important off-line data such as self-correction. Smith (2008), for example, found a higher amount of self-correction in the data collected using Camtasia (a system that records each keystroke and hence, the online text chat produced by his participants was recorded in its entirety). In a sense, the monitoring of output provided collaboratively in spoken discourse may in part be taken over by the composing process in text-SCMC. Online text chat transcripts therefore may not show all instances of monitoring or noticing.

In the current study, a more complete view of learner interaction in textSCMC was gathered during the interview session. According to a number of participants, the written modality of text-SCMC enabled them to compose and delete their writing before posting the messages. Additionally, the text messages meant learners could scroll backward and forward, which enabled them to digest information before responding. Scrolling backward enabled them to make sense of unknown lexical items that caused miscommunication. Therefore less negotiation or interactional modification was evident in the chat exchanges. In addition, some learners reported that they chose to wait before responding (posting their message) to other messages. By doing so, they claimed they had time to internalise the meaning, and think (by themselves) about the most appropriate or correct words or language expression to be used. Therefore, instead of talking or discussing the language they or others were using, they opted not to verbalise their thought on screen. As a result, few LREs were produced.

\subsubsection{The effects of language support on accuracy and complexity}

According to the Cognition Hypothesis (2001b, 2003b), a cognitively complex task along resource-dispersing dimension imposes greater cognitive demands on learners because of the need to simultaneously allocate attentional resources to procedural task demands and language forms. Hence, it will deplete learner attention from focusing on their language production, resulting in less accurate and less complex language production. In line with the prediction of the Cognition Hypothesis, the current study hypothesised that performing a task in the -LS condition would disperse learners' attentional and memory resources, which 
will negatively affect the accuracy and complexity of their language production compared to the language produced by the learners in the $+\mathrm{LS}$ condition.

Table 7.7 presents the prediction for accuracy and complexity in the +LS and -LS tasks derived from the Cognition Hypothesis and Limited Attentional Capacity Model, and the results of the current study for this variable.

Table 7.7

The effects of language support on accuracy and complexity

\begin{tabular}{|c|c|c|c|c|c|c|c|}
\hline & & $\begin{array}{r}+\mathrm{I} \\
(\mathrm{Simpl}\end{array}$ & task) & & $\begin{array}{r}-\mathrm{L} \\
\text { (Comple }\end{array}$ & task) & \\
\hline Measures & $\begin{array}{l}\text { Specific } \\
\text { measures }\end{array}$ & $\mathrm{D}$ & LAC & $\mathrm{CH}$ & $\mathrm{D}$ & LAC & $\mathrm{CH}$ \\
\hline Accuracy & & & $\uparrow$ & $\uparrow$ & & $\uparrow \downarrow$ & $\downarrow$ \\
\hline & Error/AS-unit & $\uparrow$ & & & $\downarrow$ & & \\
\hline & $\begin{array}{c}\text { TLU auxiliary } \\
\text { verbs }\end{array}$ & $\begin{array}{l}\text { Interaction } \\
\text { effect with } \\
\text { task structure }\end{array}$ & & & $\begin{array}{l}\text { Interaction } \\
\text { effect with } \\
\text { task structure }\end{array}$ & & \\
\hline & $\begin{array}{l}\text { TLU modal } \\
\text { verbs }\end{array}$ & $\uparrow$ & & & $\downarrow$ & & \\
\hline Complexity & & & $\uparrow$ & $\uparrow$ & & $\uparrow \downarrow$ & $\downarrow$ \\
\hline & Clause/AS-unit & $\begin{array}{l}\text { Interaction } \\
\text { effect with } \\
\text { task structure }\end{array}$ & & & $\begin{array}{l}\text { Interaction } \\
\text { effect with } \\
\text { task structure }\end{array}$ & & \\
\hline & $\begin{array}{l}\text { Words beyond } \\
\text { the first } 1,000 \\
\text { words }\end{array}$ & $\downarrow$ & & & $\uparrow$ & & \\
\hline & Guiraud Index & $\begin{array}{l}\text { Interaction } \\
\text { effect with } \\
\text { task structure }\end{array}$ & & & $\begin{array}{l}\text { Interaction } \\
\text { effect with } \\
\text { task structure }\end{array}$ & & \\
\hline $\begin{array}{l}\mathrm{D}(\mathrm{C} \\
\uparrow \mathrm{M}\end{array}$ & $\begin{array}{l}\text { ent data), LAC ( } \\
\text { accurate/ comple }\end{array}$ & $\begin{array}{r}\text { ited Attentional } \\
\downarrow \text { Less accurc }\end{array}$ & / comp & & $\begin{array}{l}\text {, CH (Cognition } \\
\uparrow \downarrow \text { Trade-off ef }\end{array}$ & $\begin{array}{l}\text { lypo } \\
\text { cts }\end{array}$ & \\
\hline
\end{tabular}

As indicated in table 7.7 , performing a task with $+\mathrm{LS}$ material pushed the learners to produce more accurate language. This is reflected in a decrease in error rates and more targetlike use of modal verbs. For targetlike use of auxiliary verbs, the result shows interaction effect. This effect will be discussed in Section 7.4.

With regard to complexity, the percentage of words beyond the first 1,000 words is the only measure that shows a significant difference. This illustrates that 
learners in the $+\mathrm{LS}$ condition produced less complex production than learners in the -LS condition. The other two complexity measures, Clause/AS-unit and Guiraud Index, show interaction effects. The discussion on these effects is elaborated in Section 7.4.

To summarise, based on two accuracy measures, the results indicate that in the -LS condition learners produced less accurate language, while in the +LS condition accuracy was increased. Based on one complexity measure, the result indicates that in the -LS condition learners produced more complex language, while in the $+\mathrm{LS}$ condition complexity was decreased. These results for accuracy measures corroborate the prediction made by the Cognition Hypothesis. On the other hand, the finding for one of the complexity measures shows the opposite direction of the prediction made by the Cognition Hypothesis. As shown in table 7.7 performing a cognitively simple task (+LS) led to more accurate language production. The most obvious explanation for this result is that +LS material raised the learners' consciousness of the use of targetlike form. As a consequence, they put extra effort into using the forms correctly.

Extract 7.6 exemplifies the typical text chat exchanges in the +LS condition. It shows how learners modelled the targetlike use of auxiliary verb based on the +LS material.

\section{Extract 7.6}

$\begin{array}{lcl}1 & \text { Jep } & \text { we are decided Orcad rite? } \\ 2 & \text { Bugo } & \text { orrcad? } \\ 3 & \text { Sam } & \text { not are decided, man! } \\ 4 & \text { Jep } & \text { Yes orcad } \\ 5 & \text { Sam } & \text { have decided } \\ 6 & \text { Jep } & \text { what?? } \\ 7 & \text { Tan } & \text { Yerp Jep- u shud write- we have decided } \\ 8 & \text { Bugo } & \text { read your notes! 4 goodness sake! } \\ 9 & \text { Jep } & \text { ok it is wrong.... but gimme good marks nyeh } \\ & & \text { nyeh }\end{array}$

As seen in this extract, line one shows the use of non-targetlike modal verb by Jep. In line three Sam points out the error, and in line five he modifies it. Line six shows that Jep does not understand what is going on, and in line eight Bugo responds to Jep's lack of understanding and reminds him to refer to his notes (+LS material). In line nine Jep acknowledges his mistake, but does not explicitly 
demonstrate uptake. While beyond the scope of the current study, this suggests that although +LS material is influential for learners to model language use, it may not promote uptake. This supports studies that suggest language learners simply demonstrate camouflaged uptake moves (Farrokhi \& Gholami, 2007) or general uptake in text-SCMC (Sotillo, 2005; Smith, 2004) in response to others' feedback.

It should be emphasised that the +LS material focused on the targetlike use of auxiliary and modal verbs. However, learners in the $+\mathrm{LS}$ condition produced more accurate language not only in regard to these two specific forms, but linguistic form in general. Extract 7.7 is an example taken from one of the teams in the +LS condition.

$\begin{array}{lc}\text { Extract } 7.7 \\ 1 & \text { Hus } \\ 2 & \text { Abidin } \\ 3 & \text { Hus } \\ 4 & \text { Gimbus } \\ 5 & \text { Abidin } \\ 6 & \text { Sabar } \\ 7 & \text { Hus } \\ 8 & \text { Gimbus }\end{array}$

I think is better matlab
thats incorrect
what do u mean? we agreed matlab!
no.. he means your writing
hus- $* *$ i think matlab is better
lol... direct translantion frm bm
$\wedge \_\wedge$ will b careful nxt time
must use corect English $\mathrm{k}$

In this extract, in line one Hus produced a sentence reflecting Bahasa Malaysia syntax. This was noticed by Abidin in line two, who modified the output in line five. This illustrates that although word order was not part of the focus in the $+\mathrm{LS}$ material, the learners were conscious of their language production. An earlier study of the task-based text-SCMC interaction with similar learners (Nik \& Adams, 2009) found similar use of Bahasa Malaysia syntax as a communication strategy. However, the learners in that study, who were not given pre-task language activities, did not comment on or correct each other's language use. This provides evidence that in the current study, the +LS condition enhanced attention to form, regardless of the language focus.

On the other hand, although the findings suggest that +LS material heightened learner attention to form during the interaction, this may have come at the expense of complexity. This may be evidence of the trade-off effects proposed by Skehan (1996, 1998). Because of limited attentional processing ability, preventing simultaneous attention to accuracy and complexity, learners may have 
prioritised their attention to only one aspect of language production. It should be noted that the trade-off effects as proposed by Skehan were only applied to face-toface, online language production where learners experience communicative pressure. Although text-SCMC relieves the learners of some of this online processing burden (e.g., by allowing learners to revisit earlier interaction), the tradeoff effect is still evident in the current study, as the learners prioritised their attention to accuracy over complexity. This may indicate that the LAC applies to both face-toface and online communication. During the post-task interview with one of the learners in the $+\mathrm{LS}$ condition, Omar provided evidence that he perceived such a trade-off effect:

I wanted to make sure that I used correct grammar. If I spent time trying to use difficult words or words that I don't normally use during conversation, I'm afraid I would end up producing many grammatical errors because I couldn't do both at the same time. It's difficult for me.

The prioritization of accuracy over complexity in the $+\mathrm{LS}$ condition may have occurred because the focus of language support was on the grammatical accuracy of two linguistic forms (auxiliary and modal verbs) rather than syntactic or lexical complexity. Therefore, it increased learner awareness and drew their attention to accuracy rather than complexity. This may be reflected in the low percentage of words beyond the first 1,000 words (a decrease in the use of low frequency words) in the +LS rather than the $-\mathrm{LS}$ condition. The information gathered during the post-task interview with Yusof, one of the participants who performed the task in the +LS condition, perceived an overall focus on grammatical accuracy in his group:

In my opinion, there could be many reasons why we focused on grammar during the chat session. First, my teammates kept on reminding us about the use of correct grammar. Second, we became more aware of what we wrote because of the language exercise we did earlier. As seen here, when someone produced errors, one of us would notice the errors. However, I think sometimes we got too conscious of our grammar; we disregarded other language aspects. I mean, we forgot that grammar is not the only thing that makes you an effective speaker or writer of English language!

The nature of SCMC may have contributed to this effect. During the posttask interviews, most learners in the $+\mathrm{LS}$ condition agreed that they were conscious of their own and others' production because they were able to view messages on the 
screen. However, because of the quick nature of exchanging online text messages, they tended to post the messages using frequently used words (words that belong to the first 1,000 words). According to Nur, one of the learners in the +LS condition:

Learning via chatting is a good practice for us because we can see where our language problems are on the screen. In face-to-face, we can only detect the most obvious problem. However, in chatting, sometimes you feel the need to keep up with the rapid information exchange. Because I wanted to be quick in responding, I used simple words. What I mean is, I used everyday words.

In contrast, the learners in the - LS condition were not instructed to attend to the accuracy of the language production, and may have chosen to prioritize complexity over accuracy, attending less to language form and more to the production of low frequency words.

Other SCMC researchers who have uncovered similar findings have noted that the written modality of text-SCMC may enable the learners to pay greater attention to their language production (Deusen-Scholl, et al., 2005; Sanders, 2006). As such, an interactive task-based context like text-SCMC may represent optimal psycholinguistic environment for learners to make form-meaning connections (Doughty \& Long, 2003). This, however, may have consequences for complexity. As seen above, the findings clearly support the trade-off effects in L2 production, in that those who used more accurate language, used less complex language (and vice versa).

To recapitulate, these findings show that in the $+\mathrm{LS}$ condition, learner attention to their production, particularly accuracy, is heightened. As such, the Cognition Hypothesis (2001b, 2003b, 2005) is supported. It should also be noted that this finding may be influenced by the offline processing afforded by text-SCMC as described earlier.

\subsubsection{The effects of language support on quantity}

As mentioned in Section 7.2.3, quantity is a more appropriate language production variable than fluency, but it is not accounted for in Skehan or Robinson's model for task complexity and language production measure. However, research has reported the benefits of text-SCMC in encouraging more active and equal 
participation than face-to-face settings (Böhlke, 2003; Fitze, 2006; Freiermuth \& Jarell, 2006). Therefore, the current study hypothesised that quantity of language production, defined by the amount of talk by individuals and distribution of talk within teams, would not be affected by language support, which was the second task complexity variable. Each category is further discussed below.

\subsubsection{Quantity- Amount of talk}

In the current study, it was found that language support influenced the amount of talk produced by learners under different conditions. This is summarised in table 7.8.

Table 7.8

The effects of language support on quantity (amount of talk)

\begin{tabular}{lccc}
\hline & & $\begin{array}{c}+ \text { LS } \\
\text { (Simple task) }\end{array}$ & $\begin{array}{c}\text {-LS } \\
\text { (Complex task) }\end{array}$ \\
\hline Measure & Specific measure & & $n . s$ \\
& No. of words & $n . s$ & $\downarrow$ \\
& No. of turns & $\uparrow$ & $\uparrow$ \\
& Words/Turn & $\downarrow$ & \\
\end{tabular}

Note: $\begin{aligned} & \uparrow \text { More } \quad \downarrow \text { Less } \\ & n . s-\text { non-significant }\end{aligned}$

These results show that no significant effect was found for language support on the number of words produced by each learner. However, in the +LS condition, learners produced more turns but fewer words per turn than in the -LS condition. As such, the results do not support the hypothesis.

This may be because learners in the $+\mathrm{LS}$ condition had $+\mathrm{LS}$ material as the language model prior to and during the task. As well as increased awareness from doing the pre-task activity, they could refer to the language notes during task performance. This may have, in terms of focus on form, put the learners 'on the same page', allowing more than one learner to contribute to the discussion about the language they were producing. As a result, these learners produced more turns, some of which may have been simultaneous. The instances of LREs in these data included 
many short turns. Attending to form, rather than simply carrying out the task, may have resulted in the production of more, shorter turns.

Extract 7.8 is an example of online text chat taken from the team performing the tasks under the $+\mathrm{LS}$ condition. Learner awareness of production errors led to a group discussion of the error, leading to the production of several short turns.

$\begin{array}{lll}\text { Extract } 7.8 & \\ 1 & \text { Ross } & \text { our company a big company } \\ 2 & \text { Zam } & \text { we must choose carefully } \\ 3 & \text { Wan } & \text { u missed 'is' } \\ 4 & \text { Zam } & \text { owh yup ross- } \\ 5 & \text { Tim } & \text { Ross... is a big company!! } \\ 6 & \text { Ross } & \text { i know. i know frends } \\ 7 & \text { Zam } & \text { our company is... } \\ 8 & \text { Wan } & \text { watch out ross- think b4 u write } \\ 9 & \text { Ross } & \text { dont punish me }\end{array}$

In line one of this extract, Ross omits 'is' in his output, and lines three and four show that the two learners notice the grammatical error. Lines five and seven show Tim and Zam provide the modified output (the two messages are likely to be composed simultaneously). In this sample, the learners in the group are all quickly contributing turns.

These learners were all provided with +LS material, so had language information at hand while performing the tasks. Learner comments indicate that the +LS materials may have enhanced confidence, motivating the learners to contribute more turns to the talk. For example, Akmal, a learner who had the +LS material explained that:

The language exercises and notes were very helpful when we had to do activities without the teacher's help. Whenever I was uncertain of my grammar, I could refer to the notes. I could also compare what I have typed with the notes before I posted my message. It was convenient and I feel more confident to talk.

Increasing learner confidence may have increased their motivation to actively participate in the discussion. Consequently, these learners produced more turns than those in the -LS condition. The above finding is similar to one reported by Coniam and Wong (2004). Participants in their study had language models to 
refer to during the task performance, which motivated and encouraged them to actively participate in the discussion.

A possible explanation for there being fewer words per turn produced in the +LS condition, is that as learners became motivated to contribute to the discussion, the discourse became more interactive. This is mainly because of learners wanting to be quick in posting or exchanging online text messages. As interactivity is associated with more frequent and shorter average turn length (Duff, 1986), it is evident in the +LS condition where learners produced more, but their turns were shorter (as reflected in less words per turn).

\subsubsection{Quantity- Distribution of talk}

With regard to the distribution of talk within teams, table 7.9 shows that no significant difference was found on all entropy measures representing distribution of talk within teams.

Table 7.9

The effects of language support on quantity (distribution of talk)

\begin{tabular}{|c|c|c|c|}
\hline & & $\begin{array}{c}+\mathrm{LS} \\
\text { (Simple task) }\end{array}$ & $\begin{array}{c}-\mathrm{LS} \\
\text { (Complex task) }\end{array}$ \\
\hline Measure & Specific measure & & \\
\hline \multicolumn{4}{|l|}{$\begin{array}{l}\text { Quantity (distribution of } \\
\text { talk within teams) }\end{array}$} \\
\hline & Entropy words & $n . s$ & n.s \\
\hline & Entropy turns & $n . s$ & $n . s$ \\
\hline $\begin{array}{l}\uparrow \text { More } \quad \downarrow \text { Less } \\
n . s \text { - non-significant }\end{array}$ & & & \\
\hline
\end{tabular}

The non-significant results in table 7.9 shows that learners participated equally in the text-SCMC setting, regardless of whether or not they performed the task in the +LS condition. Therefore, the finding clearly supports the hypothesis. This finding could be explained in terms of the medium where the communication took place. For example, in face-to-face classroom discourse in a group of four learners, when one asks a question, normally only one learner responds. Also, when this learner is talking or explaining, others normally become quiet as they listen. 
This is quite different in text-SCMC setting. When one learner asks a question, there is a possibility that the other three may start typing and posting their answer or message to the screen in response to the question. This results in more than one person producing output at a time. Therefore, this increases the chance for participation to be equally distributed regardless of whether or not the learners had +LS material.

Another possible explanation is that text-SCMC decreases the face threat. Therefore, learners may be encouraged to present their ideas in the target language. Based on the post-task interview with Ian, one of the participants in the +LS condition, when asked to comment on his participation during the task-based textSCMC, said:

Although people will laugh at me when I make mistake, I don't have to see their faces and they cannot see mine. For that reason, I can still continue expressing my ideas even though I know my friends' command of English language is better. I have to take this chance because I know I can't do it face-to-face.

Additionally, learners may become more motivated to participate in textSCMC because it provides them with a favourable environment to practice the target language. During the post-task interview with Adam, a participant from a team in the -LS condition, was asked about his perception on task-based text-SCMC. He explained:

We should be given more chance to practice English language using text chat. It encourages me to participate more because I can see what I want to say on the screen before posting my message. It reduces the probability of making errors. When we discuss language problems for example in a group of four or five, we can compare all opinions at the same time on one screen. It is very motivating.

This finding is similar to most of the text-SCMC studies reported so far, which show that learners participate equally in a text-SCMC setting (Cheon, 2003; Fitze, 2006; Freiermuth \& Jarrell, 2006). Similarly, Kung (2004) reported that while some learners were being criticised due to their low proficiency level, they continued participating. This resulted in equal participation among the learners. Vetter and Chanier (2006) provided evidence that participation levels in text-SCMC were higher than audio-SCMC. They proposed that text-SCMC was beneficial as a medium for language practice for the learners who were not ready to speak in audio. 
In particular, low proficiency learners do not feel too shy to communicate because nobody can see their face if they produce errors. As such, the opportunity to engage in chatting reduces anxiety about making errors and increases motivation for using the target language. This resulted in greater opportunities for target language production than normal face-to-face classroom discourse.

\subsubsection{Summary of the effects of language support on the dependent variables}

This section summarises the effects of language support on the dependent variables based on their respective hypotheses. Hypothesis $1 \mathrm{~b}$ suggested that $-\mathrm{LS}$ would elicit a higher occurrence of LREs than +LS. As shown earlier, an interactive simple task (+LS), elicited a higher occurrence of LREs than an interactive complex task (-LS). As such, hypothesis $1 \mathrm{~b}$ was not supported by the finding. It appears that when performing a cognitively simple task (+LS) learners were encouraged to produce more LREs. This suggests that the +LS material heightened learner attention to the accuracy of their production by means of negotiation.

Hypothesis $2 \mathrm{~b}$ stated that -LS would lead to less accuracy than +LS. Based on two accuracy measures (Error/AS-unit and targetlike use of modal verbs), the results demonstrated that an interactive simple task $(+\mathrm{LS})$ promoted higher accuracy than an interactive complex task (-LS). Therefore, hypothesis $2 \mathrm{~b}$ was supported, which is in line with Robinson's (2007b) prediction that tasks made complex along the resource-dispersing dimension will disperse learner attentional and memory resources, resulting in less accurate language production in contrast to its simpler counterpart. It is also possible that the resource-dispersing effects of language support are seen because of the nature of the variable itself. The provision of useful language models may have reduced the communicative demands of the task, and that this may have allowed learners to monitor their output and engage in more targetlike forms. While the findings of this study supports Robinson's predictions about the effect of increasing task complexity along the resource-directing dimension in interactive complex tasks, language support might not serve as a legitimate variable to test the Cognition Hypothesis for the reason described.

Hypothesis $3 \mathrm{~b}$ predicted that $-\mathrm{LS}$ will lead to less complexity than $+\mathrm{LS}$. Based on one complexity measure (Words beyond the first 1,000 words), the result 
showed that an interactive complex task (-LS) promoted more complexity than an interactive simple task (+LS). Therefore, hypothesis $3 b$ was not supported.

In terms of quantity, the hypotheses predicted that quantity (the amount of talk and equality of participation) would not be affected by language support. For the amount of talk the results show that an interactive simple task (+LS) promoted more turns, but less words per turn, than an interactive complex task (-LS). As such, the findings do not support the hypothesis based on two of the amount of talk measures. With regards to the equality of participation, the non-significant findings confirm that hypothesis was supported. This is supported by qualitative findings, which revealed that learners who feel inferior in face-to-face communication are more prepared to actively contribute to the discussion in text-SCMC. This affective dimension of text-SCMC may have been an important contributing factor in the equality of participation seen in the current study.

To recapitulate, the results show that the production of more accurate, but less complex language was higher when performing a cognitively simple task (+LS). This clearly supports the Trade-off Hypothesis that Skehan (2009) proposed. While the nature of the variable (language support) turned learner attention to language forms, the trade-off effects on language production were still present. The current finding supports Skehan's view that by simplifying the communication burden (which in this case providing learners with $+\mathrm{LS}$ material), learners are able to apply their cognitive resources to the production of accurate use of form, particularly by modelling the correct use of the language forms.

The finding of the current study agrees with a few studies conducted within the interactionist framework that during the interaction process some degree of attention to form could result in learners producing more accurate language (Leeser, 2004; Fortune, 2005). During this task-based interaction, learner attention to linguistic items may be heightened as a result of noticing the errors triggered through miscommunication. When this occurs they are able to attend to the forms that cause the problem, and so, reduce error rates. Thus, more accurate language is produced. 
7.4 Interaction effects between task structure and language support

As indicated earlier, interaction effects between task structure and language support were found on three measures. Table 7.10 shows the effects on one accuracy measure; the percentage of targetlike use of auxiliary verbs. It also shows the interaction effects on two complexity measures; the Clause/AS-unit and Guiraud Index.

Table 7.10

Interaction effects between task structure and language support

\begin{tabular}{lccc}
\hline & MANOVA & Univariate \\
\hline \multirow{2}{*}{ Measure } & TS *S & Dependent variable & TS * LS \\
\cline { 2 - 3 } Accuracy & \multicolumn{2}{c}{ Error per As-unit } & $n . s$ \\
& & \% TLU auxiliary verbs & $p=0.016$ \\
& & \% TLU modal verbs & n.s \\
& & & \\
\hline
\end{tabular}

$\begin{array}{lll}\text { Complexity } & \text { Clause per AS-unit } & p=0.041 \\ & \% \text { of Words beyond the } & n . s \\ & \text { first 1,000 words } & \\ & \text { Guiraud Index } & p=0.054\end{array}$

$\begin{array}{ll}\text { Note: } & p \leq 0.05 \\ & n . s-\text { non-significant }\end{array}$

Based on the above table, the following sections discuss these effects according to each variable.

7.4.1 The interaction effect between task structure and language support on accuracy

There were three specific measures for accuracy, with an interaction effect found on one; the percentage of targetlike use of auxiliary verbs (see table 7.10). However, based on the MANOVA test, the power level of this effect was well below 0.80, which suggests a weak effect. Figure 7.1 shows this interaction effect. 


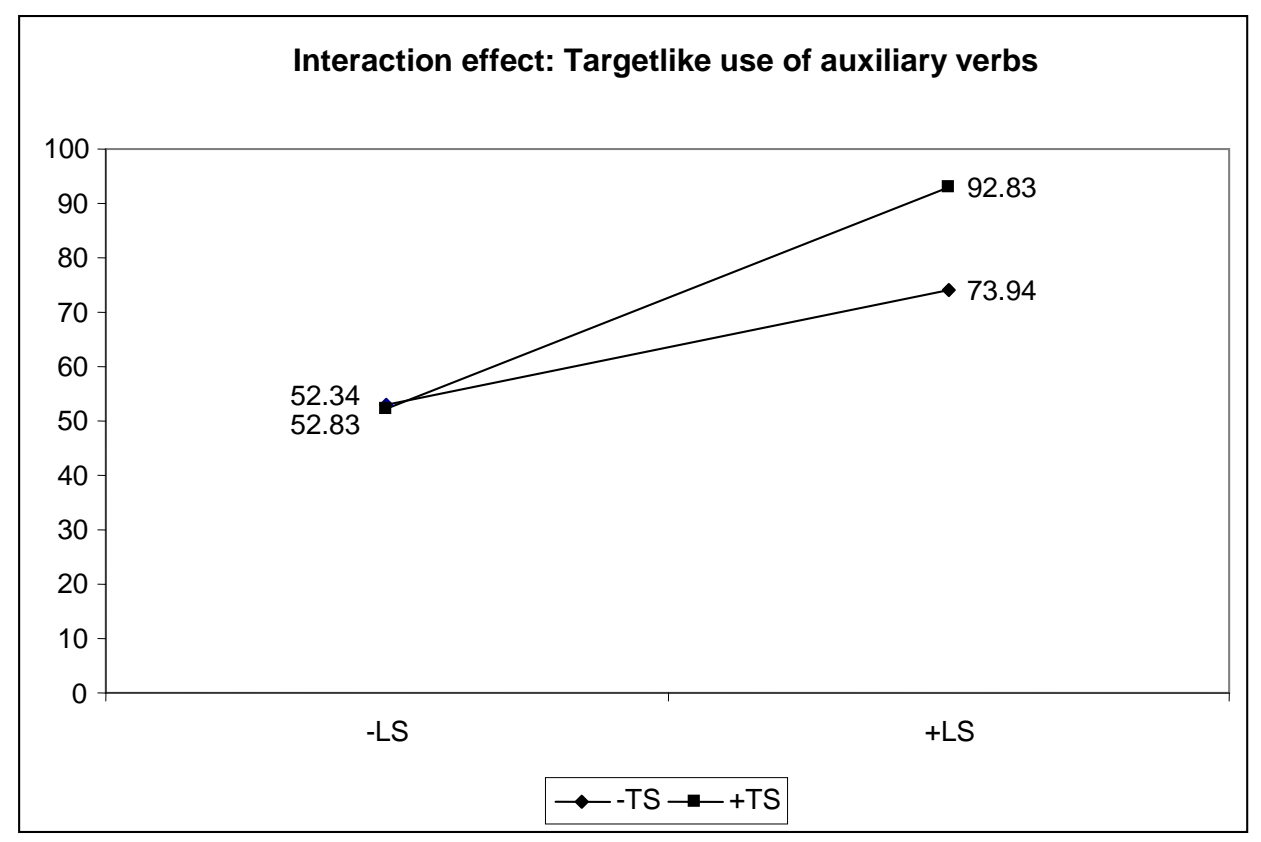

Figure 7.1 Interaction effect between TS and LS on targetlike use of auxiliary verbs

The interaction effect between language support and task structure indicates that task structure is dependent on language support to influence learner production of the correct use of auxiliary verbs. In the +LS condition, learners with the +TS material used more targetlike auxiliary verbs $(M=92.83, S D=8.97)$ than learners in the $-\mathrm{TS}$ condition $(M=73.94, S D=16.98)$. This reflects the main effect of the language support.

In contrast, in the $-\mathrm{LS}$ condition learners who had the +TS material produced less targetlike auxiliary verbs $(M=52.34, S D=22.88)$ than the learners without the material $(-\mathrm{TS})(M=52.83, S D=24.82)$. This indicates that high task structure (+TS) on its own did not influence the use of correct auxiliaries, but when combined with the language support (+LS) material, it did have a positive effect.

An explanation for this may be that for learners who received +LS material, having the +TS worksheet to help manage the discourse further reduced the cognitive load of the task. This may have freed up cognitive capacity to focus on more accurate production of auxiliary verbs. This suggests that to increase the chance of learners focusing on form or monitoring their language expression, they should be presented with a relatively cognitively simple task. Therefore, the Cognition Hypothesis proposal that cognitively complex interactive tasks may push learners to produce accurate language is supported by the finding of the current 
study. It should also be noted that it may also be that the nature of one of the variables used in the current study, i.e. language support, that heightened learner attention to language form. Also, it could be that the offline processing of textSCMC has anchored learner noticing, as discussed earlier.

7.4.2 The interaction effect between task structure and language support on complexity

As portrayed in table 7.10, out of three complexity measures, the interaction effects were found on two measures: syntactic complexity (Clause per AS-unit) and lexical complexity (Guiraud Index). Figure 7.2 illustrates the interaction effect between task structure and language support on Clause per AS-unit.

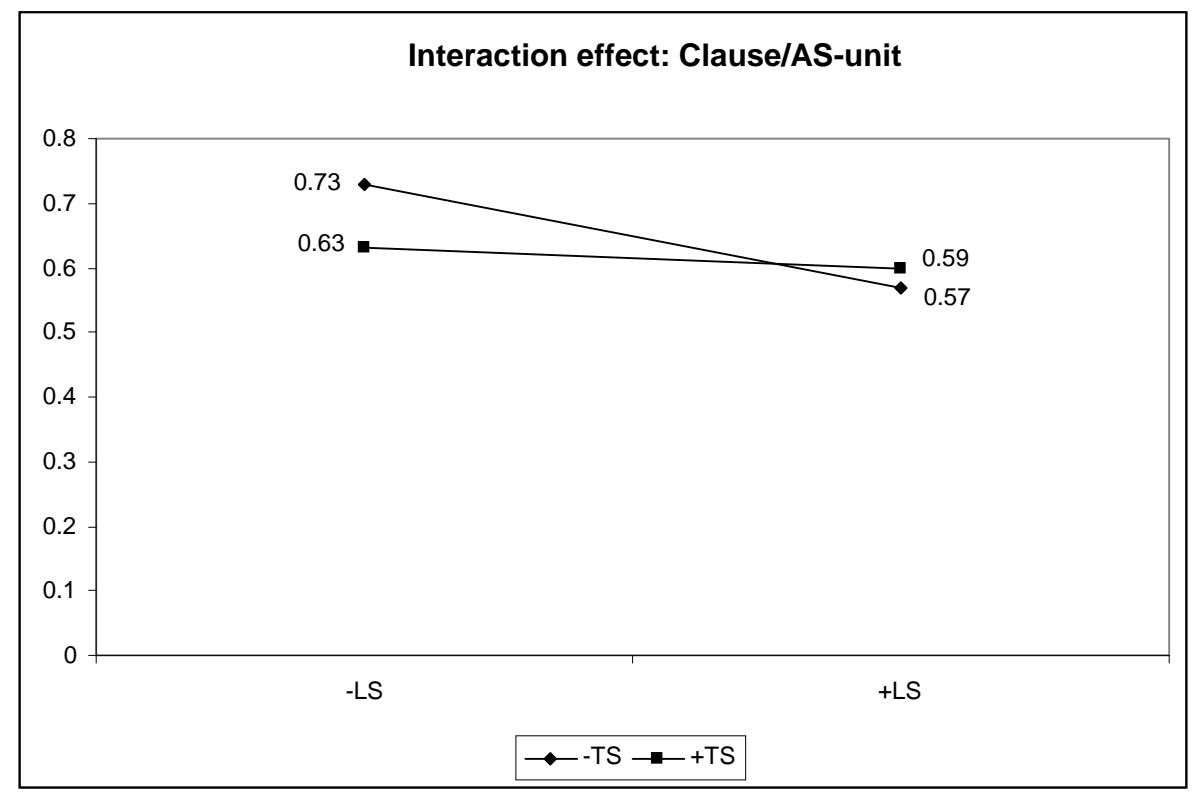

Figure 7.2 Interaction effect between TS and LS on Clauses/AS-unit

For learners in the $+\mathrm{TS}$ condition, $+\mathrm{LS}$ material made little difference to the syntactic complexity of their language production. However, for learners in the -TS condition, +LS material led to lower structural complexity in their production. Learners used the most complex syntactic structures (i.e. more Clauses per AS-unit) when they were in the - LS and -TS conditions. This finding demonstrates that even though providing more structure to the task (+TS) proved to be useful to assist learners to manage their performance, it did not appear to encourage the production 
of complex language. Similarly, providing +LS material did not necessarily contribute to structural complexity.

Perhaps the most obvious reason for this is that the +TS material was mainly used for managing task performance, while the +LS material consisted of grammatical rather than syntactical language expression. It is possible that in the TS and -LS conditions learners were pushed to use more complex language structure because not only did they have to work out how to organise the discourse themselves, they were also less conscious of the accuracy of their language production. This is because with no structural support for the task (-TS), the learners had to communicate the bulk of unstructured information to their teammates and without the language support (-LS) material, they may have been less conscious of accuracy. As a result, these learners seemed to show readiness to experiment with a range of syntactic structures resulting in more complex production. However, this increase in complexity was accompanied by lower rates of accuracy. In this regard, Foster and Skehan (1996) have argued that the more complex the sentences learners produce, the less accurate they will be because learners were unable to simultaneously allocate attention to accuracy and complexity. As such, the result does not support the Cognition Hypothesis that for interactive tasks (e.g. discussion or information transfer tasks), increasing complexity of the task along resourcedispersing dimension reduces accuracy as well as complexity of the language production. Instead, trade-off effect is evident in that the accuracy of language production is decreased while the complexity of language production is increased in the complex task manipulated along the resource-dispersing dimension.

Figure 7.3 portrays the interaction effect between task structure and language support on the Guiraud Index. 


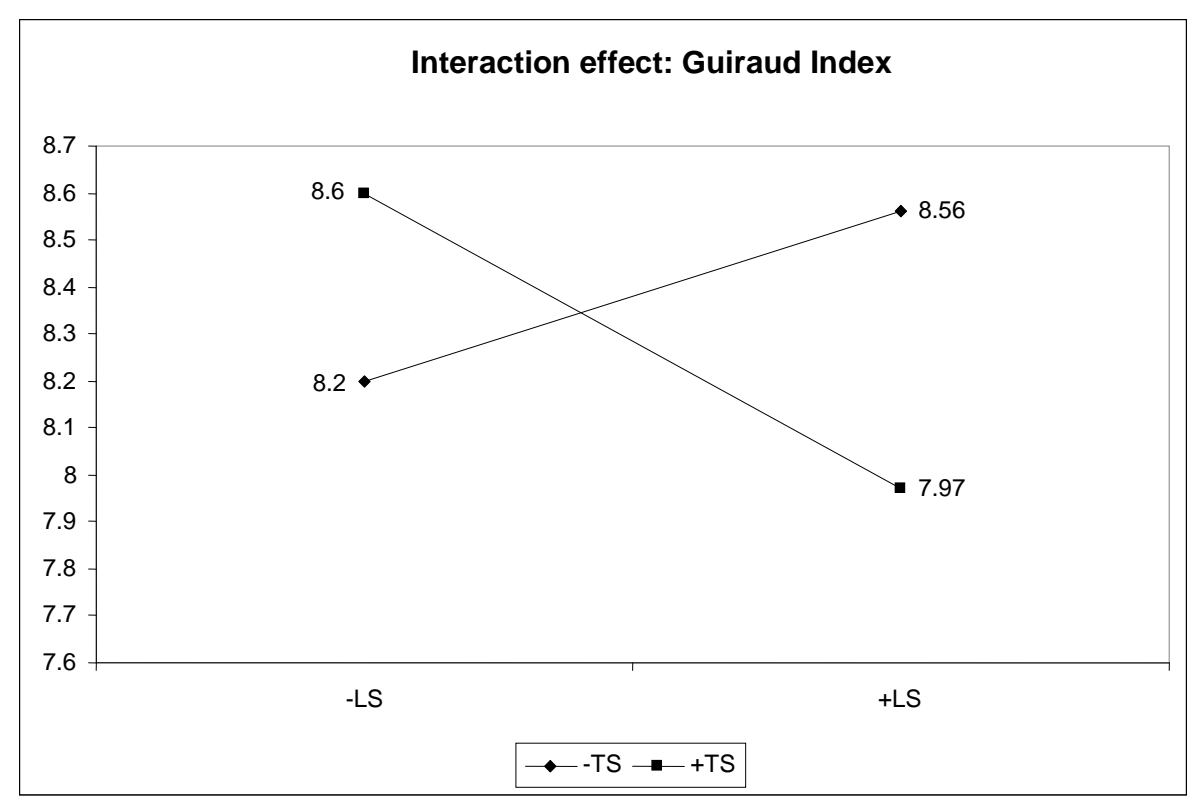

Figure 7.3 Interaction effect between TS and LS on Guiraud Index

With regard to the Guiraud Index, the interaction effect between task structure and language support suggests that when learners had no language support (-LS) material, having a +TS worksheet enabled them to produce more lexically varied words. It seems that when learners used +TS material to manage their performance their cognitive loads were decreased. This meant they tended to stretch their production and attention to produce varied lexical items. It is also possible that without language support (-LS) material the learners were less conscious of the accuracy of their language production. Therefore, they may have attended to the lexical complexity, rather than the grammatical accuracy, of their language. In contrast, when learners had +TS material that eased their processing load, also having +LS material influenced them to use the least variety of lexical items. Thus, it appears that the +LS material restricted these learners from experimenting with structural complexity and lexical varieties during the interaction.

\subsection{Summary}

To summarise the discussion above, firstly, the current study shows that cognitively simple tasks (+TS /or/ +LS) promoted more attention to language use, which resulted in more occurrences of LREs than cognitively complex tasks (-TS /or/ - LS). In addition, when learner processing demand was lowered and attention to 
their language production was heightened as they performed cognitively simple tasks, accuracy of their production was increased. On the other hand, even though providing more structure to the task did not significantly affect complexity, there was a trend towards a decrease in complexity whereas providing learners with language support significantly reduced complexity. The findings also show that a task with high task structure which represents a cognitively simple task did not significantly affect the amount of language production and equality of participation. However, a task with language support which also represents a cognitively simple task influenced the amount of language production in that it increased the production of more number of turns and decreased the number of words per turn. In spite of this significant effect, it did not influence the equality of participation.

Secondly, in regard to cognitively complex tasks (-TS /or/ -LS), the current study reveals that these tasks did not facilitate more occurrences of LREs than cognitively simple tasks (+TS /or/ +LS). Additionally, the current study found that if learner processing demand was higher and their attention to language production was lower, the accuracy of language production decreased. In contrast, although low task structure was not significantly related to complexity, there was a trend towards increasing complexity of language production. Performing the task with no language support showed a significant increase in complexity. The current study also found that quantity was not significantly affected by low task structural support, one of the factors representing cognitively complex tasks. The other factor, no language support however, affected the amount of language produced in that it reduced the number of turns and promoted more words per turn. Again, the equality of participation was not affected by cognitively complex tasks.

The findings of the current study also encompass two main points in relation to the task complexity perspective: firstly, support for the Cognition Hypothesis $(2001 b ; 2003 b ; 2005)$ was found in that the accuracy of learner language production is decreased with an increase in task complexity along the resource-dispersing dimension. Secondly, the Trade-off Hypothesis proposed by Skehan (2009) was found, whereby a decrease in accuracy is accompanied by an increase in complexity.

Finally, the findings from the current study suggest that text-SCMC is a valuable medium for L2 practicing, learning and development in two closely related ways. First, text-SCMC gave learners opportunities to focus on language because it 
allowed for off-line composing and editing. This may have freed attentional resources to focus on the accuracy of linguistic output. Secondly, text-SCMC gave learners opportunities to collaboratively construct the discourse, providing one another with immediate responses to questions about language, corrections, and other instances of focus on form. Different to pen and paper writing, text-SCMC allows for discussion of meaning and form of the composed messages during, rather than after, the composition process. This beneficial effect of using text-SCMC as the medium for L2 practice and learning can possibly be maximised with the design and use of appropriate tasks via this technology as discussed above. 


\section{CHAPTER EIGHT CONCLUSION}

\subsection{Introduction}

Chapter Seven provided the discussion of the results of the current study. In this concluding chapter, the summary of the results is reviewed along with the implications, limitations and suggestions for further research. This study used a oneshot experimental design, with learner performance investigated at one particular time. The research was carried out in a technical university in Malaysia, with second year Electrical Engineering major learners doing an English for Professional Communication course. Following a task-based approach, interactionist (Mackey \& Gass, 2006) and task complexity perspectives (Robinson, 2001b, 2003b, 2005; Skehan, 1996, 1998) served as the theoretical foundations for examining learner language production during task-based text-SCMC. The aim of the study was to determine whether and how particular ways of implementing tasks would influence learner language production.

More specifically, the current study looked at four aspects of learner language production during task performance in a text-SCMC setting: the occurrence of LREs, and the accuracy, complexity and quantity of language produced. Research has shown that manipulation of task complexity can influence learner production. However, to my knowledge when this study was conceived no research had been carried out on the effect of manipulating task complexity on task performance in a text-SCMC setting. Thus, the current research was carried out to address this gap.

\subsection{Summary of the results}

The summary of the results is presented for each of the two independent variables: task structure and language support. 
8.2.1 Summary of the effects of task structure on the dependent variables

The first part of the research question sought to determine the effects of task structure, i.e. low task structure (-TS) and high task structure (+TS), on the following dependent variables:

- Language-related Episodes (measured by LREs on meaning and LREs on form)

- Accuracy (measured by Errors/AS-unit, percentage of targetlike use of auxiliary verbs and percentage of targetlike use of modal verbs)

- Complexity (measured by Clause/AS-unit, percentage of words beyond the first 1,000 words and Guiraud index)

- Quantity (measured by number of words, number of turns, number of words/turn, entropy words and entropy turns) of learner language production.

Out of 13 measures, a significant difference was found on the following measures:

- LREs - LREs on meaning and LREs on form

- Accuracy - Errors/AS-unit and percentage of targetlike use of modal verbs.

In addition, an interaction effect was found on one of the accuracy measures, the percentage of targetlike use of auxiliary verbs.

These results revealed that, when the cognitive complexity of tasks was reduced with structural task support, more LREs were produced by the learners during their task-based text-SCMC under the +TS condition. Similarly, task performance under the +TS condition led to more accurate language. This pattern of findings suggests that learner attention to their language production is heightened when task complexity is reduced. However, there was no evidence of an effect of task structure on the complexity of language production. Additionally, all quantity measures showed non-significant findings indicating that neither the amount of language produced nor equality of participation was affected by task structure.

\subsubsection{Summary of the effects of language support on the dependent variables}

The second part of the research question attempted to determine whether the presence or absence of language support (+/-LS) affected the dependent variables 
listed in the previous section. LS was found to have significant effects on the following seven of 13 aspects of language production investigated in the research:

- LREs - LREs on meaning and LREs on form

- Accuracy - Errors/AS-unit and percentage of targetlike use of modal verbs

- Complexity - Percentage of words beyond the first 1,000 words

- Quantity - Number of turns and number of words/turn.

Interaction effects were found on three measures:

- Accuracy - Percentage of targetlike use of auxiliary verbs

- Complexity - Clause/AS-unit and Guiraud index.

First, similar to the findings for task structure, the learners produced more LREs when performing a cognitively simple task (+LS). This result suggests that attention to the quality of language use is heightened when learners have the opportunity to engage in a language-focused pre-task activity. Second, more accurate language was produced under the +LS condition than $-\mathrm{LS}$ condition. This finding also echoes the task structure findings, and suggests that decreasing the cognitive complexity of a task through task implementation may lower learners' cognitive burden, allowing them to focus on accuracy. In contrast to task structure, however, there was an effect of language support on the complexity of language production. Unlike accuracy and LREs, the complexity of learner language production increased when the learners performed a cognitively complex task (-LS). Finally, in terms of quantity, more turns but fewer words per turn were produced when the learners performed an interactive simple task (+LS) than when the learners performed an interactive complex task (-LS). The equality of participation, however, was not affected by language support as evident in the non-significant findings, providing further evidence that manipulating task implementation variables to focus attention on accuracy and complexity did not undermine the equality of learner participation described in previous studies of text-SCMC (Böhlke, 2003; Lim \& Sudweeks, 2006). Overall, the results indicate trade-off effects associated with providing language-focused pre-task activities. In this study, such support led to more LREs and heightened attention to the accuracy of language production. This, however, was at the expense of language complexity. 


\subsection{Theoretical implications}

On a theoretical level, the current study helps to broaden the application of SLA research by applying theories on task complexity and language production to the medium of SCMC. The Cognition Hypothesis (Robinson, 2001b, 2003b, 2005) proposed that when tasks are made complex along the resource-dispersing variable, learners' attentional and memory resources will be mostly dedicated to procedural demands of the task and not to any aspects of linguistic system. This factor imposes high cognitive demands on the part of learners. As the learners' attention is dispersed, their language production, particularly accuracy, complexity and fluency, is expected to degrade.

In the current study, in the -TS condition, the accuracy of language production was reduced. In the -LS condition, similar effect on accuracy was evident, however, the complexity of language production was increased. As such, the finding provides an evidence for the Cognition Hypothesis with regards to accuracy. On the other hand, the finding does not confirm the prediction made by the Cognition Hypothesis in regards to complexity. In this regard, the Trade-off Hypothesis (Skehan, 2009) in which language learners' limited attentional resources force them to prioritise their processing capacity to one or some aspects of language production (i.e. fluency or accuracy or complexity) at the expense of others is clearly supported.

The findings support the interactionists' claim that task-based learner interaction encourages learners to attend to form and thereby facilitates language learning (Adams, 2007; Loewen, 2005). The current study also found that focus on form (as evident in the occurrences of LREs) could be encouraged through manipulating task complexity. Therefore, the claim by Swan (2005) that a taskbased approach induces learners' preoccupation with finishing a task resulting in minimal use of language and little attention to language production is refuted. In the current study, manipulating task complexity through varying task structure and language-oriented planning time demonstrated that task conditions can influence the way that learners attend to language during a task. This indicates that under certain task conditions, learners may be more likely to attend to their language production (particularly accuracy) while successfully completing the task. The developmental 
benefits of interactive tasks in text-SCMC contexts may therefore be maximized through careful attention to talk implementation.

\subsection{Pedagogical implications}

The current study provides further insights into the pedagogic use of tasks via text-SCMC in language learning and teaching. These findings show that, in the absence of paralinguistic features of face-to-face communication, carefully structuring and supporting the task performance in text-SCMC may reduce online processing demands and thus free up processing capacity for attention to linguistic aspects of language production. Without structural support, learners' cognitive demand may be higher because they must focus their attention simultaneously on production and discourse management. Therefore, in the context of L2 learning in text-SCMC, when lessons are designed to address a grammatical focus, teachers may need to consider simplifying the cognitive complexity of the task by providing learners with, for example, appropriate structural task support.

In addition, the results show that the use of language support is likely to heighten learner attention to the quality of their language production during taskbased text-SCMC. Therefore, teachers who want to use text-SCMC as the medium for their learners to practice L2 learning may provide the learners with pre-task language support to enhance both attention to specific forms and attention to global accuracy. Such support may also be helpful in decreasing task complexity, freeing up learner processing capacity, and allowing learners to monitor their language accuracy, particularly in a hybrid communication setting as in text-SCMC.

The findings also indicate that more complex language was produced by the learners without the language support. As explained earlier, the focus of the language support was the targetlike use of two grammatical items- auxiliary verbs and modal verbs. These materials may have been more likely to promote attention to accuracy than complexity of language use. It is possible that designing language support activities where learners are focused on how to use structurally and lexically complex language may lead to different results. If complex production is a pedagogical goal, teachers may want to draw attention to different sentence structures or lexical items. This might orient learners to use them during the task 
performance. It is possible that the patterns of effects found in this study are more related to the nature of language support provided here, rather than language support per se. Future research could determine whether different focus of language support might influence production differently, as described in Section 8.5 below.

It should however be noted that, with both resource-dispersing variables investigated in the current study, the findings reveal that manipulating cognitive complexity of tasks was unlikely to influence syntactic complexity. However, more accurate production was likely when simpler tasks were used. The learners who had the task structure and language support materials also commented on being able to focus on forms. This may suggest that manipulating these two variables of task complexity in text-SCMC setting is more likely to promote language practice for accuracy rather than complexity.

While task implementation impacted on the amount of focus-on-form, it should be noted that LREs were found in all treatment conditions. The quality of the LREs suggested that features of text-SCMC may be beneficial for promoting focus on form. Text-SCMC provides the opportunity for learners to reflect on their language use because they could view and edit messages before posting, and review them visually following posts. Therefore, it should be noted that without language support, this visual factor itself may have pushed the learners to be more accurate in their language production. As such, these findings provide evidence for text-SCMC as a medium for learning of form during communicative practice.

Prior research on interaction in text-SCMC has indicated that this is a positive forum for promoting learner participation because of lowered anxiety (Cheon, 2003; Fitze, 2006). The current study also provides evidence that performing tasks via text-SCMC may lower the learners' anxiety level as manifested in equal distribution of talk within teams regardless of the treatment conditions. As seen in the previous chapter, some learners commented that in contrast with face-toface, text-SCMC is a more conducive place for L2 learning. In this sense, learners who feel inhibited may gradually gain more confidence to embark on communication in the target language if they are given more time to practicing the language using text-SCMC.

This study examined group performances of a single task. In instructional settings, however, post-task activities could also be used to extend the benefits of 
task practice. For example, instructors could use the text chat transcripts as learning materials by asking the students to re-examine and revise their L2 production based on their own text chat exchanges. Such reflections might encourage learners to monitor their own learning and notice their target language gaps, and may create a sense of responsibility for their own learning. Tasks conducted in text-SCMC may also be helpful in instructional settings, as the electronic form of the text chat transcripts enables instructors to have easy access to learner production, readily available for observation of the growth of learners' language competence over time.

\subsection{Limitations and suggestions for further research directions}

Generalisations based on the findings of this study are limited in several areas. Acknowledging these limitations, a few suggestions can be made for future research. Firstly, the number of learners that participated in the study was relatively small for the statistical data. This is clearly evident in the power analysis of each MANOVA test, i.e. the power for each test is below 0.8. Future studies may need to increase the sample sizes for each cell to enhance external validity.

Secondly, the nature of the language support variable in the current study may have led to it functioning in ways that were contrary to my prediction. Because language support targeted specific linguistic features (auxiliary verbs and modal verbs) rather than decreased task complexity as I predicted, it may have actually increased it. This effect is possible because in addition to providing language resources for the task it may have also inadvertently encouraged a greater focus on grammatical accuracy in using the given target forms. In this case, rather than simplifying the task as initially predicted, language support may have made the task more complex. The effect of different instantiations of language support on task complexity therefore warrants further investigation.

Thirdly, the current study manipulated only two task complexity variables within the text-SCMC setting. Future studies should manipulate other task complexity variables not only within the text-SCMC setting but also in various technology-enhanced language learning media. In addition, these two task complexity variables were derived from the resource-dispersing variables under the Triadic Componential Framework (Robinson, 2007b). Future studies may look into 
the option of combining multiple variables from resource-directing as well as resource-dispersing variables on tasks conducted in CMC.

Next, the current study manipulated task structure in an interactive task. In addition, this was done in text-SCMC. Previous task complexity studies, on the other hand, typically manipulated task structure in monologic tasks and in a face-toface setting. Thus, it may be worthwhile to conduct a comparative study between these two tasks performed in these two mediums.

In addition to the above limitations and suggestions, it should be noted that the nature of the current study in which the participants engaged in the task only once limited the focus to L2 production and not development. Future research could include long-term data from the different task implementation features which would allow for a more definite conclusion regarding the effects of task complexity on production as well as on learning opportunities.

Finally, the current study was carried out in a foreign language context, where the majority of the learners share a common L1 with a somewhat similar proficiency level. Prior research on task-based text-SCMC among foreign language learners has indicated that they may tend to rely on L1-based strategies in communication (c.f., Nik \& Adams, 2009). Learners' engagement with the task may have been different if they interact in a multilinguistic environment or in mixed language ability groups. Future studies could use participants with a mix of L1 backgrounds and different proficiency levels to determine the generalisability of these findings.

\subsection{Conclusion}

The current study has provided further empirical evidence for the value of a task-based approach to second language learning. It shows that learner-learner interaction while performing tasks provided opportunities for learners to talk about and monitor the language they use. In addition, the current study provides further evidence for the effect of task conditions on the accuracy and complexity of language produced by learners performing pedagogic tasks (Michel, et al., 2007; Yuan \& Ellis, 2003). The current study also demonstrates that high structural task support as well as drawing learner attention to form during task performances 
increases linguistic accuracy (Ellis, 2002, 2003; Loewen, 2003). This research both extends prior concepts to text-SCMC, providing evidence that text-SCMC tasks can be optimized to promote focus on form. Thus, the current study suggests that investigating how to design and implement tasks to be used in the technologyenhanced language learning tools, in this case text-SCMC, is a worthwhile challenge.

Finally, the current study shows that the roles of the computer need not be limited to that of a supplementary instructional tool in L2 learning and teaching. On the contrary, the findings confirm the value of task-based text-SCMC as a context for equal participation which increases learner motivation (Coniam \& Wong, 2004; Fitze, 2006; Freiermuth \& Jarell, 2006), and suggest how they can be optimized to promote attention to form and accuracy in production. This implies that L2 communication via computer may serve as an effective medium for L2 practice as exemplified by the use of text-SCMC in the current study. 


\section{APPENDIX A \\ INFORMATION SHEET AND CONSENT FORM}

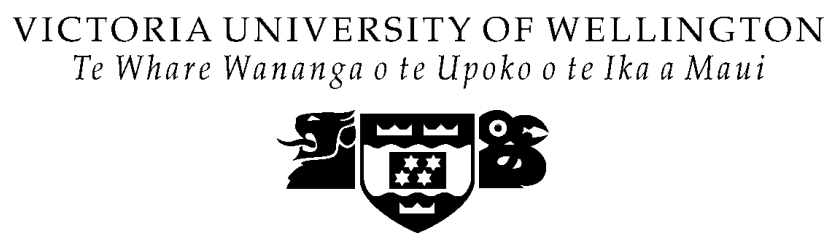

Task-based approach in synchronous computer-mediated communication: Implications for second language learning and teaching

\section{Information Sheet}

Greetings! I am a PhD student in Applied Linguistics at Victoria University of Wellington, New Zealand. I am investigating the influence of the problem-based tasks and computer-mediated communication on second language teaching and learning. I am inviting you to take part in my study. You will be asked to participate in a 45-minute internet-based activity in a small group. You will also be asked to complete a questionnaire and might be interviewed about the activity. Your participations will not influence your grades in English class in any way.

Your personal identity will be protected and pseudonyms will be used in presenting the findings. Only my supervisors and myself will have access to the data. It is expected that the research findings will be reported in scholarly publications and conferences. A brief report of the findings will be given to the University College of Engineering \& Technology Malaysia and the Ministry of Education.

Your participation is totally voluntary and hence, you may withdraw from participating in this study now or at any time during the study should you feel the need to do so.

If you have any question, please ask me now or kindly contact me later at nita.alwi@vuw.ac.nz. This research has been approved by the Victoria University of Wellington Human Ethics Committee.

Thank you! 
Researcher:

NIK ALOESNITA NIK MOHD ALWI

School of Linguistics and Applied Language Studies,

Victoria University of Wellington,

P.O. Box 600, Wellington,

New Zealand, 6001.

Tel: 0064044635233 (ext. 8678)

E-mail: nita.alwi@vuw.ac.nz

Supervisors:

JONATHAN NEWTON (PhD.)

School of Linguistics and Applied Language Studies,

Victoria University of Wellington,

P.O. Box 600, Wellington,

New Zealand, 6001.

Tel: 0064044635622

E-mail: jonathan.newton@vuw.ac.nz

REBECCA ADAMS (PhD.)

School of Linguistics and Applied Language Studies,

Victoria University of Wellington,

P.O. Box 600, Wellington,

New Zealand, 6001.

Tel: 0064044635625

E-mail: rebecca.adams@vuw.ac.nz 


\section{Task-based approach in synchronous computer-mediated communication: Implications for second language learning and teaching}

\section{Consent Form}

Please tick the appropriate box to show that you agree to take part in this study:

I have read and clearly understood the information found in the Information Sheet. I am also aware of the time needed from me to participate in this study. I agree to my chat exchanges to be saved in an electronic form as long as my identity is kept secured to the researcher and her supervisors. Besides, I understand that my participation will in no way affect the grade or classroom assessment for my English for Professional Communication course.

I understand that the research findings will be reported in scholarly publications and conferences. A brief report of the findings will be given to the University College of Engineering \& Technology Malaysia and the Ministry of Education.

I have been provided with sufficient descriptions about this project and I am satisfied with the explanations.

I agree to take part in the study. $\quad$ Yes $\square \quad$ No

Signed:

Name of participant:

Date:

March 2006

I would like to receive a brief summary of the findings after the research has been completed. Please send it to the following address: 


\section{APPENDIX B \\ UNSTRUCTURED INTERVIEW QUESTIONS}
VICTORIA UNIVERSITY OF WELLINGTON
Te Whare Wananga o te Upoko o te Ika a Maui

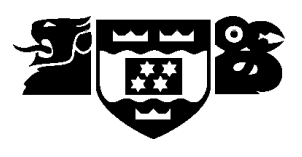

Task-based approach in synchronous computer-mediated communication: Implications for second language learning and teaching

\section{Interview Questions}

The information from the interview questions will be used for this research only. All information will be treated in a confidential manner.

1. What was going on here?

2. Why didn't you attend/ respond to this query?

3. Did you understand what he meant here?

4. Why did you decide to go on with the conversation although you didn't totally understand what he meant?

5. How did you know that was what he meant here? Were there any clues or hints?

6. Did you notice that your response was delayed here? Why did it happen?

7. Why didn't you seek for further explanation/ clarification earlier on?

8. Did you notice any grammatical errors here? Why didn't you correct the errors? 


\section{APPENDIX C}

\section{TASK}

\section{Student A}

\section{Background}

This is a virtual meeting conducted via a chat room on Tuesday, $21^{\text {st }}$ March 2006, at 14:00:00 GMT. Note that the attendees are located at different time zones.

A - An engineer based in Kuala Lumpur (Wed 14:00:00 GMT)

B - An engineer based in Tokyo (Wed 15:00:00 GMT)

$\mathrm{C}-$ An engineer based in Bangkok (Wed 13:00:00 GMT)

D - An engineer based in Helsinki (Wed 09:00:00 GMT)

You are an electrical engineer at a multinational company, Diamond Circuit Ltd. You are based at its headquarters in Kuala Lumpur. The company has other branches located at Bangkok, Tokyo, and Helsinki. Since the company is growing, it has to be equipped with more advanced facilities, among which are various types of electrical engineering software for electrical designs, simulations and analyses as well as for technical diagramming and drafting. Other possible benefits for the company of having more and up-to-date software are to ensure the company incorporates new technologies in a rapidly growing range of applications, to integrate current computer systems with new and more mobile technology and to increase network security by installing the new, latest software.

You and three of your colleagues have been asked by the CEO to select an optimal software package that meets the following criteria: its practicality, utilization and cost. You must meet online to discuss the options and have a report ready by $5 \mathrm{pm}$.

Each of you is familiar with a different kind of software from your previous experience. Hence, each colleague has his/her own software option to propose. Your software to propose is $\operatorname{OrCAD}$. Based on your experience at your previous company, it is easy to learn $\operatorname{OrCAD}$ as it perfectly handles DOS, UNIX and MAC text file formats. However, the typical difficulty you used to face was the confusion 
when using the datasheet graphs for filing the specs details whether to convert the Log scale into a linear scale and then insert the values or should straight away insert the numbers as per the Log scale.

\section{Your software}

OrCAD has the following technical descriptions:

- Core design tasks: Schematic and VHDL-based design entry, FPGA and CPLD design synthesis; digital, analog, and mixed-signal simulation and printed circuit board layout

- The online demo provides all the features and functionality of the actual software, 10am-3pm online helpdesk available. Purchase comes with comprehensive manual written in more than 10 languages

- Compatible with either Microsoft or Linux operating system

- Less time spent on the details of tool integration, devising workarounds, and manually entering data to keep files in sync

- $\mathrm{RM}$ 2, 500 for 10 licenses

\section{Your task}

You task is to meet online with your colleagues and decide together which software to recommend to your CEO. To do this, you will need to listen to, compare and contrast each other's proposal. You and your colleagues will agree on a ranking of the software. The software should be ranked from most appropriate to least appropriate for your company by filling in Sheet A.

It is your responsibility to promote your software by communicating effectively. Following the task, you will rate each other based on the criteria of effective communications found in Sheet C.

Although you will simulate a virtual meeting environment, the focus of the discussion should only be about the task mentioned. You are permitted to surf any relevant website to look for additional resources to support your arguments or to argue against your colleagues' opinions. Remember that you will need to submit Sheet A to the CEO. Note that you have to complete the task within 45 minutes. 


\section{Student B}

\section{Background}

This is a virtual meeting conducted via a chat room on Tuesday, $21^{\text {st }}$ March 2006, at 14:00:00 GMT. Note that the attendees are located at different time zones.

A - An engineer based in Kuala Lumpur (Wed 14:00:00 GMT)

B - An engineer based in Tokyo (Wed 15:00:00 GMT)

$\mathrm{C}$ - An engineer based in Bangkok (Wed 13:00:00 GMT)

D - An engineer based in Helsinki (Wed 09:00:00 GMT)

You are an electrical engineer at a multinational company, Diamond Circuit Ltd. You are based at one of the branches, i.e. Tokyo. Its headquarters is in Kuala Lumpur and its other branches are located in Bangkok and Helsinki. Since the company is growing, it has to be equipped with more advanced facilities, among which are various types of electrical engineering software for electrical designs, simulations and analyses as well as for technical diagramming and drafting. Other possible benefits for the company of having more and up-to-date software are to ensure the company incorporates new technologies in a rapidly growing range of applications, to integrate current computer systems with new and more mobile technology and to increase network security by installing the new, latest software.

You and three of your colleagues have been asked by the CEO to select an optimal software package that meets the following criteria: its practicality, utilization and cost. You must meet online to discuss the options and have a report ready by $5 \mathrm{pm}$.

Each of you is familiar with a different kind of software from your previous experience. Hence, each colleague has his/her own software option to propose. Your software to propose is $M A T L A B$. Based on your experience, it is useful to use $M A T L A B$ because it is not only a tool for doing numerical computations with matrices and vectors, it also can display information graphically. However, you are not sure whether or not it works on Linux. 


\section{Your software}

$M A T L A B$ has the following technical descriptions:

- Interactive system and programming language for general scientific and technical computation and visualization.

- Basic data element: matrix. The commands: similar to that used in mathematics and engineering.

- Quicker than programming in a high-level language.

- Hundreds of built-in functions with optional "toolboxes" of functions for specific purposes which are written in the MATLAB language. Readable source code for users to personally deal with any troubleshooting.

- Works on PC, Macintosh, and NEC personal computers, Sun, DEC, HP, IBM, and SGI workstations, VAX minicomputers, and Convex and Cray supercomputers.

- $\mathrm{RM}$ 4, 000 annual fees for 50 licenses

\section{$\underline{\text { Your task }}$}

You task is to meet online with your colleagues and decide together which software to recommend to your CEO. To do this, you will need to listen to, compare and contrast each other's proposal. You and your colleagues will agree on a ranking of the software. The software should be ranked from most appropriate to least appropriate for your company by filling in Sheet A.

It is your responsibility to promote your software by communicating effectively. Following the task, you will rate each other based on the criteria of effective communications found in Sheet C.

Although you will simulate a virtual meeting environment, the focus of the discussion should only be about the task mentioned. You are permitted to surf any relevant website to look for additional resources to support your arguments or to argue against your colleagues' opinions. Remember that you will need to submit Sheet A to the CEO. Note that you have to complete the task within 45 minutes. 


\section{Student C}

\section{Background}

This is a virtual meeting conducted via a chat room on Tuesday, $21^{\text {st }}$ March 2006, at 14:00:00 GMT. Note that the attendees are located at different time zones.

A - An engineer based in Kuala Lumpur (Wed 14:00:00 GMT)

B - An engineer based in Tokyo (Wed 15:00:00 GMT)

$\mathrm{C}$ - An engineer based in Bangkok (Wed 13:00:00 GMT)

D - An engineer based in Helsinki (Wed 09:00:00 GMT)

You are an electrical engineer at a multinational company, Diamond Circuit Ltd. You are based at one of the branches, i.e. Bangkok. Its headquarters is in Kuala Lumpur and its other branches are located in Tokyo and Helsinki. Since the company is growing, it has to be equipped with more advanced facilities, among which are various types of electrical engineering software for electrical designs, simulations and analyses as well as for technical diagramming and drafting. Other possible benefits for the company of having more and up-to-date software are to ensure the company incorporates new technologies in a rapidly growing range of applications, to integrate current computer systems with new and more mobile technology and to increase network security by installing the new, latest software.

You and three of your colleagues have been asked by the CEO to select an optimal software package that meets the following criteria: its practicality, utilization and cost. You must meet online to discuss the options and have a report ready by $5 \mathrm{pm}$.

Each of you is familiar with a different kind of software from your previous experience. Hence, each colleague has his/her own software option to propose. Your software to propose is Automation Studio. Based on your experience, it is useful to use Automation Studio because whenever a problem arises, it is easy and simple to troubleshoot with the assistance from the 9am-5pm online helpdesk. However, the CD that contains the Protection Key has to be securely kept. One of the colleagues at your previous company misplaced the $\mathrm{CD}$ and he had to spend a huge amount of his own pocket money to purchase the new complete package. 


\section{Your software}

Automation Studio has the following technical descriptions:

- Innovative schematic capture, simulation and project documentation software package for automation and fluid power systems design

- Application-oriented tool for integrators, OEMs, engineers and instructors

- Works only on PC

- Additional editing software is not needed - provides component libraries, drawing tools, basic shapes and elements to create special or complex symbols and to customize diagrams and project templates

- Features include: Design, document, simulate and animate circuits consisting of various automation technologies including Pneumatics, Hydraulics, PLCs, Sequential Function Charts (SFC), Electrical Controls

- RM 3, 250 for 10 licenses, to be renewed every 5 years

\section{Your task}

You task is to meet online with your colleagues and decide together which software to recommend to your CEO. To do this, you will need to listen to, compare and contrast each other's proposal. You and your colleagues will agree on a ranking of the software. The software should be ranked from most appropriate to least appropriate for your company by filling in Sheet A.

It is your responsibility to promote your software by communicating effectively. Following the task, you will rate each other based on the criteria of effective communications found in Sheet C.

Although you will simulate a virtual meeting environment, the focus of the discussion should only be about the task mentioned. You are permitted to surf any relevant website to look for additional resources to support your arguments or to argue against your colleagues' opinions. Remember that you will need to submit Sheet A to the CEO. Note that you have to complete the task within 45 minutes. 


\section{Student D}

\section{Background}

This is a virtual meeting conducted via a chat room on Tuesday, $21^{\text {st }}$ March 2006, at 14:00:00 GMT. Note that the attendees are located at different time zones.

A - An engineer based in Kuala Lumpur (Wed 14:00:00 GMT)

B - An engineer based in Tokyo (Wed 15:00:00 GMT)

$\mathrm{C}-$ An engineer based in Bangkok (Wed 13:00:00 GMT)

D - An engineer based in Helsinki (Wed 09:00:00 GMT)

You are an electrical engineer at a multinational company, Diamond Circuit Ltd. You are based at one of the branches, i.e. Helsinki. Its headquarters is in Kuala Lumpur and its other branches are located in Tokyo and Bangkok. Since the company is growing, it has to be equipped with more advanced facilities, among which are various types of electrical engineering software for electrical designs, simulations and analyses as well as for technical diagramming and drafting. Other possible benefits for the company of having more and up-to-date software are to ensure the company incorporates new technologies in a rapidly growing range of applications, to integrate current computer systems with new and more mobile technology and to increase network security by installing the new, latest software.

You and three of your colleagues have been asked by the CEO to select an optimal software package that meets the following criteria: its practicality, utilization and cost. You must meet online to discuss the options and have a report ready by $5 \mathrm{pm}$.

Each of you is familiar with a different kind of software from your previous experience. Hence, each colleague has his/her own software option to propose. Your software to propose is Max+Plus II. You have searched through various websites and found that Max+Plus II is the most suitable option as it offers 24 hour online customer support service. The only problem with it is that it is intended only for legacy design support. 


\section{Your software}

Max+Plus II has the following technical descriptions:

- A fully integrated programmable logic design environment. Easy-to-use tool supports the Altera ${ }^{\circledR}$ FLEX ${ }^{\circledR}$ and MAX ${ }^{\circledR}$ programmable device families

- Works perfectly well in both PC and UNIX environments

- Offers unmatched flexibility and performance and allows for seamless integration with industry-standard design entry, synthesis, and verification tools.

- Minimizes re-design work by giving design entry freedom and the ability to mix and match design entry methodologies

- Features include: Graphic Editor, Symbol Editor, Waveform Editor, Text Editor (with AHDL or VHDL templates), Compiler, Simulator, Timing Analyzer

- RM 8, 000 yearly fees, discounted price for purchased of more than 100 licenses

\section{Your task}

You task is to meet online with your colleagues and decide together which software to recommend to your CEO. To do this, you will need to listen to, compare and contrast each other's proposal. You and your colleagues will agree on a ranking of the software. The software should be ranked from most appropriate to least appropriate for your company by filling in Sheet A.

It is your responsibility to promote your software by communicating effectively. Following the task, you will rate each other based on the criteria of effective communications found in Sheet C.

Although you will simulate a virtual meeting environment, the focus of the discussion should only be about the task mentioned. You are permitted to surf any relevant website to look for additional resources to support your arguments or to argue against your colleagues' opinions. Remember that you will need to submit Sheet A to the CEO. Note that you have to complete the task within 45 minutes. 


\section{APPENDIX D \\ LANGUAGE SUPPORT MATERIALS}

\section{MODAL VERBS}

\section{Modal verbs: Pre-task activities}

\section{Activity 1: Awareness}

The following is a dialogue between two friends, Kate and Zack who are discussing purchasing the software they will need to use for a course on "Technical Diagramming and Drafting Solutions" next week. It is late at night in the weekend, and the discussion is carried out via the chatroom.

Instructions: Read the following and underline the modals and the verb following them.

Zack: Hi there!

Kate: Oh, hi Zack! I've been busy browsing the net to look for the software for EEE 3113. Remember? We need to use it on Monday, so we must purchase it by tomorrow.

Zack: Yup, that's why I'm also browsing the net. What have you found so far?

Kate: Zesty Tech. \& Evo (ZTE). You might have heard about it.

Zack: Is it the latest version of technical diagramming and drafting solutions software?

Kate: Yes, indeed! ZTE has thousands of built-in, discipline specific for "Wonderful Contours" objects for all technical diagramming and drafting applications.

Zack: What does "Wonderful Contours" do?

Kate: More than 10,000 "Wonderful Contours" objects are organised into taskspecific SubjectVoyager catalogues. It enables the users to have immediate access to the content.

Zack: Could you explain further? 
Kate: "Wonderful Contours" objects are built with the intelligent technology to automatically align, connect and resize the drawings faster... and it is codeveloped by the industry-expert partners.

Zack: That's cool! But is it user-friendly?

Kate: Sure, it is! ZTE is the easiest drawing, diagramming and data visualisation tool for creating site and space plans, building services, factory floors and office layouts as well as network and security diagrams.

Zack: What else could it $\underline{\text { do}}$ ?

Kate: It could help the users to plan, design, construct, operate, maintain, modify, retrofit and upgrade the facility.

Zack: Ok, that means the users can evaluate alternative assembly line configurations for peak performance, track assets during staffing of a major project and allocate office space in an office complex. That sounds amazing! But how much is it?

Kate: I'm not too sure about the price. However, we can probably purchase it at an affordable price. So, have you now decided to purchase ZTE?

Zack: What do you think?

Kate: I'd say yes... What about you?

Zack: Hmmm, probably yes...

Kate: Excellent! Shall we go to the shop tomorrow?

Zack: Yup, could you wait for me at the bus stop near College C?

Kate: Ok, I'll see you there at about 10am.

Zack: See you then. Good night!

Kate: Night! 


\section{Activity 2: Explicit grammar focus}

Modals express a wide range of meanings; for example, expressing the ability, possibility, permission, necessity and politeness. Examples of modals are:

\begin{tabular}{|c|c|c|}
\hline Modals & Degree of certainty & Examples \\
\hline $\begin{array}{l}\text { Can't / couldn't } \\
\text { Can / could }\end{array}$ & Most uncertain $-0 \%$ & $\begin{array}{l}\text { I can't be there. } \\
\text { I can be there. }\end{array}$ \\
\hline $\begin{array}{l}\text { May / may not } \\
\text { Might / might not }\end{array}$ & & $\begin{array}{l}\text { I may be there. } \\
\text { I might not be there. }\end{array}$ \\
\hline $\begin{array}{l}\text { Must / must not } \\
\text { Shall / shall not } \\
\text { Should / should not }\end{array}$ & $50 \%$ of certainty & $\begin{array}{l}\text { I must be there. } \\
\text { I shall not be there. } \\
\text { I shouldn't be there. }\end{array}$ \\
\hline $\begin{array}{l}\text { Will / will not } \\
\text { Would / would not }\end{array}$ & Most certain $-100 \%$ & $\begin{array}{l}\text { I will be there. } \\
\text { I wouldn't be there. }\end{array}$ \\
\hline
\end{tabular}

Modal verb forms:

1. Modals do not have an - s form

Example: The software might work on various platforms

NOT The software mights work on various platforms

2. Use a base form for the next verb

Example: We should proceed with our discussion

NOT We should proceeds with our discussion

Exercise: Underline the correct answer.

At a computer shop:

Salesman: Hello. Is there anything I can help you with today?

Amalina: I'm looking for a software for engineering calculations. Is there anything you (could suggest / could suggests)?

At a hostel:

Aryssa: Dilla, I'm thinking about attending a training on MATLAB I. What do you think?

Dilla: $\quad$ As far as I'm concerned, MATLAB I is the basic version. I (would suggest / may suggest) a training on MATLAB II. 
During tutorial session:

Rex: $\quad$ (Could / coulds) you please explain what OHM's law is?

Tutor: Basically, it is a simple relationship that exists between voltage, current, and resistance in electrical circuits. Understanding this relationship is important for fast, accurate electrical problem diagnosis and repair. 


\section{Activity 3: Production}

The following is a dialogue between three friends who are doing a Bachelor's degree in Electrical and Electronic Engineering. Sara, Harry and Anna are discussing purchasing the software they will need to use for a course on "Electronic Circuits" next semester. Since this is a semester break, the discussion is done via the chatroom as everybody is in his/her hometown.

Instruction: Complete the dialogue with the appropriate modal verbs.

Harry: Shall we discuss the software that we need to purchase for the "Electronic Circuits" course next semester?

Sara: Hmmm, I don't really have much of an idea at the moment.

Harry: Well, we should choose (choose) the best software available in the market. Anna: Yup, I agree but we have to consider the price too.

Harry: My suggestion would be (be) GeniusBoardCircuit. Have you heard about it?

Sara: I heard that the software is quite expensive. It's the latest version for the digital circuit drawings isn't it?

Harry: Probably yes, but if we purchase it in bulk the company may offer (offer) us a discounted price.

Sara: Let's put the price aside first. Let's not talk about the price first. We should find (find) a software which is user-friendly.

Harry: Well, GeniusBoardCircuit includes a simulated Trainer. So, we can still continue (continue) doing our work in situations when the trainers are not available.

Sara: How could that be (be) possible?

Harry: The software uses a unique metaphor to construct digital circuits on the computer screen rather than on a real "breadboard" with power supply...

Anna: So, the users will receive (receive) an immediate feedback as they design, test and modify the project based on the results displayed on the computer screen...

Sara: Wow! I would say (say) that is impressive!

Harry: Exactly! 
Sara: Can it work (work) on both Microsoft and Linux based OS?

Anna: Yes, it can.

Harry: It looks like it is the most suitable software! Have we decided on it?

Anna: Shall we give (shall, give) ourselves a week to think about it?

Harry: Ok, I agree.

Sara: Yup, me too.

Harry: See you guys next week. 


\section{Modal verbs: Language notes}

\section{Modal verbs forms}

1. Modals do not have an $-\mathrm{s}$ form

Example: The software might work on various platforms

NOT The software mights work on various platforms

2. Use a base form for the next verb

Example: We should proceed with our discussion

NOT We should proceeds with our discussion 


\section{Using modal verbs}

\begin{tabular}{|c|c|c|}
\hline Modal & Situation & Example \\
\hline Must & $\begin{array}{l}\text { When you feel sure that } \\
\text { something is true }\end{array}$ & Sean must be tired waiting for the feedback. \\
\hline $\begin{array}{l}\text { Need to } \\
\text { Have to } \\
\text { (should / } \\
\text { must) }\end{array}$ & $\begin{array}{l}\text { When it is necessary to } \\
\text { do something }\end{array}$ & $\begin{array}{l}\text { Our company is small. We need to consider } \\
\text { the cost. } \\
\text { Students have to read more to understand the } \\
\text { Ohm's law. }\end{array}$ \\
\hline \multirow[t]{4}{*}{ Should } & $\begin{array}{l}\text { When you give advice / } \\
\text { opinion }\end{array}$ & $\begin{array}{l}\text { You should be more careful when operating the } \\
\text { system. }\end{array}$ \\
\hline & $\begin{array}{l}\text { When you feel it is a } \\
\text { good / right thing to do }\end{array}$ & $\begin{array}{l}\text { We should recommend the best software } \\
\text { regardless its price. }\end{array}$ \\
\hline & $\begin{array}{l}\text { When you expect } \\
\text { something to happen }\end{array}$ & $\begin{array}{l}\text { The chairperson receives an emergency call. } \\
\text { The meeting should end soon. }\end{array}$ \\
\hline & $\begin{array}{l}\text { When something is not } \\
\text { right / what you } \\
\text { expected }\end{array}$ & $\begin{array}{l}\text { They wonder where the lab assistant is. He } \\
\text { should be in the lab an hour ago. }\end{array}$ \\
\hline \multirow[t]{2}{*}{$\begin{array}{l}\text { Can } \\
\text { Could }\end{array}$} & $\begin{array}{l}\text { When something is } \\
\text { possible }\end{array}$ & $\begin{array}{l}\text { CX-Programmer can be used for programming } \\
\text { OMRON PLC. }\end{array}$ \\
\hline & $\begin{array}{l}\text { When somebody has the } \\
\text { ability to do something }\end{array}$ & $\begin{array}{l}\text { Adam could draw complicated circuit by using } \\
\text { the analogue drawing system. }\end{array}$ \\
\hline \multirow[t]{2}{*}{$\begin{array}{l}\text { May } \\
\text { Might }\end{array}$} & $\begin{array}{l}\text { When something is a } \\
\text { possibility }\end{array}$ & Students may ask question later. \\
\hline & $\begin{array}{l}\text { Possible actions or } \\
\text { happening in the future }\end{array}$ & $\begin{array}{l}\text { He might teach me how to install the software } \\
\text { in MAC. }\end{array}$ \\
\hline $\begin{array}{l}\text { Will } \\
\text { Shall }\end{array}$ & $\begin{array}{l}\text { When offering / } \\
\text { agreeing / promising / } \\
\text { asking somebody to do } \\
\text { something }\end{array}$ & I shall help you with the technical drawing. \\
\hline $\begin{array}{l}\text { Would } \\
\text { (can / } \\
\text { could) }\end{array}$ & $\begin{array}{l}\text { When requesting / } \\
\text { offering / giving } \\
\text { permission / offering / } \\
\text { inviting }\end{array}$ & I would like to assist the students. \\
\hline
\end{tabular}




\section{AUXILIARY VERBS}

\section{Auxiliary verbs: Pre-task activities}

\section{Activity 1: Awareness}

The following is a dialogue between two friends, Evan and John, who are discussing purchasing the software they will need to use for a course on "Technical Diagramming and Drafting Solutions" next week. It is late at night in the weekend, and the discussion is carried out via the chatroom.

Instructions: Read the following and underline the auxiliary verbs.

Evan: Hi John! Are you browsing the net for the software to be used in EEE 3113?

John: Yup. Have you found anything?

Evan: I've found Zesty Tech. \& Evo (ZTE). It has thousands of built-in, discipline specific "Wonderful Contours" objects for all technical diagramming and drafting applications.

John: How does "Wonderful Contours" work?

Evan: More than 10,000 "Wonderful Contours" objects are organised into taskspecific SubjectVoyager catalogues. It enables the users to have immediate access to the content.

John: Could you explain further?

Evan: "Wonderful Contours" objects are built with the intelligent technology to automatically align, connect and resize the drawings faster... and it is also co-developed by the industry-expert partners.

John: That's cool! But is it user-friendly?

Evan: Sure, it is! ZTE is the easiest drawing, diagramming and data visualisation tool for creating site and space plans, building services, factory floors and office layouts as well as network and security diagrams.

John: That sounds amazing! But how much is it?

Evan: I'm not too sure about the price. However, I've heard that the company is offering the software with a student discount... 
John: So, we can probably purchase it at an affordable price.

Evan: Certainly! So, have you decided to purchase ZTE?

John: Well, I guess so...

Evan: Excellent! Shall we go to the shop tomorrow?

John: Yup, see you at the bus stop near College C.

Evan: Ok, see you at about 10am

John: See you then. Good night!

Evan: Night! 


\section{Activity 2: Explicit grammar focus}

Auxiliary verbs (sometimes known as helping verbs) are verbs that are used to assist the main verb. Three most common auxiliary verbs are be, do and have.

\begin{tabular}{lccc} 
I & Am / was & Do / did & Have / had \\
You & Are / were & Do / did & Have / had \\
He/she/ it & Is / was & Does / did & Has / had \\
We & Are / were & Do / did & Have / had \\
They & Are / were & Do / did & Have / had \\
\hline
\end{tabular}

Exercise: Correct the errors you find.

1. She have bought a Canon printer at an affordable price.

2. He is go to buy the original computer game this evening.

3. Please are not touch the circuit panel.

4. The employees was informed last night that their company was going into receivership.

5. I has had this computer for three years. 


\section{Activity 3: Production}

The following is a dialogue between three friends who are doing a Bachelor's degree in Electrical and Electronic Engineering. Lina, Dave and Mike are discussing purchasing the software they will need to use for a course on "Electronic Circuits" next semester. Since this is a semester break, the discussion is done via the chatroom as everybody is in his/her hometown.

Instruction: Complete the dialogue with the appropriate auxiliary verbs.

Lina: Which software have you found (have, find) for the "Electronic Circuits" course next semester?

Dave: My suggestion would be GeniusBoardCircuit. Have you heard (have, hear) about it?

Mike: Yup, but it is quite expensive, isn't it?

Lina: Let's not talk about the price first. We should find software which is userfriendly.

Dave: The most important thing about GeniusBoardCircuit is that a simulated trainer is included (be, include). So, we can still continue doing our work even if our trainers are not available.

Mike: How could that be possible?

Dave: The software uses a unique metaphor. Chips and wires are used (be, use) instead of the individual gates to construct digital circuits on the computer screen rather than on a real "breadboard" with power supply....

Lina: That means, an immediate feedback is received (be, receive) as the users design, test and modify the project based on the results displayed on the computer screen...

Mike: So, it provides the students with a more realistic understanding of how electronic comments are used (be, use) before they actually go into the lab... Great!

Dave: Exactly!

Lina: Can it work on both Microsoft and Linux based OS?

Dave: Yes, it can. 
Mike: It looks like it is the most suitable software! Have we decided (have, decide) on it?

Lina: Uhmmm...

Mike: Shall we give ourselves a week to think about it?

Line: Ok, I agree.

Mike: Yup, me too.

Dave: See you guys next week. 
Auxiliary verbs: Language notes

Auxiliary verbs forms

I

You

$\mathrm{He} / \mathrm{she} / \mathrm{it}$

We

They

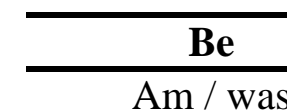

Are / were

Is / was

Are / were

Are / were

\section{Do}

Do / did

Do / did

Does / did

Do / did

Do / did
Have

Have / had

Have / had

Has / had

Have / had

Have / had

Using auxiliary verbs

\begin{tabular}{|c|c|c|c|}
\hline Auxiliaries & Uses & Rules & Examples \\
\hline \multirow[t]{4}{*}{$\begin{array}{l}\text { Is / am / are / } \\
\text { was / were }\end{array}$} & $\begin{array}{l}\text { Progressive } \\
\text { tense }\end{array}$ & Auxiliary + verb + ing & $\begin{array}{l}\text { We are using the latest } \\
\text { version of AutoCAD. }\end{array}$ \\
\hline & & & $\begin{array}{l}\text { Their lecturer was } \\
\text { performing a different } \\
\text { circuit construction when } \\
\text { the power went off. }\end{array}$ \\
\hline & Passive & $\begin{array}{l}\text { Auxiliary + past } \\
\text { participle }\end{array}$ & $\begin{array}{l}\text { The manual is needed for } \\
\text { the installation guideline. }\end{array}$ \\
\hline & & & $\begin{array}{l}\text { A sensitive voltage } \\
\text { detector was found. }\end{array}$ \\
\hline \multirow[t]{4}{*}{ Do / does / did } & Negation & Auxiliary + not + verb & $\begin{array}{l}\text { The systems don't work } \\
\text { well with the software. }\end{array}$ \\
\hline & & & $\begin{array}{l}\text { For the first time she } \\
\text { didn't ask any question. }\end{array}$ \\
\hline & Question & $\begin{array}{l}\text { Auxiliary + noun }+ \\
\text { verb }\end{array}$ & $\begin{array}{l}\text { Does the system require a } \\
\text { bigger memory space? }\end{array}$ \\
\hline & & & $\begin{array}{l}\text { Do the electrician request } \\
\text { for the wires? }\end{array}$ \\
\hline \multirow[t]{2}{*}{$\begin{array}{l}\text { Have / has / } \\
\text { had }\end{array}$} & $\begin{array}{l}\text { Perfect } \\
\text { tense }\end{array}$ & $\begin{array}{l}\text { Auxiliary + past } \\
\text { participle }\end{array}$ & $\begin{array}{l}\text { Students have used CX- } \\
\text { Programmer during the lab } \\
\text { session. }\end{array}$ \\
\hline & & & $\begin{array}{l}\text { The trainees had } \\
\text { forgotten to look for the } \\
\text { latest schedule. }\end{array}$ \\
\hline
\end{tabular}




\section{APPENDIX E}

\section{TASK STRUCTURE MATERIAL (+TS) OR SHEET B}

Instruction: Each of you has information on the software. As you discuss the software, fill in this table. This will help you compare and contrast the software to decide what is best for your company.

\begin{tabular}{|c|c|c|c|c|}
\hline Software & $\begin{array}{l}\text { General } \\
\text { information }\end{array}$ & $\begin{array}{l}\text { Practicality } \\
\text { e.g. user- } \\
\text { friendly } \\
\text { especially for } \\
\text { the new users, } \\
\text { user support } \\
\text { service }\end{array}$ & $\begin{array}{l}\text { Utilization } \\
\text { e.g. multi- } \\
\text { purpose, } \\
\text { compatibility } \\
\text { with any } \\
\text { machines }\end{array}$ & $\begin{array}{l}\text { Cost } \\
\text { e.g. cheap, } \\
\text { affordable }\end{array}$ \\
\hline OrCAD & & & & \\
\hline MATLAB & & & & \\
\hline $\begin{array}{l}\text { Automation } \\
\text { Studio }\end{array}$ & & & & \\
\hline MAXplus II & & & & \\
\hline Points & & & & \\
\hline
\end{tabular}




\section{APPENDIX F \\ RECOMMENDATION WORKSHEET OR SHEET A}

Instruction: You should complete this and submit it to the CEO.

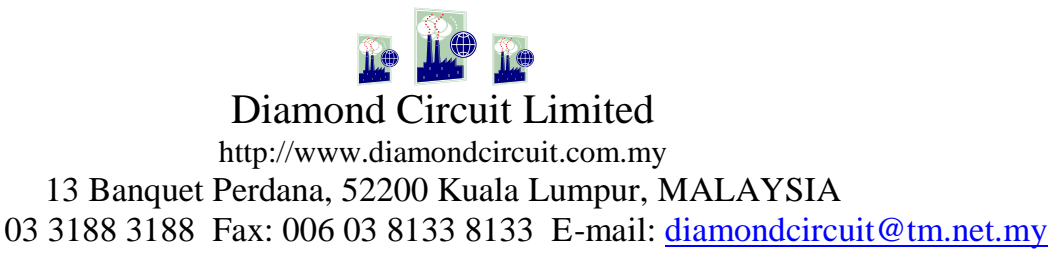

\section{INTERNAL MEMO STRICTLY CONFIDENTIAL}

Below are the results of the virtual meeting held on Tuesday, $21^{\text {st }}$ March 2006, at 14:00:00 GMT. We would like to recommend the software according to the following ranking:

\begin{tabular}{|l||l||l||}
\hline No. & Software & Reasons \\
\hline \hline 1. & & \\
& & \\
\hline 2. & & \\
\hline 3. & & \\
\hline 4. & & \\
\hline
\end{tabular}

Based on the above information, we recommend as the best software to be purchased by our company.

Thank you.

Prepared by:

Adam, Kuala Lumpur, MALAYSIA

Baseer, Tokyo, JAPAN

Chow, Bangkok, THAILAND

Diana, Helsinki, FINLAND 
APPENDIX G

EFFECTIVE COMMUNICATION SKILLS CHECKLIST OR SHEET C

Instruction: The checklist below indicates the criteria which will be used to assess your team mates during the chat session. Rate them based on the scale as follows.

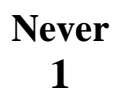

1
Occasionally

2
Always

3

\begin{tabular}{|c|c|c|c|c|c|c|c|c|c|c|}
\hline \multirow{2}{*}{\multicolumn{2}{|c|}{ During the interaction, s/he... }} & \multicolumn{9}{|c|}{ Names } \\
\hline & & & & & & & & & \multicolumn{2}{|c|}{ 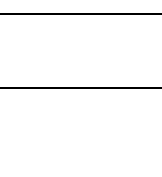 } \\
\hline 1. & used English correctly & 1 & 2 & 3 & 1 & 2 & 3 & 1 & 2 & 3 \\
\hline 2. & participated actively & 1 & 2 & 3 & 1 & 2 & 3 & 1 & 2 & 3 \\
\hline 3. & was easy to understand & 1 & 2 & 3 & 1 & 2 & 3 & 1 & 2 & 3 \\
\hline 4. & $\begin{array}{l}\text { worked well with } \\
\text { others }\end{array}$ & 1 & 2 & 3 & 1 & 2 & 3 & 1 & 2 & 3 \\
\hline 5. & offered opinions & 1 & 2 & 3 & 1 & 2 & 3 & 1 & 2 & 3 \\
\hline 6. & $\begin{array}{l}\text { provided relevant } \\
\text { information }\end{array}$ & 1 & 2 & 3 & 1 & 2 & 3 & 1 & 2 & 3 \\
\hline 7. & $\begin{array}{l}\text { expressed arguments } \\
\text { convincingly }\end{array}$ & 1 & 2 & 3 & 1 & 2 & 3 & 1 & 2 & 3 \\
\hline 8. & $\begin{array}{l}\text { offered immediate } \\
\text { feedback }\end{array}$ & 1 & 2 & 3 & 1 & 2 & 3 & 1 & 2 & 3 \\
\hline 9. & $\begin{array}{l}\text { respected others' } \\
\text { opinions and ideas }\end{array}$ & 1 & 2 & 3 & 1 & 2 & 3 & 1 & 2 & 3 \\
\hline 10. & $\begin{array}{l}\text { interrupted } \\
\text { appropriately }\end{array}$ & 1 & 2 & 3 & 1 & 2 & 3 & 1 & 2 & 3 \\
\hline 11. & $\begin{array}{l}\text { helped to maintain } \\
\text { communication flow }\end{array}$ & 1 & 2 & 3 & 1 & 2 & 3 & 1 & 2 & 3 \\
\hline & TOTAL & & & & & & & & & \\
\hline MA & $\mathbf{X S}=\frac{\text { TOTAL }}{33} \times 100 \%$ & & & & & & & & & \\
\hline
\end{tabular}




\section{References}

Abrams, Z. (2003). The effect of synchronous \& asynchronous CMC on oral performance in German. The Modern Language Journal, 87(2), 157-167.

AbuSeileek, A. F. (2007). Cooperative vs. individual learning of oral skills in a CALL environment, Computer Assisted Language Learning, 20(5) 493514.

Acar, A. (2006). Models, norms and goals for English as an international language pedagogy and task based language teaching and learning. Asian EFL Journal, 8(3). Retrieved January 19, 2007, from http://www.asian-efljournal.com/Sept_06_aa.php

Adams, R. (2003). L2 output, reformulation, and noticing: Implications for IL development. Language Teaching Research, 7(3), 347-376.

Adams, R. (2006). L2 tasks and orientation to form: A role for modality? ITLInternational Journal of Applied Linguistics, 152, 7-34.

Adams, R. (2007). Do second language learners benefit from interacting with each other? In A. Mackey (Ed.), Conversational interaction in second language acquisition: A Collection of empirical studies (pp.29-51). Oxford: Oxford University Press.

Alderson, C. J. (2007). Judging the frequency of English words. Applied Linguistics, 28(3), 383-409.

Alegría de la Colina, A. \& García Mayo, M.P. (2007) Attention to form across collaborative tasks by low proficiency learners in an EFL setting. In M.P. García Mayo (Ed.), Investigating tasks in formal language learning (pp. 91-116). Clevedon: Multilingual Matters.

Al-Jarf, R. S. (2006). Cross-cultural communication: Saudi, Ukrainian, and Russian students online. Asian EFL Journal, 8(2). Retrieved October 27, 2006, from http://www.asian-efl-journal.com/June_06_rsaj.php

Álvarez, E. G. (2007). Task-effect on the use of lexical innovation strategies in interlanguage communication. In M. P. Gárcia Mayo (Ed.), Investigating tasks in formal language learning (pp.199-220). Clevedon: Multilingual Matters.

Anderson, T. \& Elloumi, F. (2004). Theory and practice of online learning. Athabasca, Canada: Athabasca University.

Appel, C. \& Gilabert, R. (2002). Motivation and task performance in a task-based web-based tandem project. ReCALL, 14(1), 16-31. 
Arnold, N. (2007). Reducing foreign language communication apprehension with computer-mediated communication: A preliminary study. System, 35(4), 469-486.

Basturkmen. H., Loewen, S. \& Ellis, R. (2002). Metalanguage in focus on form in the communicative classroom. Language Awareness, 11(1), 1-13.

Beatty, K. \& Nunan, D. (2004). Computer-mediated collaborative learning. System, $32(2), 165-183$.

Beauvois H., M. (1998). Conversations in slow motion: Computer-mediated communication in the foreign language classroom. Canadian Modern Language Review, 54(2), 198-217.

Beauvois, H. M. \& Eledge, J. (1995). Personality types and megabytes: Student attitudes toward computer-mediated communication (CMC) in the language classroom. CALICO JOURNAL, 13(2\&3), 27-45.

Belcher, D. (2004). Trends in teaching English for Specific Purposes. Annual Review of Applied Linguistics, 24, 165-186.

Belz, J. A. (2006). At the intersection of telecollaboration and learner corpus research: Considerations for language program direction. In Julie A. Belz and Steven L. Thorne (Eds), Internet-mediated intercultural foreign language education (pp. 207-246), Boston, MA: Heinle \& Heinle.

Belz, J. A., \& Müller-Hartmann, A. (2003). Teachers as intercultural learners: Negotiating German-American telecollaboration along the institutional fault line. The Modern Language Journal, 87(1), 71-89.

Beyth-Marom, R., Saporta, K. \& Caspi, A. (2005). Synchronous vs. asynchronous tutorials: Factors affecting students' preferences and choices. Journal of Research on Technology in Education, 37(3), 245-262.

Blake, R. \& Delforge, A.M. (2004). Language learning at a distance: Spanish without walls. Selected papers from the 2004 NFLRC Symposium. Retrieved 2 December 2005 from http://nflrc.hawaii.edu/NetWorks/NW44/Blake.htm

Blake, R. \& Zyzik, E. (2003). Who's helping whom?: Learner/Heritage-speakers' networked discussions in Spanish. Applied Linguistics, 24(4), 519-544.

Blake, R. (2000). Computer mediated communication. A window on L2 Spanish interlanguage. Language Learning \& Technology, 4(1). Retrieved December 20, 2004, from http://llt.msu.edu/vol4num1/blake/

Blake, R. (2005). Bimodal CMC: The glue of language learning at a distance. CALICO JOURNAL, 22(3), 497-511. 
Blake, R. (2007). New trends in using technology in the language curriculum. Annual Review of Applied Linguistics, 27, 76-97.

Böhlke, O. (2003). A comparison of student participation levels by group size and language stages during chat room and face-to-face discussions in German. CALICO JOURNAL, 21(1), 67-87.

Bordia, P. (1996). Studying verbal interaction on the internet: The case of rumor transmission research. Behavior Research Methods, Instruments \& Computers, 28(2), 149-151.

Bosman, A. M., Huygevoort, M. \& Verhoeven, L. (2006). Spelling feedback in an ICT-learning environment: Issues of proficiency, training efficiency, and transfer. International Journal of Educational Research, 45, 341-361.

Branden, K. (2007). Second language education: Practice in perfect learning conditions? In Robert M. DeKeyser (Ed.), Practice in second language: Perspective from Applied Linguistics and Cognitive Psychology, (pp.161179). Cambridge, UK: Cambridge University Press.

Brophy, S., Klein, S., Portsmore, M. \& Rogers, C. (2008). Advancing engineering education in P-12 classrooms. Journal of Engineering Education, 97(3), 369-387.

Bump, J. (1990). Radical changes in class discussion using networked computers. Computer and the Humanities, 24, 49-65.

Burston, J. (2003). Proving IT works. CALICO JOURNAL, 20(2), 219-226.

Bygate, M., Skehan, P. \& Swain M. (2001). Researching pedagogic tasks, second language learning, teaching and testing. Harlow, UK: Longman. Cambridge University Press.

Carpenter, H., Jeon, K.S., McGregor, D. \& Mackey, A. (2006). Learners' interpretations of recasts. Studies in Second Language Acquisition, 28(2), 209-236.

Chambers, F. (1997). What do we mean by fluency? System, 25(4), 535-544.

Chang, L. (2007). The effects of using CALL on advanced Chinese foreign language learners. CALICO JOURNAL, 24(2), 331-353.

Chapelle, C. (1997). CALL in the year 2000: Still in search of research paradigms? Language Learning \& Technology, 1(1), 19-43. Retrieved August 31, 2003, from http://lit.msu.edu/vollnum1/chapelle/

Chapelle, C. (1998). Multimedia CALL: Lessons to be learned from research on instructed SLA. Language Learning \& Technology, 2(1), 22-34. Retrieved August 31, 2003, from http://llt.msu.edu/vol2num1/article1/ 
Chapelle, C. (1999). Research questions for a call research agenda:

A reply to Rafael Salaberry. Language Learning \& Technology, 3(1), 108-113. Retrieved August 31, 2003, from http://llt.msu.edu/vol3num1/comment/reply.html

Chapelle, C. (2001). Computer applications in second language acquisition: Foundations for teaching, testing and research. Cambridge: Cambridge University Press.

Chapelle, C. (2003). English language learning and technology. Philadelphia: John Benjamin Publishing.

Chapelle, C. (2004). Technology and second language learning: Expanding methods and agendas. System, 32, 593-601.

Chen, Y.H. (2005). Computer mediated communication: The use of CMC to develop EFL learners' communicative competence. Asian EFL Journal, 7(1). Retrieved December 15, 2005, from http://www.asian-efljournal.com/march_05_yhc.php

Chenoweth, N., Ushida, E. \& Murday, K. (2006). Student learning in hybrid French and Spanish courses: An overview of language online. CALICO JOURNAL, 24(1), 115-145.

Cheon, H. (2003). The viability of computer mediated communication in the Korean secondary EFL classroom. Asian EFL Journal, 5(1). Retrieved April 16, 2005, from www.asian-efl-journal.com/march03.sub2hc.pdf

Chinnery, G. (2008). Biting the hand that feeds me: The case for e-language learning and teaching: CALICO JOURNAL, 25(3), 471-481.

Chun, D. (1994). Using computer networking to facilitate the acquisition of interactive competence. System, 22(1), 17-31.

Chung, T. \& Nation, P. (2003). Technical vocabulary in specialised texts. Reading in a Foreign Language, 15(2), 103-116.

Chung, Y., Graves, B., Wesche, M. \& Barfurth, M. (2005). Computer-mediated communication in Korean-English chat rooms: Tandem learning in an international languages program. The Canadian Modern Language Review, 62(1), 49-86.

Coffin, C., Painter, C. \& Hewings, A. (2005). Patterns of debate in tertiary level asynchronous text-based conferencing. International Journal of Educational Research, 43, 464-480.

Coniam, D. \& Wong, R. (2004). Internet relay chat as a tool in the autonomous development of ESL learners' English language ability: An exploratory study. System, 32(3), 321-335. 
Crossley, S. A., Louwerse, M. M., McCarthy, P. M. \& McNamara, D. S. (2007). A linguistic analysis of simplified and authentic texts. The Modern Language Journal, 91(1), 15-30.

Cumming, A. (1989). Writing expertise and second language proficiency. Language Learning, 39, 81-141.

Curtis, D. \& Lawson, M. (2001). Exploring collaborative online learning. JALN, 5(1), 21-34.

D’Eça, T. A. \& González, D. (2006). Becoming a Webhead: Bridging the gap from classroom to blended or online learning. CALICO JOURNAL, 23(3), 569580.

Daller, H, Hout, R. \& Treffers-Daller, J. (2003). Lexical richness in the spontaneous speech of bilinguals. Applied Linguistics, 24(2), 197-222.

Darhower, M. (2002). Interactional features of synchronous computer-mediated communication in the intermediate L2 class: A sociocultural case study. CALICO JOURNAL, 19(2), 249-277.

Deusen-Scholl, N., Frei, C. \& Dixon, E. (2005). Conconstructing learning: The dynamic nature of foreign language pedagogy in a CMC environment. CALICO JOURNAL, 22(3), 657-678.

Dickinson, M., Eom, S., Kang, Y., Lee, C. M. \& Sachs, R. (2008). A balancing act: How can intelligent computer-generated feedback be provided in learnerto-learner interactions? Computer Assisted Language Learning, 21(4), 369-382.

DiGiovanni, E \& Nagaswami, G. (2001). Online peer review: An alternative to faceto-face? ELT Journal, 55(3), 263-272.

Donato, R. (2004). Aspects of collaboration in pedagogical discourse. Annual Review of Applied Linguistics. 24, 284-302.

Dörnyei, Z. \& Kormos, J. (2000). The role of individual and social variables in oral task performance. Language Teaching Research, 4(3), 275-300.

Doughty, C. \& Long, M. (2003). Optimal psycholinguistic environments for distance foreign language learning. Language Learning \& Technology, 7(3), 50-80. Retrieved May 1, 2004, from http://1lt.msu.edu/vol7num3/doughty/

Doughty, C. \& Pica, T. (1986). "Information gap" tasks: An aid to second language acquisition? TESOL Quarterly, 20, 305-325.

Doughty, C. \& Williams, J. (Eds.) (1998). Focus on form in classroom second language acquisition. New York: Cambridge University Press. 
Dreyer, C. \& Nel, C. (2003). Teaching reading strategies and reading comprehension within a technology-enhanced learning environment. System, 31, 349-365.

Duff, P. (1986). Another look at interlanguage talk: Taking task to task. In Day, R. (Ed.), Talking to learn. Conversation in second language acquisition, (pp. 147-181). Cambridge: Newbury.

Duran, P., Malvern, D., Richards, B. \& Chipere, N. (2004). Developmental trends in lexical diversity. Applied Linguistics, 25(2), 220-242.

E Sá. M. H. A. \& Melo, S. (2007). Online plurilingual interaction in the development of language awareness. Language Awareness, 16(1), 7-20.

Edge, J. (2006). Computer-mediated cooperative development: Non-judgemental discourse in online environments. Language Teaching Research, 10(2), 205-227.

Ellis, R. \& He, X. (1999). The roles of modified input and output in the incidental acquisition of word meanings. Studies in Second Language Acquisition, 21(2), 285-301.

Ellis, R. (1991). The interaction hypothesis: A critical evaluation. In E. Sadtono (Ed.). Language acquisition and the second/foreign language classroom. Singapore: RELC Anthology Series 28, pp.179-211.

Ellis, R. (1994). The study of second language acquisition. Oxford: Oxford University Press.

Ellis, R. (2000). Task-based research and language pedagogy. Language Teaching Research, 4(3), 193-220.

Ellis, R. (2002). Does form-focused instruction affect the acquisition of implicit knowledge? Studies in Second Language Acquisition, 24, 223-236.

Ellis, R. (2003). Task-based language teaching and learning. Oxford: Oxford University Press.

Ellis, R. (Ed.). (2005). Planning and task performance in a second language. Amsterdam: John Benjamin.

Ellis, R. (2009). The differential effects of three types of task planning on the fluency, complexity, and accuracy in 12 oral production, Applied Linguistics, 30(4), 474-509.

Ellis, R., \& Yuan, F. (2004). The effects of planning on fluency, complexity, and accuracy in second language narrative writing. Studies in Second Language Acquisition, 26(1), 59-84. 
Ellis, R., Basturkmen, H. \& Loewen, S. (2001a). Learners uptake in communicative ESL lessons. Language Learning, 51, 281-318.

Ellis, R., Basturkmen, H., \& Loewen, S. (2001b). Preemptive focus on form in the ESL classroom. TESOL Quarterly, 35(3), 407-432.

Ellis, R., Loewen, S. \& Erlam, R. (2006). Implicit and explicit corrective feedback and the acquisition of 12 grammar. Studies in Second Language Acquisition, 28(3), 339-368.

Ellis, R., Tanaka, Y. \& Yamazaki, A. (1994). Classroom interaction, comprehension and the acquisition of L2 meanings. Language Learning, 44(3), 449-491.

Emde, S., Schneider, J. \& Kötter, M. (2001). Technically speaking: Transforming language learning through virtual learning environment. The Modern Language Journal, 85(2), 210-225.

Ene, E., Görtler, S. \& McBride, K. (2005). Teacher participation styles in foreign language chats and their effect on student behaviour, $C A L I C O$ JOURNAL, 22(3), 603-634.

Ewald, J. (2005). Language-related episodes in an assessment context: A 'smallgroup quiz'. The Canadian Modern Language Review, 61(4), 565-586.

Farley, A. (2005). Structured input. Grammar instruction for the acquisitionoriented classroom. New York: McGraw-Hill.

Farrokhi, F. \& Gholami, J. (2007). Reactive and pre-emptive language related episodes and uptake in an EFL class. Asian EFL Journal, 9(2). Retrieved March 20, 2008, from http://www.asian-efljournal.com/June_07_ff\&jg.php

Fernández-García, M., \& Martínez-Arbelaiz, A. (2002). Negotiation of meaning in non-native speaker - non-native speaker synchronous discussions. CALICO JOURNAL, 19 (2), 279-294.

Figura, K. \& Jarvis, H. (2007). Computer-based materials: A study of learner autonomy and strategies. System, 35, 448-468.

Fiori, M. L. (2005). The development of grammatical competence through synchronous computer-mediated communication. CALICO JOURNAL, 22(3), 567-602.

Fisher, E. Usrey, M. W. \& Beasley, H. A. (2003). OWL: A wise way to enhance engineering students' writing skills. Paper presented at 33rd ASEE/IEEE Frontiers in Education Conference, November 5-8, Boulder, CO. 
Fitze, M. (2006). Discourse and participation in ESL face-to-face and written electronic conferences. Language Learning \& Technology, 10(1), 67-86. Retrieved August 31, 2007, from http://lit.msu.edu/vol10num1/fitze/default.html

Foo, B. \& Richards, C. (2004). English in Malaysia. RELC Journal, 35(2), 229-240.

Fortune, A. (2005). Learners' use of metalanguage in collaborative form-focused L2 output tasks. Language Awareness, 14(1), 21-38.

Foster, P. \& Ohta, A. (2005). Negotiation for meaning and peer assistance in second language classrooms. Applied Linguistics, 26(3), 402-430.

Foster, P. \& Skehan, P. (1996). The influence of planning and task type on second language performance. Studies in Second Language Acquisition, 18(3), 299-323.

Foster, P. \& Skehan, P. (1999). The influence of source of planning and focus of planning on task-based performance. Language Teaching Research, 3(3), 215-247.

Foster, P. (1999). A classroom perspective on the negotiation of meaning. Applied Linguistics, 19(1), 1-23.

Foster, P., Tonkyn, A., \& Wigglesworth, G. (2000). Measuring spoken discourse: A unit for all reasons. Applied Linguistics, 21(3), 354-375.

Fouger, X., Almgren, R., Gopalakrishnan, K. \& Mailhot, P. (2008). Perspective from industry. Journal of Engineering Education, 97(3), 241-244.

Freiermuth, M. \& Jarrell, D. (2006). Willingness to communicate: Can online chat help? International Journal of Applied Linguistics, 16(2), 189-212.

Fuente, M. J. (2003). Is SLA interactionist theory relevant to CALL? A study on the effects of computer- mediated interaction in 12 vocabulary acquisition. Computer Assisted Language Learning, 16(1), 47-81.

Gass, S. \& Mackey, A. (2007). Input, interaction and output in SLA. In: Williams, J. \& Van Pattern, B. (Eds.), Theories in Second Language Acquisition (pp. 175-199). New Jersey: Lawrence Erlbaum, Mahwah.

Gass, S. \& Torres, M. (2005). Attention when? An investigation of the ordering effect of input and interaction. Studies in Second Language Acquisition, 27(1), 1-31.

Gass, S. \& Varonis, E. (1985a). Variation in native speaker speech modification to nonnative speakers. Studies in Second Language Acquisition, 7(1), 37-58. 
Gass, S. \& Varonis, E. (1985b). Task variation and nonnative/nonnative negotiation of meaning. In S. M. Gass \& C. Madden (Eds.), Input in second language acquisition (pp. 149-161). Rowley, MA: Newbury House.

Gass, S. \& Varonis, E. (1994). Input, interaction and second language production. Studies in Second Language Acquisition, 16(3), 283-302.

Gass, S. (1997). Input, interaction and the second language learner. Mahwah, NJ: Lawrence Erlbaum.

Gass, S. Mackey, A. \& Ross-Feldman, L. (2005). Task-based interactions in classroom and laboratory settings. Language Learning, 55(4), 575-611.

Gass, S., Mackey, A., \& Pica, T. (1998). The role of input and interaction in second language acquisition. The Modern Language Journal, 82(3), 299-307.

Gerjets, P. H. \& Heese, F. W. (2004). When are powerful learning environments effective? The role of learner activities and of students' conceptions of educational technology. International Journal of Educational Research, 41(6), 445-465.

Gilabert, R. (2007a). Effects of manipulating task complexity on self-repairs during L2 oral production. IRAL, 45(3), 215-240.

Gilabert, R. (2007b). The simultaneous manipulation of task complexity along planning time and (+/- Here-and-Now): Effects on L2 oral production. In M.P. García Mayo (Ed.), Investigating tasks in formal language learning (pp. 44-68). Clevedon: Multilingual Matters.

Gonzalez, D. (2003). Teaching and learning through chat: A taxonomy of educational chat for EFL/ESL. IAIEFL Poland: Computer Special Interest Group, 3(4).

González-Lloret, M. (2003). Designing task-based CALL to promote interaction: En Busca de Esmeraldas. Language Learning \& Technology, 7(1), 86104. Retrieved September 11, 2004, from http://lit.msu.edu/vol7num1/gonzalez/

Goodfellow, R. (2005). Academic literacies and e-learning: A critical approach to writing in the online university. International Journal of Educational Research, 43(7-8), 481-494.

Gruba, P. (2006). Playing the videotext: A media literacy perspective on videomediated L2 listening. Language Learning \& Technology, 10(2), 77-92. Retrieved February 24, 2007, from http://llt.msu.edu/vol10num2/gruba/default.html 
Hampel, R. \& Hauk, M. (2004). Towards an effective use of audio conferencing in distance language courses. Language Learning and Technology, 8, 6682. Retrieved February 27, 2005, from http://llt.msu.edu/vol8num1/hampel/default.html

Hampel, R. (2006). Rethinking task design for the digital age: A framework for language teaching and learning in a synchronous online environment. ReCALL, 18(1), 105-121.

Hanaoka, O. (2007). Output, noticing, and learning: An investigation into the role of spontaneous attention to form in a four-stage writing task. Language Teaching Research, 11(4), 459-479.

Hardy, I.M. \& Moore, J.L. (2004). Foreign language students' conversational negotiations in different task environments. Applied Linguistics, 25(3), 340-370.

Hauck, M. \& Youngs, B. L. (2008). Telecollaboration in multimodal environments: the impact on task design and learner interaction. Computer Assisted Language Learning, 21(2), 87-124.

Hegelheimer, V. \& Tower, D. (2004). Using CALL in the classroom: Analyzing student interactions in an authentic classroom. System, 32, 185-205.

Heins, B., Duensing, A., Stickler, U. \& Batstone, C. (2007). Spoken interaction in online and face-to-face language tutorials. Computer Assisted Language Learning, 20(3), 279-295.

Herring, S. (Ed.). (1996). Computer-mediated communication: Linguistic, social and cross-cultural perspectives. Amsterdam: John Benjamins Publishing Company.

Hirvela, A. (2006). Computer-mediated communication in ESL teacher education. ELT Journal, 60(3), 233-241.

Housen, A. \& Kuiken, F. (2009). Complexity, accuracy, and fluency in second language acquisition. Applied Linguistics, 30(4), 461-473.

Hubbard, P. \& Levy, M. (Eds.). (2006). Teacher education in CALL. Amsterdam: John Benjamins Publishing Company.

Hudson, J. M. \& Bruckman, A. S. (2004). The bystander effect: A lens for understanding patterns of participation. The Journal of the Learning Sciences, 13(2), 165-195.

Ingram, A.L., Hathorn. L.G., \& Evans, A. (2000). Beyond chat on the internet. Computers \& Education, 35(1), 21-35. 
Ishihara, N. (2007). Web-based curriculum for pragmatics instruction in Japanese as a foreign language: An explicit awareness-raising approach. Language Awareness, 16(1), 21-40.

Ishikawa, T. (2007). The effect of manipulating task complexity along the [+/- Hereand-Now] dimension on L2 written discourse. In M.P. García Mayo (Ed.), Investigating tasks in formal language learning (pp. 136-156). Clevedon: Multilingual Matters.

Iwasaki, J. \& Oliver, R. (2003). Chat-line interaction and negative feedback. Australian Review of Applied Linguistics, 17, 60-73.

Iwashita, N. (2003). Negative feedback and positive evidence in task-based interaction: Differential effects on L2 development. Studies in Second Language Acquisition, 25(1), 1-36.

Iwashita, N., McNamara, T. \& Elder, C. (2001). Can we predict task difficulty in an oral proficiency test? Exploring the potential of an informationprocessing approach to task design. Language Learning, 51(3), 401-436.

Izumi, S. (2003). Comprehension and production processes in second language learning: In search of the psycholinguistic rationale of the output hypothesis. Applied Linguistics, 24 (2), 168-96.

Janssen, J., Erkens, G. Jaspers, J. \& Broeken, M. (2005). Effects of visualizing participation in computer-supported collaborative learning. Paper presented at $11^{\text {th }}$ Biennial Conference of the European Association for Research in Learning and Instruction, August 205, Nicosia, Cyprus.

Jarell, D. \& Freiermuth, M.R. (2005). Motivational power of internet chat. RELC Journal, 36(1), 59-72.

Jenks, C. J. (2007). Floor management in task-based interaction: The interactional role of participatory structures. System, 35, 609-622.

Jeon-Ellis, G., Debski. R. \& Wigglesworth, G. (2005). Oral interaction around computers in the project-oriented CALL classroom. Language Learning \& Technology, 9(3), 121-145. Retrieved January 14, 2006, from http://lit.msu.edu/vol9num3/jeon/default.html

Jepson, K. (2005). Conversations -- and negotiated interaction -- in text and voice chat rooms. Language Learning and Technology, 9(3), 79-98. Retrieved January 19, 2006, from http://llt.msu.edu/vol9num3/jepson/

Johnson, A. \& Sheehan, M. (2006). English with Shrek: A multi-media based CALL course, PacCALL Journal, 2(1), 108-125.

Kearsley, G. (2000). Online education: Learning and teaching in cyberspace. United States: Wadsworth Thomson Learning. 
Kenning, M-M. (2007). ICT and language leaning: From print to the mobile phone. New York: Palgrave MacMillan.

Kern, R. (1995). Restructuring classroom interaction with networked computers: Effects on quantity and characteristics of language production. The Modern Language Journal, 79(4), 457-476.

Kern, R. (2006). Perspectives on technology in learning and teaching languages. TESOL Quarterly, 40(1), 183-210.

Kern, R., Ware, P., \& Warschauer, M. (2008). Network-based language teaching. In N. V. Deusen-Scholl \& N. H. Hornberger (Ed.), Encyclopaedia of language and education, 2nd Ed., Vol. 4: Second and foreign language education (pp. 281-292). New York: Springer.

Kim, Y. (2009). The effects of task complexity on learner-learner interaction. System, 37(2), 254-268.

Kim, I-H., Anderson, R., Nguyen-Jahiel, K. \& Archodidou, A. (2007). Discourse patterns during children's collaborative online discussions. The Journal of the Learning Sciences, 16(3), 333-370.

Kitade, K. (2000). L2 Learners' Discourse and SLA Theories in CMC: Collaborative Interaction in Internet Chat. Computer Assisted Language Learning, 13(2), 143-166.

Klapper, J. \& Reese, J. (2003). Reviewing the case for explicit grammar instruction in the university foreign language learning context. Language Teaching Research, 7(3), 285-314.

Kormos, J. \& Dénes, M. (2004). Exploring measures and perceptions of fluency in the speech of second language learners. System, 32(2), 145-164.

Koskimaa, R., Lehtonen, M., Heinonen, U., Ruokamo, H., Tissari, V., VahtivuoriHänninen, S. \& Tella, S. (2007). A cultural approach to networked-based mobile education. International Journal of Educational Research, 46, 204-214.

Kötter, M. (2003). Negotiation of meaning and codeswitching in online tandems. Language Learning \& Technology, 7(2), 145-172.

Krashen, S. (1978). Individual variation in the use of the monitor. In W. Ritchie (Ed.), Principles of second language learning, (pp.175-183), New York: Academic Press.

Krashen, S. (1985). The input hypothesis. Beverly Hills, CA: Laredo Publishing Company.

Krashen, S. (1994). The input hypothesis and its rivals. In N. Ellis (Ed.) Implicit and explicit learning of languages. (pp. 45-77). London: Academic Press. 
Krashen, S. (1996). Under attack: The case against bilingual education. Culver City, CA: Language Education Associates.

Kuiken, F. \& Vedder, I. (2007). Task complexity and measures of linguistic performance in L2 writing. IRAL, 45(3), 261-284.

Kuiken, F. \& Vedder, I. (2008). Cognitive task complexity and written output in Italian and French as a foreign language, Journal of Second Language Writing, 17, 48-60.

Kung, S. -C., (2004). Synchronous electronic discussions in an EFL reading class. ELT Journal, 58(2), 164-173.

Lafford, P. \& Lafford, B. (2005). CMC technologies for teaching foreign languages: What's on the horizon? CALICO JOURNAL, 22(3), 679-709.

Lai, C. \& Zhao, Y. (2006). Noticing and text-based chat. Language Learning \& Technology, 10(3), 102-120. Retrieved January 9, 2007, from http://lit.msu.edu/vol10num3/laizhao/default.html

Lam, W. S. E. (2004). Second language socialization in a bilingual chat room:

Global and local considerations. Language Learning \& Technology, 8(3), 44-65. Retrieved April 18, 2006, from http://lit.msu.edu/vol8num3/lam/default.html

Lambert, C. P. \& Engler, S. (2007). Information distribution and goal orientation in second language task design. In M.P. García Mayo (Ed.), Investigating tasks in formal language learning, (pp. 27-43). Clevedon: Multilingual Matters.

Lamy, M-L. \& Hampel, R. (2007). Online communication in language learning. New York: Palgrave Macmillan.

Larsen-Freeman, D. \& Long, M. (1991). An introduction to second language acquisition research. London: Longman.

Larsen-Freeman, D. (2006). The emergence of complexity, fluency, and accuracy in the oral and written production of five Chinese learners of English. Applied Linguistics 27(4), 590-619.

Latif, M. M. A. (2008). A state-of-the-art review of the real-time computer-aided study of the writing process. International Journal of English Studies, $8(1), 29-50$.

Laufer, B. \& Nation, I.S.P. (1995). Vocabulary size and use: Lexical richness in L2 written production. Applied Linguistics, 16(3), 307-322.

Leahy, C. (2008). Learner activities in a collaborative CALL task. Computer Assisted Language Learning, 21(3), 253-26. 
Lee, C. (2007). Affordances and text-making practices in online instant messaging. Written Communication, 24(3), 223-249.

Lee, F.T. \& Yeap, B.H. (2005). Application of Effective Teaching and Learning Methods in Engineering Education. Paper presented at the $3^{\text {rd }}$ International Conference on Multimedia and Information \& Communication Technologies in Education. New Zealand, 7-10 June 2005.

Lee, L. (2002). Synchronous online exchanges: A study of modification devices on non-native discourse. System, 30(3), 275-288.

Lee, L. (2004). Learners' perspectives on networked collaborative interaction with native speakers of Spanish in the US. Language Learning \& Technology, 8(1), 83-100. Retrieved June 6, 2005, from http://lit.msu.edu/vol8num1/lee/default.html

Lee, L. (2008). Focus on form through collaborative scaffolding in expert-to-novice online interaction. Language Learning \& Technology, 12(3), 53-72. Retrieved January 13, 2009, from http://llt.msu.edu/vol12num3/lee.pdf

Leeser, M. (2004). Learner proficiency and focus on form during collaborative dialogue. Language Teaching Research, 8(1), 55-81.

Leeser, M. (2008). Pushed output, noticing, and development of past tense morphology in content-based instruction. The Canadian Modern Language Review, 65(2), 195-220.

Levelt, W. (1989). Speaking: From intention to articulation. Cambridge, MA: MIT

Levelt, W. (1993). Language use in normal speakers and its order. In G. Blanken, H. Dittman, H. Grimm, J. Marshal, \& C. Wallesch (Eds.), Linguistic disorders and pathologies (pp. 1-15). Berlin: de Gruyter.

Levy, M. \& Kennedy, C. (2004). A task-cycling pedagogy using stimulated reflection and audio-conferencing in foreign language learning. Language Learning \& Technology, 8(2), 50-68.

Levy, M. \& Stockwell, G. (2006). CALL dimensions: Options and issues in computer-assisted language learning. London: Lawrence Erlbaum Associates.

Lim, H.L \& Sudweeks, F. (2006). Student perceptions of participation opportunities in online synchronous tutorials. In A. Méndez-Vilas, A. Solano Martín, J.A. Mesa González and J. Mesa González (Eds.), Current Developments in Technology-Assisted Education: Technological Science Education, Collaborative Learning, Knowledge Management, Badajoz, Spain : FORMATEX. Retrieved December 12, 2007, from http://www.formatex.org/micte2006/pdf/1486-1490.pdf 
Lindgren, E., \& Sullivan, K. P. H. (2006). Analysing on-line revision. In G. Rijlaarsdam (Series Ed.) \& K.P.H. Sullivan \& E. Lindgren (Vol. Eds.), Studies in writing, computer keystroke-logging and writing: Methods and applications (pp. 157-188). Amsterdam: Elsevier.

Lingley, D. (2006). A task-based approach to teaching a content-based Canadian studies course in an EFL context. Asian EFL Journal, 8(3). Retrieved March 10, 2007, from http://www.asian-efl-journal.com/Sept_06_dl.php

Liu, M., Moore, Z., Graham, L., \& Lee, S. (2002). A look at the research on computer-based technology use in second language learning: A review of the literature from 1990-2000. Journal of Research on Technology in Education, 34(3), 250-273.

Loewen, S. (2003). Variation in the frequency and characteristics of incidental focus on form. Language Teaching Research, 7(3), 315-345.

Loewen, S. (2005). Incidental focus on form and second language learning. Studies in Second Language Acquisition, 27(3), 361-386.

Loewn, S. (2004). Uptake in incidental focus on form in meaning-focused ESL lessons. Language Learning, 54(1), 153-187.

Loewen, S., \& Erlam, R. (2006). Corrective feedback in the chatroom: An experimental study. Computer-Assisted Language Learning, 19(1), 1-14.

Loewen, S. \& Philp, J. (2006). Recasts in the adult English L2 classroom: Characteristics, explicitness, and effectiveness. The Modern Language Journal, 90(4), 536-556.

Loewen, S. \& Reissner, S. (2009). A comparison of incidental focus on form in the second language classroom and chatroom. Computer Assisted Language Learning, 22(2), 101-114.

Long, M. H. (1983). Native speaker/non-native speaker conversation and the negotiation of comprehensible input, Applied Linguistics, 4(2), 126-141.

Long, M. H. (1985). A role for instruction in second language acquisition: Taskbased language teaching. In Hyltenstam, K., \& Pienemann, M. (Eds.), Modeling and assessing second language development (pp. 77-99). Clevedon, Avon: Multilingual Matters.

Long, M. H. (1989). Task, group, and task-based interactions. University of Hawaii Working Papers in ESL, 8(2), 1-26.

Long, M. H. (1991). Focus on form: A design feature in language teaching methodology. In K. de Bot, R. Ginsberg and C. Kramsch (Eds.), Foreign language research in cross-cultural perspective (pp.39-52). Amsterdam: John Benjamins. 
Long, M. H. (1996). The role of the linguistic environment in second language acquisition. In W. C. Ritchie and T. K. Bhatia (Eds.), Handbook of second language acquisition (pp. 413-68). New York: Academic Press.

Long, M. H. (Ed.). (2006). Problems in SLA. Mahwah, NJ: Lawrence Erlbaum Associates.

Long, M. H., \& Crookes, G. (1992). Three approaches to task-based language teaching. TESOL Quarterly, 26(1), 27-56.

Long, M. H., \& Robinson, P. (1998). Focus on form: Theory, research and practice. In C. Doughty \& J. Williams (Eds.), Focus on form in classroom second language acquisition (pp. 15-41). Cambridge: Cambridge University Press.

Lund, A. (2006). The multiple contexts of online language teaching. Language Teaching Research, 10(2), 181-204.

Lyster, R. \& Mori, H. (2006). Interactional feedback and instructional counterbalance. Studies in Second Language Acquisition, 28, 269-300.

Lyster, R. (2004). Research on form-focused instruction in immersion classrooms: Implications for theory and practice. French Language Studies, 14, 321341.

Mackey, A. (1999). Input, interaction and second language development: An empirical study of question formation in ESL. Studies in Second Language Acquisition, 21(4), 557-587.

Mackey, A. (2002). Beyond production: Learners' perceptions about interactional processes. International Journal of Educational Research, 37, (3-4), 379394.

Mackey, A. (2006). Feedback, noticing and instructed second language learning. Applied Linguistics, 27(3), 405-430.

Mackey, A. \& Gass, S. (2005). Second language research: Methodology and design. New Jersey: Lawrence Erlbaum Associates.

Mackey, A. \& Gass, S. (2006). Introduction. Studies in Second Language Acquisition, 28, 169-178.

Mackey, A. \& Silver, R. E. (2005). Interactional tasks and English L2 learning by immigrant children in Singapore. System, 33, 239-260.

Mackey, A., Kanganas, A.P. \& Oliver, R. (2007). Task familiarity and interactional feedback in child ESL classrooms. TESOL Quarterly, 41(2), 285-312. 
Mackey, A., Oliver, R. \& Leeman, J. (2003). Interactional input and the incorporation of feedback: An exploration of NS-NNS and NNS-NNS adult and child dyads. Language Learning, 53, 35-66.

Malmqvist, A. (2005). How does group discussion in reconstruction tasks affect written language output? Language Awareness, 14(2\&3), 128-141.

Matsumura, S. \& Hann, G. (2004). Computer anxiety and students' preferred feedback methods in EFL writing. The Modern Language Journal, 88(3), 403-415.

McDonough, K. (2004). Learner-learner interaction during pair and small group activities in a Thai EFL context. System, 32, 207-224.

McDonough, K. (2005). Identifying the impact of negative feedback and learners' responses on ESL question development. Studies in Second Language Acquisition, 27(1), 79-103.

McDonough, K. (2006). Interaction and syntactic priming: English L2 speakers' production of dative constructions. Studies in Second Language Acquisition, 28(2), 179-207.

McDonough, K. \& Chaikitmingkol, W. (2007). Teachers' and learners' reactions to a task-based EFL course in Thailand. TESOL Quarterly, 41(1), 107-132.

Mehnert, U. (1998). The effects of different lengths of time for planning on second language performance. Studies in Second Language Acquisition, 20(1), 82-108.

Meskill, C. \& Anthony, N. (2005). Foreign language learning with CMC: forms of online instructional discourse in a hybrid Russian class. System, 33(1), 89-105.

Meskill, C. (2005). Triadic scaffolds: Tools for teaching English language learners with computers. Language Learning \& Technology, 9 (1), 46-59. Retrieved January 27, 2006, from http://llt.msu.edu/vol9num1/meskill/

Michel, M., Kuiken, F. \& Vedder, I. (2007). The influence of complexity in monologic versus dialogic tasks in Dutch L2. IRAL, 45(3), 241-259.

Mori, J. (2002). Task design, plan and development of talk-in-interaction: An analysis of a small group activity in a Japanese language classroom. Applied Linguistics, 23(3), 323-347.

Morris, F. (2005). Child-to-child interaction and corrective feedback in a computer mediated L2 class. Language Learning \& Technology, 9(1), 29-45.

Retrieved October 10, 2005, from http://llt.msu.edu/vol9num1/morris/default.html 
Murphy, L. (2005). Attending to form and meaning: The experience of adult distance learners of French, German and Spanish. Language Teaching Research, 9(3), 295-317.

Nakahama, Y., Tyler, A. \& Van Lier, L. (2001). Negotiation of meaning in conversational and information gap activities: A comparative discourse analysis. TESOL Quarterly, 35(3), 377-405.

Nassaji, H. (2007). Elicitation and reformulation and their relationship with learner repair in dyadic interaction. Language Learning, 57(4), 511-548.

Nation, I.S.P. (2004). A study of the most frequent word families in the British National Corpus. In P. Bogaards \& B. Laufer (Eds.), Vocabulary in a second language: Selection, acquisition, and testing (pp. 3-13). Amsterdam: John Benjamins.

Nation, I.S.P., \& Heatley, A. (2002). Range: A program for the analysis of vocabulary in texts [software]. Downloadable from http://www.vuw.ac.nz/lals/staff/paul-nation/nation.aspx

Naughton, D. (2006). Cooperative strategy training and oral interaction: Enhancing small group communication in the language classroom. The Modern Language Journal, 90(2), 169-184.

Newlands, A. Anderson, A. H. \& Mullin, J. (2003). Adapting communicative strategies to computer-mediated communication: An analysis of task performance and dialogue structure. Applied Cognitive Psychology, 17, 325-348.

Newton, J. \& Kennedy, G. (1996). Effects of communication tasks on the grammatical relations marked by second language learners. System, 24(3), 309-322.

Nguyen, H. \& Kellogg, G. (2005). Emergent identities in on-line discussions for second language learning. The Canadian Modern Language Review, 62(1), 111-136.

Nik, N. \& Adams, R. (2009). TBLT and SCMC: How do students use communication strategies? Asian Journal of English Language Teaching, 19, 135-158.

Norris, J. \& Ortega, L. (2009). Towards an organic approach to investigating CAF in instructed SLA: The case of complexity. Applied Linguistics, 30(4), 555578.

Nuevo, A-M. (2006). Task complexity and interaction: L2 learning opportunities and development. Unpublished Doctoral Dissertation, Georgetown University, Washington, DC. 
Nunan, D. (2006). Task-based language teaching in the Asia context: Defining 'task'. Asian EFL Journal, 8(3). Retrieved March 4, 2007, from http://www.asian-efl-journal.com/Sept_06_dn.php

O'Bryan, A. \& Hegelheimer, V. (2007). Integrating CALL into the classroom: The role of podcasting in an ESL listening strategies course. ReCALL, 19(2), $162-180$.

O'Rourke, B. (2008). The other C in CMC: What alternative data sources can tell us about text-based synchronous computer mediated communication and language learning. CALL, 21(3), 227-251.

O'Dowd, R. \& Ware, P. (2009). Critical issues in telecollaborative task design. Computer Assisted Language Learning, 22(2), 173-188.

O'Dowd, R. (Ed.). (2007). Online intercultural exchange: An introduction for foreign language teachers. Clevedon: Multilingual Matters

Okuyama, Y. (2005). Distance language learning via synchronous computermediated communication (SCMC): Eight factors affecting NS-NNS chat interaction. The JALT CALL Journal, 1(2), 3-20.

Oliver, R. (2002). The patterns of negotiation for meaning in child interactions. The Modern Language Journal, 86(1), 97-111.

Oliver, R. \& Mackey, A. (2003) Interactional context and feedback in child ESL classrooms. Modern Language Journal, 87(4), 519-543.

Ortega, L. (1999). Planning and focus on form in L2 Oral Performance. Studies in Second Language Acquisition, 21(1), 109-148.

Ortega, L. (2009). Interaction and attention to form in L2 text-based computermediated communication. In A. Mackey \& C. Polio (Eds.). Multiple perspectives on interaction in second language acquisition: Second language research in honor of Susan M. Gass. New York: Taylor \& Francis.

Oskoz, A. (2005). Students' dynamic assessment via online chat. CALICO JOURNAL, 22(3), 513-536.

Oxford, R. (2006). Task-based language teaching and learning: An overview. Asian EFL Journal, 8(3). Retrieved March 4, 2007, from http://www.asian-efljournal.com/Sept_06_ro.php

Pallant, J. (2007). SPSS survival manual: A step by step guide to data analysis using SPSS for windows $\left(3^{\text {rd }}\right.$ ed.). Sydney: Ligare Book Printer.

Pallotti, G. (2009). CAF: Defining, refining and differentiating constructs. Applied Linguistics, 30(4), 590-601. 
Payne, J. S. \& Ross, B. (2005). Synchronous CMC, working memory, and L2 oral proficiency development. Language Learning \& Technology, 9(3), 3554. Retrieved April 18, 2006, from http://lt.msu.edu/vol9num3/payne/default.html

Payne, J. S., \& Whitney, P. J. (2002). Developing L2 oral proficiency through synchronous CMC: Output, working memory, and interlanguage development. CALICO JOURNAL, 20(1), 7-32.

Pellettieri, J. (2000). Negotiation in cyberspace: The role of chatting in the development of grammatical competence. In M. Warschauer, \& R. Kern (Eds.), Network-based language teaching: Concepts and practice (pp.5986). Cambridge: Cambridge University Press.

Pena-Shaff, J., Martin, W. \& Gay, G. (2001). An epistemological framework for analyzing student interactions in computer-medicated communication environments. Journal of Interactive Learning Research, 2(1).

Pérez , L. (2003). Foreign language productivity in synchronous versus asynchronous computer-mediated communication. CALICO JOURNAL, 21(1), 89-104.

Peters, E. (2007). L2 vocabulary acquisition and reading comprehension: The influence of task complexity. In M.P. García Mayo (Ed.), Investigating tasks in formal language learning, (pp.178-198). Clevedon: Multilingual Matters.

Philp, J. (2003). Constraints on "noticing the gap": Nonnative speakers' noticing of recasts in NS-NNS interaction. Studies in Second Language Acquisition, 25(1), 99-126.

Philp, J., Oliver, R. \& Mackey, A. (2006). The impact of planning time on children's task-based interactions. System, 34(4), 547-565.

Pica, T. (1994). Research on negotiation: What does it reveal about second-language learning conditions, processes and outcomes? Language Learning, 44(3), 493-527.

Pica, T. (2005). Classroom learning, teaching, and research: A task-based perspective. The Modern Language Journal, 89(3), 339-352.

Pica, T., \& Doughty, C. (1985). Input and interaction in the communicative language classroom: A comparison of teacher-fronted and group activities. In S. M. Gass and C. Madden (Eds.), Input in second language acquisition (pp. 115-132). Massachusetts: Newbury House.

Pica, T., \& Doughty, C. (1988). Variations in classroom interaction as a function of participant pattern and task. In J. Fine (Ed.), Second language discourse (pp. 41-55). Norwood, New Jersey: Ablex. 
Pica, T., Kanagy, R. \& Falodun, J. (1993) Choosing and using communication tasks for second language instruction. In S. Gass, and G. Crookes (Eds.), Taskbased learning in second language acquisition (pp.9-34), Clevedon, UK: Multilingual Matters.

Pica, T., Kang, H. \& Sauro, S. (2006). Information gap tasks: Their multiple roles and contributions to interaction research methodology. Studies in Second Language Acquisition, 28(2), 301-338.

Pica, T., Lincoln-Porter, F., Paninos, D. \& Linnell, J. (1996). Language learners' interaction: How does it address the input, output, and feedback needs of L2 learners? Language Learning, 30(1), 59-84.

Pinter, A. (2006). Verbal evidence of task related strategies: Child versus adult interactions. System, 34(4), 615-630.

Platt, E. \& Brooks, F. (2002). Task engagement: A turning point in foreign language development. Language Learning, 52(2), 365-400.

Polio, C., Gass, S. \& Chapin, L. (2006). Using stimulated recall to investigate native speaker perceptions in native-non-native speaker interaction. Studies in Second Language Acquisition, 28(2), 301-338.

Poole, A. (2005). The kinds of forms learners attend to during focus on form instruction: A description of an advanced ESL writing class. Asian EFL Journal, 7(3). Retrieved May 23, 2006, from http://www.asian-efljournal.com/sept_05_ap.pdf

Qi, D. \& Lapkin, S. (2001). Exploring the role of noticing in a three-stage second language writing task. Journal of Second Language Writing, 10, $277-$ 303.

Raby, F. (2007). A triangular approach to motivation in computer-assisted autonomous language learning (CAALL), ReCALL, 19(2), 181-201.

Ramsay, G. (2003). 'Virtual' learning communities beyond the classroom: Perceptions of tertiary Chinese language and non-language learners. Australian Review of Applied Linguistics Series S, 17, 3-24.

Raof, A. \& Yusof, M. (2006). ESP project work: Preparing learners for the workplace. Asian EFL Journal, 8(1). Retrieved December 15, 2006, from http://www.asian-efl-journal.com/March_06_aar\&amyl.php

Redish, E. \& Smith, K. (2008). Looking beyond content: Skill development for engineers. Journal of Engineering Education, 97(3), 295-307.

Reese, S. (2001). Excellence in Engineering Technology Education. Techniques: Connecting Education \& Careers, 76(4), 26-27. 
Riemer, M. (2002). English and communication skills for the global engineer. Global Journal of Engineering Education, 6(1), 91-100.

Robinson, P. (1995). Task complexity and second language narrative discourse. Language Learning, 45(1), 99-140.

Robinson, P. (2001a). Task complexity, cognitive resources, and syllabus design: A triadic framework for examining task influences on SLA. In P. Robinson (Ed.), Cognition and second language instruction (pp. 287-318). Cambridge: Cambridge University Press.

Robinson, P. (2001b). Task complexity, task difficulty, and task production: Exploring interactions in a componential framework. Applied Linguistics, 22(1), 27-57.

Robinson, P. (2003a). Attention and memory during SLA. In C. Doughty \& M. Long (Eds.), Handbook of Second Language Acquisition (pp. 631-678). Oxford: Blackwell.

Robinson, P. (2003b). The Cognition Hypothesis of adult, task-based language learning. Second Language Studies, 21(2), 45-107.

Robinson, P. (2005). Cognitive complexity and task sequencing: Studies in a Componential Framework for second language task design. IRAL, 43(1), $1-33$.

Robinson, P. (2007a). Task complexity, theory of mind, and intentional reasoning: Effects on L2 speech production, interaction, uptake and perceptions of task difficulty. IRAL, 45(3), 193-213.

Robinson, P. (2007b). Criteria for grading and sequencing pedagogic tasks. In M.P. García Mayo (Ed.). Investigating tasks in formal language learning (pp. 7-27). Clevedon: Multilingual Matters.

Robinson, P. \& Gilabert, R. (2007). Task complexity, the Cognition Hypothesis and second language learning and performance, IRAL, 45, 161-176.

Roed, J. (2003). Language learner behaviour in a virtual environment. Computer Assisted Language Learning, 16(2), 155-172.

Rompelman, O. (2001). Assessment of student learning: Evolution of objectives in engineering education and the consequences for assessment. Retrieved August 19, 2004, from http://www.engenheiro2001.org.br/artigos/Rompelman.doc

Salaberry, M. R. (2000). L2 morphosyntactic development in text-based Computermediated communication. Computer Assisted Language Learning, 13(1), $5-27$. 
Samuel, C. (2001). Computer-mediated communication: A motivator in the foreign language classroom. The Korea TESOL Journal, 4(1), 119-132.

Sanders, R. (2006). A comparison of a chat room productivity: In-class versus outof-class. CALICO JOURNAL, 24(1), 59-76.

Sauro, S. (2009). Computer-mediated corrective feedback and the development of L2 grammar. Language Learning \& Technology, 13(1), 96-120.

Retrieved March 12, 2009, from llt.msu.edu/vol13num1/sauro.pdf

Savignon, S. \& Roithmeier, W. (2004). Computer-mediated communication: Texts and strategies. CALICO JOURNAL, 21(2), 265-290.

Schmidt, R. (1993) Consciousness, learning, and interlanguage pragmatics. In G. Kasper \& S. Blum-Kulka. (Eds.), Interlanguage pragmatics (pp. 21-42). Oxford: Oxford University Press.

Schmidt, R. (1995). Consciousness and foreign language learning: A tutorial on the role of attention and awareness in learning. In R. Schmidt (Ed.), Attention and awareness in foreign language learning (pp. 1-64). [Technical report no. 9.] Honolulu: University of Hawai'i Press.

Schmidt, R. (2001). Attention. In P. Robinson (Ed.), Cognition and second language instruction (pp. 3-32). Cambridge, England: Cambridge University Press.

Schwienhorst, K. (2004). Native-speaker/non-native-speaker discourse in the MOO: Topic negotiation and initiation in a synchronous text-based environment. Computer Assisted Language Learning, 17(1), 35-50.

Sercu, L., de Wachter, L., Peters, E., Kuiken, F. \& Vedder, I. (2006). The effect of task complexity and task conditions on foreign language development and performance: Three empirical studies. ITL- International Journal of Applied Linguistics, 152, 55-84.

Shamsudin, S. \& Nesi, H. (2006). Computer-mediated communication in English for specific purposes: A case study with computer science students at Universiti Teknologi Malaysia. Computer Assisted Language Learning, 19(4), 317-339.

Shang, H-F. (2007). An exploratory study of e-mail application on FL writing performance. Computer Assisted Language Learning, 20(1), 79-96.

Sheen, R. (1994). A critical analysis of the advocacy of the task-based syllabus. TESOL Quarterly 28(1), 127-151.

Sheen, R. (2003). Focus on form- A myth in the making? ELT Journal, 57(3), 225233. 
Sheen, Y. (2004). Corrective feedback and learner uptake in communicative classrooms across instructional settings. Language Teaching Research, $8(3), 263-300$.

Shehadeh, A. (2002). Comprehensible output, from occurrence to acquisition: An agenda for acquisitional research. Language Learning, 52(3), 597-647.

Shekary, M. \& Tahririan, M. H. (2006). Negotiation of meaning and noticing in textbased online chat. The Modern Language Journal, 90(4), 557-573.

Simpson, J. (2005a). Conversational floors in synchronous text-based CMC discourse. Discourse Studies, 7(3), 337-361.

Simpson, J. (2005b). Learning electronic literacy skills in an online language learning community. Computer Assisted Language Learning, 18(4), 327345.

Skehan, P. (1996). A framework for the implementation of task-based instruction. Applied Linguistics, 17(1), 38-62.

Skehan, P. (1998). A cognitive approach to language learning. Oxford: Oxford University Press.

Skehan, P. (2003a). Task-based instruction. Language Teaching, 36, 1-14.

Skehan, P. (2003b). Focus on form, tasks and technology. Computer Assisted Language Learning, 16(5), 391-411.

Skehan, P. (2009). Modelling second language performance: Integrating complexity, accuracy, fluency, and lexis. Applied Linguistics, 30(4), 510-532.

Skehan, P. \& Foster, P. (1997). Task type and task processing conditions as influences on foreign language performance. Language Teaching Research, 1(3), 185-211.

Skehan, P. \& Foster, P. (1999). The influence of task structure and processing conditions on narrative retellings. Language Learning, 49, 93-120.

Skehan, P. \& Foster, P. (2001). Cognition and tasks. In P. Robinson (Ed.). Cognition and second language instruction (pp.183-205), Cambridge: Cambridge University Press.

Slimani-Rolls, A. (2005). Rethinking task-based language learning: What we can learn from the learners. Language Teaching Research, 9(2), 195-218.

Smith, B. (2003a). Computer-mediated negotiated interaction: An expanded model. The Modern Language Journal, 87(1), 38-57.

Smith, B. (2003b). The use of communication strategies in computer-mediated communication. System, 31, 29-53. 
Smith, B. (2004). Computer-mediated negotiated interaction and lexical acquisition. Studies in Second Language Acquisition, 26, 365-398.

Smith, B. (2005). The relationship between negotiated interaction, learner uptake, and lexical acquisition in task-based computer-mediated communication. TESOL Quarterly, 39(1), 33-58.

Smith, B. (2008). Methodological hurdles in captures CMC data: The case of the missing self-repair. Language Learning \& Technology, 12(1), 85-103. Retrieved October 10, 2008, from http://lit.msu.edu/vol12num1/pdf/smith.pdf

Smith, M. (1993). Input enhancement in instructed SLA: Theoretical bases. Studies in Second Language Acquisition, 15(2), 165-179.

Smith, B. \& Gorsuch, G. J. (2004). Synchronous computer mediated communication captured by usability lab technologies: New interpretations. System, 32(4), 553-575.

Sotillo, M. S. (2000). Discourse functions and syntactic complexity in synchronous and asynchronous communication. Language Learning \& Technology, 4(1), 82-119. Retrieved April 18, 2005, from http://lit.msu.edu/vol4num1/sotillo/default.html

Sotillo, M. S. (2005). Corrective feedback via instant messenger learning activities in NS-NNS and NNS-NNS dyads. CALICO JOURNAL, 22(3), 467-496.

Stevens, R., O’Connor, K., Garrison, L., Jocuns, A \& Amos, D. (2008). Becoming an engineer: Toward a three dimensional view of engineering learning. Journal of Engineering Education, 97(3), 355-368.

Stockwell, G. (2007). A review of technology choice for teaching language skills and areas in the CALL literature. ReCALL, 19(2), 105-120.

Storch, N. \& Wigglesworth, G. (2007). Writing tasks: The effects of collaboration. In M.P. García Mayo (Ed.), Investigating tasks in formal language learning.. Clevedon: Multilingual Matters.

Storch, N. (1999). Are two heads better than one? Pair work and grammatical accuracy. System, 27(3), 363-374.

Storch, N. (2001). How collaborative is pair work? ESL tertiary students composing in pairs. Language Teaching Research, 5(1), 29-53.

Storch, N. (2005). Collaborative writing: Product, process and students' reflections. Journal of Second Language Writing, 14(3), 157-173.

Su, C.C. (2005). Online chat for English learning. The Proceedings of 2005 Taiwan TESOL Conference, Taipei: Taiwan ELT Publishing Co. Ltd., 288-298. 
Sullivan, N. \& Pratt, E. (1996). A comparative study of two ESL writing environments: A computer-assisted classroom and a traditional oral classroom, System 29(4), 491-501.

Suzuki, C., Watanabe, Y. \& Yoshihara, S. (2006). Pedagogical implications of a collaborative e-learning environment with a tutorial system. International Journal of Pedagogies and Learning, 2(1), 89-98.

Svalberg, A. \& Chuchu, H. F. (1998). Are English and Malay world apart? Typological distance and the learning of tense and aspects concepts. International Journal of Applied Linguistics, 8(1), 27-60.

Swain, M. (1985). Communicative competence: Some roles of comprehensible input and comprehensible output in its development. In S. Gass \& C. Madden (Eds.), Input in second language acquisition (pp. 235-253), Rowley, Mass: Newbury House.

Swain, M. (1995). Three functions of output in second language learning. In G. Cook and B. Seidelhofer (Eds.), Principle and practice in applied linguistics: Studies in honour of H. G. Widdowson (pp. 125-144). Oxford: Oxford University Press.

Swain, M. (1998). Focus on form through conscious reflection. In C. Doughty \& J. Williams (Eds.) Focus on form in classroom SLA (pp. 64-81). New York: Cambridge University Press.

Swain, M. (2005). The output hypothesis: Theory and research. In E. Hinkel (Ed.), Handbook on research in second language teaching and learning (pp. 471-484). Mahwah, NJ: Lawrence Erlbaum.

Swain, M. \& Lapkin S. (1995). Problems in output and the cognitive processes they generate: A step towards second language learning. Applied Linguistics, 16(3), 370-391.

Swain, M., \& Lapkin, S. (1998). Interaction and second language learning: Two adolescent French immersion students working together. The Modern Language Journal, 82(3), 320-337.

Swain, M., \& Lapkin, S. (2001). Focus on form through collaborative dialogue: exploring task effects. In M. Bygate, P. Skehan, and M. Swain (Eds.), Researching pedagogic tasks: Second language learning, teaching, and testing (pp.99-118), New York: Longman.

Swain, M., \& Lapkin, S. (2002). Talking it through: Two French immersion learners' response to reformulation. International Journal of Educational Research, 37, 285-304.

Swan, M. (2005). Legislation by hypothesis: The case of task-based instruction. Applied Linguistics, 26(3), 376-401. 
Tavakoli, P. \& Foster, P. (2008). Task design and second language performance:

The effect of narrative type on learner output. Language Learning, 58(2), 439-473.

Tavakoli, P. \& Skehan, P. (2005). Strategic planning, task structure, and performance testing. In R. Ellis (Ed.), Planning and task performance in a second language (pp. 239-273). Philadelphia: John Benjamins.

Thoms, J., Liao, J. \& Szustak, A. (2005). The use of L1 in an on-line chat activity. The Canadian Modern Language Review, 62(1), 161-182.

Thorne, S, L. \& Payne, J.S. (2005). Evolutionary trajectories, internet-mediated expression, and language education. CALICO JOURNAL, 22(3), 371397.

Thorne, S. \& Black, R. (2007). Language and literacy development in computermediated contexts and communities. Annual Review of Applied Linguistics, 27, 133-160.

Toyoda, E. \& Harrison, R. (2002). Categorization of text chat communication between learners and native speakers of Japanese. Language Learning \& Technology, 6(1), 82-99. Retrieved June 21, 2003, from http://llt.msu.edu/vol6num1/toyoda/

Trahey, M \& White, L. (1993).Positive evidence and preemption in the second language classroom. Studies in Second Language Acquisition 15(2), 181204.

Truong, T. A. \& Storch, N. (2007). Investigating group planning in preparation for oral presentations in an EFL class in Vietnam. RELC Journal, 38(1), 104-124.

Tudini, V. (2003). Using native speakers in chat. Language Learning \& Technology, 7(3), 141-159. http://llt.msu.edu/vol7num3/tudini/

Turani, A. \& Calvo, R. (2006). Beehive: A software application for synchronous collaborative learning. Campus-Wide Information Systems, 23(3), 196209.

Valcke, M. (2005). Rising to the challenge of being relevant for industry: Stretching the boundaries of educational institutes. Keynote speech: presented at the e-Fest, New Zealand, 19-21 September 2005.

Van den Branden, K. (Ed.). (2006). Task-based language education, Cambridge: Cambridge University Press.

Varonis, E. \& Gass, S. (1985). Non-native/non-native conversations: A model for the negotiation of meaning. Applied Linguistics, 6(1), 71-90. 
Vermeer, A. (2000). Coming to grips with lexical richness in spontaneous speech data. Language Testing, 17(1), 65-83.

Vetter, A. \& Chanier, T. (2006). Supporting oral production for professional purposes in synchronous communication with heterogenous learners, ReCALL, 18(1), 5-23.

Wang, Y. (2004). Distance language learning: Interactivity and fourth-generation internet-based videoconferencing. CALICO JOURNAL, 21(2), 373-395.

Ware, P. D. \& Kramsch, C. (2005). Toward an intercultural stance: Teaching German and English through telecollaboration. The Modern Language Journal, 89(2), 190-205.

Ware, P. D. \& Warschauer, M. (2005). Hybrid literacy texts and practices in technology-intensive environments. International Journal of Educational Research, 43(7-8), 432-445.

Warschauer, M. (1996). Comparing face-to-face and electronic discussion in the second language classroom. CALICO JOURNAL Journal, 13(2), 7-26.

Warschauer, M. (1997). Computer-mediated collaborative learning: Theory and practice. Modern Language Journal, 81(4), 470-481.

Warschauer, M. (1998). Researching technology in TESOL: Determinist, instrumental, and critical approaches. TESOL Quarterly, 32(4), 757-761.

Warschauer, M. (2001). On-line communication. In D. Nunan \& R. Carter (Eds.), The Cambridge guide to teaching English to speakers of other languages (pp. 207-212). Cambridge: Cambridge University Press.

Warschauer, M. (2003). Dissecting the "Digital Divide": A case study in Egypt. The Information Society, 19, 297-304.

Warschauer, M. \& Grimes, D. (2007). Audience, authorship, and artifact: The emergent semiotics of web 2.0. Annual Review of Applied Linguistics, $27,1-23$.

Warschauer, M., \& Healey, D. (1998). Computers and language learning: An overview. Language Teaching, 31, 57-71.

Warschauer, M., Grant, D., Del Real, G. \& Rousseau, M. (2004). Promoting academic literacy with technology: Successful laptop programs in K-12 schools. System. 32(4), 525-537.

Watanabe, Y. \& Swain, M. (2007). Effects of proficiency differences and patterns of pair interaction on second language learning: Collaborative dialogue between adult ESL learners. Language Teaching Research, 11(2), 121142. 
Weininger M. J. \& Shield L. (2004). Promoting oral production in a written channel: An investigation of learner language in MOO. Computer Assisted Language Learning, 16(4), 329-349.

Werry, C. C. (1996). Linguistic and interactional features of Internet Relay Chat. In S. C. Herring (Ed.), Computer-mediated communication: Linguistic, social and cross-cultural perspectives (pp. 47-63). Amsterdam and Philadelphia: John Benjamins.

Wildner-Bassett, M. (2005). CMC as written conversation: A critical socialconstructivist view of multiple identities and cultural positioning in the L2/C2 Classroom. CALICO JOURNAL, 22(3), 635-656.

Williams, J. (1995). Focus on form in communicative language teaching: Research findings and the classroom teacher. TESOL Journal 4(4), 12-16.

Williams, J. (2001). The effectiveness of spontaneous attention to form. System, 29(3), 325-340.

Williams, J. (2002). Technical communication, engineering and ABET's engineering criteria 2000: What lies ahead? Technical Communication, 49(1), 89-95.

Williams, J. (2005). Form-focused instruction. In E. Hinkel (Ed.), Handbook of research in second language teaching and learning (pp. 671-691). Mahwah, NJ: Lawrence Erlbaum Associates.

Willis, D. \& Willis, J. (2007). Doing task-based teaching. Oxford: Oxford University Press.

Wolfe-Quintero, K., Inagaki, S., \& Kim, H. Y. (1998). Second language development in writing: Measures of fluency, accuracy, and complexity (Tech. Rep. No. 17). Honolulu: National Foreign Language Resource Center.

Yates, S.J. (1996). Oral and written linguistic aspects of computer conferencing. In S. Herring (Ed.). Computer-mediated communication: Linguistic, social and cross-cultural perspectives. Amsterdam: John Benjamins.

Yuan, F. \& Ellis, R. (2003). The effects of pretask planning and on-line planning on fluency, complexity and accuracy in L2 monologic oral production. Applied Linguistics, 24(1), 1-27. 